HENRIQUE NUNES LAMAS DA SILVA

Modelagem e estudo computacional da formação de oleogéis

São Paulo

2021 


\section{Modelagem e estudo computacional da formação de oleogéis}

\section{Versão Corrigida}

Dissertação apresentada a Escola Politécnica da Universidade de São Paulo para obtenção do Título de Mestre em Engenharia Química.

Área de Concentração: Engenharia Química

Orientador: Prof. Dr. Moisés Teles dos Santos

São Paulo 
Autorizo a reprodução e divulgação total ou parcial deste trabalho, por qualquer meio convencional ou eletrônico, para fins de estudo e pesquisa, desde que citada a fonte.

Este exemplar foi revisado e corrigido em relação à versão original, sob responsabilidade única do autor e com a anuência de seu orientador.
São Paulo, 18 de
maio de 2021

Assinatura do autor:

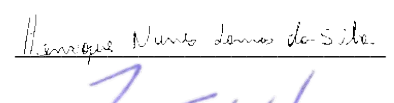

Assinatura do orientador:

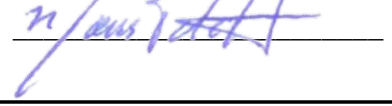

\section{Catalogação-na-publicação}

Silva, Henrique Nunes Lamas da

Modelagem e estudo computacional da formação de oleogéis / H. N. L.

Silva -- versão corr. -- São Paulo, 2021.

$115 \mathrm{p}$.

Dissertação (Mestrado) - Escola Politécnica da Universidade de São Paulo. Departamento de Engenharia Química.

1.oleogéis 2.modelagem computacional 3.projeto de produtos 4.óleos vegetais I.Universidade de São Paulo. Escola Politécnica. Departamento de Engenharia Química II.t. 


\section{RESUMO}

SILVA, H. N. L. Modelagem e estudo computacional da formação de oleogéis. 2021. Dissertação (Mestrado em Engenharia Química) - Escola Politécnica, Universidade de São Paulo, São Paulo, 2021.

A consistência de alguns produtos alimentícios é altamente dependente das gorduras trans e saturadas em sua composição, porém o consumo desses tipos de gordura tem efeitos adversos à saúde, como aumento do colesterol e o risco de doenças cardiovasculares. Os oleogéis são candidatos potenciais para substituir essas gorduras, uma vez que podem apresentar características de sólidos à temperatura ambiente, embora sejam compostos principalmente de óleo líquido aprisionado por uma rede tridimensional formada pelo agente estruturante. Identificar se uma determinada molécula é capaz de gelificar um determinado óleo ainda é uma tarefa árdua, que, normalmente, só pode ser resolvida na tentativa e erro. Neste trabalho, dados de gelificação de óleos vegetais disponíveis na literatura aberta foram compilados e serviram de base para um estudo de modelos matemáticos capazes de descrever a formação de géis. Foram estudados os modelos dos Parâmetros de solubilidade de Hansen e Técnicas de aprendizado de máquina (Análise Discriminante Linear, Rede Neural Artificial e Análise de Componentes Principais). A influência do conteúdo de gordura sólida na formação do gel foi estudada com base em previsões feitas a partir de um modelo de equilíbrio sólido-líquido desenvolvido anteriormente. Foram catalogados 428 agentes estruturantes, 67 óleos e 268 experimentos de gelificação. Embora os dados disponíveis sobre gelificação de óleos sejam abundantes, os dados ainda não foram padronizados e não contêm informações suficientes para aplicar os parâmetros de solubilidade de Hansen para óleos individuais e o uso em vários óleos ao mesmo tempo possui aplicações limitadas. As técnicas de aprendizado de máquina, entretanto, mostraram excelentes capacidades de classificação com $81 \%$ a $95 \%$ de precisão, mesmo utilizando conjuntos de dados irregulares. O conteúdo de gordura sólida não parece ter muita influência na formação de gel de óleos vegetais. Por fim, ainda são necessárias mais pesquisas com procedimentos padronizados para validar e aprimorar esses modelos e metodologias.

Palavras-chave: Parâmetros de solubilidade de Hansen, oleogéis, óleos vegetais. 


\begin{abstract}
SILVA, H. N. L. Computational modeling and study of oleogel formation. 2021. Dissertation (Master in Chemical Engineering) - Escola Politécnica, Universidade de São Paulo, São Paulo, 2021.
\end{abstract}

The consistency of some food products are highly dependent on the Trans and saturated fats in its composition, however the consumption of these types of fat has adverse health effects such as increased cholesterol and the risk of cardiovascular disease. Oleogels are potential candidates to substitute these fats, since they can present characteristics of solids at room temperature, although they are composed mostly of liquid oil entrapped by a 3D-network formed by the gelator. Identifying if a specific molecule is capable to gelate a specific oil is still an arduous task, which usually, can only be solved serendipitously. In this work, vegetable oil gelation data available in the open literature was compiled and used as the basis for a study of mathematical models capable of describing the formation of gels. Hansen's solubility parameters and machine learning techniques (Linear Discriminant Analysis, Artificial Neural Network and Principal Component Analysis) models were studied. The influence of solid fat content on gel formation was further studied based on predictions made from a previously developed Solid-Liquid Equilibrium model. In this work 428 gelators, 67 oils and 268 gelation experiments were cataloged. Although available data on oleogelation is abundant, the data has not yet been standardized and does not contain enough information to apply Hansen solubility parameters for individual oils and the use in several oils at the same time has limited applications. Machine learning techniques have shown great classification capabilities from $81 \%$ to $95 \%$ accuracy even with irregular data sets. The solid fat content does not seem to have much influence on gel formation of vegetable oils. Finally, further research with standardized procedures is still needed to validate and improve these models and methodologies.

Keywords: Hansen solubility parameters, oleogels, vegetable oils. 


\section{LISTA DE ILUSTRAÇÕES}

Figura 1 - Hierarquia estrutural das redes cristalinas de triacilgliceróis. 16

Figura 2 - A) Micrografia eletrônica da estrutura do oleogel de óleo de soja e etilcelulose mostrando a estrutura tridimensional de aprisionamento do óleo. B) Oleogel composto por $\beta$-sitosterol e $\gamma$-orizanol em óleo de girassol em diferentes moldes. .18

Figura 3 - Representação da formação de gel em diferentes estágios. 19

Figura 4 - Agentes estruturantes potenciais para formulação de oleogéis 21

Figura 5 - Representação de dados experimentais no espaço de Hansen para o sistema de um agente estruturante N-[2-(hexanoylamino)cyclohexyl]hexanamide e diferentes solvente orgânicos. [Esfera de Gelificação: $\delta_{d}=16,25 ; \delta_{p}=10,94 ; \delta_{h}$ = 13.76; RGel = 19,91MPa ${ }^{1 / 2}$; Esfera de Solubilidade: $\delta_{d}=18,56 ; \delta_{p}=9,82 ; \delta_{h}$ $=15,08 ;$ Rsol $\left.=10,9 \mathrm{MPa}^{1 / 2}\right]$.

Figura 6 - a) Ajuste da esfera de gelificação com o método de esferas com pouca sobreposição; b) Ajuste da esfera de gelificação com o método de esferas concêntricas; c) Ajuste de um segundo conjunto de dados utilizando o método de pouca sobreposição, para uma ou duas esferas de gelificação; d) Ajuste onde se permite sobreposição mas não é forçado que as esferas sejam concêntricas ..33

Figura 7 - Exemplo de molécula estruturante com Identificador, nome comum, IUPAC e representação SMILES. .40

Figura 8 - Agentes estruturantes distribuídos no espaço de Hansen. 49

Figura 9 - Histograma de frequência para cada componente dos parâmetros de Hansen dos agentes estruturantes de compostos orgânicos .50

Figura 10 - Distribuição dos óleos vegetais no espaço de Hansen 52

Figura 11 - Representação do espaço de Hansen contendo óleos (em preto), AE que formaram solução (em azul), AE que formaram gel (em verde) e AE que formou precipitado (em vermelho)

Figura 12 - Representação dos ajustes das esferas de Hansen não concêntricas (à esquerda) e esferas independentes (à direita). A esfera de solubilidade é representada em azul, enquanto a esfera de gelificação está representada em verde. .54 
Figura 13 - Pontos de ajuste para as esferas de solubilidade e gelificação do óleo de girassol em preto. $A E$ solúveis em azul, $A E$ formadores de gel em verde e $A E$ insolúveis em vermelho.

Figura 14 - Representação dos ajustes das esferas de Hansen não concêntricas (à esquerda) e esferas independentes (à direita) para óleo de girassol e diferentes agentes estruturantes. A esfera de solubilidade é representada em azul, enquanto a esfera de gelificação está representada em verde

Figura 15 - Histograma de frequência para cada componente dos parâmetros de Hansen dos agentes estruturantes de óleos.

Figura 16 - Performance preditiva dos diferentes métodos de aprendizagem de máquina para todos os conjuntos de dado $\mathrm{n}^{\circ}$ 1-16. A performance dada a um método que classificasse todos os experimentos como gel é dada pelo benchmark.

Figura 17 - Plano de classificação LDA com dois discriminantes lineares para o conjunto de dados $\mathrm{n}^{\circ} 5$ .63

Figura 18 - Estrutura da rede neural artificial para o conjunto de dados $n^{0} 4$ 64

Figura 19 - Estrutura da rede neural artificial para o conjunto de dados $n \circ 11$. .65

Figura 20 - Estrutura da rede neural artificial para o conjunto de dados nำ14. 65

Figura 21 - Estrutura da rede neural artificial após PCA para o conjunto de dados no 1 . .66

Figura 22 - Conteúdo de gordura sólida da mistura de óleo de girassol e gordura de Kokum (agente estruturante) em diferentes concentrações. 69

Figura 23 - Gráfico de conteúdo de gordura sólida da mistura de óleo de girassol e agentes estruturantes em diferentes concentrações. 69

Figura 24 - Gráfico de conteúdo de gordura sólida da mistura de óleo de girassol e diferentes agentes estruturantes. .70

Figura 25 - Conteúdo de gordura sólida da mistura FHR-B/SFO calculado em diferentes temperaturas. .73

Figura 26 - Gráfico de conteúdo de gordura sólida da mistura de óleo com baixo ponto de fusão e agentes estruturantes com alto ponto de fusão em concentrações de $2 \%$ 


\section{LISTA DE TABELAS}

Tabela 1 - Principais parâmetros avaliados em estudos de gelificação de solventes orgânicos.

Tabela 2 - Exemplo da base de dados de agentes estruturantes de solventes orgânicos e seus HSP calculados através do IBSS $\AA_{\text {... }}$ .48

Tabela 3 - Tabela com valores de HSP para diferentes óleos. .51

Tabela 4 - Resultado do ajuste das esferas de solubilidade (S) e Gelificação (G) utilizando 3 métodos de ajustes. .54

Tabela 5 - Esferas de solubilidade (S) e Gelificação (G) utilizando 3 métodos de ajustes para o óleo de girassol.

Tabela 6 - Fragmento da base de dados de agentes estruturantes de óleos e seus respectivos óleos estruturados. .59

Tabela 7 - Estruturação de óleo de girassol purificado por triacilgliceróis saturados 68 


\section{LISTA DE ABREVIATURAS E SIGLAS}

$\begin{array}{ll}\text { AAA } & \text { Triaraquidonina } \\ \text { AE } & \text { Agente Estruturante } \\ \text { ANN } & \text { Artificial Neural Networks } \\ \text { Anvisa } & \text { Agência Nacional De Vigilância Sanitária } \\ \text { BBB } & \text { Tribenina } \\ \text { CAMD } & \text { Computer-Aided Molecular Design } \\ \text { CAMixD } & \text { Computer-Aided Mixture Design } \\ \text { CAPD } & \text { Computer-Aided Product Design } \\ \text { CB } & \text { Cocoa Butter } \\ \text { CFC } & \text { Clorofluorcarbono } \\ \text { COSMO-SAC } & \text { Conductor-Like Screening Model For Real Solvent Segment } \\ & \text { Activity Coefficient } \\ \text { FCF } & \text { Faculdade De Ciências Farmacêuticas } \\ \text { FDA } & \text { Food And Drug Administration } \\ \text { FHR-B } & \text { Fully Hydrogenated Rapeseed Oil With A High Amount Of } \\ & \text { Behenic Acid } \\ \text { FHR-S } & \text { Fully Hydrogenated Rapeseed Oil With A High Amount Of } \\ & \text { Stearic Acid } \\ \text { G } & \text { Gel } \\ \text { GRAS } & \text { Generally Recognized As Safe } \\ \text { HSP } & \text { Hansen Solubility Parameters } \\ \text { I } & \text { Agente Estruturante Insolúvel } \\ \text { IBSS } & \text { Integrated Bio Sourced Search } \\ \text { ID } & \text { Código De Identificação } \\ \text { IUPAC } & \text { International Union Of Pure And Applied Chemistry } \\ \text { Lau } & \text { Trilaurina } \\ \text { LC50 } & \text { Lethal Dose } \\ \text { LDA } & \text { Linear Discriminant Analysis } \\ \text { MATLAB } & \text { Matrix Laboratory } \\ \text { MINLP } & \text { Mixed Integer Nonlinear Programming } \\ \text { MW } & \text { Molecular Weight } \\ \text { Myr } & \text { Trimiristina } \\ \text { NACP } & \text { N-Alquil-4-Carboxipirrolidinona } \\ \text { OMS } & \text { Organização Mundial Da Saúde } \\ \text { OO } & \text { Óleo De Oliva } \\ \text { Pam } & \text { Tripalmitina } \\ \text { PCA } & \text { Principal Component Analysis } \\ \text { PSO } & \text { Palm Super Olein } \\ \text { S } & \text { Solução } \\ \text { SFO } & \text { Sal Fat Olein } \\ \text { SMILES } & \text { Simplified Molecular Input Line Entry Specification } \\ \text { SSS } & \text { Tristearina } \\ \text { Ste } & \text { Tristearina } \\ \text { TAGs } & \text { Triacilgliceróis } \\ \text { TMQ } & \text { 2,2,4-Trimetil-1,2-H-Dihidroquinolina } \\ \text { UMD } & \text { University Of Maryland } \\ \text { USP } & \text { Universidade De São Paulo } \\ & \end{array}$




\section{SUMÁRIO}

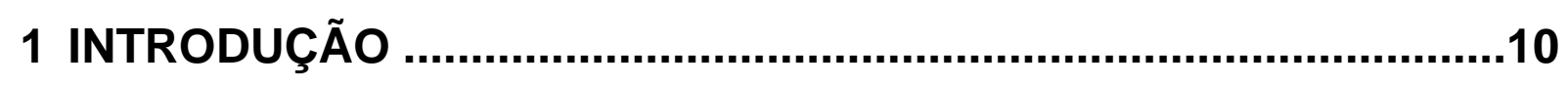

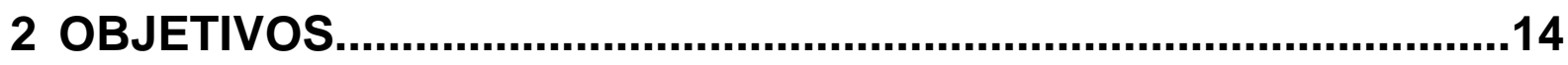

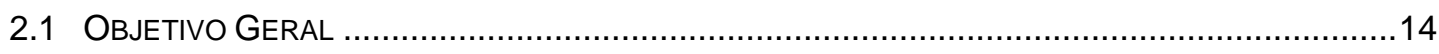

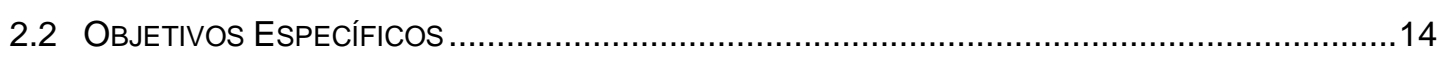

3 REVISÃO BIBLIOGRÁFICA ....................................................15

3.1 MÉtOdOS TRADICIONAIS DE ESTRUTURAÇÃO DE ÓLEOS E GORDURAS ..................................15

3.2 OlEOGÉIS COMO ESTRATÉGIA TECNOLÓGICA EM ALIMENTOS, COSMÉTICOS E PRODUTOS FARMACÊUTICOS.

3.3 PRODUCT-DESIGN: UM NOVO PARADIGMA NA ENGENHARIA QUÍMICA ..................................23

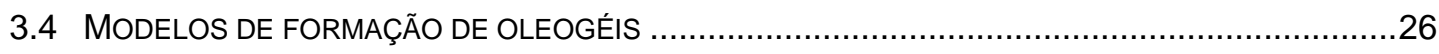

3.4.1 Parâmetros de solubilidade de Hansen .......................................................... 28

3.4.2 Outros modelos de formação de oleogéis .................................................. 35

3.4.3 Aprendizado de máquina aplicado no desenvolvimento de oleogéis................ 36

4 METODOLOGIA.........................................................................39

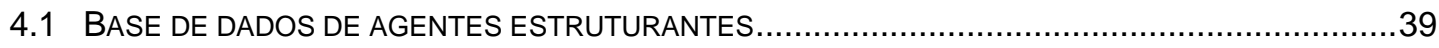

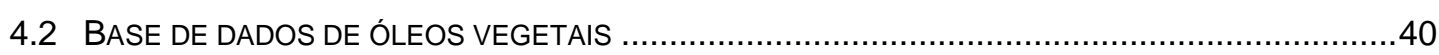

4.3 DETERMINAÇÃO DA ESFERA DE SOLUBILIDADE E GELIFICAÇÃO PARA ÓLEOS ….......................41

4.4 MODELOS CLASSIFICATÓRIOS DE FORMAÇÃO DE GEL USANDO APRENDIZADO DE MÁQUINA.....42

4.5 CONTEÚDO DE GORDURA SÓLIDA DE OLEOGÉIS COM TRIACILGLICERÓIS COMO AGENTE ESTRUTURANTE .45

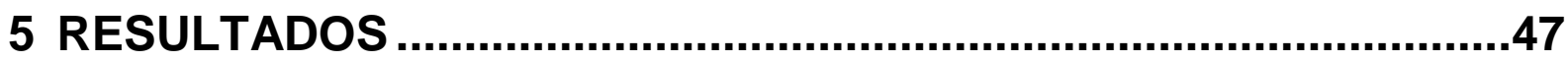

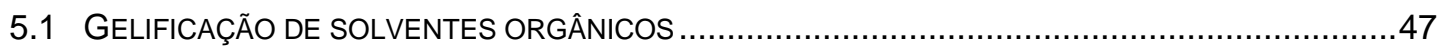

5.2 ESTUdO dA CAPACIDADE PREDITIVA DOS PARÂMETROS DE SOLUBILIDADE DE HANSEN NA

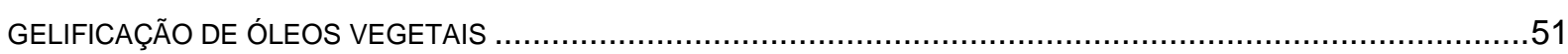

5.3 PeRformanCE de CLASSIFICAÇÃO dE MÉTOdOS DE APRENDIZAGEM DE MÁQUINA .................61

5.4 CONTEÚDO DE GORDURA SÓLIDA DE OLEOGÉIS COM TRIACILGLICERÓIS.................................67

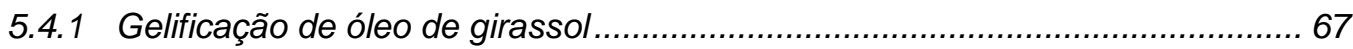

5.4.2 Gelificação de oleína de gordura de Shorea (SFO), manteiga de cacau (CB),

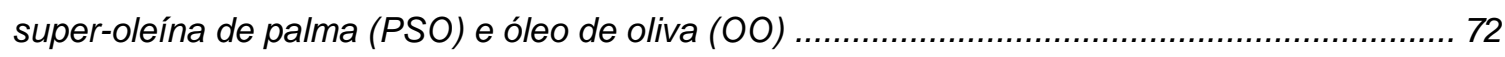

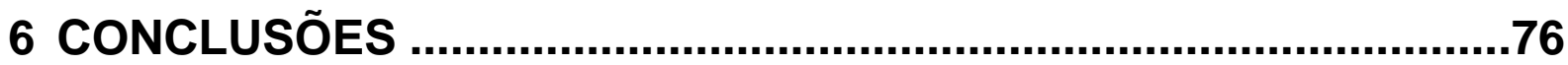

REFERÊNCIA BIBLIOGRÁFICA....................................................79 


\section{INTRODUÇÃO}

Em meados da década de 90 a comunidade cientifica associou o consumo excessivo de gorduras trans e saturadas a diversos efeitos nocivos à saúde humana, como o aumento do colesterol e do risco de doenças cardiovasculares, além de estar relacionado a deficiências no processo de crescimento e desenvolvimento infantil (CHIARA et al., 2002; MU; PORSGAARD, 2005; REMIG et al., 2010; ROGERS; WRIGHT; MARANGONI, 2009).

Existe um movimento global de resposta a esta problemática, onde governos criam legislações visando coibir o consumo desse tipo de gordura (WANG; ROGERS, 2015). Nos Estados Unidos, a Food and Drug Administration (FDA) determinou que os óleos parcialmente hidrogenados perdessem o status de Generally Recognized as Safe (GRAS) (FDA, 2015). A Organização Mundial da Saúde (OMS) divulgou em maio de 2018 o "REPLACE", um guia que fornece seis ações estratégicas para a eliminação rápida, completa e sustentada das gorduras trans produzidas industrialmente da cadeia de alimentos, solicitando aos governos que o utilizem (WORLD HEALTH ORGANIZATION, 2019). Por fim, no Brasil, a Agência Nacional de Vigilância Sanitária (Anvisa) aprovou muito recentemente (dezembro de 2019) regras que limitam a presença de gorduras trans industriais em alimentos, além de estipular o banimento de gorduras parcialmente hidrogenadas até 2023 (ANVISA, 2019).

Óleos e gorduras possuem como principais constituintes os triacilgliceróis que são lipídios formados por três ácidos graxos esterificados em uma molécula de glicerol. Os ácidos graxos por sua vez são ácidos carboxílicos de cadeia alifática, podendo ser classificados como saturados (sem duplas ligações entre carbonos), ou insaturados, com uma ou mais ligações duplas que podem ocorrer nas configurações cis ou trans. Na primeira, os hidrogênios ligados aos carbonos da cadeia alifática estão do mesmo lado da dupla ligação; na configuração trans, os hidrogênios ligados aos carbonos da cadeia estão em lados opostos da dupla ligação (MCMURRY, 2005).

Dentre as propriedades mais importantes das formulações contendo óleos e gorduras pode-se destacar: aparência, propriedades organolépticas, textura, cremosidade, espalhamento e plasticidade (TELES DOS SANTOS; GERBAUD; LE ROUX, 2014). Estas propriedades são fundamentais para a aceitação comercial de diversos produtos, tais como alternativas à manteiga de cacau e margarinas. $\mathrm{O}$ desenvolvimento de formulações que apresentem propriedades físicas desejadas, 
com matérias-primas adequadas do ponto de vista nutricional, ambiental e de baixo custo tem sido uma linha de pesquisa permanente por parte da indústria de alimentos.

Para que a formulação da maior parte dos produtos alimentícios proporcione as propriedades desejadas é necessário o uso de gorduras semissólidas que são possíveis devido ao aprisionamento físico de óleo líquido nas redes formadas pelos cristais de triacilgliceróis de alto ponto de fusão (PATEL, 2015). Para Bot et al. (2009) esse processo, conhecido como estruturação tradicional de óleos, é o benchmarking que precisa ser superado por métodos que se proponham a desenvolver novas formas de estruturação de óleos.

Segundo Co e Marangoni (2012), a redução ou mesmo a eliminação de ácidos graxos trans e saturados em alimentos representa um verdadeiro enigma para os fabricantes. De um lado, há a necessidade de se reduzir estes ácidos graxos para satisfazer as expectativas dos consumidores por produtos mais saudáveis; por outro lado, é difícil (se não impossível) eliminar estes compostos como ingredientes (principalmente em produtos de confeitaria), pois produtos contendo grandes quantidades destes ácidos graxos apresentam diversas funcionalidades desejadas, como plasticidade e elasticidade.

Processos físicos (blending e fracionamento) e químicos (hidrogenação e interesterificação) têm sido tradicionalmente usados para modelar as propriedades dos óleos pela mudança de composição química em termos de triacilgliceróis. A principal fonte de gorduras trans é o processo de hidrogenação de óleos. Este processo confere plasticidade aos óleos originalmente líquidos que, por sua vez, conferem propriedades mecânicas, funcionalidade tecnológica e textura a produtos como chocolates, sorvetes e margarinas, ao mesmo tempo em que estende a vida útil dos alimentos (MAT DIAN; SUNDRAM; IDRIS, 2006; ROGERS; WRIGHT; MARANGONI, 2009). Segundo Remig et al. (2010), a hidrogenação catalítica, apesar de largamente utilizada como opção para a redução do consumo de gorduras saturadas no início do século XX, apresenta os já mencionados inconvenientes à saúde humana devido à formação de ácidos graxos trans.

Uma alternativa à utilização de gorduras trans (formadas no processo de hidrogenação) na estruturação de óleos é o uso de matérias-primas com maior teor de ácidos graxos saturados, como o óleo de palma, que por suas propriedades de cristalização, pode ser usado em produtos como margarinas (MAT DIAN; SUNDRAM; IDRIS, 2006; WANG; ROGERS, 2015). Esta prática entretanto, possui uma percepção 
negativa por parte do consumidor e por isso nas últimas décadas, intensificou-se a investigação de alternativas para a estruturação de óleos que não envolvam o tradicional uso de triacilgliceróis saturados ou trans presentes nos óleos e gorduras (HWANG; WINKLER-MOSER, 2020).

Neste cenário, o uso dos chamados oleogéis tem sido avaliado como uma alternativa tecnológica. Esta técnica consiste na utilização de moléculas capazes de formar géis ao serem misturadas com óleos; tais moléculas capazes de estruturar óleos líquidos são chamadas de agentes estruturantes. Géis são sistemas coloidais que apresentam comportamento reológico de um sólido mesmo possuindo uma fração volumétrica majoritariamente líquida, além de possuir uma estrutura macroscópica que não muda no intervalo de um experimento (BLAKE; CO; MARANGONI, 2014). Os chamados organogéis são géis formados por solventes hidrofóbicos que, devido à variedade de estruturas disponíveis, reversibilidade térmica e sensibilidade química possibilitam o emprego desse material em uma diversidade de aplicações (BIELEJEWSKI et al., 2009).

Os oleogéis são um tipo particular de organogel, em que se usam lipídios (ex.: óleos vegetais) como fase líquida. Esse tipo de gel tem despertado interesse crescente das indústrias de cosméticos, farmacêutica e de alimentos. Segundo Patel \& Dewettinck (2016), a crescente demanda por substitutos de gorduras saturadas e trans na composição de produtos, ou ainda a necessidade de opções ambientalmente sustentáveis de matérias-primas tem impulsionado a pesquisa em oleogéis. Algumas indústrias já vêm utilizando esse material e outras aplicações ainda estão em fase de desenvolvimento.

O uso de oleogéis como sistema reduzido em ácidos graxos saturados e trans em formulações alimentícias ainda é uma raridade comercial. Isso ocorre porque saber se determinado agente estruturante (AE) em baixas concentrações é capaz de gelificar um determinado óleo vegetal é um desafio, que muitas vezes, só é resolvido por inúmeras tentativas e erros (HU et al., 2018; PARK; MALEKY, 2020; PATEL, 2017; ROGERS, 2018; WEISS, 2014).

Atualmente, admite-se que o processo de gelificação depende de balanços complexos entre parâmetros que influenciam a solubilidade e aqueles que governam a formação de agregados. Um balanço complexo entre interações $A E-A E$ e líquidoAE contribui de forma central no processo de formação destes géis. Dessa forma, o estudo das propriedades que governam esse processo é de extrema importância para 
a predição da formação dos géis (DASGUPTA et al., 2011; DELBECQ et al., 2020; GAO; WU; ROGERS, 2012; HU et al., 2018; LAN et al., 2014; ROGERS, 2018).

Raynal e Bouteiller (2011) destacam que o desenvolvimento de um novo agente estruturante para uma aplicação particular é uma tarefa difícil, mas que a grande quantidade de dados experimentais acumulados ao longo dos anos deveria agora servir para uma nova abordagem, em que ferramentas/modelos possam servir como norteadores para verificar se um dado composto irá gelificar um dado fluido.

É exatamente com essa motivação destacada por Raynal e Bouteiller (2011) que o presente trabalho se propõe a determinar uma metodologia para identificar bons candidatos a agentes estruturantes capazes de gelificar diferentes tipos de óleos, com o intuito de desenvolver um protótipo de um software para auxílio no desenvolvimento de produtos à base de oleogéis, de forma a contribuir com o desenvolvimento de novos produtos que apresentem plasticidade desejada sem recorrer ao uso de matérias-primas ou processos que gerem propriedades nocivas à saúde humana. 


\section{OBJETIVOS}

\subsection{Objetivo Geral}

O objetivo geral deste trabalho é desenvolver uma metodologia computacional para auxílio no desenvolvimento de produtos à base de oleogéis.

\subsection{Objetivos Específicos}

- Comparar diferentes modelos matemáticos para descrição da formação de oleogéis.

- Analisar a capacidade preditiva do modelo de solubilidade de Hansen na formação de oleogéis.

- Identificar os parâmetros mais significativos na formação de oleogéis. 


\section{REVISÃO BIBLIOGRÁFICA}

\subsection{Métodos tradicionais de estruturação de óleos e gorduras}

As gorduras são materiais que apresentam características macroscópicas influenciadas pelos diferentes níveis de organização estrutural. Gorduras plásticas são formadas por uma interação entre cristais de gordura (sólida) e óleo (líquido) (ROGERS, 2009). Essas propriedades plásticas - necessárias na maioria dos produtos baseados em óleos e gorduras comercialmente disponíveis - são obtidas pela estruturação a partir de redes cristalinas compostas por triacilgliceróis saturados ou trans. Essas redes cristalinas são capazes de estruturar efetivamente óleos e são responsáveis pelas propriedades físicas, onde a quantidade de material cristalino é um importante fator para a determinação das características dos lipídios (CO; MARANGONI, 2012).

Para que ocorra estruturação é necessário que os triacilgliceróis saturados ou trans que se encontram no estado líquido passem por um resfriamento que reduz sua solubilidade, dando início ao processo de nucleação, formando pequenos cristais. A posterior interação desse material cristalino forma uma rede cristalina tridimensional contínua, similar ao que acontece com géis coloidais. Essa rede cristalina é responsável pelas características plásticas desse material (DEMAN; DEMAN; BLACKMAN, 1983; ROGERS, 2009). Na Figura 1 é possível observar a hierarquia da estruturação de lipídios desde a interação molecular até a formação de redes tridimensionais. 
Figura 1 - Hierarquia estrutural das redes cristalinas de triacilgliceróis

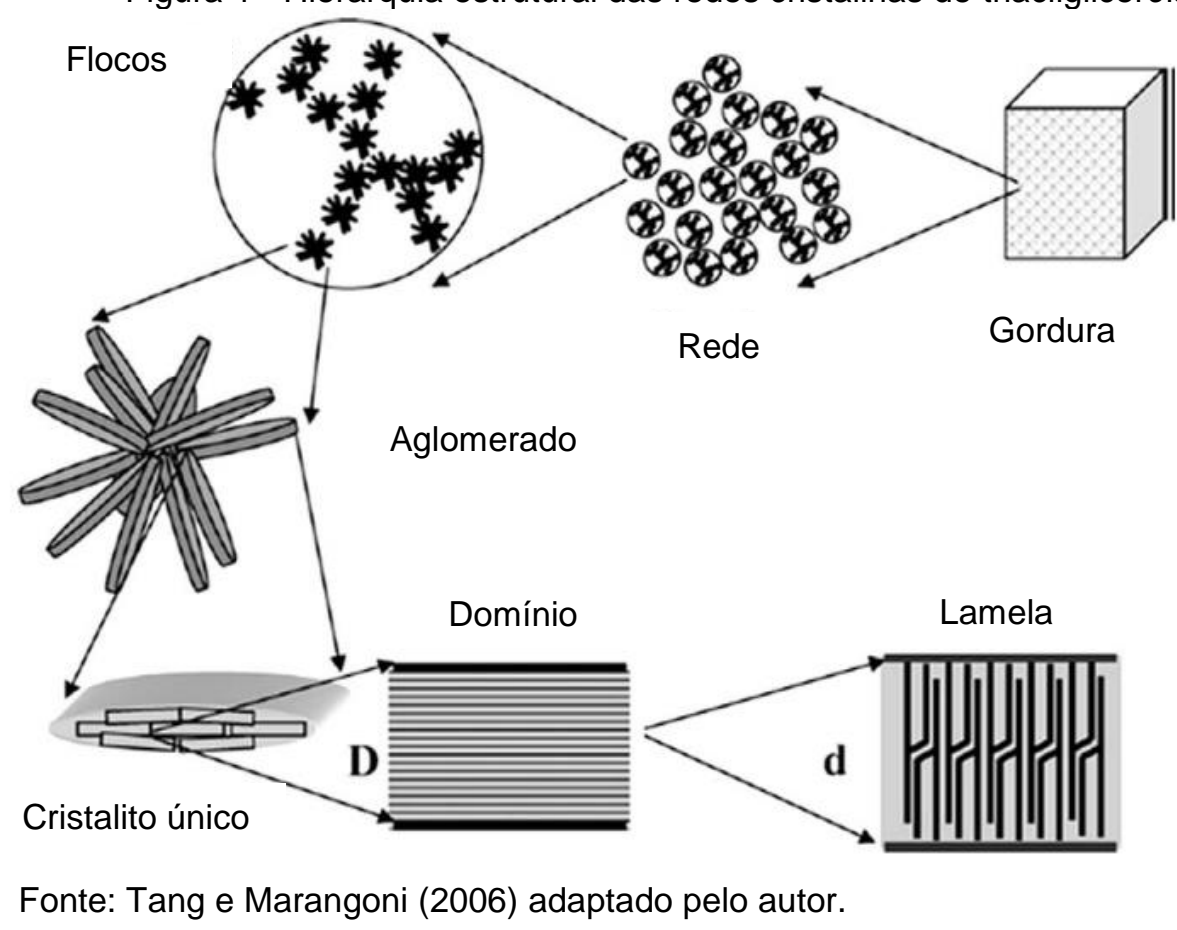

A existência de uma grande variedade de moléculas é considerada a principal vantagem na utilização de triacilgliceróis na estruturação de lipídios, permitindo um controle preciso de propriedades físicas durante a confecção de produtos. Diferentes tecnologias para a modificação da composição de misturas formadas por triacilgliceróis podem ser aplicadas através de processos físicos (blending e fracionamento) e químicos (hidrogenação e interesterificação) ou ainda uma combinação desses processos (MAT DIAN; SUNDRAM; IDRIS, 2006; ROGERS, 2009).

O fracionamento é um processo físico que visa a obtenção de novas frações lipídicas. Durante esse processo, o óleo ou gordura fundido é resfriado de forma controlada, assim os triacilgliceróis saturados que compõe a fase lipídica cristalizamse de forma fracionada, possibilitando a separação. Atualmente a principal matériaprima do fracionamento é o óleo de palma devido ao seu perfil único de fusão (WASSELL; YOUNG, 2007).

A hidrogenação parcial ou total de óleos é um processo que vem sendo largamente utilizado desde o início do século XX. Wassell e Young (2007) explicam que o objetivo desse processo é promover a saturação total ou parcial das duplas ligações, para possibilitar a obtenção de gorduras sólidas ou plásticas, aumentar a estabilidade oxidativa e conferir melhores características organolépticas aos produtos 
de base lipídica. Contudo, quando um ácido graxo insaturado passa pelo processo de hidrogenação parcial, a dupla ligação que é encontrada naturalmente na configuração cis é geralmente alterada para a configuração trans, o que é indesejável do ponto de vista nutricional.

Para produtos mais sofisticados em que uma simples mistura física ou mesmo o uso do fracionamento não são suficientes, a interesterificação surge como uma alternativa à hidrogenação. Esse processo utiliza catalisadores químicos ou enzimáticos para reorganizar os ácidos graxos nas três posições da molécula de glicerol. Dessa forma, a composição de triacilgliceróis muda, mantendo a composição de ácidos graxos constante. Trata-se de um processo efetivo para a produção de alguns produtos macios e com espalhabilidade que não contenham gorduras trans (TELES DOS SANTOS; GERBAUD; LE ROUX, 2014; WASSELL; YOUNG, 2007).

No final de qualquer um desses processos, o conteúdo de gordura sólida é responsável por diferentes propriedades ligadas à aceitação do produto pelo consumidor, como aparência física, espalhabilidade e propriedades organolépticas (TELES DOS SANTOS; GERBAUD; LE ROUX, 2014).

\subsection{Oleogéis como estratégia tecnológica em alimentos, cosméticos e produtos farmacêuticos}

Além de triacilgliceróis, existem outros compostos ou misturas de compostos capazes de estruturar óleos sem alterar a composição do líquido, tais como o monoestearato de sorbitano, ceramidas, monoacilgliceróis, mistura de fitoesteróis com orizanol, ácidos graxos e seus derivados, álcoois graxos, mistura de ácidos graxos com álcoois graxos, ceras naturais, ésteres de cera, ácidos dicarboxílicos e lecitina em conjunto com tristearato de sorbitano, para citar alguns agentes estruturantes que formam géis com óleos vegetais (DASSANAYAKE; KODALI; UENO, 2011).

A pesquisa envolvendo organogéis, em geral, e oleogéis, em particular, tem crescido vertiginosamente à medida que diferentes áreas do conhecimento têm tomado para si o desafio de identificar diferentes agentes capazes de estruturar óleos (PATEL, 2017). Modificar óleos com o objetivo de criar uma gordura plástica com propriedades semelhantes às de um sólido, mantendo propriedades nutricionais adequadas, é uma área de pesquisa de grande importância acadêmica e industrial, conforme indica vasta literatura (CO; MARANGONI, 2012; DAVID et al., 2021; 
DICKINSON, 2012; GUTIÉRREZ-LUNA; ASTIASARÁN; ANSORENA, 2021; HWANG, 2020; HWANG; WINKLER-MOSER, 2020; JIMENEZ-COLMENERO et al., 2015; OKURO et al., 2020; PATEL et al., 2014; PATEL; NICHOLSON; MARANGONI, 2020; ZETZL; MARANGONI; BARBUT, 2012).

Oleogéis possuem um grande potencial de mudar a maneira como óleos são estruturados. Para que um oleogel seja formado, são necessários dois materiais: o óleo no estado líquido (vegetal, animal, mineral ou microbiano) e uma espécie química que funcione como agente estruturante. Por esta técnica, o óleo inicialmente em estado líquido torna-se, junto com o agente estruturante, um material semissólido, com aspecto gelatinoso e com propriedades viscoelásticas. Trata-se de um líquido orgânico formado por triacilgliceróis aprisionado em um material viscoelástico, termorreversível e anidro por uma rede tridimensional de gel (JIMENEZCOLMENERO et al., 2015; ROGERS, 2018). A Figura 2 apresenta a estrutura tridimensional de um oleogel, além de um exemplo de um oleogel composto por $\beta$ sitosterol e $y$-orizanol, apresentando um grau de transparência e firmeza que permite que o gel seja moldado de diferentes formas.

Figura 2 - A) Micrografia eletrônica da estrutura do oleogel de óleo de soja e etilcelulose mostrando a estrutura tridimensional de aprisionamento do óleo. B) Oleogel composto por $\beta$-sitosterol e $\gamma$-orizanol em óleo de girassol em diferentes moldes.

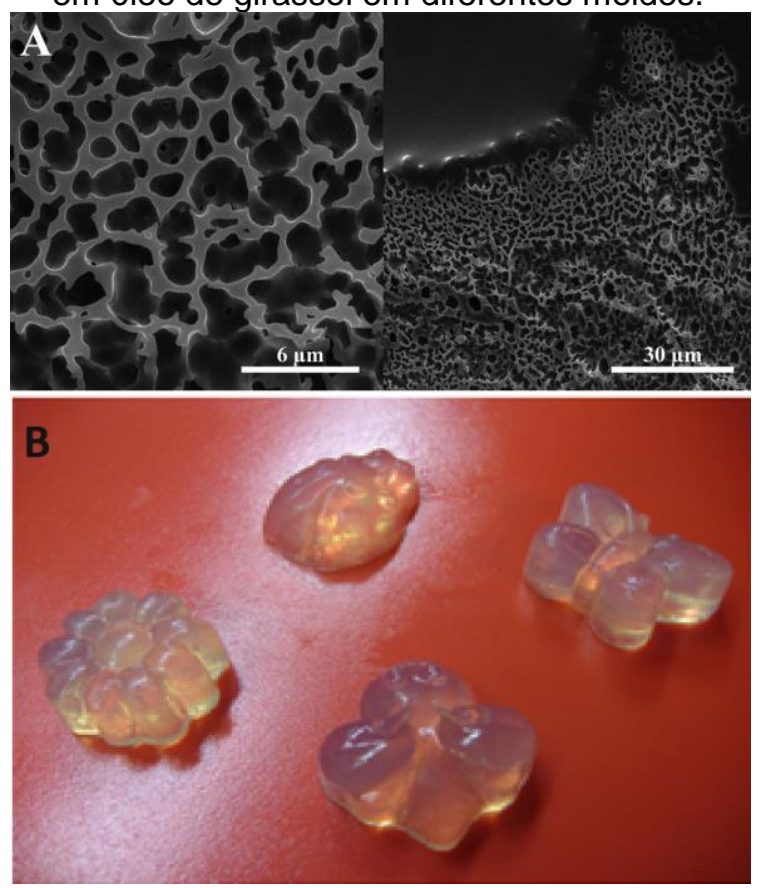

Fonte: Rogers et al. (2014) e Zetzl, Marangoni e Barbut (2012) adaptado pelo autor. 
Organogéis assim como o subgrupo de oleogéis possuem uma característica instigante que os diferenciam dos demais géis. Enquanto historicamente a maioria dos géis possuem agentes estruturantes de natureza polimérica, uma grande parte dos organogéis é formada por agentes estruturantes de natureza não polimérica. Esses agentes estruturantes de baixa massa molecular se reúnem em estruturas supramoleculares com interações não covalentes específicas. O mecanismo que permite que um material estruture óleos está relacionado a um balanço entre sua afinidade com o solvente (o óleo) e insolubilidade suficiente para desencadear o processo de automontagem, no qual moléculas formam um agregado definido e estruturas fibrilares alongadas que podem se organizar em estruturas tridimensionais capazes de aprisionar o óleo e então formar o gel (ABDALLAH; WEISS, 2000; CO; MARANGONI, 2012; LAN et al., 2015; PATEL, 2017; TERECH; WEISS, 1997). Na Figura 3 é possível observar as etapas do processo de formação de oleogel com agentes estruturantes de baixa massa molecular.

Figura 3 - Representação da formação de gel em diferentes estágios.

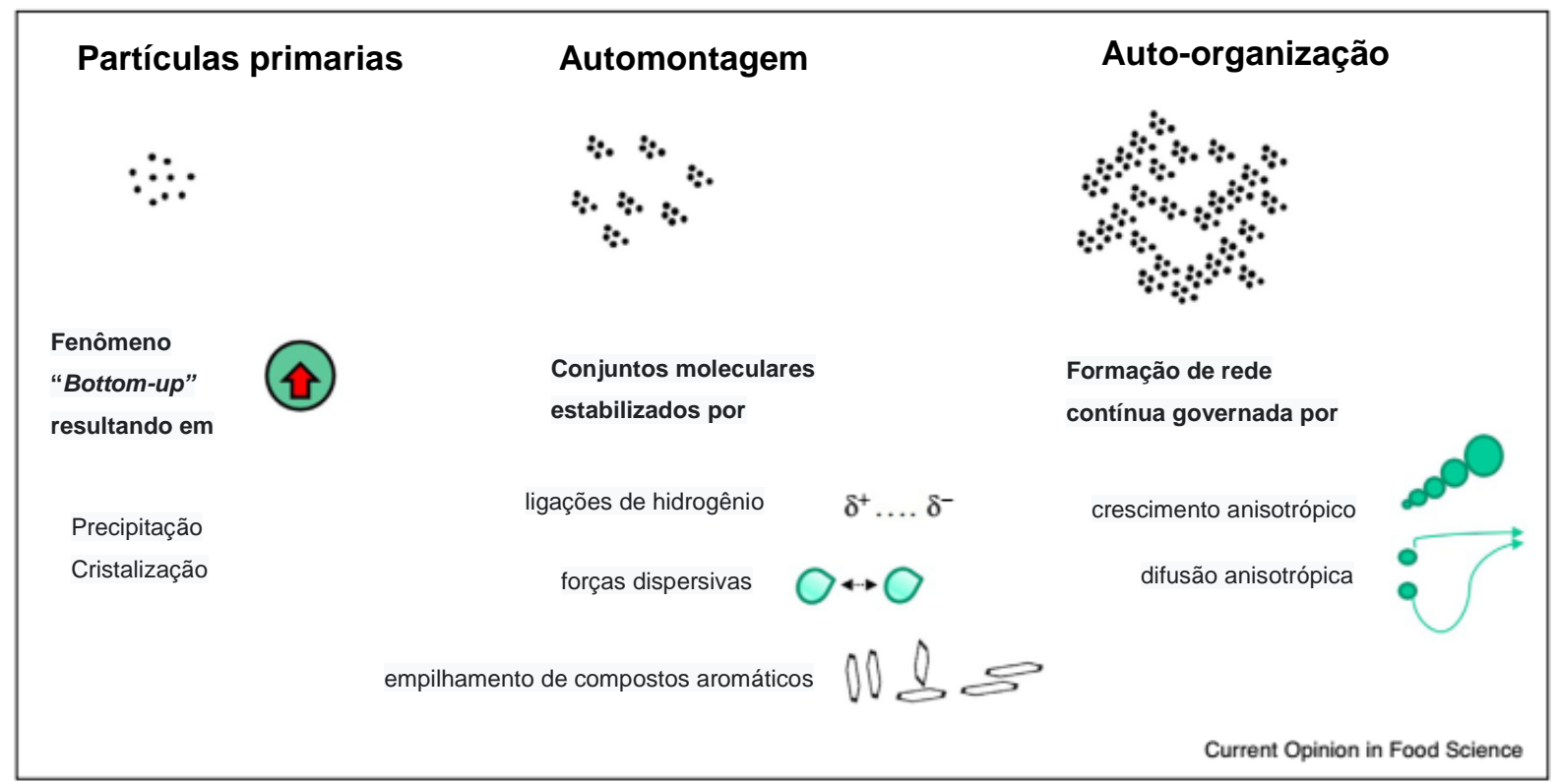

Fonte: Patel (2017) adaptado pelo autor.

O processo tecnológico de formação de oleogéis começa com o aquecimento e dissolução do agente estruturante no óleo. Durante o resfriamento dessa solução, a fraca interação entre o soluto (agente estruturante) e o solvente (óleo) desencadeia a formação de partículas primárias (partículas com diâmetro inferior a 100nm) por precipitação e/ou cristalização (fenômeno "bottom-up"). Estruturas supramoleculares de ordem superior são formadas a partir das partículas primarias através de processos 
conhecidos como automontagem e auto-organização que são estabilizadas por interações especificas que incluem, mas não se limitam a: ligações de hidrogênio, empilhamento de compostos aromáticos (quando presentes), interações eletrostáticas e interações de van der Waals. Essas estruturas são eventualmente responsáveis por ocasionar a gelificação do solvente, se for alcançado um equilíbrio adequado entre as interações AE-AE e AE-solvente (LAN et al., 2015; PATEL, 2017). De acordo com Patel (2017) a gelificação ocorre devido ao crescimento anisotrópico das estruturas supramoleculares e a cinética de difusão direcional de moléculas ou aglomerados de moléculas. O resultado é a formação de uma rede tridimensional que retém o líquido (óleo vegetal) e que é responsável por dar a firmeza esperada no material final.

A capacidade de estruturar óleos através da utilização de agentes estruturantes não convencionais ainda se trata de uma tecnologia em desenvolvimento e a literatura vem reportando um crescente número de agentes estruturantes capazes de formar géis com óleos (ROGERS et al., 2014). A Figura 4 mostra as principais categorias de agentes estruturantes reportados na literatura. 
Figura 4 - Agentes estruturantes potenciais para formulação de oleogéis

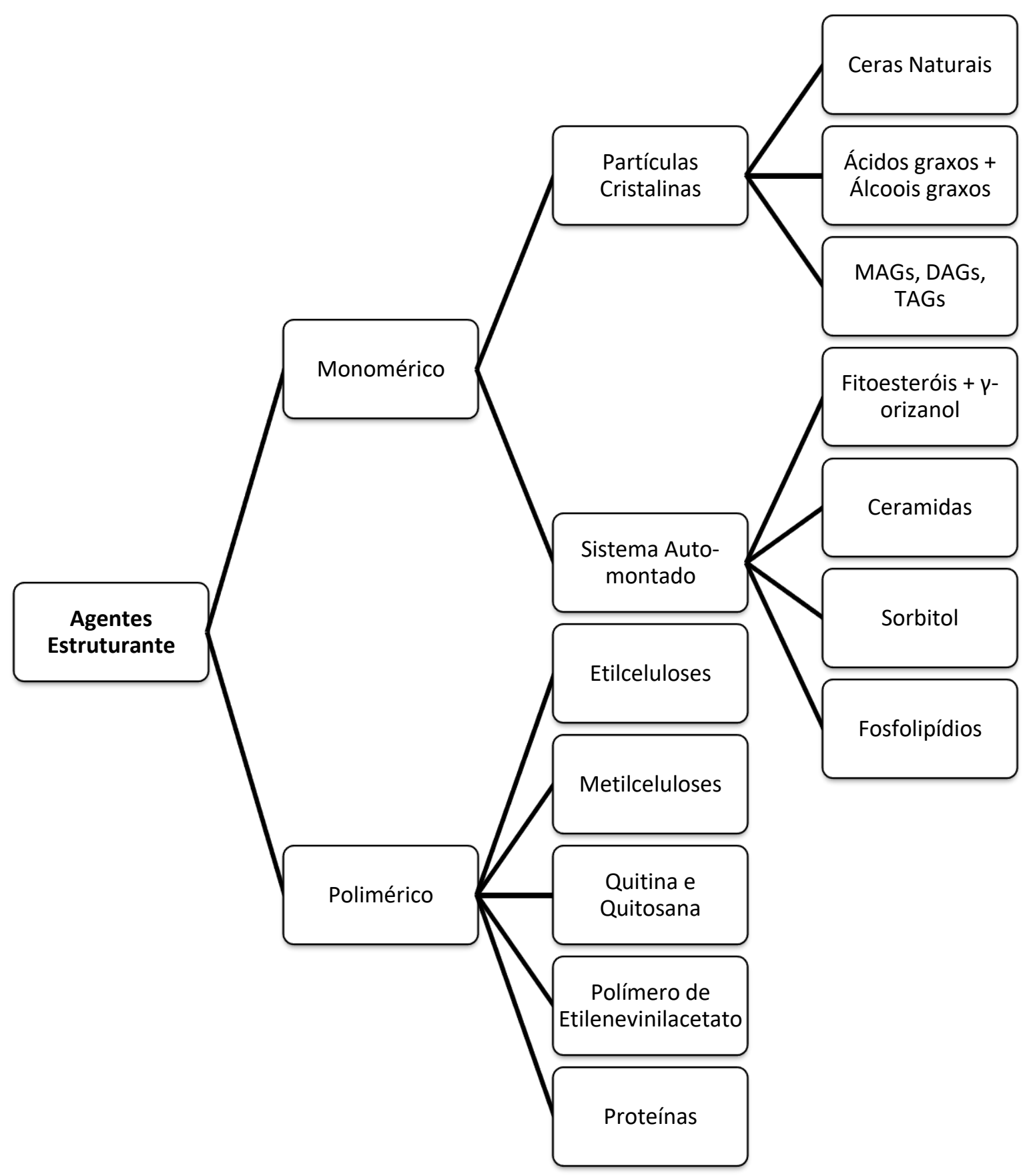

Fonte: Pehlivanoğlu et al. (2018) adaptado pelo autor. 
Os agentes estruturantes apresentados podem atuar isoladamente ou sinergicamente com outros na estruturação de óleos. Essa grande variedade de agentes estruturantes, a possibilidade de se usar mais de um agente estruturante de forma sinérgica e a diversidade de óleos tornam o processo de identificação de bons agentes estruturantes uma tarefa desafiadora, do ponto de vista científico e industrial.

Dentre as aplicações conhecidas de oleogéis destacam-se: a substituição de petrolatos em produtos cosméticos (STORTZ; MARANGONI, 2014), uso como biolubrificantes (BORRERO-LÓPEZ et al., 2020; MARTíN-ALFONSO et al., 2020; MARTÍN-ALFONSO; VALENCIA, 2015; SÁNCHEZ et al., 2011), como excipientes na formulação de medicamentos e fitoterápicos (BASTIAT; LEROUX, 2009; BEHERA et al., 2012; LI et al., 2016; LUPI et al., 2013; MACOON; ROBEY; CHAUHAN, 2020; MOTULSKY et al., 2005; OKTAY et al., 2020; PLOURDE et al., 2005; VINTILOIU; LEROUX, 2008) e como substitutos de triacilgliceróis na formulação de produtos alimentícios (CO; MARANGONI, 2012; HUGHES et al., 2009; HWANG; WINKLERMOSER, 2020; PALLA; WASINGER; CARRÍN, 2020; PARK; MALEKY, 2020; ROGERS, 2009; SCHARFE; FLÖTER, 2020; SOLEIMANIAN et al., 2020; STORTZ et al., 2012; ZETZL; MARANGONI; BARBUT, 2012). Os oleogéis podem ainda ser utilizados com sucesso na encapsulação de compostos nutracêuticos como isoflavonas, licopeno, esteróis vegetais, entre outros, controlando a taxa de liberação destes compostos no organismo (SIRAJ et al., 2015).

Devido a esse grande potencial na aplicação dos oleogéis, existe um interesse na descoberta de novos agentes estruturantes capazes de estruturar um dado óleo. De um ponto de vista de aplicação, quando se deseja gelificar um dado líquido, é prática comum buscar na literatura por compostos que tenham sido descritos como formadores de gel para esse líquido em particular. No entanto, conforme destacam Raynal e Bouteiller (2011), é comum que para muitas aplicações, o fluido de interesse (óleo comestível, formulação cosmética, mistura de solventes para revestimentos, etc.) ainda não tenha sido estudado. Avaliar sistematicamente diferentes formulações líquido - agente estruturante por métodos experimentais acarreta custos e tempo para o desenvolvimento de produtos. De forma a contornar esse problema, este trabalho propõe o uso de técnicas de Chemical Product Design, uma abordagem computacional que possa permitir uma avaliação inicial de formulações óleo-AE, para que os experimentos possam ser direcionados apenas às formulações mais promissoras. 


\subsection{Product-Design: um novo paradigma na Engenharia Química}

Para Gani (2004) o projeto de um produto compreende duas das etapas do projeto de processos químicos: a definição de uma necessidade e a geração de ideias capazes de satisfazer essas necessidades. Esta abordagem adaptada a este trabalho compreende então a diminuição de gorduras trans em produtos alimentícios e a identificação de agentes estruturantes não convencionais capazes de formar oleogéis. A geração de soluções potenciais pode ser então de dois tipos: projeto de moléculas e o projeto de misturas.

O desenvolvimento de ferramentas computacionais para screening virtual de formulações, a fim de se reduzir experimentos, otimizando tempo e custo na elaboração de novos produtos, é uma metodologia moderna e promissora em Engenharia Química, considerada como um novo paradigma na área (HILL, 2009). Métodos heurísticos de identificação de novos produtos, apesar de muitas vezes produzirem resultados confiáveis e seguros, são incapazes, do ponto de vista prático, de avaliar todas as alternativas para um dado problema. Conforme destacado por Zhang et al. (2020), nos últimos anos, métodos de projeto de produtos baseados em modelos computacionais tem ganhado espaço devido sua capacidade de avaliar um número muito maior de candidatos ao mesmo tempo em que diminui o tempo e o custo de desenvolvimento do produto final.

A técnica de Computer-Aided Molecular Design (CAMD) foi desenvolvida como uma metodologia para identificar moléculas que atendam certos requisitos de propriedades físicas e já foi utilizada com sucesso em diversas aplicações como projeto de solventes, fluidos refrigerantes sem CFC's (clorofluorcarbonos) e polímeros. A CAMD funciona utilizando uma representação molecular computacional como ponto de partida para o cálculo de propriedades através de modelos matemáticos; essas propriedades calculadas são então comparadas com os valores alvos e uma nota (performance) é dada para a molécula candidata. As moléculas candidatas são então classificadas de acordo com a nota e então são mantidas, modificadas ou rejeitadas de acordo com o algoritmo de otimização utilizado. Para lidar com misturas que, muitas vezes, apresentam sinergias entre as espécies presentes e cujos valores de propriedades não podem ser previstos apenas pelas contribuições individuais das espécies, foi desenvolvida a metodologia ComputerAided Mixture Design (CAMixD). Em conjunto essas metodologias compreendem o 
Computer-Aided Product Design (CAPD), que trata de um problema inverso de predição de propriedades, ou seja, dado um conjunto de propriedades desejadas qual o produto (molécula, mistura ou formulação) que possui essas propriedades (GANI, 2004; GERBAUD et al., 2017; HEINTZ et al., 2014).

De acordo com Heintz et al. (2014) o CAPD é sustentado em quatro conceitos principais: um modelo de representação molecular, um conjunto de modelos de cálculo de propriedades, um algoritmo para solução e um critério de performance. Uma base de dados pode ser utilizada para uma triagem de moléculas candidatas ou as mesmas podem ser construídas a partir de fragmentos moleculares. Comparando a propriedades estimadas com os valores alvo é possível classificar os produtos finais de acordo com a aptidão.

Nesse contexto, Gerbaud et al. (2017) investigaram o uso de ferramentas de CAMD combinadas com ferramentas de síntese orgânica computacional para avaliar a sustentabilidade de possíveis moléculas sintetizadas a partir de biomassa, que pudessem ser usadas como solventes alternativos ao N-metil-2-pirrolidona ou dimetilformamida. Nesse estudo de caso foi considerado a necessidade de um solvente ecologicamente sustentável para substituir os solventes tóxicos atualmente utilizados. Para encontrar candidatos substitutos, os autores fizeram a correlação de propriedades reais (baixa toxicidade) com propriedades calculáveis (LC50); uma vez feita essa correlação, valores alvos, funções de performance e pesos para diferentes propriedades foram determinados. Moléculas derivadas do ácido itacônico foram geradas utilizando a ferramenta de síntese orgânica computacional e delas foram destacados cinco candidatos a solventes. Essas moléculas foram então comparadas com os solventes comerciais e o éster de $\mathrm{N}$-alquil-4-carboxipirrolidinona (NACP) foi avaliado como um bom candidato. NACP então foi submetido a etapa de CAMD onde diferentes fragmentos moleculares foram adicionados a grupos funcionais do NACP produzindo derivados. $O$ algoritmo de busca foi capaz de em menos de 20 minutos avaliar centenas de moléculas baseadas no NACP e sua performance de acordo com o algoritmo estipulado por Heintz et al. (2014). As moléculas que mais se aproximam das propriedades desejadas puderam então ser selecionadas seguindo critérios como viabilidade tecnológica, disponibilidade de matéria prima e oportunidade econômica entre outros.

Gerbaud et al. (2017) destacam ainda que a principal vantagem do uso de técnicas como o CAMD é a capacidade de avaliar de forma eficiente um enorme 
número de possibilidades (milhares ou milhões); entretanto cada possibilidade precisa passar pela análise de especialista pra avaliar sua viabilidade tanto em termos de síntese e estabilidade química como de aplicação industrial. Nesse trabalho os autores utilizaram uma metodologia similar para um estudo de caso de biolubrificantes derivados do ácido ricinoleico.

Essa metodologia pode ser usada para diversos fins, com o auxílio de diferentes ferramentas. Zhang et al. (2020a), com o objetivo de identificar solventes promissores de forma a melhorar o rendimento e seletividade da reação de produção de 2,2,4-trimetil-1,2-H-dihidroquinolina (TMQ), utilizaram método de contribuição de grupos e COSMO-SAC como ferramentas para predizer propriedades da TMQ e solventes . Na etapa de CAMD do trabalho, o algoritmo de busca foi formulado como um problema de Programação Não Linear Inteira Mista (MINLP), no qual restrições estruturais foram impostas para garantir a viabilidade da molécula e restrições de propriedades foram especificadas para atender as necessidades do produto. A moléculas mais promissoras demonstraram capacidade de elevar a produção de TMQ em mais de $30 \%$ e dependendo do objetivo pode haver a mudança na escolha do melhor candidato.

O uso de técnicas de CAMD no desenvolvimento de novos oleogéis pode ser uma alternativa promissora ao teste exaustivo baseado na tentativa e erro. No entanto, para que novas estruturas moleculares possam ser criadas (uso direto de CAMD) de forma a atuar como agentes estruturantes de óleos, é necessário que um dos pilares da técnica - as propriedades desejadas - seja melhor estudado e compreendido. Quais são as propriedades relevantes na formação de oleogéis? Quais valores destas propriedades devem ser buscados na identificação de um bom agente estruturante? Quais modelos matemáticos de predição destas propriedades podem ser usados acoplados a um algoritmo de busca de forma a identificar in-silico a formação de oleogéis? Estas são algumas das questões ainda não plenamente respondidas pela literatura e que este trabalho tem por objetivo contribuir nas respostas.

A utilização de CAMD para classificar moléculas em uma base de dados de acordo com a sua capacidade de formar géis com óleos é um passo importante para o desenvolvimento dessa tecnologia em produtos alimentares. Para tal, são necessários modelos capazes de predizer o resultado da mistura de um óleo e um agente estruturante, e posteriormente ser capaz de predizer propriedades especificas e desejadas do produto final. 


\subsection{Modelos de formação de oleogéis}

Existe um esforço na comunidade cientifica em predizer (ao menos qualitativamente) se ocorrerá gelificação ou não, a partir de dados sobre a estrutura molecular do agente estruturante e do fluido a ser estruturado. Apesar disso, ainda existem poucas ferramentas computacionais e modelos matemáticos com eficiência comprovada na predição da gelificação de óleos. A gelificação de solventes orgânicos é determinada por diferentes fatores, tais como a estrutura do agente estruturante, as interações entre o solvente e o agente estruturante e as condições de preparo do gel. A interação desses fatores define se um dado agente estruturante solubiliza, precipita ou forma gel num dado solvente. Dessa forma, identificar os fatores mais influentes no resultado desse processo é uma etapa crucial para o desenvolvimento de ferramentas computacionais de auxílio ao desenvolvimento de produtos baseados em oleogéis (CORRADINI; ROGERS, 2016).

Diferentes propriedades físicas de solventes e parâmetros de solubilidade vêm sendo avaliados para correlacionar a capacidade de um composto (agente estruturante) de gelificar um dado líquido (solvente). A Tabela 1 apresenta as principais propriedades ou parâmetros usados no estudo da gelificação. 
Tabela 1 - Principais parâmetros avaliados em estudos de gelificação de solventes orgânicos.

\begin{tabular}{cc}
\hline Parâmetros & Referência \\
\hline Constante dielétrica & (GAO; WU; ROGERS, 2012; HIRST; \\
Parâmetro Reichardt's ET-30 para & SMITH, 2004; KASZYŃNKA et al., 2012) \\
solventes & (KASZYNSKA et al., 2012; ZHAO et al., \\
Parâmetro de solubilidade de & 2013; ZHU; DORDICK, 2006) \\
Hildelbrand & (BUSTAMANTE et al., 2011; HIRST; \\
Parâmetros de Kamlet-Taft & SMITH, 2004; ZHU; DORDICK, 2006) \\
& (EDELSZTEIN et al., 2013; EDWARDS; \\
& SMITH, 2013) \\
Parâmetros de solubilidade de & (BONNET et al., 2014, 2015; GAO; WU; \\
Hansen & ROGERS, 2012; LAN; CORRADINI; \\
& ROGERS, 2014; RAYNAL; BOUTEILLER, \\
& 2011; ROGERS, 2018; ROSA NUNES et \\
& al., 2018, 2019) \\
\hline
\end{tabular}

Fonte: Próprio autor.

Lan et al. (2015) avaliaram a performance de predição de propriedades físicas (constante dielétrica), solvatocrômicas (Reichardt's ET-30) e termodinâmicas (Hildebrand) individuais para 22 moléculas estruturantes e 80 solventes. Ficou claro para os autores que parâmetros globais possuem pouca especificidade para predizer o resultado do processo de formação de géis para uma grande variedade de agentes estruturantes. Algumas correlações podem ser observadas entre um parâmetro e uma molécula específica, como por exemplo a capacidade de azo-compostos ( $\left.\mathrm{R}-\mathrm{N}=\mathrm{N}-\mathrm{R}^{\prime}\right)$ formarem gel com solventes com $\mathrm{E}_{\mathrm{T}}(30)$ entre 30 e $55 \mathrm{kcal}^{\mathrm{mol}}{ }^{-1}$. Entretanto, dada a complexidade e variedade de moléculas que podem ser usadas na gelificação, uma única constante física se torna insuficiente para predizer o resultado desse processo.

Quando parâmetros de múltiplos termos foram avaliados (parâmetros de Kamlet-Taft e os parâmetros de solubilidade de Hansen) a capacidade de predição foi melhorada. Isso ocorreu provavelmente pela melhor descrição das moléculas estudadas que esses parâmetros podem fornecer quando comparados com parâmetros únicos. Dentre os parâmetros com múltiplos termos, os parâmetros de solubilidade de Hansen têm recebido um destaque especial como o principal modelo utilizado para a predição de formação de gel (LAN et al., 2015). Como consequência do destaque que os parâmetros de Hansen possuem na literatura sobre gelificação e do desenvolvimento prévio de ferramentas computacionais de predição destes parâmetros feito pelo grupo de pesquisa deste trabalho, esta metodologia foi abordada com maior profundidade neste trabalho. 


\subsubsection{Parâmetros de solubilidade de Hansen}

Os parâmetros de solubilidade de Hansen (HSP: do inglês Hansen Solubility Parameters) são uma derivação do parâmetro de solubilidade de Hildebrand, originalmente proposto para o uso em dissolução de polímeros. O parâmetro de solubilidade de Hildebrand define que a entalpia é o fator determinante para a dissolução de polímeros e que esta é proporcional à raiz da energia de vaporização de uma espécie sobre seu volume molar, como visto na Equação 1.

$$
\Delta H_{m}=V\left(\left[\frac{\Delta E_{1}^{v}}{V_{1}}\right]^{\frac{1}{2}}-\left[\frac{\Delta E_{2}^{v}}{V_{2}}\right]^{\frac{1}{2}}\right) \varphi_{1} \varphi_{2}
$$

Onde $\Delta H_{m}$ é a entalpia de mistura, $V$ é o volume da mistura, $\Delta E_{i}^{v}$ é a energia de vaporização, $V_{i}$ é o volume molar e $\varphi_{i}$ é a fração volumétrica do componente $i$. $O$ parâmetro de Hildebrand $\left(\delta_{i}\right)$ é correspondente à energia de vaporização por $\mathrm{cm}^{3}$, durante vaporização isotérmica do líquido saturado (Equação 2) (ROGERS, 2018).

$$
\delta_{i}=\left(\frac{\Delta E_{i}^{v}}{V_{i}}\right)^{\frac{1}{2}}
$$

Utilizando apenas o parâmetro de Hildebrand não é possível quantificar interações moleculares específicas (como por exemplo, interações de hidrogênio e polares), assim, para contornar essa limitação, os HSP foram introduzidos por Hansen em 1960. Os parâmetros de Hansen consideram a energia de vaporização das espécies como uma medida da soma individual de três componentes energéticos (Equação 3). Estes três componentes são: o componente dispersivo ( $\delta_{d}$ : dominante em estruturas simples e de baixa polaridade), o componente dipolo-dipolo ( $\delta_{p}$ : que leva em consideração os grupos polares da molécula) e o componente de ligações de hidrogênio ( $\delta_{h}$ : que resulta das ligações de hidrogênio). A soma dos quadrados dos termos individuais dos HSP é equivalente ao quadrado do parâmetro de Hildebrand $\left(\delta_{t}\right)$ (Equação 4) (LOUWERSE et al., 2017; ROGERS, 2018).

$$
\begin{aligned}
& \frac{E}{V}=\frac{E_{d}}{V}+\frac{E_{p}}{V}+\frac{E_{h}}{V} \\
& \delta_{t}^{2}=\delta_{d}^{2}+\delta_{p}^{2}+\delta_{h}^{2}
\end{aligned}
$$


Os parâmetros de Hansen têm sido sistematicamente usados na exploração de novos solventes (LI et al., 2014a, 2014b; ZHUANG et al., 2018), no desenvolvimento de novos lubrificantes (FARFAN-CABRERA; PÉREZ-GONZÁLEZ; GALLARDO-HERNÁNDEZ, 2018), entre outras aplicações (BÉTRON et al., 2017; FARFAN-CABRERA et al., 2018; LIU; XIE; QIU, 2017; ZHANG; KESSLER, 2015). Mais recentemente, estes parâmetros têm sido usados como metodologia no estudo da formação de organogéis, desde que foram introduzidos por Raynal e Bouteiller (2011). Segundo Rogers (2018), HSP são capazes de classificar solventes e agentes estruturantes com base na sua capacidade de formar géis.

Quando duas espécies são solúveis entre si, pode-se afirmar que elas estão localizadas próximas uma da outra no espaço de Hansen (espaço tridimensional, no qual cada coordenada é indicada por um dos HSP). Este comportamento é esperado, uma vez que espécies próximas possuem interações não covalentes similares. Quando as espécies se tornam dissimilares e consequentemente se afastam no espaço de Hansen, elas tendem a formar géis até o ponto em que as diferenças são grandes o suficiente para que ocorra precipitação. A região do espaço de Hansen onde todas as espécies são solúveis é chamada de esfera de solubilidade; onde ocorre a formação de gel, de esfera de gelificação. Para uma dada espécie, a esfera de gelificação é sempre maior que a de solubilidade, o que ilustra que o processo de gelificação necessita de um complicado balanço entre parâmetros que influenciam a solubilidade e forças que governam o crescimento de fibras (ROGERS, 2018).

Uma ilustração desse modelo é apresentada na Figura 5: no centro está localizada a espécie a ser avaliada, $\mathrm{N}$-[2-(hexanoilamino)ciclohexil]hexanamida $\left(\delta_{d}=\right.$ 18,$\left.56 ; \delta_{p}=9,82 ; \delta_{h}=15,08 ;\right)$, em azul são representados os solventes que formaram solução, em verde os que formaram gel e em vermelho os que formaram precipitado. É também possível observar o ajuste das esferas de solubilidade (azul) e gelificação (verde). 
Figura 5 - Representação de dados experimentais no espaço de Hansen para o sistema de um agente estruturante $\mathrm{N}$-[2-(hexanoilamino)ciclohexil]hexanamida e diferentes solvente orgânicos. [Esfera de Gelificação: $\delta_{d}=16,25 ; \delta_{p}=10,94 ; \delta_{h}=13.76$; $R_{G e l}=19,91 \mathrm{MPa}^{1 / 2}$; Esfera de Solubilidade: $\left.\delta_{d}=18,56 ; \delta_{p}=9,82 ; \delta_{h}=15,08 ; R_{s o l}=10,9 \mathrm{MPa}^{1 / 2}\right]$.

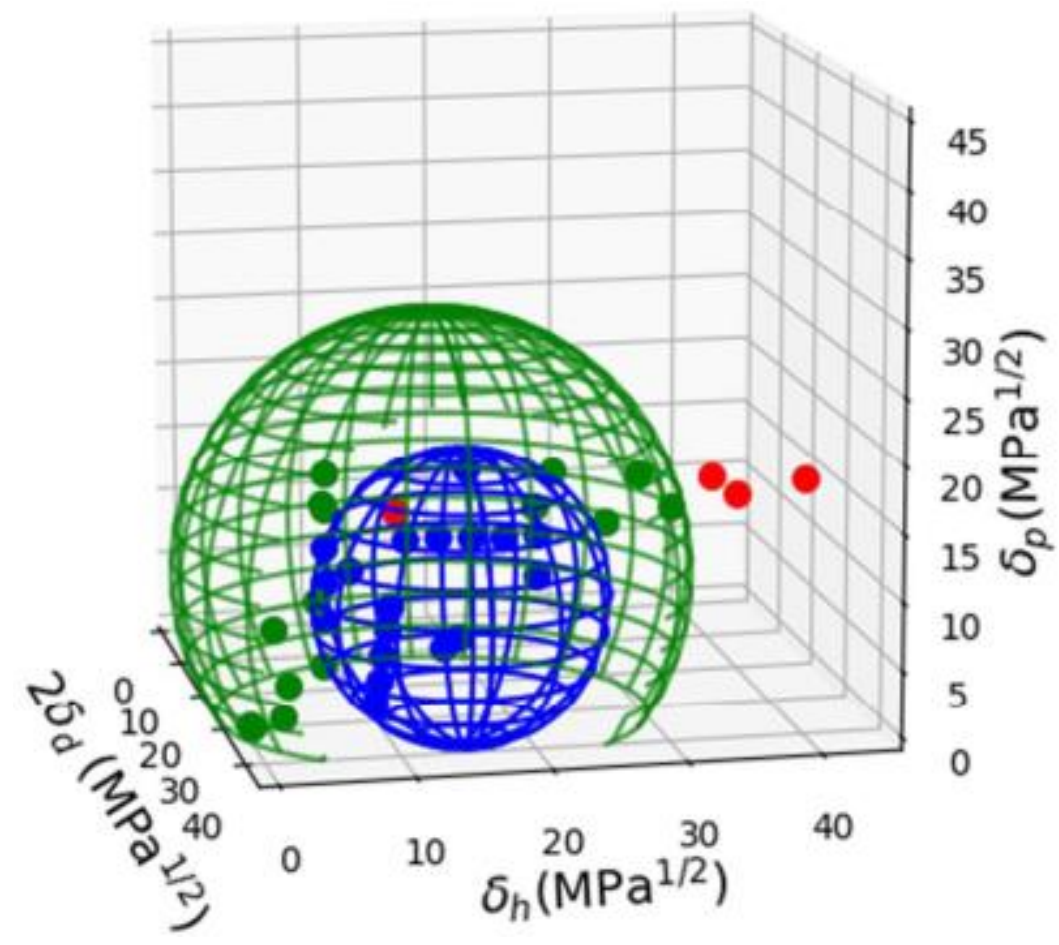

Fonte: Rosa Nunes et al. (2018)

A utilização de correlações que envolvam os HSP e a capacidade de formação de géis de agentes estruturantes de baixa massa molecular (não poliméricos) está presente em diversas publicações com diferentes métodos de tratamento dos dados experimentais. Alguns estudos utilizaram uma abordagem meramente qualitativa (onde não foi determinada a esfera de gelificação), outros utilizam projeções uni- ou bidimensionais (1D ou 2D) do espaço de Hansen (Teas Plot) para simplificação da representação e tratamento de dados (LAl et al., 2016; SHEN et al., 2014; WANG et al., 2017; XIAO et al., 2017).

Em seu trabalho, Bonnet et al. (2014) discutem alguns importantes pontos sobre o uso dos HSP para a predição da gelificação utilizando agentes estruturantes de baixa massa molecular. Segundo os autores, ainda não existe um consenso de se o domínio de gelificação deveria ser delimitado a uma esfera única, como o domínio de solubilidade. Enquanto para a maioria dos dados experimentais disponíveis, os pontos de gelificação se aglomeram em domínios compactos e globulares, para alguns desses dados um elipsoide ou mesmo duas esferas separadas parecem melhor representar o conjunto de dados, fato que pode ser explicado pela diferença 
de mecanismos associados com a formação de agregados do agente estruturante em diferentes solventes. Os autores ainda alertam do risco da perda de informações importantes ao se usar Teas plots ou apenas um ou dois HSP para a simplificação da análise (BONNET et al., 2014).

A determinação da esfera de gelificação foi inicialmente proposta por analogia com a metodologia na qual se determina a esfera de solubilidade em solventes. A metodologia consiste em determinar o centro e o raio de uma esfera para incluir o máximo de substâncias que formam solução dentro da esfera e manter fora da esfera o máximo de substâncias que formam gel ou precipitado. Dessa forma, para a determinação do raio e centro da esfera de gelificação, procura-se encapsular o maior número de substâncias que formem gel enquanto se exclui compostos que formam solução ou precipitado. Espera-se que as esferas apresentem baixo grau de sobreposição. Essa metodologia se mostrou eficiente para a descrição de dados de agentes estruturantes presentes na literatura, tais como amino-derivados do ácido 12 hidroxiesteárico (BONNET et al., 2015), derivados da antraquinona contendo hidrazina, derivados de gluconamida e naftaleno-2-sulfonamida e sal de ácido metabromocinâmico e diciclohexilamina (BONNET et al., 2014; RAYNAL; BOUTEILLER, 2011; ROSA NUNES et al., 2018).

Outros métodos para a determinação da esfera de gelificação foram reportados. Dentre eles, o método que impõe esferas concêntricas foi adotado de forma a evitar complicações durante a análise de dados. Esse método permitiu uma interpretação mais simples de dados experimentais e apresentou bom ajuste em alguns estudos (DIEHN et al., 2014; YAN et al., 2013b), enquanto se mostrou inadequado para diversos casos posteriores (LAN et al., 2014; LAN; CORRADINI; ROGERS, 2014; LIU; CORRADINI; ROGERS, 2015; SINGH et al., 2017; ZHANG et al., 2015).

Uma tentativa para melhorar a primeira abordagem com pouca sobreposição foi feita utilizando duas esferas de gelificação que poderiam ser explicadas pela existência de diferentes estruturas cristalinas do agente estruturante em diferentes solventes. Apesar da melhoria observada no ajuste e medições em raio- $X$ indicarem diferenças significativas nas estruturas cristalinas, essas estruturas foram encontradas em ambas as esferas, indicando que este polimorfismo não se trata de um fator discriminante entre as duas esferas, não corroborando o uso dessa metodologia (ROSA NUNES et al., 2018). 
Uma quarta abordagem para esse problema é alteração do método de esferas centradas onde as esferas compartilham uma região, mas não o mesmo centro. Nessa abordagem busca-se conter o máximo de géis dentro da esfera de gelificação e o máximo de precipitados fora, sem levar em consideração os pontos em que se forma solução (LAN et al., 2014; LAN; CORRADINI; ROGERS, 2014).

Na Figura 6 é mostrado um exemplo de diferentes formas de ajustes das esferas de gelificação. 
Figura 6 - a) Ajuste da esfera de gelificação com o método de esferas com pouca sobreposição; b) Ajuste da esfera de gelificação com o método de esferas concêntricas; c) Ajuste de um segundo conjunto de dados utilizando o método de pouca sobreposição, para uma ou duas esferas de gelificação; d) Ajuste onde se permite sobreposição mas não é forçado que as esferas sejam concêntricas

a)
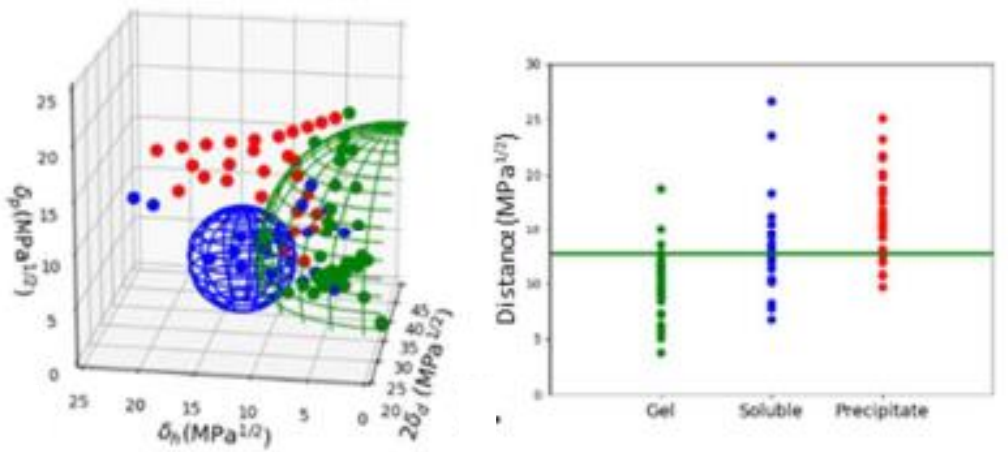

b)
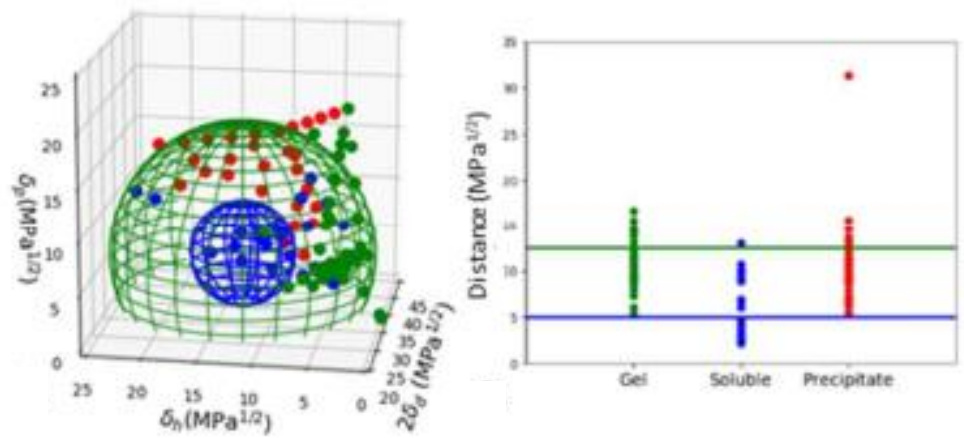

c)
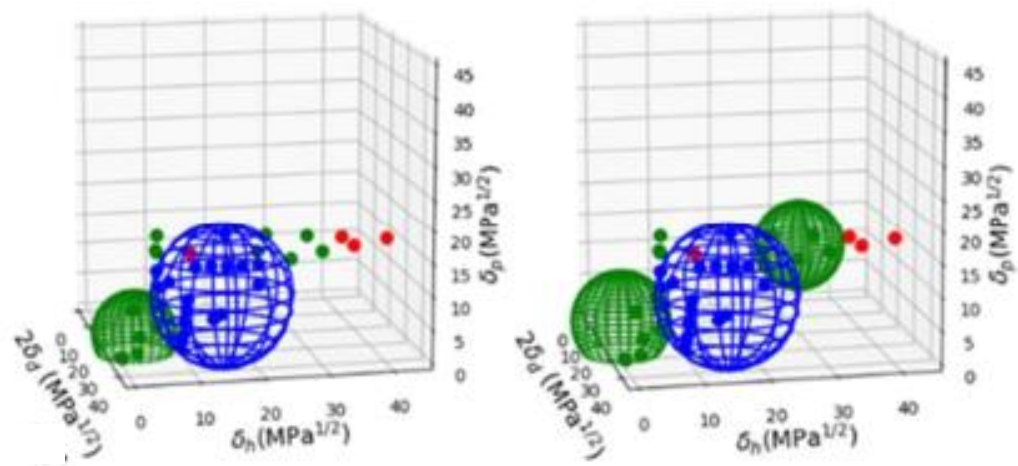

d)
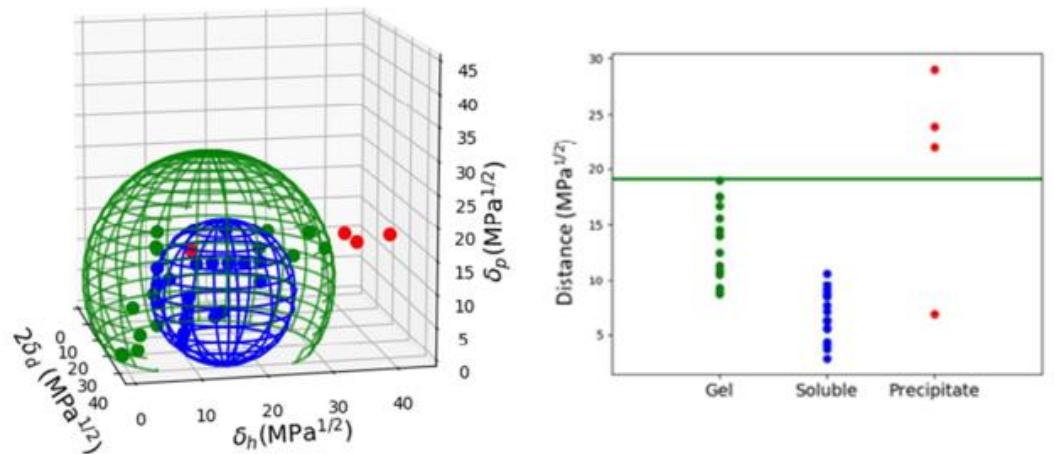

Fonte: Rosa Nunes et al. (2018) 
Como é possível observar pela Figura $6 \mathrm{~d}$, o ajuste de um segundo grupo de dados melhorou quando comparado com o método de duas esferas. Além disso, esse método é compatível com os dados publicados e analisados no trabalho de Rosa Nunes et al. (2018).

É interessante observar que os trabalhos que tomam para si a tarefa de avaliar as esferas de solubilidade e gelificação para a aplicação em organogéis, normalmente avaliam as esferas centralizando um agente estruturante e variando os solventes a serem avaliados. Para a aplicação no processo de estruturação de óleos vegetais, essa abordagem pode não ser a mais adequada, visto que os óleos têm mais similaridades entre si do que os agentes estruturantes candidatos e que a diversidade de óleos é bem menor do que a dos agentes estruturantes. Portanto, é possível supor que uma generalização pode surgir mais facilmente avaliando os agentes estruturantes capazes de formar gel em um dado óleo de composição conhecida. Esta é uma proposta nova em relação à literatura e que será considerada neste trabalho.

Para entender como os agentes estruturantes de óleos se apresentam no espaço de Hansen, Rogers (2018) realizou uma meta-análise de estudos que reportaram 34 agentes estruturantes capazes de gelificar 17 óleos vegetais. De acordo com o autor, a literatura que envolve a formação de oleogéis ainda não possuía dados o suficiente sobre a não formação de gel (solubilização ou precipitação do agente estruturante) de forma a estimar as esferas de solubilidade de Hansen. Além disso, a falta de padronização nos protocolos experimentais pode diminuir a confiabilidade das conclusões da análise. Apesar disso, foi possível observar tendências nos valores dos HSP dos agentes estruturantes. A grande maioria possuía o componente dispersivo na faixa de $16,0<\delta_{d}<17,5 M P a^{\frac{1}{2}}$. Para o componente polar, metade possuía valores que caíam na faixa de $7,0<\delta_{p}<11,0 M P a^{\frac{1}{2}}$ e não foi encontrado nenhum cujo valor foi menor do que 5,0. Por fim, para o componente influenciado pelas ligações de hidrogênio, para todos os agentes estruturantes foi observado $\delta_{h}>5 \mathrm{MPa}^{\frac{1}{2}}$, dos quais pouco menos da metade apresentou valor $7,0<$ $\delta_{h}<9,0 M P a^{\frac{1}{2}}$.

Apesar das limitações dessa análise, Rogers aponta o potencial na utilização dos parâmetros de Hansen na identificação de novos agentes estruturantes capazes de estruturar óleos comestíveis para serem aplicados na indústria alimentícia (ROGERS, 2018), além de ser um ponto de partida para trabalhos que busquem o 
desenvolvimento de ferramentas computacionais capazes de identificar agentes estruturantes, seja utilizando os parâmetros de Hansen de forma isolada ou em conjunto com outros modelos de predição de propriedades.

\subsubsection{Outros modelos de formação de oleogéis}

Do ponto de vista de estruturas coloidais, os mecanismos envolvidos na estruturação de solventes orgânicos podem variar desde processos de equilíbrio envolvendo a formação de agregados que crescem formando estruturas tridimensionais até processos em não equilíbrio em que a transição da micro até a macro fase é interrompida levando à gelificação do solvente (PATEL, 2017; ZACCARELLI, 2007).

Devido à complexidade dos mecanismos de estruturação de solventes orgânicos, diferentes estratégias para entender a formações de géis e projetar novos agentes estruturantes foram aplicadas além dos parâmetros de solubilidade de Hansen previamente discutidos. Dastidar (2008) relata a relevância da possível contribuição da engenharia de cristais no projeto de novos agentes estruturantes, onde se procura entender as interações intermoleculares na formação de cristais. $O$ autor ainda relata a importância de entender os mecanismos por trás da formação de géis; dos parâmetros que governam a nucleação das fibras; como ocorre a automontagem das fibras e como as fibras interagem com o solvente.

Metodologias baseadas em engenharia de cristais capazes de predizer se uma molécula, que não seja um isômero ou homologo de um agente estruturante conhecido, pode formar gel em um dado solvente, ainda possuem aplicações limitadas (GESQUIĖRE et al., 2000; LI et al., 2010; SCHOONBEEK et al., 2000; ZWEEP et al., 2009).

De acordo com Dastidar (2008), ainda são necessários mais estudos para a utilização dessas metodologias de forma isolada ou em combinação com os parâmetros de Hansen para o projeto de oleogéis aplicáveis à indústria de alimentos. À medida que esses modelos possam ser aprimorados com o melhor entendimento dos mecanismos de formação de géis, essas ferramentas serão um diferencial no processo de desenvolvimento de novos agentes estruturantes. 


\subsubsection{Aprendizado de máquina aplicado no desenvolvimento de oleogéis}

A utilização de modelos capazes de predizer propriedade físicas e químicas de moléculas é de fundamental importância para o sucesso da aplicação de metodologias como o CAMD e o CAPD. Entretanto, modelos com fundamentação fenomenológica nem sempre estão disponíveis para a aplicação desejada. Quando os dados para um determinado processo são abundantes, confusos ou quando não existe uma hipótese clara a ser testada, modelos baseados em aprendizado de máquina podem ser uma alternativa para estabelecer a relação entre parâmetros e propriedades necessárias (HALLINAN, 2012; ZHANG et al., 2020b).

A grande vantagem na utilização de técnicas de aprendizagem de máquina é a capacidade de aproximar funções complexas das quais as relações entre os parâmetros medidos e as propriedades resultantes não são exatamente conhecidas. O aprendizado de máquinas simplificou problemas complexos como reconhecimento de imagens, recomendação de conteúdo e programas de tradução (COLEY; GREEN; JENSEN, 2018). Métodos contemporâneos de aprendizado de máquina combinados com o crescente volume de dados tem o potencial de mudar o papel da computação aplicada a engenharia e sua aplicação na indústria química vem crescendo em ritmo acelerado nos últimos anos (BUTLER et al., 2018).

Técnicas de aprendizado de máquina vem sendo usadas com sucesso no projeto de produtos, como para o desenvolvimento de princípios ativos para a indústria farmacêutica (GAUDÊNCIO; PEREIRA, 2020; LAVECCHIA, 2015), de fragrâncias para a indústria cosmética (RADHAKRISHNAPANY et al., 2020; ZHANG et al., 2018), na produção de solventes (LIU et al., 2021) e de tintas e recobrimentos para a indústria química (JHAMB et al., 2020).

No campo de gelificação, Gupta et al. (2016) realizaram a primeira tentativa de usar aprendizado de máquina para predizer o comportamento de agentes estruturantes de solventes orgânicos. Nesse trabalho os autores utilizaram as seguintes metodologias de aprendizado de máquina: Máquina de Vetores de Suporte; Floresta Aleatória; Rede neural artificial; K-ésimo Vizinho mais próximo; Regressão por Mínimos Quadrados Parciais; algoritmo "Naive Bayes"; Algoritmo C5.0. Esses modelos foram utilizados para regredir as relações quantitativas estrutura-propriedade (QSRP do inglês, quantitative structure-property relationships) utilizando um conjunto de dados de teste, com o objetivo de melhorar a predição de formação de géis para 
agentes estruturantes derivados de peptídeos. Os modelos utilizando algoritmos de Máquina de Vetores de Suporte, Floresta Aleatória e Rede neural artificial foram capazes de corretamente predizer $\circ$ resultado de gelificação dos agentes estruturantes em um conjunto de dados de validação.

Mais recentemente, Delbecq et al. (2020) avaliaram a capacidade preditiva de diferentes métodos de aprendizado de máquina (K-ésimo Vizinho mais próximo; algoritmo "Naive Bayes"; Floresta Aleatória; Regressão logística; Rede neural artificial; Máquina de Vetores de Suporte; Árvore de decisão; Gradient boosting) para a classificação de agentes estruturantes de uma família de 6 aminoácidos de cadeias longas de acordo com sua capacidade de formar gel em diversos solventes orgânicos.

Para o treinamento desses modelos Delbecq et al. (2020) utilizaram conjuntos de dados contendo apenas os HSP dos solventes e o resultado da gelificação de cada um dos agentes estruturantes. A performance de cada modelo para cada agente estruturante foi comparada a com a de um classificador aleatório que, para esse caso, tem performance de $50 \%$ (Gel e Não Gel). De acordo com os autores a performance de todos os métodos de classificação foram similares e consistentemente melhores que um classificador aleatório para quatro dos 6 agentes estruturantes.

Delbecq et al. (2020) selecionaram o algoritmo de Máquina de Vetores de Suporte para ajustar um classificador com 3 classes (Solução, Gel, Insolúvel). Este método foi selecionado porque, de acordo com os autores, era o que apresentava resultados com visualização mais simples. Com esse modelo os autores foram capazes de visualizar no espaço de Hansen as regiões de solução, gel e insolubilidade para os agentes estruturantes. De acordo com os autores, 5 dos 6 agentes estruturantes apresentaram duas regiões de gelificação distintas. Além disso as regiões encontradas por Delbecq et al. (2020) não apresentam formas esféricas diferindo assim dos métodos tradicionais de uso dos HSP.

Quando usadas com as devidas precauções, metodologias de aprendizado de máquina são capazes de produzir não só excelentes modelos preditivos e classificatórios, como também visualizações de relações ainda não pensadas pela comunidade cientifica que podem levar a novas compreensões de diversos processos.

A aplicação de oleogéis como alternativa ao uso de gorduras saturadas ou trans em produtos alimentícios é uma estratégia promissora na tentativa de obter produtos com propriedades menos prejudiciais à saúde. Para que a tecnologia de 
oleogéis se torne realidade, entretanto, são necessários esforços para a identificação de novos agentes estruturantes capazes de formar géis em óleos comestíveis de forma a projetar produtos com propriedades controladas, tais como aparência, textura, cremosidade, espalhamento e plasticidade.

Os parâmetros de solubilidade de Hansen apresentam potencial na identificação de novos agentes estruturantes de baixa massa molecular, enquanto a literatura apresenta cada vez mais estudos com novos testes de gelificação que podem ser usados na formulação de modelos cada vez mais precisos. Os HSP podem servir como um primeiro filtro na formulação de novos oleogéis, prevendo a capacidade de um óleo ser estruturado por um dado AE.

A falta de protocolo experimental para a produção de oleogéis ainda limita a capacidade de predição e extrapolação dos modelos. Dessa forma, criam-se precedentes para a investigação de mais agentes estruturantes a fim de se refinar as metodologias atuais e criar modelos mais precisos. 


\section{METODOLOGIA}

\subsection{Base de dados de agentes estruturantes}

A primeira etapa na construção de uma ferramenta capaz de estimar o resultado da gelificação de óleos vegetais foi a construção sistemática de uma base de dados contendo agentes estruturantes de solvente orgânicos identificados na literatura. Ter uma base de dados computacional coerente e sistemática com todos os AEs conhecidos é uma etapa importante para a identificação de modelos. Esta base de dados - até então inexistente na literatura - foi criada neste trabalho por meio da coleta, classificação e registro de diferentes AEs.

As estruturas dos agentes estruturantes (AEs) foram retiradas das seguintes referências: (ABDALLAH; LU; WEISS, 1999; ABDALLAH; WEISS, 2000; ABRAHAM et al., 2012; ALMEIDA et al., 2008; AYABE et al., 2003; BASTIAT; LEROUX, 2009; BEHERA et al., 2012; BELÉN MARCO et al., 2018; BIELEJEWSKI et al., 2009; BONNET et al., 2015; BOT; AGTEROF, 2006; CO; MARANGONI, 2012; CURCIO et al., 2011; DANIEL; RAJASEKHARAN, 2003; DASSANAYAKE; KODALI; UENO, 2011; DIEHN et al., 2014; ELLIGER; GUADAGNI; DUNLAP, 1972; FENG et al., 2014; FURMAN; WEISS, 1993; GRASSI et al., 2011; HANABUSA et al., 1993, 1996, 1997a, 1997b; HIGAKI et al., 2003; HISHIKAWA et al., 1998; HU et al., 2018; HUGHES et al., 2009; LAM; ROGERS, 2011; LAN et al., 2015; LAN; CORRADINI; ROGERS, 2014; LI et al., 2016; LUPI et al., 2013; MALLIA et al., 2009; NIU et al., 2013; OKESOLA et al., 2015; PERNETTI et al., 2007b; QING et al., 2014; RAYNAL; BOUTEILLER, 2011; ROGERS, 2018; ROGERS et al., 2014; ROGERS; WEISS, 2015; ROGERS; WRIGHT; MARANGONI, 2009; SINGH; AUZANNEAU; ROGERS, 2017; STAN et al., 2006; SUZUKI et al., 2008; SUZUKI; UEMATSU; HANABUSA, 2016; TERECH; WEISS, 1997; TRIVEDI et al., 2004; VINTILOIU; LEROUX, 2008; WEISS, 2014; YAMASAKI et al., 1995; YAN et al., 2013a, 2013b; YU et al., 2016, 2017).

Uma vez identificados os diferentes AEs conhecidos, foi utilizado o software ChemSketch ${ }^{\circledR}$ (ACD/LABS, 2019) para desenho de cada estrutura molecular. O objetivo de se desenhar a molécula no software foi gerar os respectivos SMILES (Simplified Molecular Input Line Entry Specification) que servem de entrada para o módulo de estimativa de propriedades baseado em contribuição de grupos do software IBSS $\AA$ desenvolvido pelo grupo de pesquisa do orientador dessa 
dissertação. Para o presente trabalho, foram calculadas as seguintes propriedades para cada agente estruturante: massa molar, parâmetros de solubilidade de Hansen e volume molar.

Ao final dessa etapa, para cada AE, foram estabelecidos: um identificador, um nome comum, nome IUPAC, SMILES e as propriedades calculadas pelo software IBSS®. Neste software, os parâmetros de Hansen e o volume molar são estimados pela metodologia Yamamoto-Molecular Break (HANSEN; ABBOTT; YAMAMOTO, 2021)

A Figura 7 ilustra um exemplo de estrutura molecular identificada na literatura como agente estruturante e as informações típicas a serem usadas no banco de dados (identificador, nome comum e IUPAC e sua representação SMILES).

Figura 7 - Exemplo de molécula estruturante com Identificador, nome comum, IUPAC e representação SMILES.

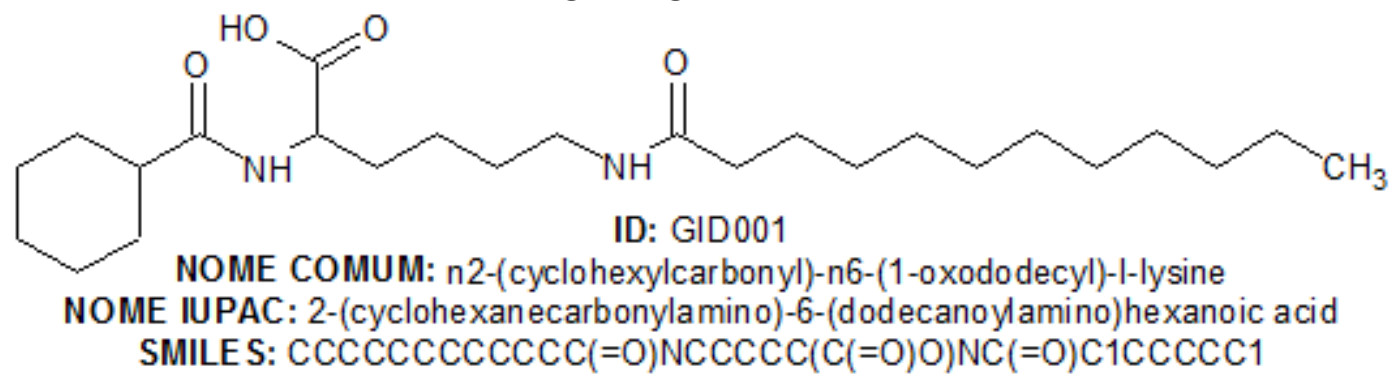

Fonte: Próprio autor.

\subsection{Base de dados de óleos vegetais}

Uma base de dados para óleos vegetais foi criada usando como ponto de partida valores de HSP de óleos reportados na literatura. Foram encontrados 32 óleos com valores de HSP calculados (BATISTA; GUIRARDELLO; KRÄHENBÜHL, 2015; DE LA PEÑA-GIL; TORO-VAZQUEZ; ROGERS, 2016; FARFAN-CABRERA et al., 2018; FARFAN-CABRERA; PÉREZ-GONZÁLEZ; GALLARDO-HERNÁNDEZ, 2018; GRAVELLE et al., 2016; LI et al., 2014b; SOVTIĆ et al., 2020; STORTZ; MARANGONI, 2014).

Essa base de dados ainda foi aprimorada utilizando os dados contidos no software VODesign, desenvolvido anteriormente pelo grupo de trabalho do orientador dessa dissertação. Esse software utiliza a composição de ácidos graxos dos óleos, facilmente obtida na literatura, e retorna à composição dos principais triacilgliceróis 
(TAGs) componentes desse óleo. Os TAGs são então convertidos em SMILES pela mesma metodologia do item anterior e os HSP são calculados por regra de mistura de acordo com a Equação (5).

$$
\delta_{p}^{m i x}=\sum \delta_{p i} \cdot \varphi_{i} ; \delta_{h}^{m i x}=\sum \delta_{h i} \cdot \varphi_{i} ; \delta_{d}^{m i x}=\sum \delta_{d i} \cdot \varphi_{i}
$$

Onde $\delta_{p}^{m i x} \cdot, \delta_{h}^{\text {mix }}, \delta_{d}^{\text {mix }}$ são os HSP da mistura de triacilgliceróis (óleo vegetal) calculados a partir dos parâmetros individuais de cada triacilglicerol e suas respectivas frações volumétricas na mistura $\left(\varphi_{i}\right)$ (HANSEN, 2007). Essa metodologia foi aplicada aos seguintes óleos e gorduras cuja composição foi extraída da literatura: oleína de gordura de Shorea (Shorea robusta), manteiga de cacau, super-oleína de palma e óleo de oliva (HIGAKI et al., 2003); óleo de girassol (DANIEL; RAJASEKHARAN, 2003); óleo de gergelim, óleo de avelã, óleo de amendoim, óleo de camélia, óleo de semente de algodão, óleo de amêndoa doce, óleo de rícino, óleo de linhaça e óleo de colza (FIRESTONE, 2006) e a um óleo de soja cuja composição foi cedida pelo Laboratório de Tecnologia de Alimentos da Faculdade de Ciências Farmacêuticas da USP.

\subsection{Determinação da esfera de solubilidade e gelificação para óleos}

Foi feito também um levantamento de resultados de gelificação conhecidos na literatura aberta (ALMEIDA et al., 2008; BASTIAT; LEROUX, 2009; BLAKE; CO; MARANGONI, 2014; BOT; AGTEROF, 2006; CO; MARANGONI, 2012; DANIEL; RAJASEKHARAN, 2003; DASSANAYAKE et al., 2009; DASSANAYAKE; KODALI; UENO, 2011; FENG et al., 2014; GANDOLFO; BOT; FLÖTER, 2004; HANABUSA et al., 1993, 1997a, 1997b, 1999a, 1999b; HIGAKI et al., 2003; LI et al., 2016; MOTULSKY et al., 2005; ÖĞÜTCÜ; YILMAZ, 2014; OJIJO et al., 2004; PERNETTI et al., 2007a, 2007b; ROGERS, 2018; ROGERS; WRIGHT; MARANGONI, 2009; SCHAINK et al., 2007; SINGH; AUZANNEAU; ROGERS, 2017; SURYA PRAKASH RAO et al., 2014; SUZUKI et al., 2008; SUZUKI; UEMATSU; HANABUSA, 2016; TRIVEDI et al., 2004; WANG; ROGERS, 2015; YU et al., 2016, 2017). O objetivo desse levantamento é investigar a possibilidade de determinação sistemática das esferas de gelificação para diferentes óleos vegetais. 
Com esse objetivo, os dados coletados foram os mais abrangentes possíveis, considerando como agente estruturante moléculas simples com baixa massa molecular (ex.: monoestearato de sorbitano), mistura de moléculas simples com baixa massa molecular em diferentes proporções (ex.: ácido esteárico + $\beta$-sitosterol (4:1)) e ingredientes naturais não poliméricos (ex.: cera de Carnauba (Copernicia prunifera)). Os valores de HSP desses agentes estruturantes foram calculados seguindo a metodologia já definida anteriormente e o resultado de gelificação foi definido em três categorias: formação de solução (S), formação de gel (G) e AE insolúvel (I).

Com esses dados foi possível criar gráficos tridimensionais no espaço de Hansen e ajustar as esferas de gelificação e solubilidade utilizando a aplicação UMD Complex Fluids HSP Program ${ }^{\odot}$ (DIEHN et al., 2014) desenvolvido e gentilmente cedido pelo Grupo de Fluidos Complexos e Nanomateriais da University of Maryland. Essa rotina desenvolvida em MATLAB ${ }^{\circledR}$ (MATHWORKS, 2015) é capaz de ajustar as esferas de Hansen com 3 diferentes metodologias de ajustes: 1) Ajuste de esferas concêntricas: neste método de ajuste, as esferas serão consideradas concêntricas; para o primeiro conjunto de dados o programa ajusta o centro e o raio da esfera e então ajusta os raios das esferas seguintes considerando o mesmo centro; 2) Ajuste de esferas não concêntricas: para esse método o centro de cada esfera é recalculado para cada nova classe de dados a ser ajustada, mantendo, entretanto, uma esfera contida na seguinte e 3) O método de esferas independentes, que ajusta cada esfera de forma independente para cada conjunto de dados (DIEHN et al., 2014).

Foram também criados gráficos de distribuição de ocorrência de cada HSP para verificar onde ocorre o agrupamento dos agentes estruturantes dos óleos vegetais estudados.

\subsection{Modelos classificatórios de formação de gel usando aprendizado de máquina}

Considerando a possibilidade da formação de oleogéis ser um processo complexo para ser descrito com um simples ajuste de esferas, optou-se por investigar também a utilização da metodologia de Machine Learning (aprendizado de máquina) para a predição da formação de oleogéis. A utilização do aprendizado de máquina tem sido usada em diferentes trabalhos para predizer a formação de géis em trabalhos 
que se propõe a modelar etapas experimentais (DELBECQ et al., 2020; GUPTA; ADAMS; BERRY, 2016).

Com esse propósito foram utilizadas diferentes metodologias de aprendizado de máquina e suas capacidades de predição foram comparadas. Uma desvantagem comum das abordagens de aprendizado de máquina é que, embora possam ser excelentes ferramentas na previsão de classes (solução, gel, precipitado), são essencialmente modelos do tipo "caixas pretas" que fornecem resultados sem explicação de causalidade ou descrição em bases fenomenológicas. Portanto, é importante que os modelos desse tipo forneçam algum mecanismo que favoreça a interpretação humana para um entendimento mais completo dos fenômenos envolvidos.

A implementação de aprendizado de máquina foi feita em linguagem $R$ versão 4.0.2 (R CORE TEAM, 2020). Foram comparadas a capacidade preditiva de 3 diferentes métodos: análise de discriminantes lineares (LDA), redes neurais artificiais (ANN) e combinação de análise de componentes principais e redes neurais artificiais (PCA\&ANN). Esses modelos foram escolhidos de acordo com sua simplicidade de implementação assim como sua aplicabilidade em problemas de classificação.

Análises de discriminantes são algoritmos que utilizam dados de treinamento rotulados para construir modelos capazes de classificar novos dados. Esses algoritmos, similarmente às regressões, podem ser lineares, onde o algoritmo busca uma linha reta que separe os dados em classes, ou não lineares, onde o algoritmo pode ajustar uma variedade de curvas para a separação dos dados (HALLINAN, 2012). A LDA busca encontrar as combinações lineares de características dos dados de treino com o objetivo de maximizar a distância entre as médias de duas classes enquanto, ao mesmo tempo minimiza variações dentro de uma classe (JIANG; CHEN, 2020). Nesse trabalho a LDA foi utilizada para a separação dos dados em 3 classes, solução $(S)$, gel (G) e insolúvel (I), utilizando dois discriminantes lineares que podem ser representados em um plano.

As ANN são uma metodologia que vem ganhando muita popularidade nas últimas décadas. Inspiradas no cérebro humano as ANN são compostas por "neurônios" artificiais conectados por sinapses ponderadas. Utilizando um conjunto de dados rotulado é possível ajustar os pesos da rede neural e produzir uma ferramenta capaz de classificar dados complexos (HALLINAN, 2012). Neste trabalho foi utilizado um algoritmo de otimização de primeira ordem backpropagation resiliente 
(RIEDMILLER, 1994) para o ajuste dos pesos da rede neural. As redes neurais utilizadas nesse trabalho foram construídas com apenas 1 camada de neurônios oculta e o número de neurônios variou entre 1 e o total de variáveis de entrada do conjunto de dados.

Além de serem usadas isoladamente, as ANN foram combinadas com o método de análise de componentes principais. Essa metodologia tem como objetivo extrair as informações importantes do conjunto de dados e apresentá-las na forma de variáveis ortogonais chamadas de componentes principais. Idealmente, um pequeno número de componentes principais é capaz de explicar a maior parte da variabilidade dos dados. Essa ferramenta é muito útil para reduzir a dimensionalidade de grandes conjuntos de dados. Para esse trabalho a análise de componentes principais foi utilizada para reduzir a dimensionalidade dos modelos a serem ajustados retirando dos dados de treinamento qualquer componente principal que não contribuísse mais do que $1 \%$ na variância dos dados. Os demais componentes principais foram acoplados a um algoritmo do tipo ANN que utilizou os componentes principais para classificar os dados.

Para o treinamento dos modelos de aprendizado de máquina foram construídas 16 bases de dados contendo parâmetros selecionados para cada mistura de oleogel e agente estruturante. Em cada modelo foi selecionado um conjunto específico de parâmetros que servem para diferenciar um experimento de gelificação do outro. Todos as 16 bases de dados continham alguma combinação dos HSP e

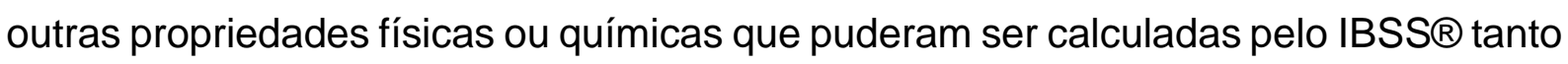
para o agente estruturante quanto para o óleo vegetal.

As variáveis consideradas nesse modelo foram as seguintes: HSP, parâmetro de Hildebrand e volume molecular para o óleo vegetal e o agente estruturante; adicionalmente foram considerados apenas para o agente estruturante: a massa molecular, densidade, ponto de fusão, ponto de ebulição, ponto de fulgor, log do coeficiente de partição octanol-água (log K), temperatura crítica, pressão crítica, volume critico, entalpia de fusão, tensão superficial, fator acêntrico $(\omega)$, entalpia de formação, energia livre de Gibbs de formação e entalpia de formação, todos calculados pelo software IBSS® tendo como dados de entrada a notação SMILES do agente estruturante.

Além dos valores obtidos pelo IBSS $\mathbb{B}$ também foram utilizados valores calculados do parâmetro de Flory-Huggins, obtido pela Equação 6 e Equação 7: 


$$
\begin{gathered}
\chi_{1}=\frac{V_{s}\left(\delta_{g}-\delta_{s}\right)^{2}}{R T} \\
\chi_{2}=a^{*} \frac{V_{s}}{R T}\left[\left(\delta_{d g}-\delta_{d s}\right)^{2}+0,25\left(\delta_{p g}-\delta_{p s}\right)^{2}+0,25\left(\delta_{h g}-\delta_{h s}\right)^{2}\right]
\end{gathered}
$$

onde $\chi_{1}$ e $\chi_{2}$ são o parâmetro de Flory-Huggins, $V_{s}$ é o volume molecular do solvente, $R$ é a constante dos gases, $T$ é a temperatura ambiente, $g$ e $s$ sobescritos representam as propriedade do agente estruturante e solvente respectivamente, $\delta$ é o parâmetro de solubilidade de Hildebrand, $\delta_{d}, \delta_{p}, \delta_{h}$ são os HSP e, por fim, $a^{*}$ é um termo constante para a mistura em base volumétrica (LAN et al., 2014).

Para avaliar a qualidade de predição e evitar o risco de sobre-ajuste foi utilizado o método de validação cruzada leave-one-out com três classes de distinção, solução (S), gel (G) e insolúvel (I). Isso significa que para cada iteração foi retirada uma linha da lista de experimentos e então o modelo é ajustado para as linhas restantes. Uma vez que o modelo é ajustado com os $\mathrm{n}-1$ experimentos, é testado se o modelo pode predizer corretamente o resultado do experimento contido na linha que ficou de fora do ajuste. Esse procedimento é repetido $n$ vezes e contabilizado quantas vezes o modelo foi capaz de predizer corretamente o experimento que foi deixado de fora.

A capacidade preditiva de cada modelo variou com o banco de dados utilizado. Como foram utilizadas 3 classes de resultados, os modelos podem ser comparados com um classificador aleatório com 1/3 de probabilidade de acerto. Entretanto, como o banco de dados original é assimétrico, contendo uma proporção muito maior de experimentos resultando em géis, optou-se por avaliar sua performance frente a um classificador viciado que escolhesse apenas a classe majoritária.

\subsection{Conteúdo de gordura sólida de oleogéis com triacilgliceróis como agente estruturante}

Alguns trabalhos relatam o uso de ácidos graxos, triacilgliceróis e outras gorduras com alto ponto de fusão como agentes estruturantes para a produção de oleogéis (DANIEL; RAJASEKHARAN, 2003; HIGAKI et al., 2003, 2004a, 2004b). Com o intuito de investigar como o conteúdo de gordura sólida afeta a formação de 
oleogéis, os dados experimentais de Daniel e Rajasekharan (2003) e Higaki et al. (2003), incluindo composição dos óleos e gorduras e resultado do teste de gelificação, foram usados no software VODesign. O software é capaz de combinar dois óleos ou gorduras com composições em ácidos graxos conhecida e obter como resposta a composição da mistura em triacilgliceróis e o conteúdo de gordura sólida, para uma faixa de temperatura escolhida, usando um modelo termodinâmico de equilíbrio sólido-líquido (TELES DOS SANTOS; GERBAUD; ROUX, 2013).

Dessa forma, o conteúdo de gordura sólida em função da temperatura para diferentes concentrações de agente estruturante pode ser avaliado. Esses resultados foram então comparados com as conclusões dos trabalhos originais para uma melhor interpretação da formação de gel. 


\section{RESULTADOS}

\subsection{Gelificação de solventes orgânicos}

Foi realizado um levantamento de agentes estruturantes capazes de gelificar líquidos hidrofóbicos em baixas concentrações. Foram incluídos agentes estruturantes capazes de gelificar uma ou mais substâncias orgânicas. Numa primeira triagem foram identificadas mais de 500 estruturas moleculares; os SMILES dessas estruturas foram usados como dados de entrada para o programa IBSS $\AA$ que calculou suas propriedades como definido na sessão anterior.

Em seguida, foram excluídas do conjunto substâncias cujas propriedades não puderam ser calculadas pelo software IBSS $\AA^{\circ}$ e cujos valores não puderam ser encontrados na literatura. Foram consideradas apenas substâncias de baixa massa molecular, eliminando assim compostos poliméricos identificados. O motivo de tal exclusão é que do uso dos HSP para descrição da formação de géis tem tido relevância apenas para substâncias de baixa massa molecular. Ao final, restaram 428 agentes estruturantes. A Tabela 2 contém um exemplo com 6 compostos presentes na base de dados. 
Tabela 2 - Exemplo da base de dados de agentes estruturantes de solventes orgânicos e seus HSP calculados através do IBSS $\AA$

\begin{tabular}{|c|c|c|c|c|c|c|c|c|}
\hline ID & COMMON_NAME & IUPAC_NAME & SMILES & $\begin{array}{c}\mathrm{MW} \\
{[\mathrm{g} / \mathrm{mol}]}\end{array}$ & $\delta_{p}$ & $\delta_{h}$ & $\delta_{d}$ & REFERENCES \\
\hline $\begin{array}{l}\text { GID } \\
127\end{array}$ & dicyclohexylcarbodiamide & $\begin{array}{c}1,3- \\
\text { dicyclohexylurea }\end{array}$ & $\begin{array}{c}\mathrm{C} 1 \mathrm{CCC}(\mathrm{CC} 1) \mathrm{NC}(=\mathrm{O}) \mathrm{NC2} C \mathrm{CC} \\
\mathrm{CCC} 2\end{array}$ & 224.3 & 7.5 & 7.3 & 18.1 & $\begin{array}{l}\text { (LAN; CORRADINI; } \\
\text { ROGERS, 2014) }\end{array}$ \\
\hline $\begin{array}{l}\text { GID } \\
129\end{array}$ & sym-dibenzylurea & 1,3-dibenzylurea & $\begin{array}{c}\mathrm{C} 1=\mathrm{CC}=\mathrm{C}(\mathrm{C}=\mathrm{C} 1) \mathrm{CNC}(=\mathrm{O}) \mathrm{NC} \\
\mathrm{C} 2=\mathrm{CC}=\mathrm{CC}=\mathrm{C} 2\end{array}$ & 240.3 & 9.3 & 12.1 & 19.9 & $\begin{array}{l}\text { (LAN; CORRADINI; } \\
\text { ROGERS, 2014) }\end{array}$ \\
\hline $\begin{array}{l}\text { GID } \\
143\end{array}$ & melamine & $\begin{array}{l}\text { 1,3,5-triazine- } \\
\text { 2,4,6-triamine }\end{array}$ & $\mathrm{C} 1(=\mathrm{NC}(=\mathrm{NC}(=\mathrm{N} 1) \mathrm{N}) \mathrm{N}) \mathrm{N}$ & 126.1 & 20.3 & 31.7 & 21.8 & (NIU et al., 2013) \\
\hline $\begin{array}{l}\text { GID } \\
382\end{array}$ & adipic acid & hexanedioic acid & $\mathrm{C}(\mathrm{CCC}(=\mathrm{O}) \mathrm{O}) \mathrm{CC}(=\mathrm{O}) \mathrm{O}$ & 146.1 & 10.5 & 16.6 & 16.9 & $\begin{array}{c}\text { (DASSANAYAKE; KODALI; } \\
\text { UENO, 2011) }\end{array}$ \\
\hline $\begin{array}{l}\text { GID } \\
387\end{array}$ & sebacic acid & decanedioic acid & $C(\operatorname{cccc}(=0) 0) \operatorname{ccc}(=0) 0$ & 202.3 & 6.1 & 12.4 & 16.7 & $\begin{array}{c}\text { (DASSANAYAKE; KODALI; } \\
\text { UENO, 2011) }\end{array}$ \\
\hline $\begin{array}{l}\text { GID } \\
388\end{array}$ & suberic acid & octanedioic acid & $C(\operatorname{cccc}(=0) 0) \operatorname{ccc}(=0) 0$ & 174.2 & 7.3 & 13.7 & 16.9 & $\begin{array}{c}\text { (DASSANAYAKE; KODALI; } \\
\text { UENO, 2011) }\end{array}$ \\
\hline
\end{tabular}

Fonte: Próprio autor. 
A Figura 8 mostra a posição de cada agente estruturante no espaço de Hansen. É possível notar que há uma região do espaço de Hansen com maior frequência de ocorrência de agentes estruturantes.

Figura 8 - Agentes estruturantes distribuídos no espaço de Hansen. Low molecular-mass organic gelators

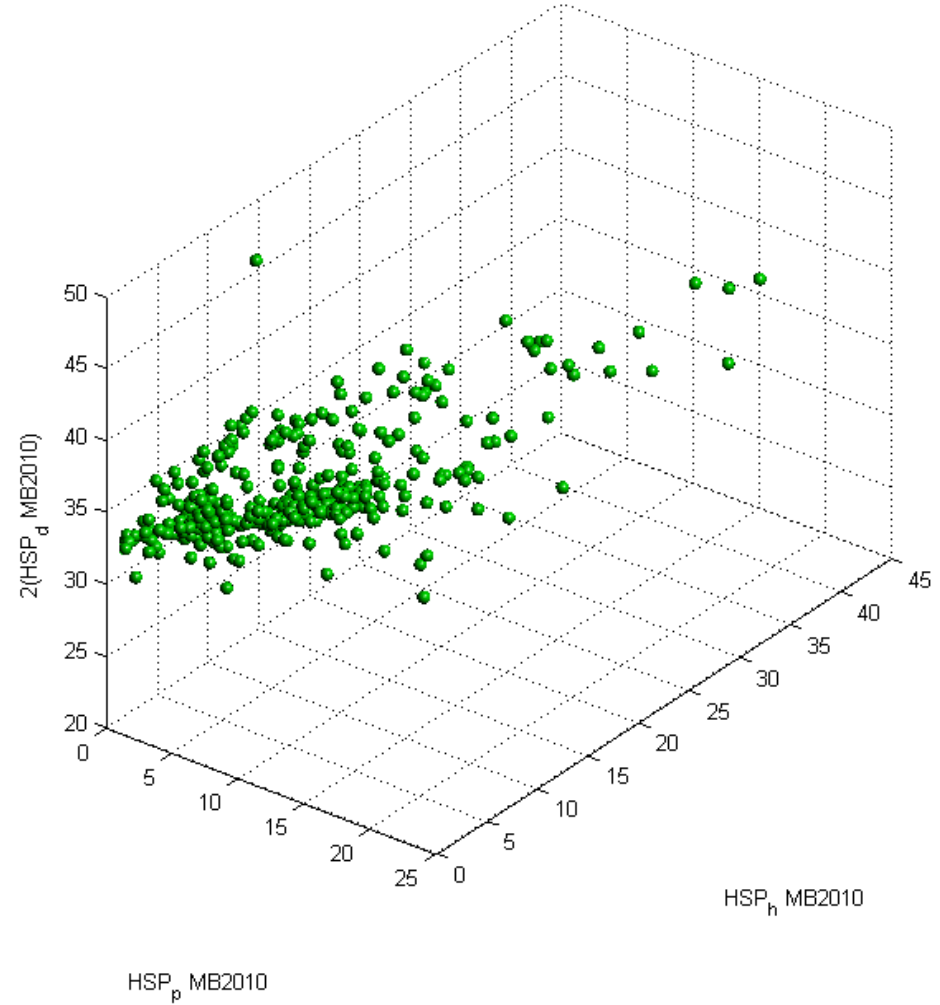

Fonte: Próprio autor.

Levando em consideração que esses agentes estruturantes foram capazes de gelificar uma enorme variedade de solventes, foi feita uma análise da frequência de ocorrência para cada um dos HSP. Na Figura 9 é possível observar que o parâmetro $H S P_{d}$ é o que apresenta menor variabilidade: mais de $80 \%$ das ocorrências estão localizados em valores de $16<\delta_{d}<19$ e nenhum valor reportado é menor que 10 ou maior que 25.

Ao comparamos os valores do $H S P_{d}$ (que representa as forças dispersivas) dos agentes estruturantes capazes de formar gel com algum dos principais solventes orgânicos utilizados em testes de gelificação (como por exemplo benzeno, clorofórmio, acetona, etanol e octano) é possível observar que os agentes estruturantes capazes de gelificar tais solventes possuem valores similares em $H S P_{d}$, um critério importante uma vez que as forças dispersivas é a principal força de interação de muitos solventes orgânicos. 
Figura 9 - Histograma de frequência para cada componente dos parâmetros de Hansen dos agentes estruturantes de compostos orgânicos.
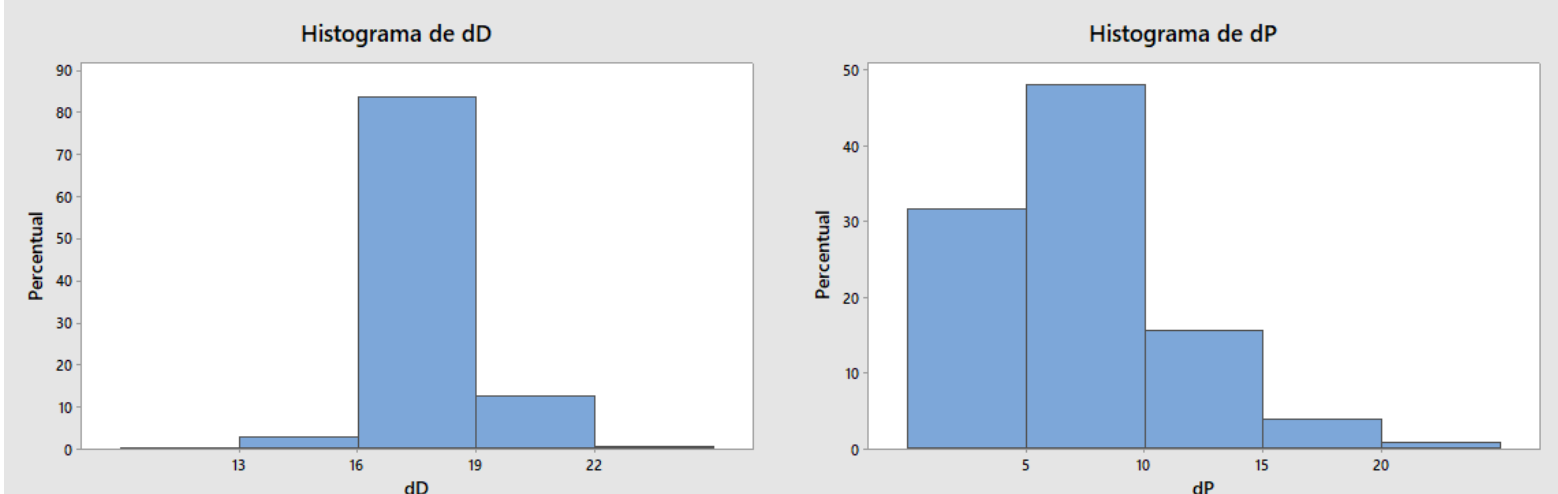

Histograma de $\mathrm{dH}$

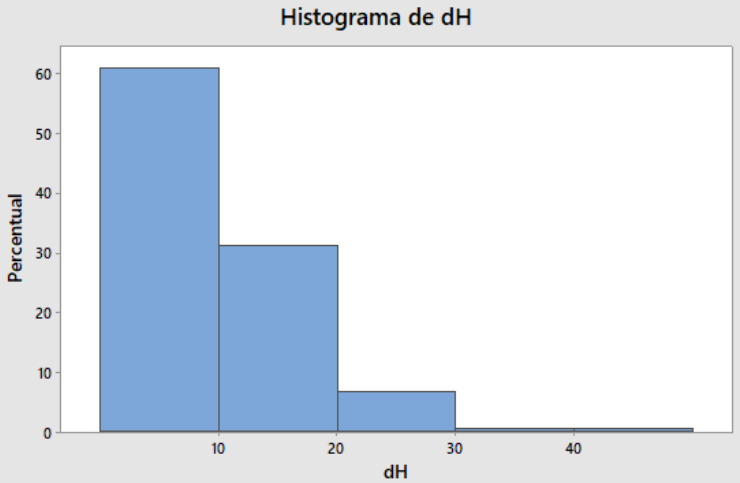

Fonte: Próprio autor.

Para o parâmetro $H S P_{p}$ nota-se que nenhum valor acima de 24 foi observado e que cerca de $80 \%$ das ocorrências possuem valores $\delta_{p}<10$. Esses valores não são surpreendentes uma vez que uma das características mais marcantes dos solventes orgânicos é sua baixa polaridade.

Por fim, o componente com maior variabilidade foi o componente $H_{S} P_{h}$, contido no intervalo de $0<\delta_{h}<45$. Em mais de $90 \%$ dos casos $\delta_{h}<20$, sendo que valores $\delta_{h}<10$ são predominantes, e a frequência cai rapidamente com o aumento de $H S P_{h}$.

É possível esperar que as faixas de HSP encontradas para os agentes estruturantes de óleos sejam mais estreitas do que as reportadas nesta seção, uma vez que esses óleos possuem mais similaridades entre si do que os demais solventes orgânicos. 


\subsection{Estudo da capacidade preditiva dos Parâmetros de Solubilidade de Hansen na gelificação de óleos vegetais}

A Tabela 3 apresenta um exemplo com 20 óleos vegetais e os respectivos valores de HSP. Os óleos com sobrescrito 1 na referência apresentam valores de HSP retirados diretamente da referência citada; os óleos com sobrescrito 2 tiveram seus valores de HSP calculados neste trabalho usando o software IBSS $\AA$, conforme descrito anteriormente (item 4.2). Para estes últimos, a referência citada foi usada apenas como fonte da composição.

Tabela 3 - Tabela com valores de HSP para diferentes óleos.

\begin{tabular}{|c|c|c|c|c|c|}
\hline ID & ÓLEO & $\delta_{p}$ & $\delta_{h}$ & $\delta_{d}$ & REFERÊNCIA \\
\hline OID004 & óleo de canola & 2.1 & 2.6 & 16.5 & $\begin{array}{c}\text { (DE LA PENAA-GIL; TORO- } \\
\text { VAZQUEZ; ROGERS, 2016)1 }\end{array}$ \\
\hline OID008 & óleo de rícino & 6.0 & 10.5 & 13.6 & (SOVTIĆ et al., 2020) ${ }^{1}$ \\
\hline OID011 & óleo de coco & 4.6 & 7.0 & 15.0 & $\begin{array}{l}\text { (BATISTA; GUIRARDELLO; } \\
\text { KRÄHENBÜHL, 2015) }\end{array}$ \\
\hline OID012 & óleo de coco & 2.8 & 6.2 & 16.7 & (SOVTIĆ et al., 2020) ${ }^{1}$ \\
\hline OID014 & óleo de coco & 2.5 & 2.8 & 16.2 & (SOVTIĆ et al., 2020) \\
\hline OID018 & óleo de peixe & 1.5 & 3.6 & 16.5 & $\begin{array}{l}\text { (DE LA PEÑA-GIL; TORO- } \\
\text { VAZQUEZ; ROGERS, 2016)1 }\end{array}$ \\
\hline OID023 & óleo de pinhão manso & 3.1 & 5.9 & 16.5 & $\begin{array}{c}\text { (FARFAN-CABRERA et al., } \\
2018)^{1}\end{array}$ \\
\hline OID024 & óleo de pinhão manso & 3.1 & 0.6 & 16.6 & $\begin{array}{c}\text { (FARFAN-CABRERA; } \\
\text { PÉREZ-GONZÁLEZ; } \\
\text { GALLARDO-HERNÁNDEZ, } \\
2018)^{1}\end{array}$ \\
\hline OID025 & óleo de jojoba & 1.3 & 2.0 & 16.8 & (LI et al., 2014b) ${ }^{1}$ \\
\hline OID032 & óleo de oliva & 3.7 & 3.4 & 16.1 & (HIGAKI et al., 2003) $)^{2}$ \\
\hline OID037 & óleo de palma & 3.3 & 4.1 & 17.5 & $\begin{array}{l}\text { (BATISTA; GUIRARDELLO; } \\
\text { KRÄHENBÜHL, 2015) }\end{array}$ \\
\hline OID040 & super-oleína de palma & 3.5 & 3.7 & 16.2 & (HIGAKI et al., 2003) $)^{2}$ \\
\hline OID048 & óleo de colza & 4.7 & 4.2 & 15.8 & (LI et al., 2014b) $)^{1}$ \\
\hline OID051 & $\begin{array}{c}\text { oleína de gordura de } \\
\text { Shorea }\end{array}$ & 3.4 & 4.5 & 16.2 & $(\text { HIGAKI et al., 2003) })^{2}$ \\
\hline OID053 & óleo de soja & 4.1 & 2.5 & 16.0 & $\mathrm{FCF}-\mathrm{USP}^{2}$ \\
\hline OID054 & óleo de soja & 2.0 & 2.7 & 16.5 & $\begin{array}{l}\text { (DE LA PEÑA-GIL; TORO- } \\
\text { VAZQUEZ; ROGERS, 2016)' }\end{array}$ \\
\hline OID058 & óleo de girassol & 4.1 & 1.9 & 16.0 & $\begin{array}{l}\text { (DANIEL; RAJASEKHARAN, } \\
2003)^{2}\end{array}$ \\
\hline OID059 & óleo de girassol & 1.5 & 4.7 & 16.0 & $\begin{array}{c}\text { (STORTZ; MARANGONI, } \\
2014)^{1}\end{array}$ \\
\hline OID066 & óleo de fritura usado & 3.8 & 6.9 & 15.4 & $\begin{array}{l}\text { (BATISTA; GUIRARDELLO; } \\
\text { KRÄHENBÜHL, 2015) }\end{array}$ \\
\hline OID067 & óleo vegetal & 1.5 & 4.7 & 16.0 & (GRAVELLE et al., 2016) ${ }^{1}$ \\
\hline
\end{tabular}

Fonte: Próprio autor. ( ${ }^{1}$ - Fonte dos valores de HSP; ${ }^{2}$ - Fonte da composição do óleo) 
Da mesma forma que para os agentes estruturantes, os valores dos parâmetros de Hansen para os diversos óleos vegetais foram plotados no espaço de Hansen (Figura 10). É possível observar que os óleos se agrupam em uma região do espaço de Hansen caracterizada por baixos valores de $H S P_{p}$ e $H S P_{h}$.

Figura 10 - Distribuição dos óleos vegetais no espaço de Hansen

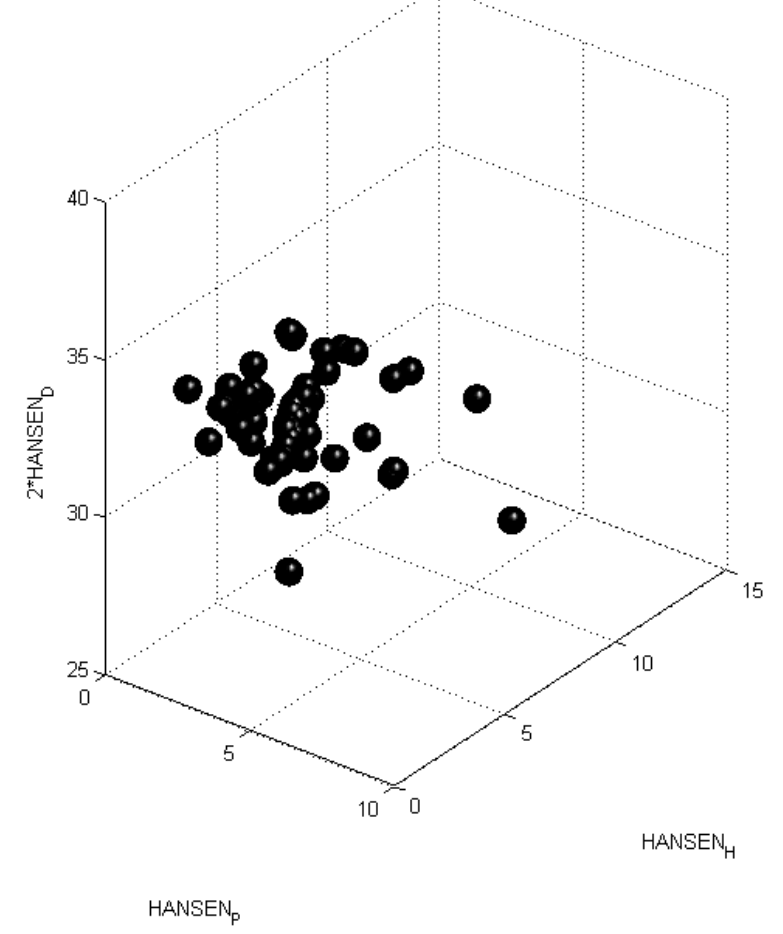

Fonte: Próprio autor.

O ponto mais afastado do grupo $\left(\delta_{p}=6,0 ; \delta_{h}=10,5 ; \delta_{d}=13,6\right)$ representa o óleo de mamona (castor oil). O comportamento deste óleo é explicado pela composição particular: ao contrário dos demais óleos, o principal componente do óleo de mamona é o ácido ricinoleico $(\mathrm{C} 18: 1(\mathrm{OH}))$, que difere quimicamente do ácido oleico por ter uma hidroxila no carbono 12 (C12). Isto ocasiona um aumento significativo nos termos polares e de ligações de hidrogênio do óleo, diferenciando-o dos demais.

Para identificar novos agentes estruturantes é necessário revisar o conhecimento acumulado na gelificação de óleos para identificar uma potencial região onde se acumulem as estruturas reportadas capazes de gelificar tais óleos. Para tal, foi feito um levantamento em 40 trabalhos da literatura aberta, identificando 268 pares de agentes estruturantes e óleos vegetais para os quais é conhecido o resultado do experimento de gelificação. Neste conjunto de dados, estão presentes 25 óleos e 125 agentes estruturantes. Dos casos estudados, há 25 casos em que o experimento 
resultou em solução, 231 onde ocorreu a formação de géis e 12 casos onde foi reportada a formação de precipitado.

Nessa análise preliminar procurou-se ser o mais abrangente possível, sendo assim o trabalho não se limitou a moléculas simples, optando por considerar misturas de moléculas simples e ingredientes naturais, como ceras. Além disso, optou-se por considerar os resultados como reportados na literatura, sem levar em considerações condições específicas, como temperatura ambiente e concentração mínima de gelificação. A Figura 11 ilustra o espaço de Hansen calculado no presente trabalho para diferentes óleos vegetais e agentes estruturantes. Observa-se que o número de pontos de formação de gel supera em muito o de respostas negativas (solução ou precipitação) representando $86 \%$ dos dados coletados. Além disso, um mesmo agente estruturante que formou gel em um óleo pode ter formado precipitado em outro ou mesmo solubilizado em um terceiro, como pode ser observado pelo número de pontos azuis sobrepostos por pontos verdes ou vermelhos.

Figura 11 - Representação do espaço de Hansen contendo óleos (em preto), AE que formaram solução (em azul), AE que formaram gel (em verde) e AE que formou precipitado (em vermelho).

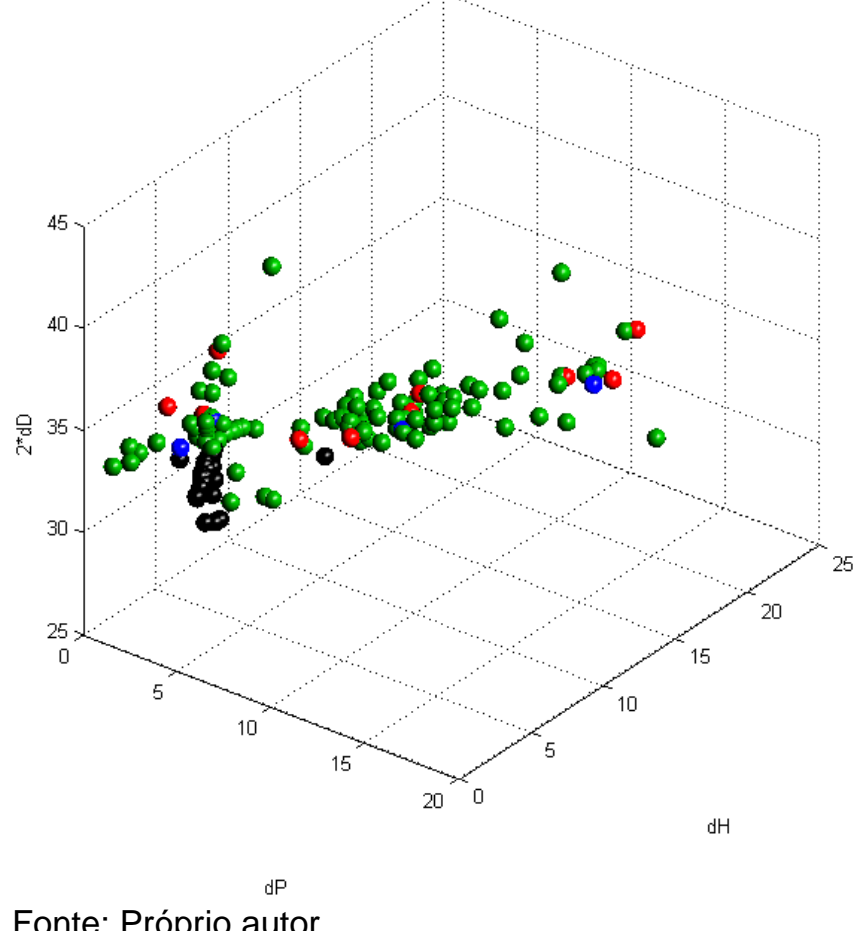

Fonte: Próprio autor.

Com base nestes dados, foi feito um ajuste das esferas de solubilidade e gelificação para os agentes estruturantes de óleos (Tabela 4). As esferas obtidas estão representadas na Figura 12. 
Tabela 4 - Resultado do ajuste das esferas de solubilidade (S) e Gelificação (G) utilizando 3 métodos

\begin{tabular}{c|c|c|c|c|c|c} 
& \multicolumn{2}{|c|}{$\begin{array}{c}\text { ESFERAS } \\
\text { CONCÊNTRICAS }\end{array}$} & \multicolumn{2}{c|}{$\begin{array}{c}\text { ESFERAS NÃO } \\
\text { CONCENTRICAS }\end{array}$} & \multicolumn{2}{c}{$\begin{array}{c}\text { ESFERAS } \\
\text { INDEPENDENTES }\end{array}$} \\
\hline & $\mathbf{S}$ & $\mathrm{G}$ & $\mathrm{S}$ & $\mathrm{G}$ & $\mathrm{S}$ & $\mathrm{G}$ \\
\hline $\mathbf{R}^{\mathbf{2}}$ & 0.8503 & 0 & 0.9900 & 0.6500 & 0.8467 & 0.9044 \\
\hline $\mathbf{R a i o}$ & 3.5000 & 0.1000 & 4.9000 & 1.6000 & 3.8000 & 3.6000 \\
\hline $\mathbf{d P}$ & 3.2965 & 3.2965 & 3.7465 & 3.7600 & 4.0465 & 5.0564 \\
\hline $\mathbf{d H}$ & 4.1270 & 4.1270 & 3.0770 & 3.4746 & 2.4770 & 10.3724 \\
\hline $\mathbf{2 *}^{*} \mathbf{d D}$ & 31.0149 & 31.0149 & 29.5149 & 31.7218 & 32.3649 & 33.3141 \\
\hline
\end{tabular}

Fonte: Próprio autor.

Figura 12 - Representação dos ajustes das esferas de Hansen não concêntricas (à esquerda) e esferas independentes (à direita). A esfera de solubilidade é representada em azul, enquanto a esfera de gelificação está representada em verde.
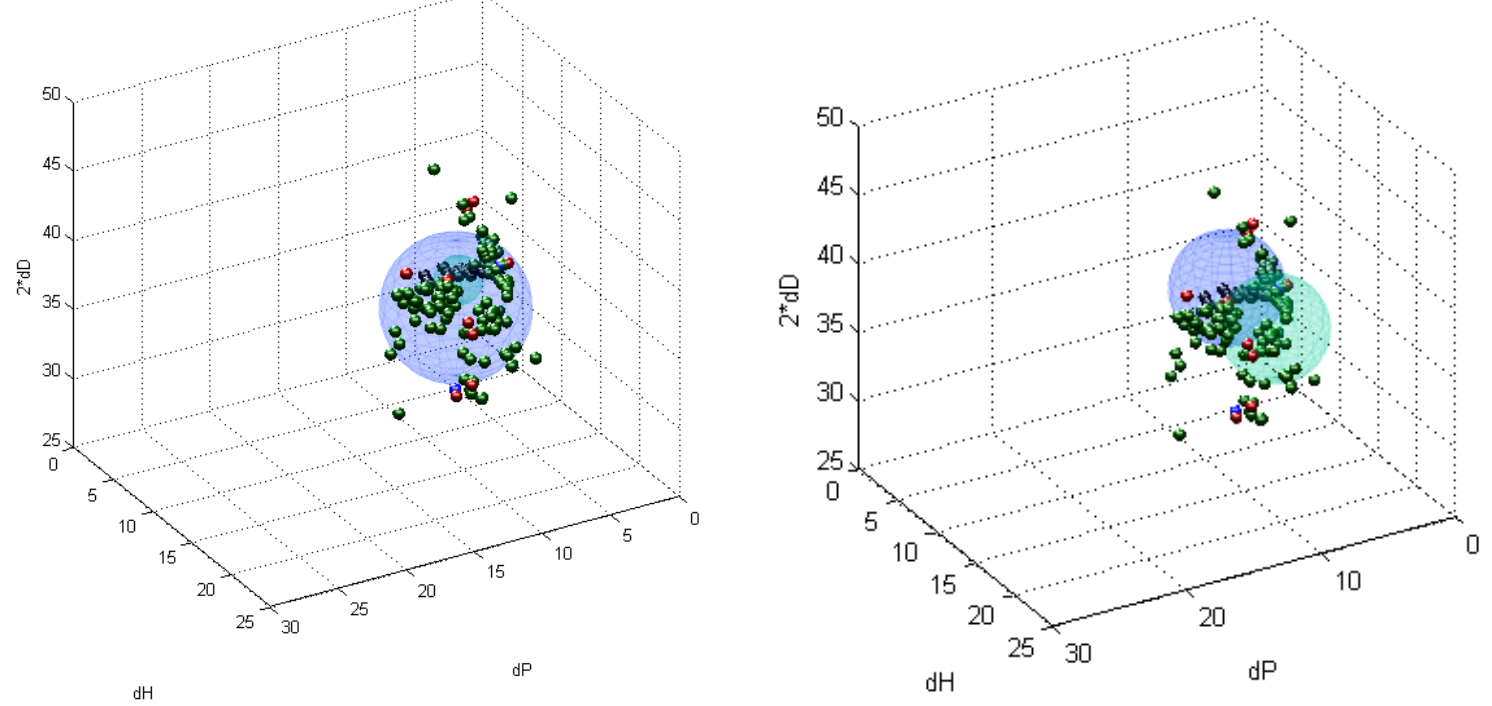

Fonte: Próprio autor.

O ajuste pelo método das esferas concêntricas mostrou-se inviável, uma vez que o algoritmo não conseguiu fazer um bom ajuste dos dados para a esfera de gelificação $\left(R^{2}=0,000\right)$. Dos 3 modelos avaliados, o modelo com esferas independentes apresentou o ajuste mais satisfatório $\left(\bar{R}^{2}=0,8756\right)$. Um óleo hipotético $\left(\delta_{p}=3,90 ; \delta_{h}=3,52 ; \delta_{d}=16,11\right)$ baseado na média dos HSP para os óleos vegetais estaria contido na esfera de solubilidade ajustada por essa metodologia (distância $=1,07$ ) um ajuste condizente com os encontrados na literatura, uma vez que é esperado que o centro da esfera de solubilidade seja aproximadamente o HSP do solvente (óleo) avaliado. Por outro lado, a esfera de gelificação, ficou mais afastada do solvente hipotético $(d=7,03)$, deixando assim o solvente fora da esfera, o que é incomum quando comparado com a literatura. Para o ajuste das esferas não 
concêntricas, o óleo hipotético passa a ficar contido tanto na esfera de solubilidade quanto na de gelificação, entretanto uma esfera de gelificação contida na esfera de solubilidade contradiz a teoria por trás desse modelo utilizando HSP. As esferas da Figura 12 possuem pouco significado real, uma vez que foram ajustadas com dados experimentais provenientes de diferentes estudos com diferentes objetivos. Trata-se apenas de um modelo preliminar para as esferas de solubilidade e gelificação de óleos.

Apesar do bom ajuste matemático, é prematuro afirmar que essas esferas apresentariam uma capacidade satisfatória de predição de gelificação para uma grande diversidade de agentes estruturantes e óleos. Assim como reportado por Rogers (2018), existe falta de padronização nos óleos estudados, de forma que a diferença na composição dos óleos interfere no valor dos HSP e na capacidade de gelificação do agente estruturante. Para contornar esse problema, tratar cada óleo vegetal separadamente e ajustar esferas individuais é uma etapa essencial no processo de predição da gelificação.

Com base nesse resultado preliminar, os óleos vegetais foram então tratados separadamente. No entanto, dos dados disponíveis, apenas 12 óleos possuíam qualquer resultado negativo (não formação de gel), enquanto apenas 6 óleos tinham tanto formação de solução quanto de precipitado para que pudessem ser usados no ajuste das curvas de solubilidade e gelificação. Dos óleos que apresentam resultados negativos foi selecionado o óleo de girassol. O óleo apresentou $2 \mathrm{AE}$ solúveis, $41 \mathrm{AE}$ formadores de géis e $3 \mathrm{AE}$ insolúveis., totalizando 46 pontos para o ajuste. Os pontos isolados para ajustes desse óleo podem ser observados na Figura 13. 
Figura 13 - Pontos de ajuste para as esferas de solubilidade e gelificação do óleo de girassol em preto. $\mathrm{AE}$ solúveis em azul, $\mathrm{AE}$ formadores de gel em verde e $\mathrm{AE}$ insolúveis em vermelho.

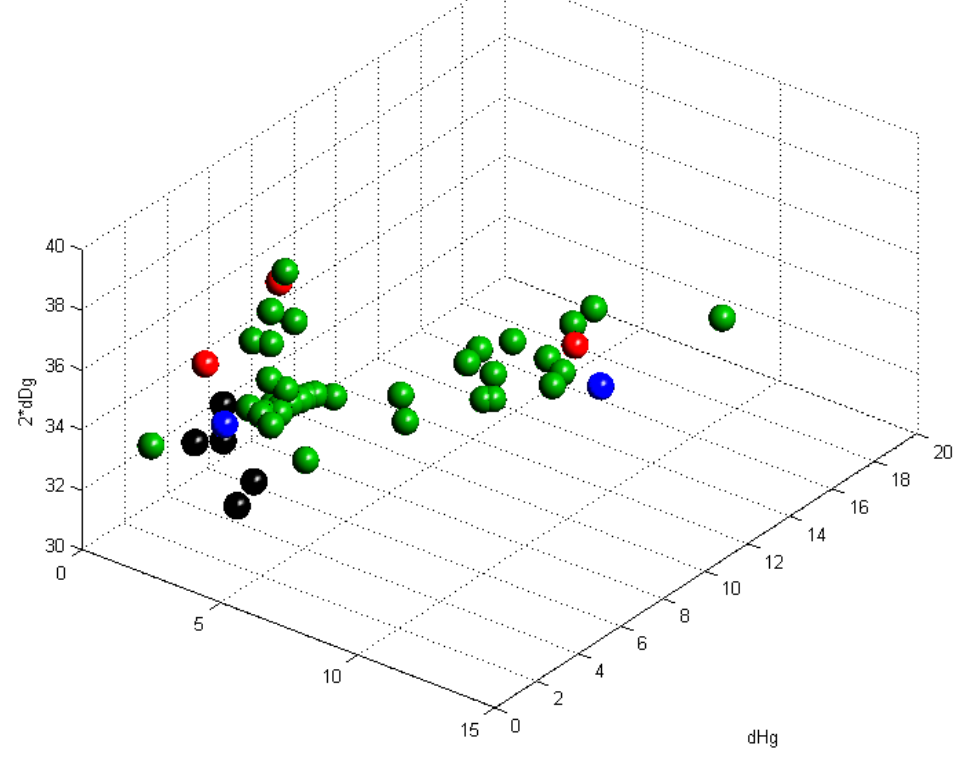

Fonte: Próprio autor.

Como pode ser notado na Figura 13, apesar dos AEs formadores de gel se agruparem em uma região particular do espaço de Hansen próximos aos diferentes óleos de girassol com HSP conhecidos, os casos insolúveis e solúveis ficaram próximos entre si e mais distantes do que os agentes formadores de gel, o que não era esperado de acordo com a teoria do "semelhante dissolve semelhante" (quanto mais próximas duas espécies estão localizadas no espaço de Hansen, maiores as chances de serem solúveis entre si). Uma possível explicação para esses resultados pode ser o fato que os óleos de girassol reportados em experimentos de gelificação nem sempre apresentam composições conhecidas, sendo que esta pode diferir de um estudo para o outro e não coincidir com a composição dos óleos para o qual os parâmetros de Hansen são conhecidos. Apesar de ser uma explicação razoável, ela não explica a existência de agentes estruturantes solúveis e insolúveis tão próximos no espaço para o mesmo solvente (óleo de girassol) de forma que mais investigações para esse caso são necessárias.

A Tabela 5 traz os resultados obtidos para os ajustes das esferas de solubilidade e gelificação para o óleo de girassol. A Figura 14 ilustra as esferas obtidas para este caso. 
Tabela 5 - Esferas de solubilidade (S) e Gelificação (G) utilizando 3 métodos de ajustes para o óleo

\begin{tabular}{c|c|c|c|c|c|c} 
& \multicolumn{2}{c}{$\begin{array}{c}\text { ESFERAS } \\
\text { CONCÊNTRICAS }\end{array}$} & \multicolumn{2}{c|}{$\begin{array}{c}\text { de girassol. } \\
\text { ESFERAS NÃO }\end{array}$} & \multicolumn{2}{c}{$\begin{array}{c}\text { ESFERAS } \\
\text { CONCENTRICAS }\end{array}$} \\
\hline & INDEPENDENTES \\
\hline $\mathbf{R}^{\mathbf{2}}$ & 0.9947 & 0.0000 & 0.9930 & 0.9871 & 0.9976 & $\mathbf{G}$ \\
\hline $\mathbf{R a i o}$ & 2.7000 & 3.5000 & 3.1000 & 1.7000 & 2.4000 & 2.4000 \\
\hline $\mathbf{d P}$ & 1.8210 & 1.8210 & 2.7210 & 3.3721 & 1.2210 & 5.4500 \\
\hline $\mathbf{d H}$ & 1.4977 & 1.4977 & 2.9977 & 4.7412 & 2.3977 & 8.6500 \\
\hline $\mathbf{2}^{\star} \mathbf{d D}$ & 31.8762 & 31.8762 & 30.0762 & 32.4544 & 31.5762 & 33.1500 \\
\hline
\end{tabular}

Fonte: Próprio autor.

Figura 14 - Representação dos ajustes das esferas de Hansen não concêntricas (à esquerda) e esferas independentes (à direita) para óleo de girassol e diferentes agentes estruturantes. A esfera de solubilidade é representada em azul, enquanto a esfera de gelificação está representada em verde.
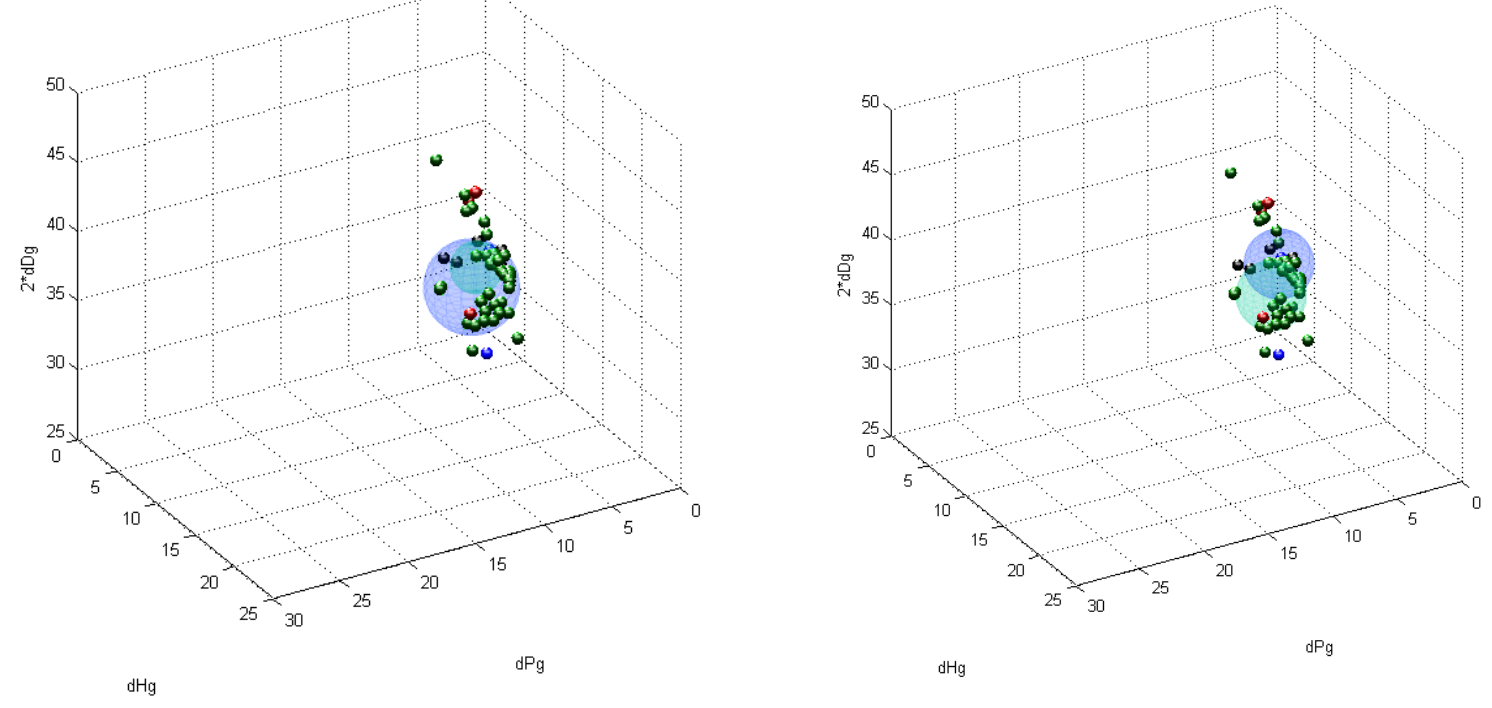

Fonte: Próprio autor.

Assim como no caso anterior, o modelo de esferas concêntricas não foi viável para este conjunto de dados; além disso, as esferas independentes foram as que apresentaram melhor ajustes, seguidas das esferas não concêntricas. Para as esferas independentes 3 dos 6 óleos de girassol com HSP conhecidos não estão contidos na esfera de solubilidade, o que pode ser considerado um desvio. Foram classificados como solução: 3 óleos, 1 solução e 1 gel. Para a esfera de gelificação apenas 3 géis foram corretamente classificados. Os demais experimentos onde houve a formação de gel foram classificados como precipitação por não estarem contidas em nenhuma das esferas, assim como todas as precipitações reportadas experimentalmente.

Para o ajuste das esferas não concêntricas, apenas 5 dos 6 óleos de girassol avaliados estão contidos na esfera de solubilidade, nenhum dos agentes estruturantes 
solúveis foi classificado como tal para esse modelo. Ainda, 7 géis foram corretamente classificados enquanto 1 solução foi erroneamente classificada como gel. Por fim, foram classificados como precipitação: 1 óleo; 1 solução; 34 géis e as 3 precipitações. Vale ressaltar que o algoritmo não leva em consideração a substância estudada para fazer o ajuste, o que aumenta a necessidade de padronização dos experimentos e variedade das moléculas estudas para assim, evitar o viés no ajuste. Como os óleos de girassol considerados não necessariamente são bons representantes dos óleos utilizados nos trabalhos experimentais, mais análises precisam ser feitas antes de se retirar conclusões sobre esse ajuste.

Devido à falta de dados para realizar uma análise satisfatória no espaço de Hansen, e baseado no trabalho de Rogers (2018), foi realizada uma análise de frequência de ocorrência dos valores dos HSP para os agentes estruturantes que podem formar gel em óleos. Nessa análise foram avaliados os agentes estruturantes com resultados positivos em testes de gelificação a fim de encontrar faixas dos HSP que possam nortear as buscas por novas moléculas estruturantes. Foram encontrados 114 agentes estruturantes capazes de formar gel em 25 óleos vegetais. Alguns exemplos desses agentes estruturantes estão contidos na Tabela 6, assim como os óleos que são capazes de gelificar e os trabalhos que reportaram a gelificação. 
Tabela 6 - Fragmento da base de dados de agentes estruturantes de óleos e seus respectivos óleos estruturados.

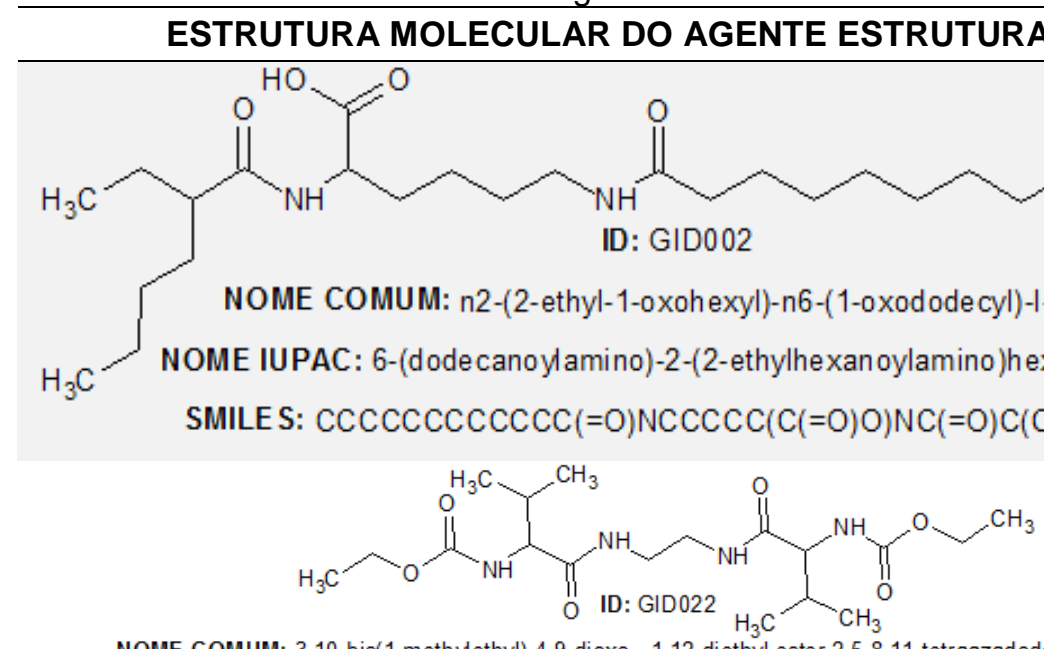

NOME COMUM: 3,10-bis(1-methylethyl)-4, 9-dioxo-, 1,12-diethyl ester 2,5,8,11-tetraazadodecanedioic acid NOME IUPAC:

ethyl n-[1-[2-[[2-(ethoxycarbonylamino)-3-methylbutanoyl] amino] ethylamino]-3-methyl-1-oxobutan-2-yl]carbamate SMILES: $C \operatorname{COC}(=0) N C(C(C) C) C(=0) N C C N C(=0) C(C(C) C) N C(=0) O C C$

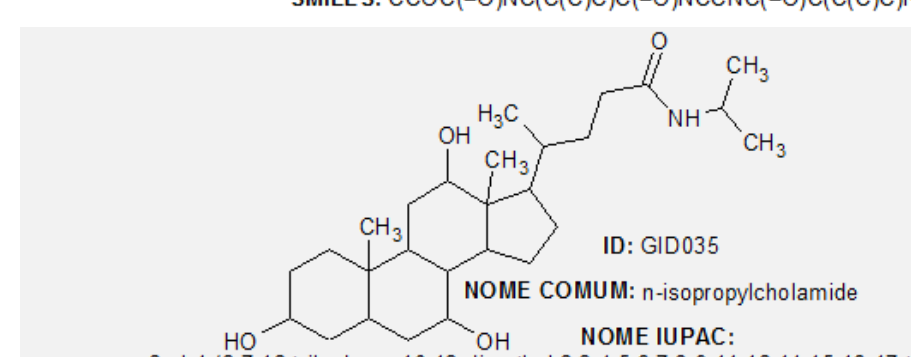

$\begin{array}{lll}8.7 & 21.8 & 17.9 \quad \text { óleo de colza }\end{array}$

óleo de salada óleo de soja

(HANABUSA et al., 1997a)

\section{REFERÊNCIA}

(SUZUKI et al., 2008) $\begin{array}{cccc}10.5 & 11.6 \quad 16.9 \quad \begin{array}{c}\text { óleo de linhaça } \\ \text { trioleína }\end{array}\end{array}$

$\begin{array}{lll}13.3 & 11.9 & 17.2 \quad \text { óleo de soja }\end{array}$

\section{.}

ÓLEO

n-propan-2-yl-4-(3,7, 12 -trihydroxy-10,13-dimethyl-2,3,4,5,6,7,8,9,11,12,14,15,16,17-tetradecahydro-1h-cyclopenta[a]phe

SMILES: $\mathrm{CC}(\mathrm{C}) \mathrm{NC}(=0) \mathrm{CCC}(\mathrm{C}) \mathrm{C} 1 \mathrm{CCC} 2 \mathrm{C} 1(\mathrm{C}(\mathrm{CC} 3 \mathrm{C} 2 \mathrm{C}(\mathrm{CC} 4 \mathrm{C} 3(\mathrm{CCC}(\mathrm{C} 4) \mathrm{O}) \mathrm{C}) \mathrm{O}) \mathrm{O}) \mathrm{C}$

Fonte: Próprio autor. 
A Figura 15 apresenta o histograma de frequência dos agentes estruturantes de óleos vegetais estudados nesse trabalho. Assim como para os solventes orgânicos, o componente dispersivo apresenta pouca variabilidade quando comparado aos demais. Cerca de $90 \%$ dos agentes estruturantes possuem componente dispersivo entre $16<\delta_{d}<18$, nenhum valor reportado foi maior que 20 ou menor do que 15 . Um resultado muito similar ao dos solventes orgânicos e compatível com o que foi reportado por Rogers (2018), onde $85 \%$ dos valores de $\delta_{d}$ estavam entre 16 e 17,5 sendo que para o presente estudo essa faixa corresponde a $80 \%$ dos valores considerados.

Figura 15 - Histograma de frequência para cada componente dos parâmetros de Hansen dos agentes estruturantes de óleos.

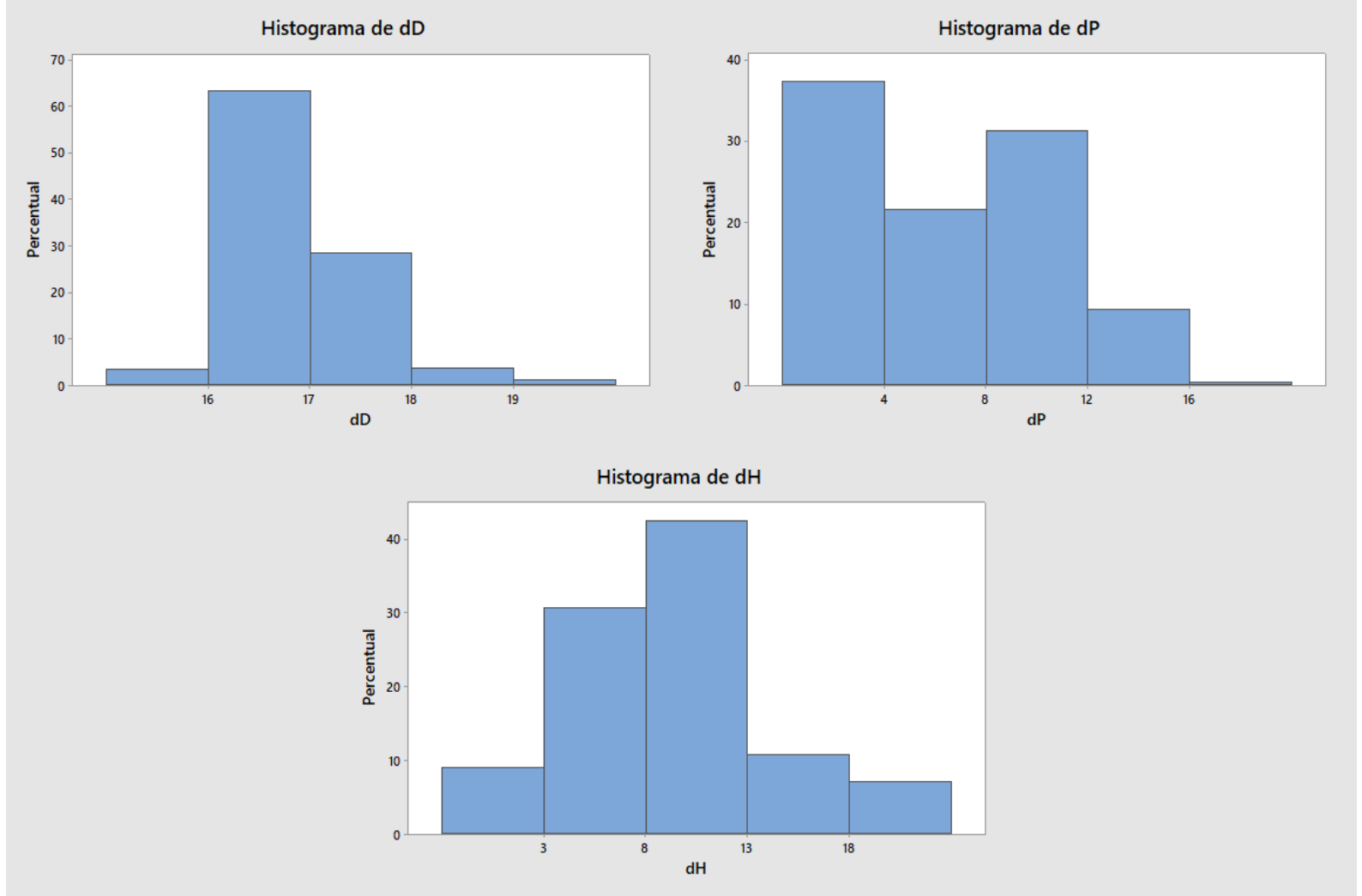

Fonte: Próprio autor.

Considerando o parâmetro $\delta_{p}$, observa-se a formação de dois picos em $\delta_{p}<$ 4 e $8<\delta_{p}<12$, cada um dos picos contendo em torno de 1/3 das ocorrências. Quando essas faixas são somadas à faixa intermediaria de $4<\delta_{p}<8$, a faixa de $\delta_{p}<12$ totaliza $90 \%$ das ocorrências. 
Pode-se destacar que o presente trabalho amplia e traz novas informações ao trabalho de Rogers (2018): neste trabalho $1 / 3$ das ocorrências possuem valores de $\delta_{p}<5$; no estudo de Rogers (2018) não foi encontrado nenhum caso nesta faixa. O presente trabalho inclui compostos que não foram considerados no estudo anterior de Rogers (2018) como ceras, hardfats e misturas de moléculas simples. Dessa forma, a faixa que representava $50 \%$ dos compostos levantados por Rogers (2018) $7<\delta_{p}<$ 11 representa apenas 35\% das ocorrências nesse estudo.

Para o componente $\delta_{h}$ (ligações de hidrogênio), cerca de $40 \%$ dos agentes estruturantes apresentaram valores entre $8<\delta_{h}<13$. Assim como no caso anterior, valores de $\delta_{h}<5$ foram reportados, representando $17 \%$ das ocorrências, enquanto Rogers (2018) não reportou nenhum. Destaca-se que as estruturas nesta faixa são compostas principalmente por ceras e misturas de moléculas simples. Além disto, foi observada uma frequência muito maior para compostos com $\delta_{h}>11$, de quase $40 \%$ para o presente estudo, contra cerca de $10 \%$ para o estudo de Rogers (2018). Nessa categoria de agentes estruturantes, os principais componentes são ésteres, ácidos graxos e sais orgânicos, que não foram considerados por Rogers (2018).

Há duas utilidades de se identificar essas faixas de ocorrência para cada parâmetro de Hansen: 1) identificar a probabilidade de um novo AE formar ou não gel em um dado óleo e 2) usar essas faixas como propriedade alvo em um algoritmo de CAMD.

\subsection{Performance de classificação de métodos de aprendizagem de máquina}

A avaliação das 3 metodologias (LDA, ANN e PCA \& ANN) resultaram em um total de 48 modelos de classificação. A Figura 16 apresenta a capacidade de classificação de cada modelo avaliado além da proporção de géis no conjunto de dados utilizados para servir de comparação. No gráfico da Figura 16 o eixo $X$ representa o conjunto de dados utilizado para o treinamento do modelo e no eixo $\mathrm{Y}$ a capacidade de predição do modelo. A linha vermelha é a proporção de géis, a classe mais representada, para cada conjunto de dados. Para ser considerado útil, um modelo tem que ser capaz de superar o benchmark, uma vez que classificar qualquer experimento como gel apresentaria performance equivalente. 
Figura 16 - Performance preditiva dos diferentes métodos de aprendizagem de máquina para todos os conjuntos de dado № 1-16. A performance dada a um método que classificasse todos os experimentos como gel é dada pelo benchmark.

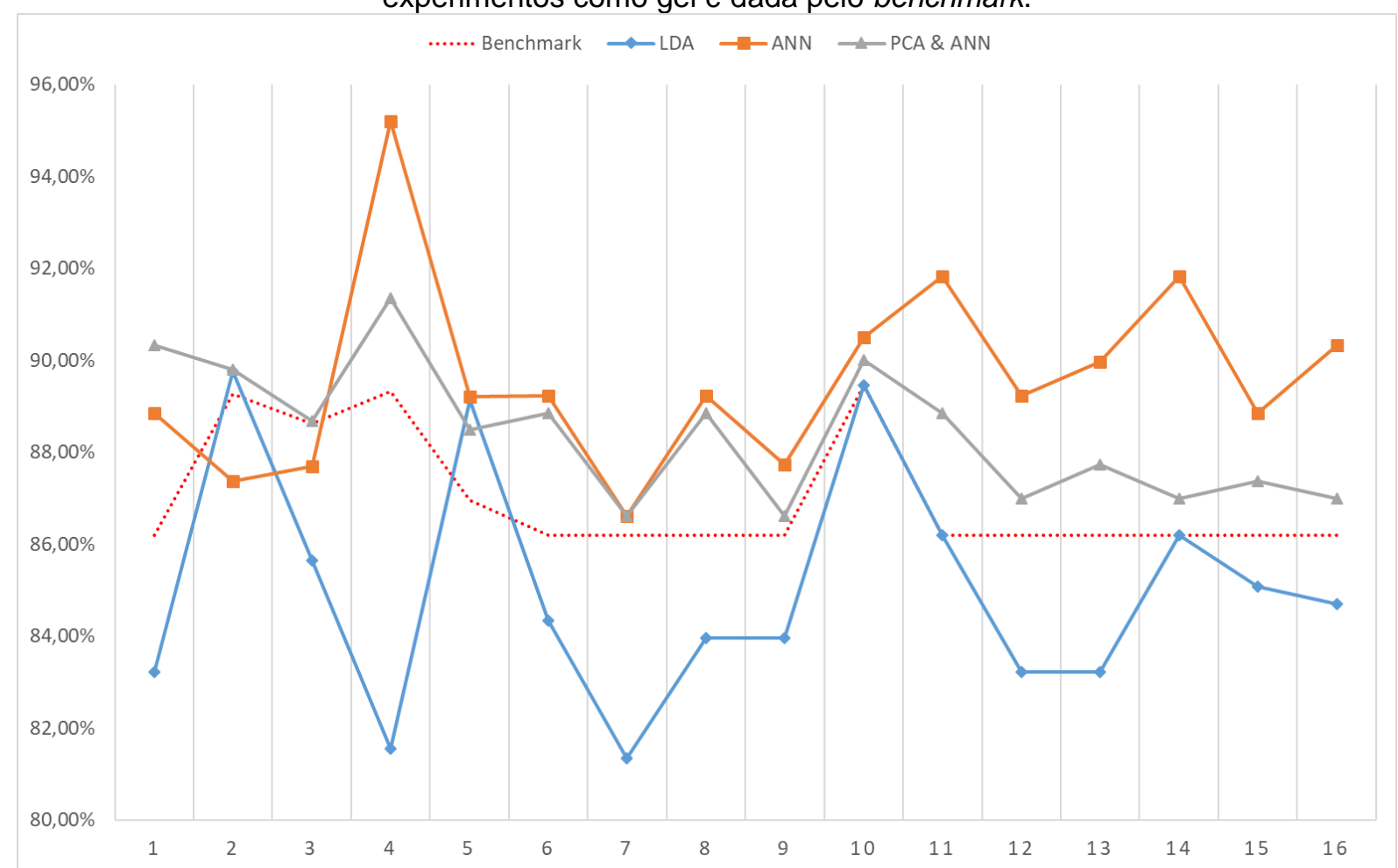

Fonte: Próprio autor. LDA: Linear Discriminant Analysis ou Análise Discriminante Linear. ANN: Artificial Neural Network ou Redes Neurais Artificiais. PCA: Principal Component Analysis ou Análise de Componentes Principais.

A metodologia de LDA foi a que apresentou os piores resultados quando comparada aos demais métodos. Dentre as metodologias, a LDA apresenta melhor visualização do resultado de classificação podendo ser representada facilmente em um plano. Dentre os modelos LDA, aquele treinado com o conjunto de dados 5 foi o que melhor superou o benchmark, com uma capacidade preditiva de 89,13\% superando o benchmark em 2,17\%. A Figura 17 mostra o plano criado pelo LDA. Nesta figura, pode-se observar que para esse conjunto de dados ainda existe muita sobreposição entre as elipses de classificação. Idealmente para esse método, as elipses teriam pouca ou nenhuma sobreposição de forma a separar os experimentos em 3 grupos distintos. 
Figura 17 - Plano de classificação LDA com dois discriminantes lineares para o conjunto de dados ํㅜ․ 5.

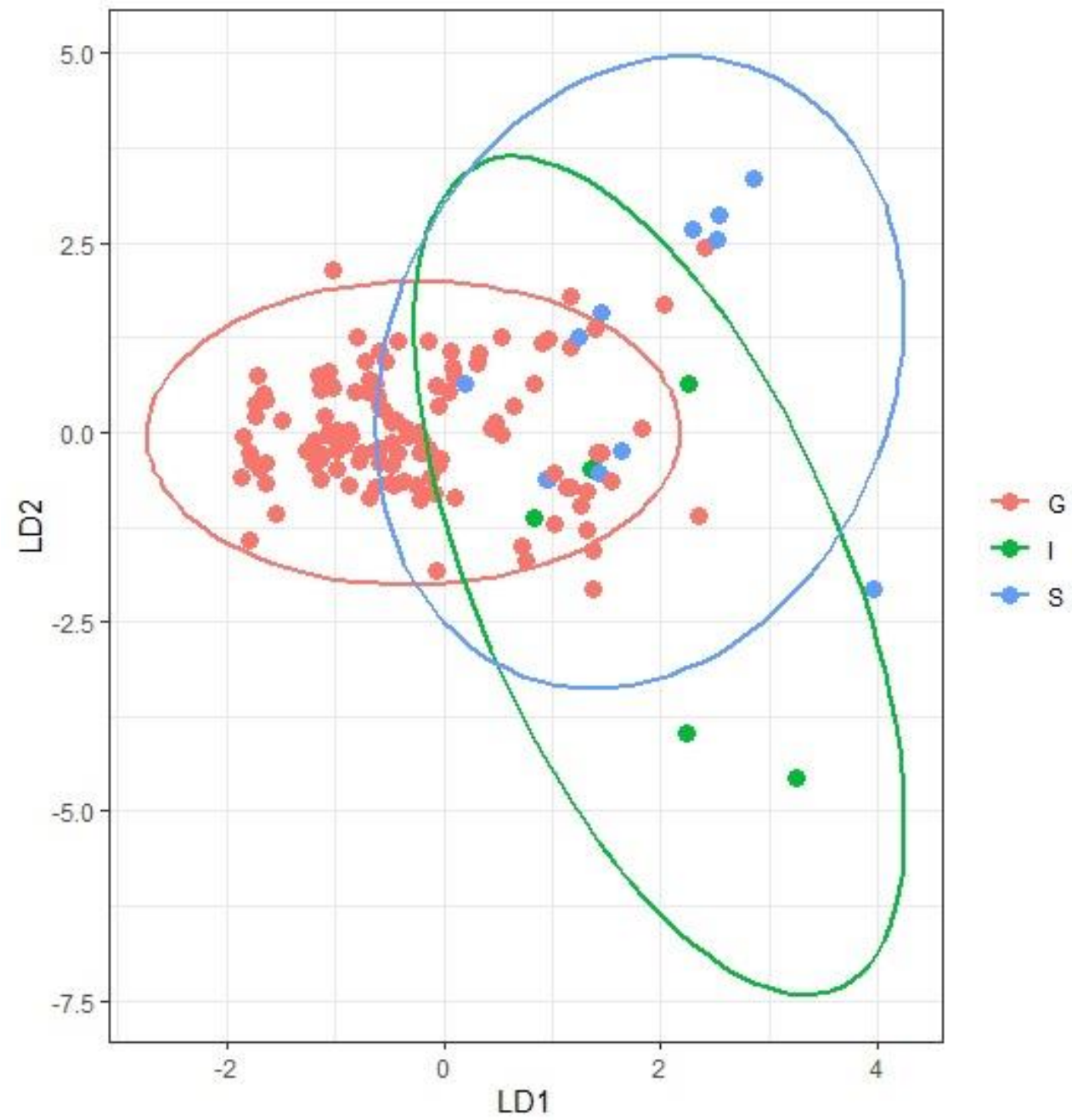

Fonte: Próprio autor. G: AE formador de Gel; I: AE Insolúvel; S: AE Solúvel.

Os discriminantes lineares são obtidos através da combinação linear das variáveis de entrada. Para o conjunto de dados 5 foram utilizadas 21 variáveis sendo elas: HSP e volume molecular do solvente e soluto, além de massa molecular, ponto de fusão, ebulição e ignição, tensão superficial, fator acêntrico, densidade, propriedades críticas, entalpias de formação e fusão e energia livre de Gibbs de formação do soluto em 138 observações. A LDA não foi uma metodologia eficiente para a classificação de misturas não formadoras de gel. No entanto, há uma limitação na literatura que compromete os ajustes: a escassez de resultados negativos reportados (não formação de gel).

A construção da rede neural foi obtida por um algoritmo que, para fins de simplicidade, ajustou a rede neural com apenas uma camada oculta e o número de neurônios nessa camada variou de 1 ao número de variáveis de entrada, sendo selecionado o modelo com melhor capacidade preditiva. 
As redes neurais artificias foram os modelos com melhor capacidade de classificação entre as metodologias avaliadas. O modelo com melhor capacidade preditiva entre as redes neurais foi o que utilizou a base de dados 4. Essa base de dados possuía 103 observações de 22 variáveis sendo elas: HSP e volume molecular do solvente e soluto, além de massa molecular, ponto de fusão, ebulição e ignição, tensão superficial, fator acêntrico, densidade, propriedades críticas, entalpias de formação, fusão e vaporização, e energia livre de Gibbs de formação do soluto.

A Figura 18 apresenta a estrutura da ANN no4 com 1 neurônio oculto. Essa rede neural apresentou capacidade preditiva de 95,19\% superando o benchmark em $5,87 \%$, o melhor resultado entre todos os modelos avaliados. Apesar do bom resultado, vale ressaltar que esse modelo, assim como o LDA $n \div 5$, foi ajustado com um conjunto limitado de dados, uma vez que para muitos dos experimentos levantados nesse trabalho não era possível fazer o cálculo das propriedades utilizadas nesses modelos.

Figura 18 - Estrutura da rede neural artificial para o conjunto de dados ํㅡㄴ.

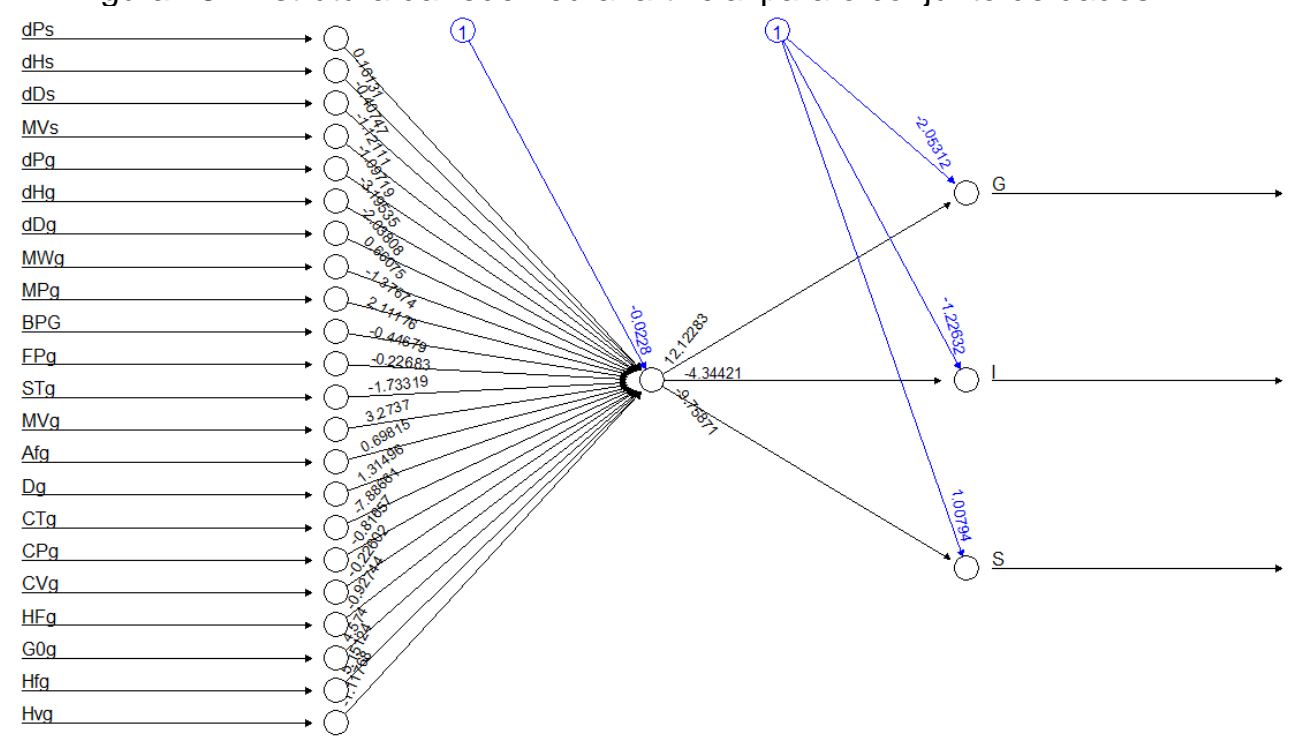

Fonte: Próprio autor.

Dois modelos que apresentaram performances elevadas e foram ajustados com um conjunto completo de dados foram as ANN no 11 e no 14 (Figura 19 e Figura 20 respectivamente). Ambas ANN obtiveram performance de 91,82\% superando o benchmark em 5,63\%. Os conjuntos de dados utilizados para o treinamento das redes continham um total de 268 observações. As variáveis utilizadas na ANN nำ 11 foram: HSP, parâmetro de Hildebrand, para solvente e soluto, o volume molecular do 
solvente, além da distância entre as espécies no espaço de Hansen e o parâmetro de Flory-Huggins calculado tanto pela Equação 6 quanto pela Equação 7. Na Figura 19 observa-se a estrutura obtida para a ANN no 11 com 12 variáveis de entrada e 7 neurônios ocultos.

Figura 19 - Estrutura da rede neural artificial para o conjunto de dados no 11 .

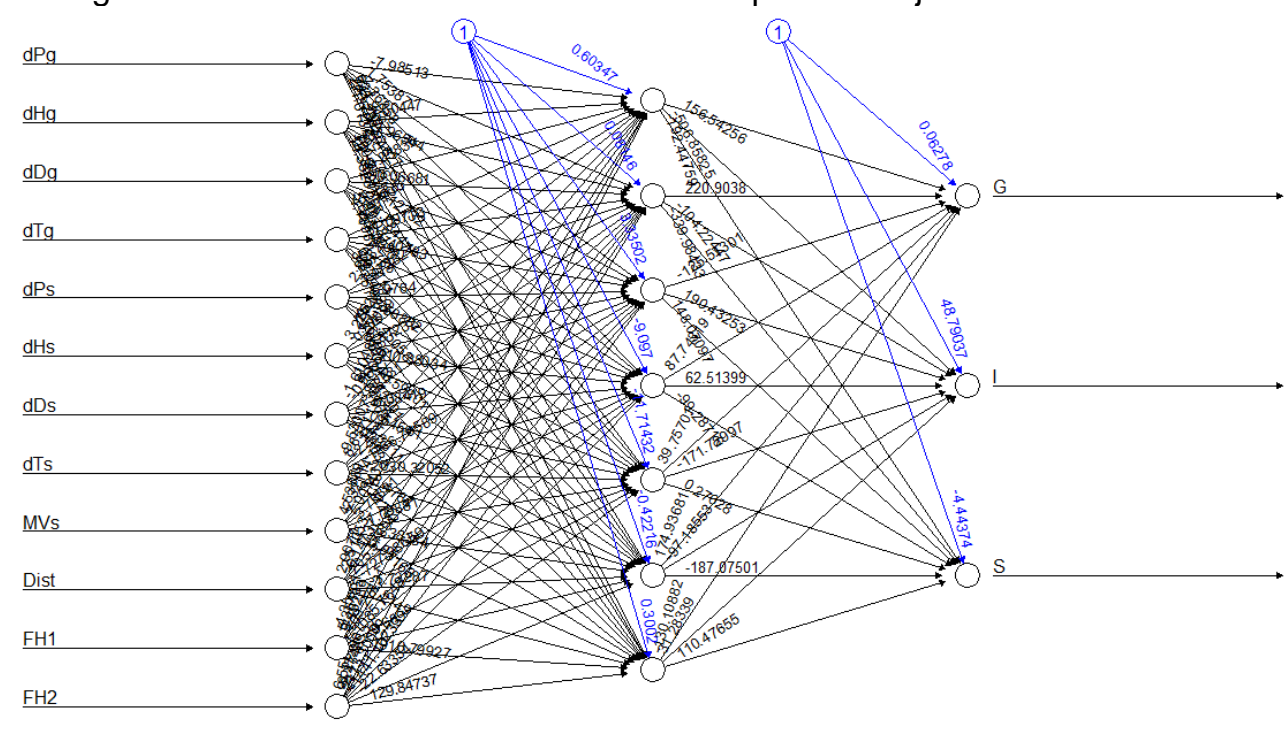

Fonte: Próprio autor.

A ANN no 14 obteve a mesma performance sem considerar o volume molecular do solvente com estrutura apresentada na Figura 20.

Figura 20 - Estrutura da rede neural artificial para o conjunto de dados no 14 .

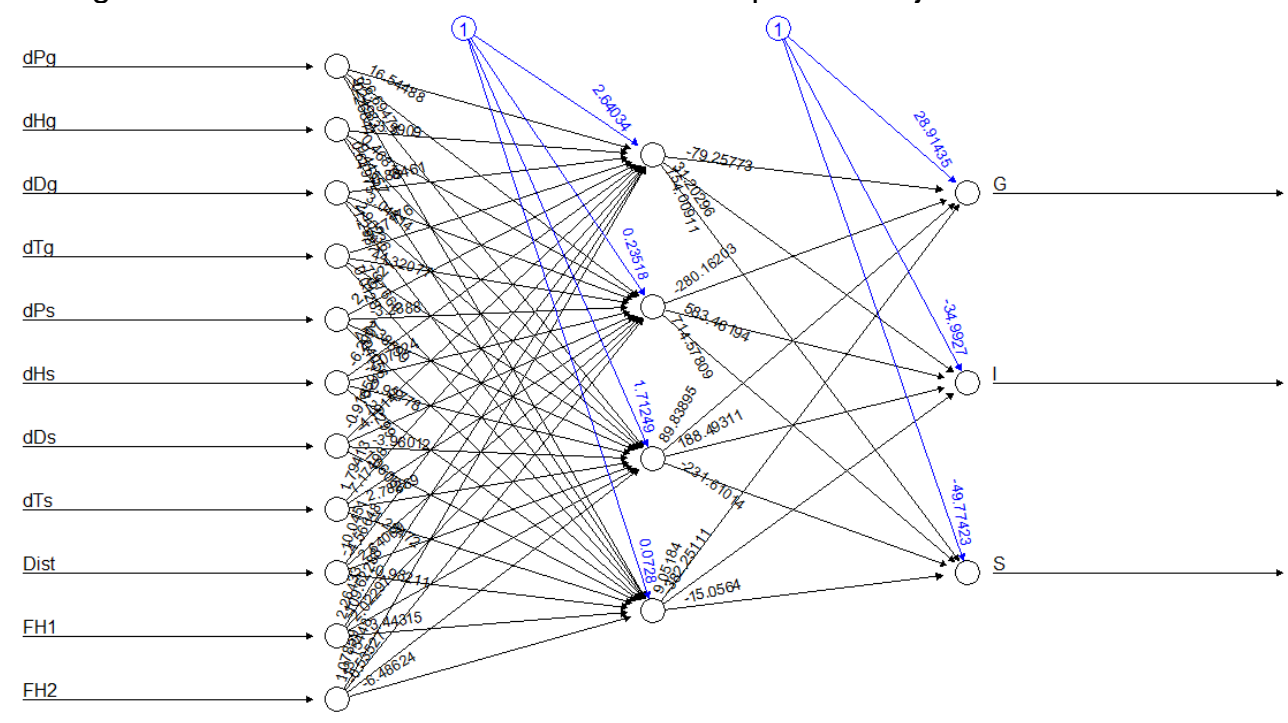

Fonte: Próprio autor. 
Por fim, os últimos modelos a serem avaliados são o que utilizam PCA (Principal Component Analysis ou Análise de Componentes Principais) para redução de dimensionalidade. Antes de utilizar o algoritmo de rede neural, um algoritmo de PCA foi executado nos dados e apenas as variáveis que contribuíam com mais de $1 \%$ da variância do conjunto de dados foram consideradas. Entre os modelos PCA \& ANN o modelo $\mathrm{n}^{-} 1$ foi o que apresentou a melhor capacidade preditiva acima do benchmark, com 90,33\% de capacidade preditiva e 4,14\% acima do benchmark. A estrutura para esse modelo pode ser vista na Figura 21.

Figura 21 - Estrutura da rede neural artificial após PCA para o conjunto de dados no 1 .

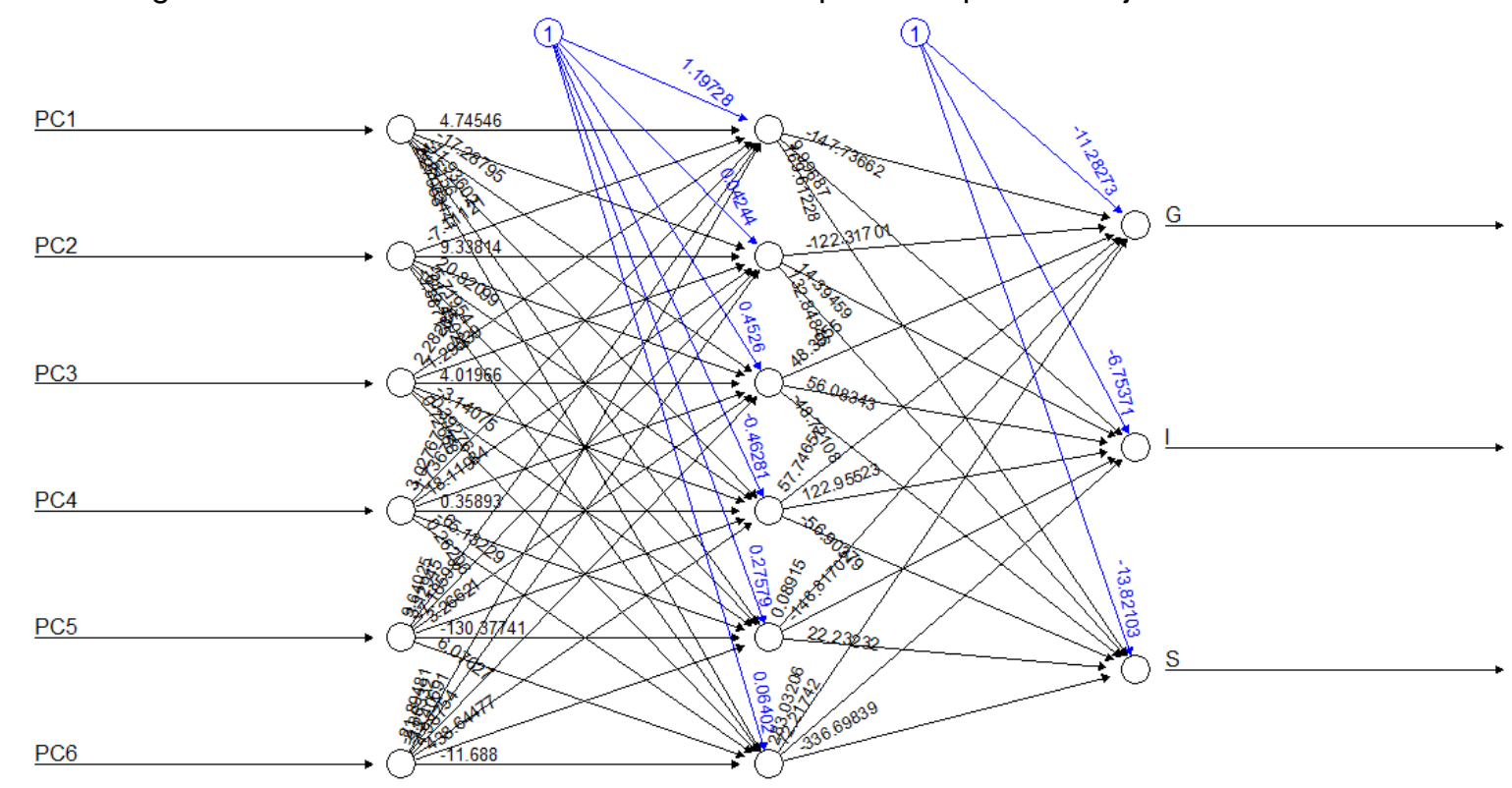

Fonte: Próprio autor.

A principal vantagem desse modelo é sua simplicidade, pois necessita apenas dos parâmetros de solubilidade de Hansen de ambos, solvente (óleo vegetal) e soluto (agente estruturante), como dado de entrada e obtendo ainda assim uma boa capacidade preditiva. Sobre a metodologia PCA \& ANN deve-se ressaltar que a mesma foi a única capaz de superar o benchmark em todos os modelos avaliados, tornando a metodologia promissora para o uso em modelos dessa natureza.

Apesar da capacidade preditiva desses modelos avaliados superar os $80 \%$ chegando até $95 \%$, nenhum dos modelos se mostrou muito efetivo na classificação de não formação de gel, sejam essas soluções ou precipitações. Essa falta de dados negativos pode influenciar a capacidade dos modelos em aplicações industriais. Dessa forma é importante refinar os resultados obtidos por esses modelos ampliando 
a base de dados tomando um cuidado especial para a adição de resultados negativos de formação de gel no banco de dados, aumentando a confiabilidade dos modelos.

Outro obstáculo importante encontrado durante a construção da base de dados utilizada nesse trabalho diz respeito à composição de óleos e estruturantes naturais. A revisão de resultados contraditórios sobre a formação de gel levou Hwang muito recentemente (HWANG, 2020) a concluir que componentes minoritários de óleos e agentes estruturantes naturais podem afetar o resultado de gelificação. Ter isso em mente é importante na hora de se ajustar modelos onde a consideração de composições mais simplificadas pode afetar significantemente a capacidade de predição. Para contornar esse problema é necessário o cuidado de levar em consideração mais componentes em produtos naturais, o que muitas vezes só é possível em trabalhos experimentais que possuam técnicas disponíveis para detecção e identificação destes componentes minoritários.

\subsection{Conteúdo de gordura sólida de oleogéis com triacilgliceróis}

O conteúdo de gordura sólida é uma característica fundamental em lipídios utilizados para produtos alimentícios. Portanto, foi avaliado como esta característica afeta a gelificação de óleos com baixo ponto de fusão. Todos os valores de gordura sólida apresentados nesta seção referem-se a valores preditos pelo modelo de equilíbrio-sólido líquido desenvolvido por Teles dos Santos et al. (2013).

\subsubsection{Gelificação de óleo de girassol}

Para este estudo de caso, foi considerado os dados experimentais de gelificação de óleo de girassol obtidos por Daniel e Rajasekharan (2003). Os autores utilizaram gordura de Kokum (Garcinia indica), trilaurina (Lau), trimiristina (Myr), tripalmitina (Pam) e tristearina (Ste) como agentes estruturantes de óleo de girassol. Os géis foram preparados aquecendo-se a mistura de óleo de girassol purificado e AE a temperatura adequada para a completa dissolução do agente estruturante. A solução é então resfriada a temperatura ambiente $\left(25^{\circ} \mathrm{C}\right)$ por $12 \mathrm{~h}$ e a $4^{\circ} \mathrm{C}$ por $1 \mathrm{~h}$ (DANIEL; RAJASEKHARAN, 2003). Foi considerado gel qualquer mistura que não apresentou escoamento em um teste de inversão de recipiente. A temperatura de fusão foi considerada onde o gel começava a apresentar derretimento. As 
concentrações mínimas de formação de gel e as temperaturas de fusão dos géis formados são informadas na Tabela 7.

Tabela 7 - Estruturação de óleo de girassol purificado por triacilgliceróis saturados

\begin{tabular}{ccc}
\hline Estruturante & $\begin{array}{c}\text { Concentração mínima } \\
\text { de gelificação }(\%, \mathbf{m} / \mathbf{m})\end{array}$ & $\begin{array}{c}\text { Temperatura de } \\
\text { Fusão (oC) }\end{array}$ \\
\hline Gordura de Kokum & $20,0 \pm 0,7$ & $26-29$ \\
Trilaurina & $36,0 \pm 2,1$ & $25-28$ \\
Trimiristina & $31,0 \pm 1,8$ & $26-30$ \\
Tripalmitina & $27,0 \pm 1,5$ & $29-32$ \\
Tristearina & $22,0 \pm 0,7$ & $34-37$ \\
\hline
\end{tabular}

Fonte: Daniel e Rajasekharan (2003)

Utilizando os dados de composição presentes no trabalho de Daniel e Rajasekharan (2003) foram traçados gráficos do conteúdo de gordura sólida para diferentes concentrações de agente estruturantes no óleo de girassol até alcançar a concentração mínima de gelificação. A Figura 22 apresenta o comportamento do conteúdo de gordura sólida simulado neste trabalho do óleo de girassol estudado por Daniel e Rajasekharan (2003), assim como o comportamento para a mistura contendo diferentes concentrações de gordura de Kokum como agente estruturante. É possível notar que a adição da gordura não provocou uma alteração severa no perfil de derretimento do óleo de girassol, apenas aumentou a temperatura onde não há gordura sólida.

O mesmo gráfico foi traçado para os demais agentes estruturantes onde foi observado que quanto maior a concentração de agente estruturante maior a alteração da forma da curva de derretimento da gordura. Essa distorção da curva de derretimento das gorduras pode ser útil para o desenvolvimento de produtos alimentícios uma vez que diferentes agentes estruturantes podem produzir produtos com propriedades sensoriais diferentes de acordo com a necessidade. 
Figura 22 - Conteúdo de gordura sólida da mistura de óleo de girassol e gordura de Kokum (agente estruturante) em diferentes concentrações.

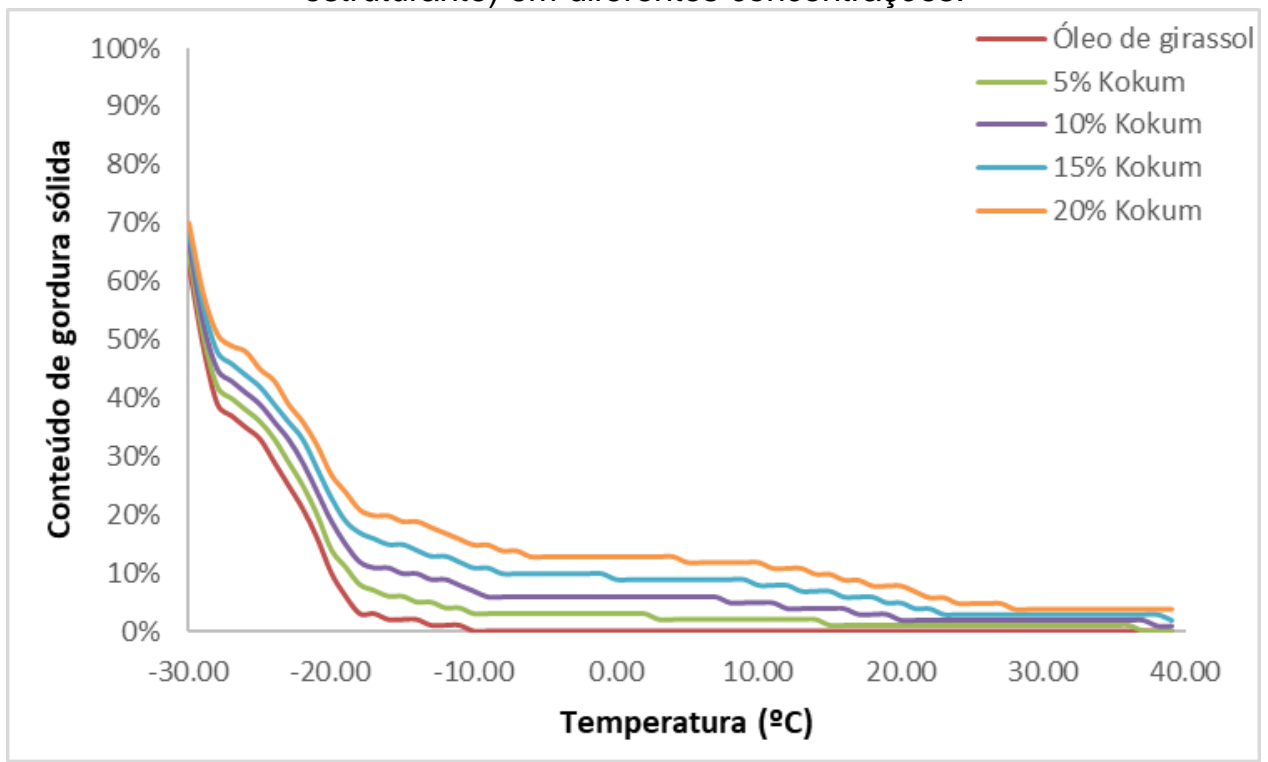

Fonte: Próprio autor.

Figura 23 - Gráfico de conteúdo de gordura sólida da mistura de óleo de girassol e agentes estruturantes em diferentes concentrações.
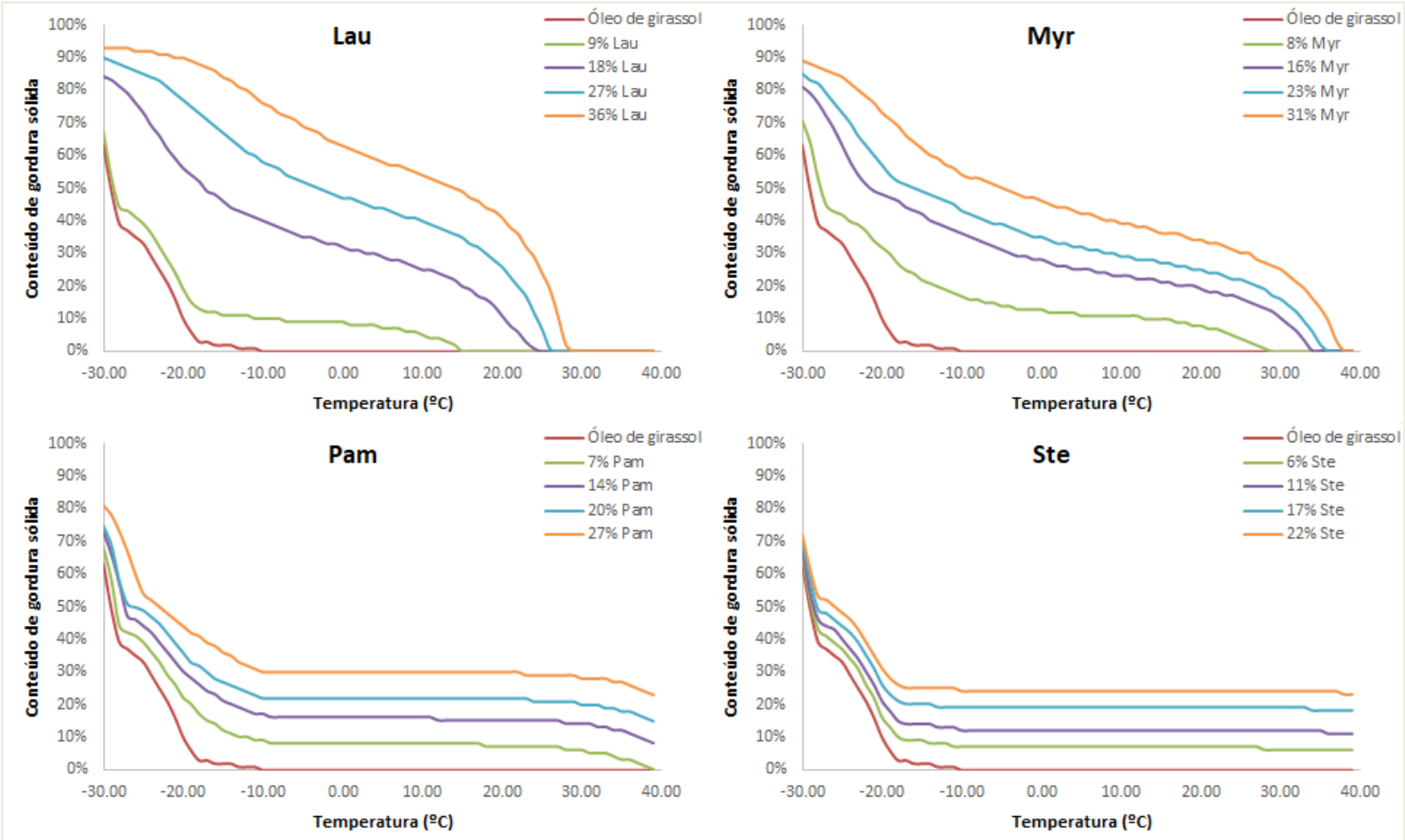

Fonte: Próprio autor.

Nas Figura 22 e Figura 23 não é possível observar nenhum comportamento comum que indicasse a formação de gel nas concentrações reportadas. Na Figura 24 é apresentado as curvas de fusão dos oleogéis com os diferentes agentes 
estruturantes, com o intuito de comparar o conteúdo de gordura sólida nas faixas de fusão dos diferentes géis.

Figura 24 - Gráfico de conteúdo de gordura sólida da mistura de óleo de girassol e diferentes agentes estruturantes.

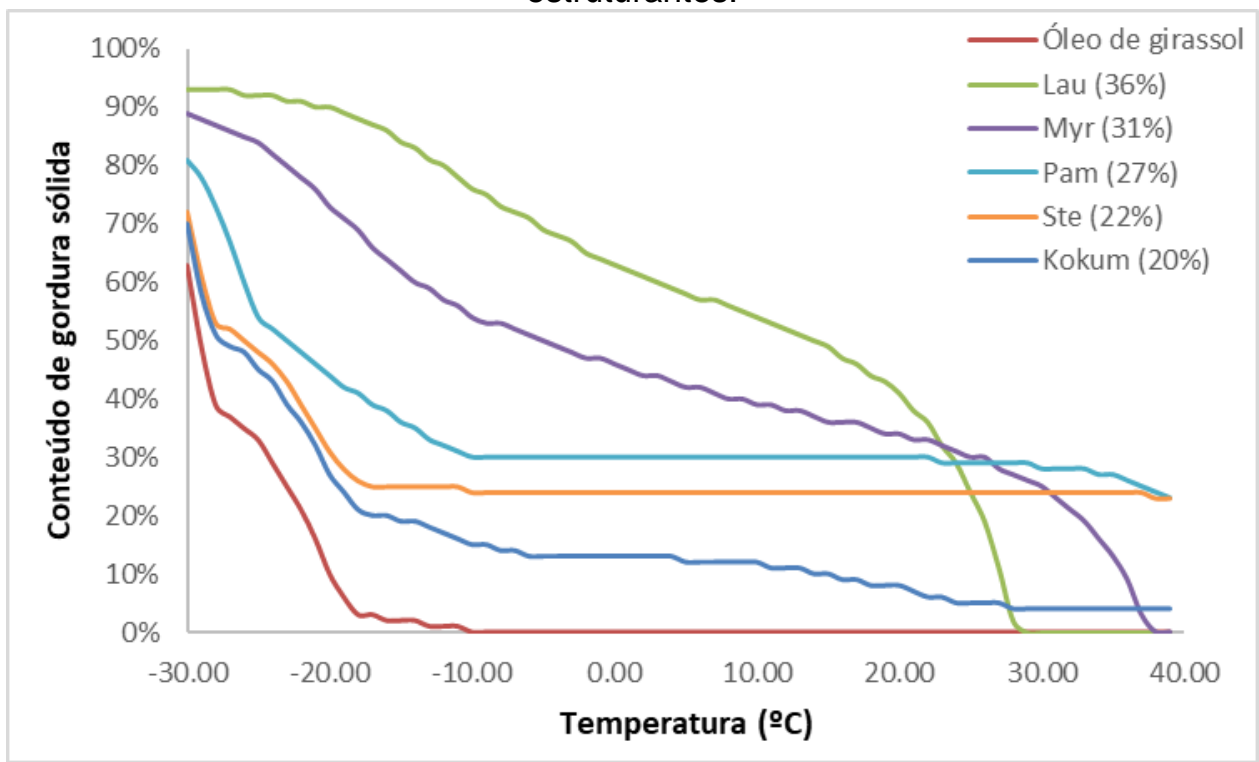

Fonte: Próprio autor.

O óleo de girassol puro não contém gordura sólida em temperaturas superiores a $-10^{\circ} \mathrm{C}$; portanto qualquer conteúdo de gordura sólida encontrado nos géis estruturados é proveniente de interações do óleo com o agente estruturante. Para a trilaurina (Lau) o conteúdo de gordura sólida foi mais elevado que a quantidade de agente estruturante adicionada no óleo até temperaturas de ${ }^{2} 2^{\circ} \mathrm{C}$, o que indica a existência de interações que provocam a cristalização de triacilgliceróis presente no óleo de girassol, uma vez que em uma mistura ideal, onde as interações entre os componentes são ideais, o conteúdo de gordura sólida na mistura seria a soma individual dos sólidos de cada componente.

Na faixa de temperatura de fusão do gel formado por óleo de girassol e Lau $\left(25-28^{\circ} \mathrm{C}\right)$, o conteúdo de gordura sólida variou entre $24 \%$ e $2 \%$ a maior variação dos estruturantes estudados. Acima de 29 $\mathrm{C}$ já não existe mais gordura sólida na mistura indicando a dissolução completa AE (Lau). Na temperatura ambiente na qual o teste de gelificação foi realizado $\left(25^{\circ} \mathrm{C}\right)$ o conteúdo de gordura previsto é de $24 \%$.

Um comportamento similar foi observado no gel formado por óleo de girassol e trimiristina (Myr), onde mais gordura sólida do que o de uma mistura ideal foi prevista em temperaturas até $24^{\circ} \mathrm{C}$. Na faixa de temperatura de fusão $\left(26-30^{\circ} \mathrm{C}\right)$ deste gel, os 
valores variaram entre $30 \%$ e $25 \%$, uma variação bem menor do que para o agente estruturante trilaurina. Em temperatura ambiente o gel apresenta 30\% de gordura sólida. Mesmo acima da temperatura de fusão da mistura de óleo e trimiristina a simulação ainda indica a presença de até $23 \%$ de gordura sólida. O gel de tripalmitina com óleo de girassol proporciona conteúdo de gordura sólida mais elevado do que o adicionado ao óleo até temperaturas de $35^{\circ} \mathrm{C}$. Na faixa de fusão (29-32ํㅡ) o conteúdo de gordura sólida variou apenas entre 29\% e 28\%. Em temperatura ambiente 0 modelo prevê $30 \%$ de gordura sólida no gel formado.

O conteúdo de gordura sólida no gel de tristearina se manteve praticamente constante em $24 \%$ para temperaturas acima de $-10^{\circ} \mathrm{C}$ e inferiores a $37^{\circ} \mathrm{C}$ onde, de acordo com Daniel e Rajasekharan (2003), o gel já havia se desfeito. A gordura de Kokum por sua vez apresentou um comportamento inverso das demais: em nenhuma temperatura simulada o conteúdo de gordura sólida foi superior ao que seria esperado caso toda a gordura sólida presente no agente estruturante fosse somado ao do óleo. $\mathrm{Na}$ faixa de temperatura avaliada $\left(-30^{\circ} \mathrm{C}-40^{\circ} \mathrm{C}\right)$, o conteúdo de gordura sólida da gordura de Kokum varia de $100 \%$ a $24 \%$ enquanto para o gel esse valor variou de $70 \%$ a $4 \%$. Partes dos sólidos presentes na gordura de Kokum foram solubilizados pelo óleo de girassol e ainda assim a gordura foi capaz de estruturar o óleo. Em temperatura ambiente $\left(\mathrm{T}=25^{\circ} \mathrm{C}\right)$, o conteúdo de gordura sólida do gel ficou em $8 \%$ enquanto na faixa de fusão $\left(26-29^{\circ} \mathrm{C}\right)$ variou entre $5 \%$ e $4 \%$.

Daniel e Rajasekharan (2003) não detalharam o processo de gelificação e também não chegaram a fazer análises profundas no gel formado, uma vez que o estudo da formação de géis por triacilgliceróis foi apenas uma etapa preliminar do estudo dos autores que concentraram seu esforço na investigação de ácidos graxos como agente estruturantes. É válido de nota que apesar de os autores relatarem que as misturas apresentam propriedades de oleogéis, do ponto de vista prático é difícil diferenciar o processo utilizado pelos autores de processos tradicionais de estruturação de óleos como o blending, que utiliza grandes quantidades de gordura saturada ou trans para alterar as propriedades de óleos. 
5.4.2 Gelificação de oleína de gordura de Shorea (SFO), manteiga de cacau (CB), super-oleína de palma (PSO) e óleo de oliva (OO)

Neste estudo de caso, os dados experimentais são os de Higaki et al. (2003). Os autores investigaram as propriedades de gel de misturas binarias de gorduras com alto ponto de fusão e óleos de baixo ponto de fusão. Como agentes estruturantes, os autores utilizaram óleo de colza totalmente hidrogenado com uma grande quantidade de ácido beênico (FHR-B do inglês: fully hydrogenated rapeseed oil with a high amount of behenic acid), óleo de colza totalmente hidrogenado com uma grande quantidade de ácido esteárico (FHR-S do inglês: fully hydrogenated rapeseed oil with a high amount of stearic acid), tristearina (SSS), triaraquidonina (AAA), e tribenina (BBB) em concentrações não superiores a 4\%. Esses estruturantes foram combinados com oleína de gordura de Shorea (Shorea robusta) (SFO do inglês: sal fat olein), manteiga de cacau (CB do inglês: cocoa butter), super-oleína de palma (PSO do inglês: palm super olein) e óleo de oliva (OO), que foram selecionados devido ao seu baixo ponto de fusão.

Os testes de gelificação ocorreram dissolvendo o agente estruturante no óleo a uma temperatura de $70^{\circ} \mathrm{C}$. Após a dissolução completa a mistura foi resfriada até a temperatura de cristalização $\left(20^{\circ} \mathrm{C}\right)$ (HIGAKI et al., 2003). Por fim, o gel foi reaquecido até $38^{\circ} \mathrm{C}$ onde foi realizado o teste visual de inversão e verificado se houve escoamento.

Higaki et al. (2003) reportaram o comportamento de gel em misturas contendo FHR-B/SFO e FHR-B/CB com concentração de FHR-B variando entre 1,5-4,0\% $(\mathrm{m} / \mathrm{m})$. Um gráfico contendo o perfil de conteúdo de gordura sólida para a mistura de FHR-B/SFO é apresentado na Figura 25, para diferentes frações do agente estruturante na mistura. 
Figura 25 - Conteúdo de gordura sólida da mistura FHR-B/SFO calculado em diferentes temperaturas.

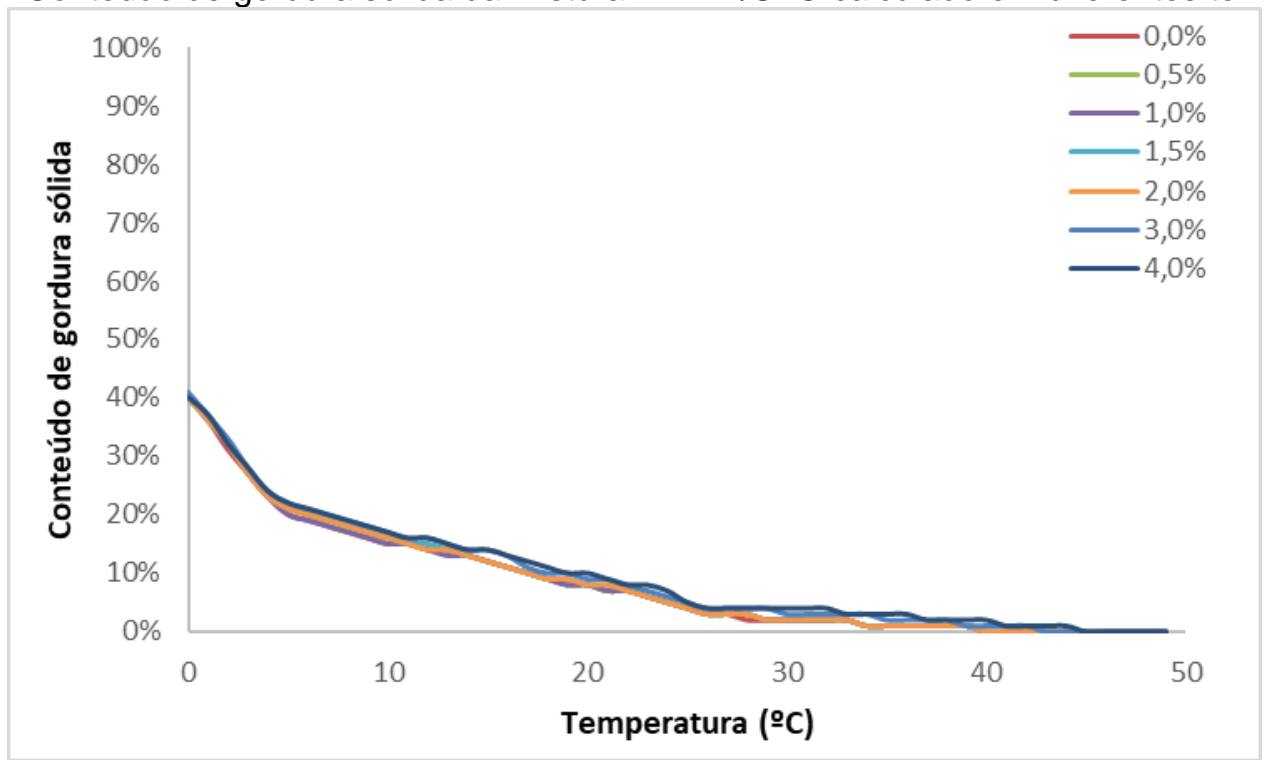

Fonte: Próprio autor.

É possível observar na Figura 25 que a adição de pequenas quantidades de agente estruturante pouco influencia o comportamento da curva de fusão da mistura, tornando difícil a distinção das curvas nas quais houve a formação de gel (2,0-4,0\%) e daquelas onde não houve formação de gel (0,0-1,0\%). Destaca-se que, de acordo com os autores dos experimentos de gelificação, com 1,5\% de estruturante a mistura ficou em um estado intermediário entre gel e solução. Na temperatura de cristalização $\left(20^{\circ} \mathrm{C}\right)$ o conteúdo de gordura sólida foi de $8 \%$ para concentrações de 0,0-2,0\% de agente estruturante, de $9 \%$ para a mistura contendo 3,0\% de agente estruturante e $10 \%$ para a mistura contendo $4,0 \%$ de agente estruturante. Na temperatura final do experimento $\left(38^{\circ} \mathrm{C}\right)$ o conteúdo de gordura sólida variou de $1 \%$ para as concentrações de $0,0-2,0 \%$ e $2 \%$ para as concentrações de 3,0-4,0\% de agente estruturante. Esse comportamento pode ser observado para os demais experimentos relatados pelos autores e simulados na Figura 26. 
Figura 26 - Gráfico de conteúdo de gordura sólida da mistura de óleo com baixo ponto de fusão e agentes estruturantes com alto ponto de fusão em concentrações de $2 \%$.
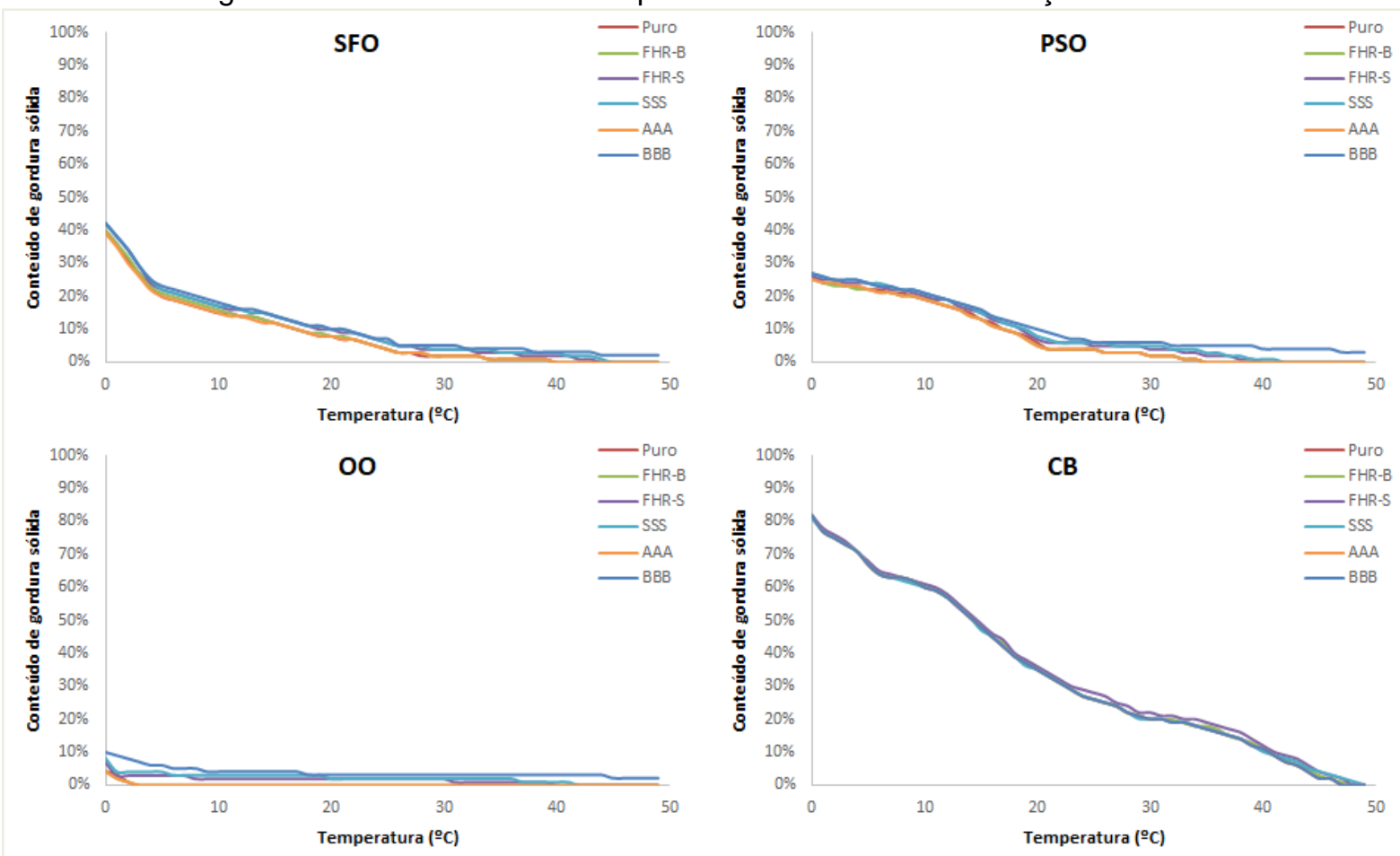

Fonte: Próprio autor. FHR-B - fully hydrogenated rapeseed oil with a high amount of behenic acid. FHR-S - fully hydrogenated rapeseed oil with a high amount of stearic acid. SSS - tristearina. AAA triaraquidonina. BBB - tribenina. SFO - sal fat olein. CB - cocoa butter. PSO - palm super olein. OO óleo de oliva.

As misturas reportadas na Figura 26 referem-se a $2 \%$ de agente estruturante. Apenas as misturas de FHR-B/SFO e FHR-B/CB apresentaram comportamento de gel após a realização do teste de inversão. Na temperatura de cristalização $\left(20^{\circ} \mathrm{C}\right) \mathrm{O}$ conteúdo de gordura sólida variou entre $8-10 \%$ para o SFO, entre $5-10 \%$ para o PSO, entre $0-3 \%$ para $\circ \mathrm{OO}$ e entre $35-36 \%$ para a $\mathrm{CB}$ com diferentes agentes estruturantes. Na temperatura final do experimento $\left(38^{\circ} \mathrm{C}\right)$ o conteúdo de gordura sólida variou entre $1-3 \%$ para o SFO, entre $0-5 \%$ para o $\mathrm{PSO}$, entre $0-3 \%$ para o $\mathrm{OO}$ e entre $14-16 \%$ para a CB com diferentes agentes estruturantes.

Como uma das principais conclusões desta etapa resultantes da análise dos estudos de caso apresentados nos itens 5.4 .1 e 5.4.2, pode-se afirmar que, o conteúdo de gordura sólida não parece ter correlação direta com a capacidade de um triacilglicerol com alta temperatura de fusão formar gel em óleos com baixo ponto de fusão.

Tal afirmação é baseada em alguns pontos principais: a) para um mesmo óleo o conteúdo de gordura sólida de uma solução não gel pode ser superior ao de um gel 
formado por outro agente estruturante; b) óleos com curvas de derretimento muito similares apresentam propriedades físicas de escoamento e espalhamento completamente diferentes quando na forma de gel, indicando assim que não é o aumento ou diminuição do conteúdo de gordura sólida que confere a capacidade de gelificação desses agentes estruturantes lipídicos; c) foram reportados géis para ambos os casos onde o AE induziu a cristalização de triacilgliceróis presentes no óleo e onde o óleo solubilizou parte da gordura solida presente no agente estruturante, sugerindo que esse tipo de interação também não está relacionado com a formação de gel. 


\section{CONCLUSÕES}

Os parâmetros de Hansen se mostram promissores como ferramenta para seleção inicial de agentes estruturantes, uma vez que podem ser observados padrões no espaço de Hansen para diferentes AEs e óleos vegetais. Uma das desvantagens que o uso das esferas de Hansen possui é que só é possível avaliar uma espécie por vez, tradicionalmente os trabalhos que se propõe a determinar esferas de gelificação avaliam o agente estruturante no centro da esfera o que limita a sua aplicação.

Uma metodologia muito mais promissora para a indústria de oleogéis seria a avaliação de diferentes óleos no lugar do agente estruturante. Os óleos, apesar de possuírem composições diversas, são muito mais semelhantes entre si do que os candidatos a agentes estruturantes. Esse fato torna a construção de esferas de Hansen para óleos um caminho mais promissor no desenvolvimento de uma ferramenta computacional do que a abordagem comum das esferas de gelificação comumente adotada na literatura; entretanto ainda existem poucos dados experimentais para a criação de esferas de Hansen para diferentes óleos. Alternativamente, é possível agrupar óleos com composições similares para a construção de uma única esfera de forma a aproveitar o maior número de dados disponíveis ou mesmo avaliar a capacidade de gelificação de acordo com a frequência individual dos HSP.

Um problema identificado com a utilização do espaço de Hansen é que não se pode assegurar que os centros das esferas de gelificação ajustados modelam a realidade ou foram deslocados devido a um viés experimental na utilização de moléculas muito similares que por sua natureza se aglomeram no espaço de Hansen. Esse tipo de viés pode comprometer a formulação de qualquer modelo empírico que venha a ser desenvolvido.

A utilização de aprendizado de máquina como uma alternativa às esferas de Hansen se mostra promissor. Modelos de redes neurais artificiais se mostraram eficazes em predizer corretamente a classificação de uma mistura de óleo-AE superior a $90 \%$ dos casos, utilizando poucos indicadores iniciais. A principal vantagem na utilização destas metodologias é a capacidade de tratar diferentes óleos ao mesmo tempo possibilitando o desenvolvimento de um único modelo preditivo e posteriormente, após refinamento e validação, a utilização em óleos ainda não estudados. 
Para todos os modelos estudados, a falta de protocolos experimentais ficou evidente como uma possível fonte de erros na modelagem. Além disso, recomendase que os trabalhos experimentais enfatizem e reportem resultados negativos (não formação de gel), pois estes dados são fundamentais no desenvolvimento de modelos preditivos de formação de oleogéis.

Em relação à possível correlação entre o Conteúdo de Gordura Sólida e a formação de géis, os resultados obtidos com os sistemas de óleo de girassol, oleína de gordura de Shorea, manteiga de cacau, super-oleína de palma e óleo de oliva e diferentes agentes estruturantes lipídicos (hardfats e triacilgliceróis purificados com alto ponto de fusão) simulados no VODesign mostraram haver pouca ou nenhuma relação entre o Conteúdo de Gordura Sólida e a capacidade de hardfats e triacilgliceróis com alto ponto de fusão em formar géis em óleos.

Este trabalho representa ainda uma ampliação do trabalho de Rogers (2018), ao considerar novos agentes estruturantes formadores de géis em óleos vegetais, incluindo além de moléculas puras, misturas de moléculas e agentes estruturantes naturais como ceras e gorduras com alto ponto de fusão. Esses novos agentes estruturante ampliam as faixas listadas por Rogers (2018) para os parâmetros de solubilidade de Hansen para agentes estruturantes de óleos vegetais.

Como sugestão para trabalhos futuros, recomenda-se a definição e padronização de protocolos experimentais mais rígidos e o aumento no registro e divulgação de resultados negativos nos testes de gelificação (solubilidade e precipitação). Tais recomendações, combinadas com a utilização de óleos com composições bem determinadas para a definição de resultados de gelificação, pode ocasionar o ponto de inflexão na capacidade de modelos matemáticos serem usados na seleção de novos agentes estruturantes capazes de gelificar um dado óleo de interesse, fomentando o desenvolvimento de oleogéis como substitutos de gorduras trans em produtos alimentícios.

Utilizando como ponto de partida a base de dados de agentes estruturantes de solventes orgânicos, procura-se classificar moléculas candidatas que estejam contidas nesse intervalo e que apresentem características desejadas para a finalidade do problema. A utilização das esferas de solubilidade e gelificação criam então um parâmetro ainda mais preciso para classificar um agente estruturante a partir da sua capacidade de estruturar óleos, desde que haja dados experimentais suficientes. 
A partir desse primeiro passo, é desejável desenvolver modelos que sejam capazes de prever propriedades e funcionalidades dos géis formados por diferentes AEs, possibilitando dessa forma a criação de produtos únicos com propriedades desejáveis para uma determinada aplicação. Para esses modelos mais robustos se faz necessário uma avaliação minuciosa das propriedades alcançadas experimentalmente com os AEs conhecidos e como a mudança dos grupos moleculares dos AEs afetam essas propriedades. 


\section{REFERÊNCIAS ${ }^{1}$}

ABDALLAH, D. J.; LU, L.; WEISS, R. G. Thermoreversible Organogels from Alkane Gelators with One Heteroatom. Chemistry of Materials, v. 11, n. 10, p. 29072911, out. 1999.

ABDALLAH, D. J.; WEISS, R. G. Organogels and low molecular mass organic gelators. Advanced Materials, v. 12, n. 17, p. 1237-1247, 2000.

ABRAHAM, S. et al. Influence of Positional Isomers on the Macroscale and Nanoscale Architectures of Aggregates of Racemic Hydroxyoctadecanoic Acids in Their Molecular Gel, Dispersion, and Solid States. Langmuir, v. 28, n. 11, p. 49554964, 20 mar. 2012.

ACD/LABS. ACD/ChemSketchToronto, 2019. Disponível em: $<$ www.acdlabs.com>

ALMEIDA, I. F. et al. Moisturizing Effect of Oleogel/Hydrogel Mixtures. Pharmaceutical Development and Technology, v. 13, n. 6, p. 487-494, 6 jan. 2008.

ANVISA. Publicada norma sobre gordura trans em alimentos. Disponível em: <https://bit.ly/35WhUJV>. Acesso em: 23 fev. 2020.

AYABE, M. et al. Binary organogelators which show light and temperature responsiveness. Organic \& Biomolecular Chemistry, v. 1, n. 15, p. 2744, 2003.

BASTIAT, G.; LEROUX, J.-C. Pharmaceutical organogels prepared from aromatic amino acid derivatives. Journal of Materials Chemistry, v. 19, n. 23, p. 3867, 2009.

BATISTA, M. M.; GUIRARDELLO, R.; KRÄHENBÜHL, M. A. Determination of the Hansen Solubility Parameters of Vegetable Oils, Biodiesel, Diesel, and BiodieselDiesel Blends. Journal of the American Oil Chemists' Society, v. 92, n. 1, p. 95109, 4 jan. 2015.

BEHERA, B. et al. Span-60-based organogels as probable matrices for transdermal/topical delivery systems. Journal of Applied Polymer Science, v. 125, n. 2, p. 852-863, 15 jul. 2012.

BELÉN MARCO, A. et al. (Super)gelators derived from push-pull chromophores: synthesis, gelling properties and second harmonic generation. Organic \& Biomolecular Chemistry, v. 16, n. 14, p. 2470-2478, 2018.

BÉTRON, C. et al. Diffusion of modified vegetables oils in thermoplastic polymers. Materials Chemistry and Physics, v. 200, p. 107-120, out. 2017.

BIELEJEWSKI, M. et al. Solvent Effect on 1,2- O -(1-Ethylpropylidene)- $\alpha$ - $d$ glucofuranose Organogel Properties. Langmuir, v. 25, n. 14, p. 8274-8279, 21 jul. 2009.

BLAKE, A. I.; CO, E. D.; MARANGONI, A. G. Structure and Physical Properties of Plant Wax Crystal Networks and Their Relationship to Oil Binding Capacity. Journal of the American Oil Chemists' Society, v. 91, n. 6, p. 885-903, 16 jun. 2014.

BONNET, J. et al. Organogel formation rationalized by Hansen solubility parameters: dos and don'ts. Soft Matter, v. 10, n. 18, p. 3154, 2014.

BONNET, J. et al. Organogel formation rationalized by Hansen solubility parameters: influence of gelator structure. Soft Matter, v. 11, n. 11, p. 2308-2312, 2015.

BORRERO-LÓPEZ, A. M. et al. Evaluation of lignin-enriched side-streams from different biomass conversion processes as thickeners in bio-lubricant formulations. International Journal of Biological Macromolecules, v. 162, p. 13981413, 2020.

${ }^{1}$ De acordo com a Associação Brasileira de Normas Técnicas (ABNT NBR 6023). 
BOT, A. et al. Non-TAG structuring of edible oils and emulsions. Food Hydrocolloids, v. 23, n. 4, p. 1184-1189, jun. 2009.

BOT, A.; AGTEROF, W. G. M. Structuring of edible oils by mixtures of $y$ oryzanol with $\beta$-sitosterol or related phytosterols. Journal of the American Oil Chemists' Society, v. 83, n. 6, p. 513-521, jun. 2006.

BUSTAMANTE, $P$. et al. Hildebrand solubility parameter to predict drug release from hydroxypropyl methylcellulose gels. International Journal of Pharmaceutics, v. 414, n. 1-2, p. 125-130, jul. 2011.

BUTLER, K. T. et al. Machine learning for molecular and materials science. Nature, v. 559, n. 7715, p. 547-555, 25 jul. 2018.

CHIARA, V. L. et al. Ácidos graxos trans: doenças cardiovasculares e saúde materno-infantil. Revista de Nutrição, v. 15, n. 3, p. 341-349, set. 2002.

CO, E. D.; MARANGONI, A. G. Organogels: An Alternative Edible OilStructuring Method. Journal of the American Oil Chemists' Society, v. 89, n. 5, p. 749-780, 29 maio 2012.

COLEY, C. W.; GREEN, W. H.; JENSEN, K. F. Machine Learning in ComputerAided Synthesis Planning. Accounts of Chemical Research, v. 51, n. 5, p. 12811289, 15 maio 2018.

CORRADINI, M. G.; ROGERS, M. A. Molecular gels: improving selection and design through computational methods. Current Opinion in Food Science, v. 9, p. 84-92, jun. 2016.

CURCIO, P. et al. A Favorable, Narrow, סh Hansen-Parameter Domain for Gelation of Low-Molecular-Weight Amino Acid Derivatives. Chemistry - A European Journal, v. 17, n. 48, p. 13603-13612, 2011.

DANIEL, J.; RAJASEKHARAN, R. Organogelation of plant oils and hydrocarbons by long-chain saturated FA, fatty alcohols, wax esters, and dicarboxylic acids. Journal of the American Oil Chemists' Society, v. 80, n. 5, p. 417-421, maio 2003.

DASGUPTA, D. et al. Solvent-mediated fiber growth in organogels. Soft Matter, v. 7, n. 19, p. 9311, 2011.

DASSANAYAKE, L. S. K. et al. Physical Properties of Rice Bran Wax in Bulk and Organogels. Journal of the American Oil Chemists' Society, v. 86, n. 12, p. 1163-1173, 1 dez. 2009.

DASSANAYAKE, L. S. K.; KODALI, D. R.; UENO, S. Formation of oleogels based on edible lipid materials. Current Opinion in Colloid \& Interface Science, v. 16 , n. 5, p. 432-439, out. 2011.

DASTIDAR, P. Supramolecular gelling agents: can they be designed? Chemical Society Reviews, v. 37, n. 12, p. 2699, 2008.

DAVID, A. et al. Oleogelation of rapeseed oil with cellulose fibers as an innovative strategy for palm oil substitution in chocolate spreads. Journal of Food Engineering, v. 292, p. 110315, mar. 2021.

DE LA PEÑA-GIL, A.; TORO-VAZQUEZ, J. F.; ROGERS, M. A. Simplifying Hansen Solubility Parameters for Complex Edible Fats and Oils. Food Biophysics, v. 11, n. 3, p. 283-291, 23 set. 2016.

DELBECQ, F. et al. Gelation properties of various long chain amidoamines: Prediction of solvent gelation via machine learning using Hansen solubility parameters. Journal of Molecular Liquids, v. 303, p. 112587, 2020.

DEMAN, J. M.; DEMAN, L.; BLACKMAN, B. Melting-point determination of fat products. Journal of the American Oil Chemists' Society, v. 60, n. 1, p. 91-94, jan. 1983.

${ }^{1}$ De acordo com a Associação Brasileira de Normas Técnicas (ABNT NBR 6023). 
DICKINSON, E. Emulsion gels: The structuring of soft solids with proteinstabilized oil droplets. Food Hydrocolloids, v. 28, n. 1, p. 224-241, jul. 2012.

DIEHN, K. K. et al. Insights into organogelation and its kinetics from Hansen solubility parameters. Toward a priori predictions of molecular gelation. Soft Matter, v. 10, n. 15, p. 2632, 2014.

EDELSZTEIN, V. C. et al. Self-assembly of 2,3-dihydroxycholestane steroids into supramolecular organogels as a soft template for the in-situ generation of silicate nanomaterials. Beilstein Journal of Organic Chemistry, v. 9, p. 1826-1836, 9 set. 2013.

EDWARDS, W.; SMITH, D. K. Dynamic Evolving Two-Component Supramolecular Gels-Hierarchical Control over Component Selection in Complex Mixtures. Journal of the American Chemical Society, v. 135, n. 15, p. 5911-5920, 17 abr. 2013.

ELLIGER, C. A.; GUADAGNI, D. G.; DUNLAP, C. E. Thickening action of hydroxystearates in peanut butter. Journal of the American Oil Chemists' Society, v. 49 , n. 9 , p. $536-537$, set. 1972.

FARFAN-CABRERA, L. I. et al. Deterioration of seals of automotive fuel systems upon exposure to straight Jatropha oil and diesel. Renewable Energy, v. 127, p. 125-133, nov. 2018.

FARFAN-CABRERA, L. I.; PÉREZ-GONZÁLEZ, J.; GALLARDOHERNÁNDEZ, E. A. Solubility analysis of elastomers in a bio-based lubricant using Hansen parameters. Materials Research Express, v. 6, n. 1, p. 015311, 30 out. 2018.

FDA. Trans Fat. Disponível em: <https://www.fda.gov/food/food-additivespetitions/trans-fat>. Acesso em: 2 ago. 2019.

FENG, G. et al. L-Phenylalanine Based Low-Molecular-Weight Efficient Organogelators and Their Selective Gelation of Oil from Oil/Water Mixtures. Soft Materials, v. 12, n. 4, p. 403-410, 2 out. 2014.

FIRESTONE, D. (ED.). Physical and Chemical Characteristics of Oils, Fats, and Waxes. 2nd Editio ed. [s.l.] AOCS Press, 2006.

FURMAN, I.; WEISS, R. G. Factors influencing the formation of thermally reversible gels comprised of cholesteryl 4-(2-anthryloxy)butanoate in hexadecane, 1octanol, or their mixtures. Langmuir, v. 9, n. 8, p. 2084-2088, ago. 1993.

GANDOLFO, F. G.; BOT, A.; FLÖTER, E. Structuring of edible oils by longchain FA, fatty alcohols, and their mixtures. Journal of the American Oil Chemists' Society, v. 81, n. 1, p. 1-6, jan. 2004.

GANI, R. Chemical product design: challenges and opportunities. Computers \& Chemical Engineering, v. 28, n. 12, p. 2441-2457, nov. 2004.

GAO, J.; WU, S.; ROGERS, M. A. Harnessing Hansen solubility parameters to predict organogel formation. Journal of Materials Chemistry, v. 22, n. 25, p. 12651, 2012.

GAUDÊNCIO, S. P.; PEREIRA, F. A Computer-Aided Drug Design Approach to Predict Marine Drug-Like Leads for SARS-CoV-2 Main Protease Inhibition. Marine Drugs, v. 18, n. 12, p. 633, 10 dez. 2020.

GERBAUD, V. et al. Computer aided framework for designing bio-based commodity molecules with enhanced properties. Chemical Engineering Science, v. 159, p. 177-193, fev. 2017.

GESQUIĖRE, A. et al. Molecular Organization of Bis-urea Substituted Thiophene Derivatives at the Liquid/Solid Interface Studied by Scanning Tunneling Microscopy. Langmuir, v. 16, n. 26, p. 10385-10391, dez. 2000.

GRASSI, S. et al. d-Sorbitol, a structurally simple, low molecular-mass gelator.

1De acordo com a Associação Brasileira de Normas Técnicas (ABNT NBR 6023). 
New J. Chem., v. 35, n. 2, p. 445-452, 2011.

GRAVELLE, A. J. et al. Influence of solvent quality on the mechanical strength of ethylcellulose oleogels. Carbohydrate Polymers, v. 135, p. 169-179, jan. 2016.

GUPTA, J. K.; ADAMS, D. J.; BERRY, N. G. Will it gel? Successful computational prediction of peptide gelators using physicochemical properties and molecular fingerprints. Chemical Science, v. 7, n. 7, p. 4713-4719, 2016.

GUTIÉRREZ-LUNA, K.; ASTIASARÁN, I.; ANSORENA, D. Gels as fat replacers in bakery products: a review. Critical Reviews in Food Science and Nutrition, p. 1-14, 7 jan. 2021.

HALLINAN, J. S. Data mining for microbiologists. 1. ed. [s.I.] Elsevier Ltd, 2012. v. 39

HANABUSA, K. et al. Small molecular gelling agents to harden organic liquids: alkylamide of N-benzyloxycarbonyl-L-valyl-L-valine. Journal of the Chemical Society, Chemical Communications, n. 4, p. 390, 1993.

HANABUSA, K. et al. Formation of Organogels by Intermolecular Hydrogen Bonding between Ureylene Segment. Chemistry Letters, v. 25, n. 10, p. 885-886, out. 1996.

HANABUSA, K. et al. Excellent gelators for organic fluids: Simple bolaform amides derived from amino acids. Advanced Materials, v. 9, n. 14, p. 1095-1097, 1997a.

HANABUSA, K. et al. Small Molecular Gelling Agents to Harden Organic Liquids: Trialkyl cis -1,3,5-Cyclohexanetricarboxamides. Chemistry Letters, v. 26, n. 3, p. 191-192, mar. 1997b.

HANABUSA, K. et al. Easy Preparation and Useful Character of Organogel Electrolytes Based on Low Molecular Weight Gelator. Chemistry of Materials, v. 11, n. 3, p. 649-655, mar. 1999a.

HANABUSA, K. et al. Physical Gelation of Organic Solvents by Low Molecular Weight Gelators and Preparation of Organogel Electrolytes. Polymer Journal, v. 31, n. 11_2, p. 1159-1164, nov. 1999b.

HANSEN, C. M. Hansen Solubility Parameters. 2nd. ed. [s.I.] CRC Press, 2007.

HANSEN, C. M.; ABBOTT, S.; YAMAMOTO, H. Hansen Solubility Parameters in Practice (HSPiP). Disponível em: <https://www.hansensolubility.com/>.

HEINTZ, J. et al. Computer aided product design tool for sustainable product development. Computers \& Chemical Engineering, v. 71, p. 362-376, dez. 2014.

HIGAKI, K. et al. Physical analyses of gel-like behavior of binary mixtures of high- and low-melting fats. Journal of the American Oil Chemists' Society, v. 80, n. 3, p. 263-270, mar. 2003.

HIGAKI, K. et al. Rheological properties of $\beta$-fat gel made of binary mixtures of high-melting and low-melting fats. Food Research International, v. 37, n. 8, p. 799804, jan. 2004a.

HIGAKI, K. et al. In situ optical observation of microstructure of $\beta$-fat gel made of binary mixtures of high-melting and low-melting fats. Food Research International, v. 37, n. 1, p. 2-10, jan. 2004b.

HILL, M. Chemical Product Engineering-The third paradigm. Computers \& Chemical Engineering, v. 33, n. 5, p. 947-953, maio 2009.

HIRST, A. R.; SMITH, D. K. Solvent Effects on Supramolecular Gel-Phase Materials: Two-Component Dendritic Gel. Langmuir, v. 20, n. 25, p. 10851-10857, dez. 2004. 
HISHIKAWA, Y. et al. A Novel Class of Organogelator Based on NIsopropylcholamide and the First Observation of Fibrous Colloidal Aggregates. Chemistry Letters, v. 27, n. 8, p. 795-796, ago. 1998.

HU, B. et al. Application of Solvent Parameters for Predicting Organogel Formation. AAPS PharmSciTech, v. 19, n. 5, p. 2288-2300, 29 jul. 2018.

HUGHES, N. E. et al. Potential food applications of edible oil organogels. Trends in Food Science \& Technology, v. 20, n. 10, p. 470-480, out. 2009.

HWANG, H.-S. A critical review on structures, health effects, oxidative stability, and sensory properties of oleogels. Biocatalysis and Agricultural Biotechnology, v. 26, p. 101657, jul. 2020.

HWANG, H. S.; WINKLER-MOSER, J. K. Properties of margarines prepared from soybean oil oleogels with mixtures of candelilla wax and beeswax. Journal of Food Science, v. 85, n. 10, p. 3293-3302, 2020.

JHAMB, S. et al. A review of computer-aided design of paints and coatings. Current Opinion in Chemical Engineering, v. 27, p. 107-120, mar. 2020.

JIANG, C.; CHEN, L. Filtering-based approaches for functional data classification. WIREs Computational Statistics, v. 12, n. 4, 6 jul. 2020.

JIMENEZ-COLMENERO, F. et al. Novel applications of oil-structuring methods as a strategy to improve the fat content of meat products. Trends in Food Science \& Technology, v. 44, n. 2, p. 177-188, ago. 2015.

KASZYŃSKA, J. et al. On the relation between the solvent parameters and the physical properties of methyl-4,6-O-benzylidene- $\alpha$ - $d$-glucopyranoside organogels. Tetrahedron, v. 68, n. 20, p. 3803-3810, maio 2012.

LAI, T.-L. et al. Internal Probing of the Supramolecular Organization of PyreneBased Organogelators. Chemistry - An Asian Journal, v. 11, n. 1, p. 81-85, jan. 2016.

LAM, R. S. H.; ROGERS, M. A. Activation Energy of Crystallization for Trihydroxystearin, Stearic Acid, and 12-Hydroxystearic Acid under Nonisothermal Cooling Conditions. Crystal Growth \& Design, v. 11, n. 8, p. 3593-3599, 3 ago. 2011.

LAN, Y. et al. Comparing and Correlating Solubility Parameters Governing the Self-Assembly of Molecular Gels Using 1,3:2,4-Dibenzylidene Sorbitol as the Gelator. Langmuir, v. 30, n. 47, p. 14128-14142, 2 dez. 2014.

LAN, Y. et al. To gel or not to gel: correlating molecular gelation with solvent parameters. Chemical Society Reviews, v. 44, n. 17, p. 6035-6058, 2015.

LAN, Y.; CORRADINI, M. G.; ROGERS, M. A. Do Molecular Gelators Cluster in Hansen Space? Crystal Growth \& Design, v. 14, n. 9, p. 4811-4818, 3 set. 2014.

LAVECCHIA, A. Machine-learning approaches in drug discovery: methods and applications. Drug Discovery Today, v. 20, n. 3, p. 318-331, mar. 2015.

LI, J.-L. et al. Microengineering of Supramolecular Soft Materials by Design of the Crystalline Fiber Networks. Crystal Growth \& Design, v. 10, n. 6, p. 2699-2706, 2 jun. 2010.

LI, Y. et al. Evaluation of alternative solvents for improvement of oil extraction from rapeseeds. Comptes Rendus Chimie, v. 17, n. 3, p. 242-251, mar. 2014a.

$\mathrm{LI}, \mathrm{Y}$. et al. Direct green extraction of volatile aroma compounds using vegetable oils as solvents: Theoretical and experimental solubility study. LWT - Food Science and Technology, v. 59, n. 2, p. 724-731, dez. 2014b.

LI, Z. et al. Self-assembled drug delivery system based on low-molecularweight bis-amide organogelator: synthesis, properties and in vivo evaluation. Drug Delivery, v. 23, n. 8, p. 3168-3178, 12 out. 2016.

LIU, C.; CORRADINI, M.; ROGERS, M. A. Self-assembly of 12-hydroxystearic

1De acordo com a Associação Brasileira de Normas Técnicas (ABNT NBR 6023). 
acid molecular gels in mixed solvent systems rationalized using Hansen solubility parameters. Colloid and Polymer Science, v. 293, n. 3, p. 975-983, 11 mar. 2015.

LIU, Q. et al. Machine learning-based atom contribution method for the prediction of surface charge density profiles and solvent design. AIChE Journal, v. 67, n. 2, 11 fev. 2021.

LIU, W.; XIE, T.; QIU, R. Biobased Thermosets Prepared from Rigid Isosorbide and Flexible Soybean Oil Derivatives. ACS Sustainable Chemistry \& Engineering, v. 5 , n. 1, p. 774-783, 3 jan. 2017.

LOUWERSE, M. J. et al. Revisiting Hansen Solubility Parameters by Including Thermodynamics. ChemPhysChem, v. 18, n. 21, p. 2999-3006, 3 nov. 2017.

LUPI, F. R. et al. Olive oil/policosanol organogels for nutraceutical and drug delivery purposes. Food \& Function, v. 4, n. 10, p. 1512, 2013.

MACOON, R.; ROBEY, M.; CHAUHAN, A. In vitro release of hydrophobic drugs by oleogel rods with biocompatible gelators. European Journal of Pharmaceutical Sciences, v. 152, p. 105413, 2020.

MALLIA, V. A. et al. Robust Organogels from Nitrogen-Containing Derivatives of ( R )-12-Hydroxystearic Acid as Gelators: Comparisons with Gels from Stearic Acid Derivatives †. Langmuir, v. 25, n. 15, p. 8615-8625, 4 ago. 2009.

MARTÍN-ALFONSO, J. E. et al. Rheological and tribological approaches as a tool for the development of sustainable lubricating greases based on nanomontmorillonite and castor oil. Friction, 2020.

MARTÍN-ALFONSO, J. E.; VALENCIA, C. Tribological, rheological, and microstructural characterization of oleogels based on EVA copolymer and vegetables oils for lubricant applications. Tribology International, v. 90, p. 426-434, out. 2015.

MAT DIAN, N. L. H.; SUNDRAM, K.; IDRIS, N. A. DSC study on the melting properties of palm oil, sunflower oil, and palm kernel olein blends before and after chemical interesterification. Journal of the American Oil Chemists' Society, v. 83, n. 8, p. 739-745, ago. 2006.

MATHWORKS. MATLAB, 2015. Disponível em: $<$ https://www.mathworks.com/?s_tid=gn_logo>

MCMURRY, J. Química orgânica. [s.l.] Pioneira Thomson Learning, 2005.

MOTULSKY, A. et al. Characterization and biocompatibility of organogels based on I-alanine for parenteral drug delivery implants. Biomaterials, v. 26, n. 31, p. 6242-6253, nov. 2005.

MU, H.; PORSGAARD, T. The metabolism of structured triacylglycerols. Progress in Lipid Research, v. 44, n. 6, p. 430-448, nov. 2005.

$\mathrm{NIU}$, L. et al. Solvent effects on the gelation performance of melamine and 2ethylhexylphosphoric acid mono-2-ethylhexyl ester in water-organic mixtures. Soft Matter, v. 9, n. 32, p. 7780, 2013.

ÖĞÜTCÜ, M.; YILMAZ, E. Oleogels of virgin olive oil with carnauba wax and monoglyceride as spreadable products. Grasas y Aceites, v. 65, n. 3, p. e040, 30 set. 2014.

OJIJO, N. K. et al. Effects of monoglyceride content, cooling rate and shear on the rheological properties of olive oil/monoglyceride gel networks. Journal of the Science of Food and Agriculture, v. 84, n. 12, p. 1585-1593, set. 2004.

OKESOLA, B. O. et al. 1,3:2,4-Dibenzylidene- $<\mathrm{scp}>\mathrm{d}</ \mathrm{scp}>$-sorbitol (DBS) and its derivatives - efficient, versatile and industrially-relevant low-molecular-weight gelators with over 100 years of history and a bright future. Soft Matter, v. 11, n. 24, p. 4768-4787, 2015.

OKTAY, A. N. et al. Preparation and in vitro / in vivo evaluation of flurbiprofen 
nanosuspension-based gel for dermal application. European Journal of Pharmaceutical Sciences, v. 155, n. April, p. 105548, 2020.

OKURO, P. K. et al. Perspective on oleogelator mixtures, structure design and behaviour towards digestibility of oleogels. Current Opinion in Food Science, v. 35, p. 27-35, out. 2020.

PALLA, C. A.; WASINGER, M. F.; CARRÍN, M. E. Monoglyceride oleogels as fat replacers in filling creams for sandwich cookies. Journal of the Science of Food and Agriculture, 2020.

PARK, C.; MALEKY, F. A Critical Review of the Last 10 Years of Oleogels in Food. Frontiers in Sustainable Food Systems, v. 4, n. September, p. 1-8, 15 set. 2020.

PATEL, A. R. et al. Edible applications of shellac oleogels: spreads, chocolate paste and cakes. Food Funct., v. 5, n. 4, p. 645-652, 2014.

PATEL, A. R. Alternative Routes to Oil Structuring. Cham: Springer International Publishing, 2015.

PATEL, A. R. A colloidal gel perspective for understanding oleogelation. Current Opinion in Food Science, v. 15, p. 1-7, jun. 2017.

PATEL, A. R.; DEWETTINCK, K. Edible oil structuring: an overview and recent updates. Food \& Function, v. 7, n. 1, p. 20-29, 2016.

PATEL, A. R.; NICHOLSON, R. A.; MARANGONI, A. G. Applications of fat mimetics for the replacement of saturated and hydrogenated fat in food products. Current Opinion in Food Science, v. 33, p. 61-68, jun. 2020.

PEHLIVANOĞLU, $\mathrm{H}$. et al. Oleogels, a promising structured oil for decreasing saturated fatty acid concentrations: Production and food-based applications. Critical Reviews in Food Science and Nutrition, v. 58, n. 8, p. 1330-1341, 24 maio 2018.

PERNETTI, M. et al. Structuring edible oil with lecithin and sorbitan tri-stearate. Food Hydrocolloids, v. 21, n. 5-6, p. 855-861, jul. 2007a.

PERNETTI, M. et al. Structuring of edible oils by alternatives to crystalline fat. Current Opinion in Colloid \& Interface Science, v. 12, n. 4-5, p. 221-231, out. 2007b.

PLOURDE, F. et al. First report on the efficacy of I-alanine-based in situforming implants for the long-term parenteral delivery of drugs. Journal of Controlled Release, v. 108, n. 2-3, p. 433-441, nov. 2005.

QING, G. et al. Solvent-Driven Chiral-Interaction Reversion for Organogel Formation. Angewandte Chemie International Edition, v. 53, n. 8, p. 2124-2129, 17 fev. 2014.

R CORE TEAM. R: A language and environment for statistical computing.Vienna, AustriaR Foundation for Statistical Computing, , 2020. Disponível em: <https://www.r-project.org/>

RADHAKRISHNAPANY, K. T. et al. Design of fragrant molecules through the incorporation of rough sets into computer-aided molecular design. Molecular Systems Design \& Engineering, v. 5, n. 8, p. 1391-1416, 2020.

RAYNAL, M.; BOUTEILLER, L. Organogel formation rationalized by Hansen solubility parameters. Chemical Communications, v. 47, n. 29, p. 8271, 2011.

REMIG, V. et al. Trans Fats in America: A Review of Their Use, Consumption, Health Implications, and Regulation. Journal of the American Dietetic Association, v. 110, n. 4, p. 585-592, abr. 2010.

RIEDMILLER, M. Advanced supervised learning in multi-layer perceptrons From backpropagation to adaptive learning algorithms. Computer Standards \& Interfaces, v. 16, n. 3, p. 265-278, jul. 1994.

${ }^{1}$ De acordo com a Associação Brasileira de Normas Técnicas (ABNT NBR 6023). 
ROGERS, M. A. Novel structuring strategies for unsaturated fats - Meeting the zero-trans, zero-saturated fat challenge: A review. Food Research International, v. 42, n. 7, p. 747-753, ago. 2009.

ROGERS, M. A. et al. Edible oleogels in molecular gastronomy. International Journal of Gastronomy and Food Science, v. 2, n. 1, p. 22-31, 2014.

ROGERS, M. A. Hansen Solubility Parameters as a Tool in the Quest for New Edible Oleogels. Journal of the American Oil Chemists' Society, v. 95, n. 4, p. 393405, abr. 2018.

ROGERS, M. A.; WEISS, R. G. Systematic modifications of alkane-based molecular gelators and the consequences to the structures and properties of their gels. New Journal of Chemistry, v. 39, n. 2, p. 785-799, 2015.

ROGERS, M. A.; WRIGHT, A. J.; MARANGONI, A. G. Oil organogels: the fat of the future? Soft Matter, v. 5, n. 8, p. 1594, 2009.

ROSA NUNES, D. et al. Organogel formation rationalized by Hansen solubility parameters: improved methodology. Soft Matter, v. 14, n. 23, p. 4805-4809, 2018.

ROSA NUNES, D. et al. Organogel Formation Rationalized by Hansen Solubility Parameters: Shift of the Gelation Sphere with the Gelator Structure. Langmuir, v. 35, n. 24, p. 7970-7977, 18 jun. 2019.

SÁNCHEZ, R. et al. Use of chitin, chitosan and acylated derivatives as thickener agents of vegetable oils for bio-lubricant applications. Carbohydrate Polymers, v. 85, n. 3, p. 705-714, jun. 2011.

SCHAINK, H. M. et al. Crystal network for edible oil organogels: Possibilities and limitations of the fatty acid and fatty alcohol systems. Food Research International, v. 40, n. 9, p. 1185-1193, nov. 2007.

SCHARFE, M.; FLÖTER, E. Oleogelation: From Scientific Feasibility to Applicability in Food Products. European Journal of Lipid Science and Technology, v. 2000213, p. 1-24, 2020.

SCHOONBEEK, F. S. et al. Geminal Bis-ureas as Gelators for Organic Solvents: Gelation Properties and Structural Studies in Solution and in the Gel State. Chemistry - A European Journal, v. 6, n. 14, p. 2633-2643, 17 jul. 2000.

SHEN, H. et al. Application of Solubility Parameters in 1,3:2,4-Bis(3,4dimethylbenzylidene)sorbitol Organogel in Binary Organic Mixtures. Langmuir, v. 30, n. 30, p. 9176-9182, 5 ago. 2014.

SINGH, A. et al. Molecular Nuances Governing the Self-Assembly of 1,3:2,4Dibenzylidene- $<s c p>d</ s c p>$-sorbitol. Langmuir, v. 33, n. 41, p. 10907-10916, 17 out. 2017.

SINGH, A.; AUZANNEAU, F.-I.; ROGERS, M. A. Advances in edible oleogel technologies - A decade in review. Food Research International, v. 97, p. 307-317, jul. 2017.

SIRAJ, N. et al. Organogelators as a Saturated Fat Replacer for Structuring Edible Oils. International Journal of Food Properties, v. 18, n. 9, p. 1973-1989, 2 set. 2015.

SOLEIMANIAN, Y. et al. Wax-based delivery systems: Preparation, characterization, and food applications. [s.l: s.n.].

SOVTIĆ, N. et al. A review of environmentally friendly rubber production using different vegetable oils. Polymer Engineering and Science, n. January, p. 1-21, 2020.

STAN, R. et al. D-SORBITOL based organogelators with nitrogen groups. Revue Roumaine De Chimie, v. 51, n. 7-8, p. 609-613, 2006.

STORTZ, T. A. et al. Edible oleogels in food products to help maximize health

1De acordo com a Associação Brasileira de Normas Técnicas (ABNT NBR 6023). 
benefits and improve nutritional profiles. Lipid Technology, v. 24, n. 7, p. 151-154, jul. 2012.

STORTZ, T. A.; MARANGONI, A. G. The replacement for petrolatum: thixotropic ethylcellulose oleogels in triglyceride oils. Green Chem., v. 16, n. 6, p. 3064-3070, 2014.

SURYA PRAKASH RAO, $\mathrm{H}$. et al. Characterization and phase transition study of a versatile molecular gel from a glucose-triazole-hydrogenated cardanol conjugate. RSC Advances, v. 4, n. 24, p. 12175, 2014.

SUZUKI, M. et al. A family of low-molecular-weight organogelators based on $\mathrm{Na}, \mathrm{N} \varepsilon$-diacyl-I-lysine: effect of alkyl chains on their organogelation behaviour. Tetrahedron, v. 64, n. 45, p. 10395-10400, 2008.

SUZUKI, M.; UEMATSU, H.; HANABUSA, K. Novel organogelators based on phytosphingosine. Tetrahedron Letters, v. 57, n. 25, p. 2807-2810, jun. 2016.

TANG, D.; MARANGONI, A. G. Quantitative study on the microstructure of colloidal fat crystal networks and fractal dimensions. Advances in Colloid and Interface Science, v. 128-130, p. 257-265, dez. 2006.

TELES DOS SANTOS, M.; GERBAUD, V.; LE ROUX, G. A. C. A. C. Solid Fat Content of vegetable oils and simulation of interesterification reaction: Predictions from thermodynamic approach. Journal of Food Engineering, v. 126, p. 198-205, abr. 2014.

TELES DOS SANTOS, M.; GERBAUD, V.; ROUX, G. A. C. L. A. C. L. Modeling and simulation of melting curves and chemical interesterification of binary blends of vegetable oils. Chemical Engineering Science, v. 87, p. 14-22, jan. 2013.

TERECH, P.; WEISS, R. G. Low Molecular Mass Gelators of Organic Liquids and the Properties of Their Gels. Chemical Reviews, v. 97, n. 8, p. 3133-3160, dez. 1997.

TRIVEDI, D. R. et al. Structure-Property Correlation of a New Family of Organogelators Based on Organic Salts and Their Selective Gelation of Oil from Oil/Water Mixtures. Chemistry - A European Journal, v. 10, n. 21, p. 5311-5322, 5 nov. 2004.

VINTILOIU, A.; LEROUX, J.-C. Organogels and their use in drug delivery - A review. Journal of Controlled Release, v. 125, n. 3, p. 179-192, fev. 2008.

WANG, T.-M.; ROGERS, M. A. Biomimicry - An approach to engineering oils into solid fats. Lipid Technology, v. 27, n. 8, p. 175-178, ago. 2015.

WANG, T. et al. Robust, Self-Healing, and Multistimuli-Responsive Supergelator for the Visual Recognition and Separation of Short-Chain Cycloalkanes and Alkanes. ACS Applied Materials \& Interfaces, v. 9, n. 15, p. 13666-13675, 19 abr. 2017.

WASSELL, P.; YOUNG, N. W. G. G. Food applications of trans fatty acid substitutes. International Journal of Food Science \& Technology, v. 42, n. 5, p. 503-517, maio 2007.

WEISS, R. G. The Past, Present, and Future of Molecular Gels. What Is the Status of the Field, and Where Is It Going? Journal of the American Chemical Society, v. 136, n. 21, p. 7519-7530, 28 maio 2014.

WORLD HEALTH ORGANIZATION. REPLACE Trans fat. Disponível em: $<$ https://www.who.int/nutrition/topics/replace-transfat>. Acesso em: 2 ago. 2019.

$\mathrm{XIAO}, \quad \mathrm{T}$. et al. Aliphatic-Alcohol-Induced Opaque-to-Transparent Transformation and Application of Solubility Theory in a Bis-Dipeptide-Based Supramolecular Gel. ChemPlusChem, v. 82, n. 6, p. 879-887, jun. 2017.

YAMASAKI, S. et al. The Aggregated Higher-Structure of 1,3:2,4-Di- O -

1De acordo com a Associação Brasileira de Normas Técnicas (ABNT NBR 6023). 
benzylidene-D-sorbitol in Organic Gels. Bulletin of the Chemical Society of Japan, v. 68, n. 1, p. 146-151, jan. 1995.

YAN, N. et al. Pyrenyl-Linker-Glucono Gelators. Correlations of Gel Properties with Gelator Structures and Characterization of Solvent Effects. Langmuir, v. 29, n. 2, p. 793-805, 15 jan. 2013a.

YAN, N. et al. How Do Liquid Mixtures Solubilize Insoluble Gelators? SelfAssembly Properties of Pyrenyl-Linker-Glucono Gelators in Tetrahydrofuran-Water Mixtures. Journal of the American Chemical Society, v. 135, n. 24, p. 8989-8999, 19 jun. $2013 b$.

YU, Y. et al. Organogels from different self-assembling novel I-proline dihydrazide derivatives: gelation mechanism and morphology investigations. Journal of Sol-Gel Science and Technology, v. 78, n. 1, p. 218-227, 22 abr. 2016.

YU, Y. et al. Synthesis, characterization and gelation mechanism of Lphenylalanine-based dihydrazide derivative as excellent gelator. Russian Journal of Physical Chemistry B, v. 11, n. 1, p. 121-128, 8 jan. 2017.

ZACCARELLI, E. Colloidal gels: equilibrium and non-equilibrium routes. Journal of Physics: Condensed Matter, v. 19, n. 32, p. 323101, 15 ago. 2007.

ZETZL, A. K.; MARANGONI, A. G.; BARBUT, S. Mechanical properties of ethylcellulose oleogels and their potential for saturated fat reduction in frankfurters. Food \& Function, v. 3, n. 3, p. 327, 2012.

ZHANG, C.; KESSLER, M. R. Bio-based Polyurethane Foam Made from Compatible Blends of Vegetable-Oil-based Polyol and Petroleum-based Polyol. ACS Sustainable Chemistry \& Engineering, v. 3, n. 4, p. 743-749, 6 abr. 2015.

ZHANG, L. et al. A machine learning based computer-aided molecular design/screening methodology for fragrance molecules. Computers \& Chemical Engineering, v. 115, p. 295-308, jul. 2018.

ZHANG, L. et al. Integrated solvent-process design methodology based on COSMO-SAC and quantum mechanics for TMQ (2,2,4-trimethyl-1,2- $\mathrm{H}$ dihydroquinoline) production. Chemical Engineering Science, v. 226, p. 115894, 2020a.

ZHANG, L. et al. Chemical product design - recent advances and perspectives. Current Opinion in Chemical Engineering, v. 27, p. 22-34, mar. $2020 b$.

ZHANG, M. et al. Structural and Solubility Parameter Correlations of Gelation Abilities for Dihydroxylated Derivatives of Long-Chain, Naturally Occurring Fatty Acids. Chemistry - A European Journal, v. 21, n. 23, p. 8530-8543, 1 jun. 2015.

ZHAO, C. et al. Organogels from unsymmetrical m-conjugated 1,3,4oxadiazole derivatives. New Journal of Chemistry, v. 37, n. 5, p. 1454, 2013.

ZHU, G.; DORDICK, J. S. Solvent Effect on Organogel Formation by Low Molecular Weight Molecules. Chemistry of Materials, v. 18, n. 25, p. 5988-5995, dez. 2006.

ZHUANG, X. et al. The effect of alternative solvents to $n$-hexane on the green extraction of Litsea cubeba kernel oils as new oil sources. Industrial Crops and Products, v. 126, n. September, p. 340-346, dez. 2018.

ZWEEP, N. et al. Balancing Hydrogen Bonding and van der Waals Interactions in Cyclohexane-Based Bisamide and Bisurea Organogelators †. Langmuir, v. 25, n. 15, p. 8802-8809, 4 ago. 2009.

${ }^{1}$ De acordo com a Associação Brasileira de Normas Técnicas (ABNT NBR 6023). 


\section{APÊNDICES}

APÊNDICE A - Lista de agentes estruturantes de solventes orgânicos.

\begin{tabular}{|c|c|c|}
\hline ID & ESTRUTURANTE & REFERÊNCIA \\
\hline GID001 & $\operatorname{cccccccccccc}(=0) \operatorname{NCcccc}(\mathrm{C}(=0) \mathrm{O}) \mathrm{NC}(=0) \operatorname{C1CCCCC} 1$ & (ROGERS, 2018) \\
\hline GID002 & $\operatorname{cccccccccccc}(=0) N \operatorname{ccccc}(C(=0) O) N C(=O) C(C C) \operatorname{cccc}$ & (ROGERS, 2018) \\
\hline GID003 & 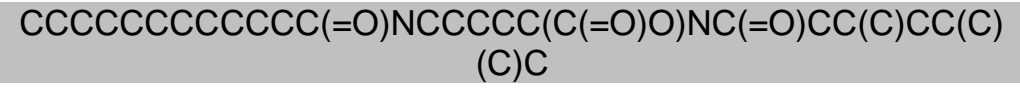 & (ROGERS, 2018) \\
\hline GID004 & $\begin{array}{c}\operatorname{cccccccccccc}(=0) \operatorname{Nccccc}(C(=0) O) N C(=0) C(\operatorname{cccccc} \\
\operatorname{C}) \operatorname{ccccccccc}\end{array}$ & (ROGERS, 2018) \\
\hline GID005 & $\begin{array}{l}\mathrm{C} 1 \mathrm{C} 2 \mathrm{C}(\mathrm{C}(\mathrm{OC}(\mathrm{O} 2) \mathrm{C} 3=\mathrm{CC}=\mathrm{C}(\mathrm{C}=\mathrm{C} 3)[\mathrm{N}+](=\mathrm{O})[\mathrm{O}- \\
]) \mathrm{C}(\mathrm{CO}) \mathrm{O}) \mathrm{OC}(\mathrm{O} 1) \mathrm{C} 4=\mathrm{CC}=\mathrm{C}(\mathrm{C}=\mathrm{C} 4)[\mathrm{N}+](=\mathrm{O})[\mathrm{O}-]\end{array}$ & (STAN et al., 2006) \\
\hline GID006 & $\begin{aligned} \mathrm{C} 1 \mathrm{C} 2 \mathrm{C}(\mathrm{C}(\mathrm{OC}(\mathrm{O} 2) \mathrm{C} 3=\mathrm{CC} & =\mathrm{C}(\mathrm{C}=\mathrm{C} 3)(\mathrm{N})) \mathrm{C}(\mathrm{CO}) \mathrm{O}) \mathrm{OC}(\mathrm{O} 1) \mathrm{C} 4=\mathrm{CC} \\
& =\mathrm{C}(\mathrm{C}=\mathrm{C} 4)(\mathrm{N})\end{aligned}$ & (STAN et al., 2006) \\
\hline GID007 & $\begin{aligned} \mathrm{C} 1 \mathrm{C} 2 \mathrm{C}(\mathrm{C}(\mathrm{OC}(\mathrm{O} 2) \mathrm{C} 3=\mathrm{CC}=\mathrm{C}(\mathrm{C}=\mathrm{C} 3)(\mathrm{NCCCCC})) \mathrm{C}(\mathrm{CO}) \mathrm{O}) \mathrm{OC}(\mathrm{O} 1 \\
) \mathrm{C} 4=\mathrm{CC}=\mathrm{C}(\mathrm{C}=\mathrm{C} 4)(\mathrm{NCCCCC})\end{aligned}$ & (STAN et al., 2006) \\
\hline GID008 & $\begin{aligned} & \mathrm{C} 1 \mathrm{C} 2 \mathrm{C}(\mathrm{C}(\mathrm{OC}(\mathrm{O} 2) \mathrm{C} 3=\mathrm{CC}=\mathrm{C}(\mathrm{C}=\mathrm{C} 3)(\mathrm{NCCCCCCC})) \mathrm{C}(\mathrm{CO}) \mathrm{O}) \mathrm{OC}( \\
&\mathrm{O} 1) \mathrm{C} 4=\mathrm{CC}=\mathrm{C}(\mathrm{C}=\mathrm{C} 4)(\mathrm{NCCCCCCC})\end{aligned}$ & (STAN et al., 2006) \\
\hline GID009 & $\begin{aligned} \mathrm{C} 1 \mathrm{C} 2 \mathrm{C}(\mathrm{C}(\mathrm{OC}(\mathrm{O} 2) \mathrm{C} 3=\mathrm{CC}=\mathrm{C}(\mathrm{C}=\mathrm{C} 3)(\mathrm{NCCCCCCCCC})) \mathrm{C}(\mathrm{CO}) \mathrm{O}) \\
\mathrm{OC}(\mathrm{O} 1) \mathrm{C} 4=\mathrm{CC}=\mathrm{C}(\mathrm{C}=\mathrm{C} 4)(\mathrm{NCCCCCCCCC})\end{aligned}$ & (STAN et al., 2006) \\
\hline GID010 & $\operatorname{cccccccccccccccc}(\mathrm{C}(\mathrm{C}(\mathrm{CO}) \mathrm{NC}(\mathrm{NCCCC})=0) 0) \mathrm{O}$ & (ROGERS, 2018) \\
\hline GID011 & $\begin{array}{c}\operatorname{Cccccccccccccccc}(\mathrm{C}(\mathrm{C}(\mathrm{CO}) \mathrm{NC}(\mathrm{NC} 1=\mathrm{CC}=\mathrm{CC}=\mathrm{C} 1)=\mathrm{O}) \mathrm{O}) \\
\mathrm{O}\end{array}$ & (ROGERS, 2018) \\
\hline GID012 & $\operatorname{cccccccccccccccc}(\mathrm{C}(\mathrm{C}(\mathrm{CO}) \mathrm{NC}(\mathrm{CccC}) \mathrm{CC}) \mathrm{O}) \mathrm{O}$ & (ROGERS, 2018) \\
\hline GID013 & $\begin{array}{c}\operatorname{cccccccccccc}(=0) N N C(=O) \operatorname{C} 1 \operatorname{cccN} 1 \mathrm{C}(=0) O C C 2=C C=C \\
\mathrm{C}=\mathrm{C} 2\end{array}$ & (ROGERS, 2018) \\
\hline GID014 & 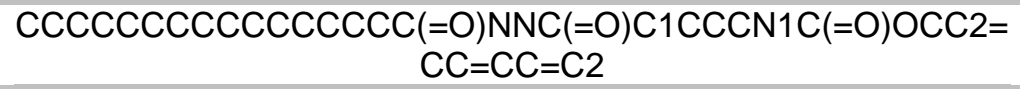 & (ROGERS, 2018) \\
\hline GID015 & $\begin{array}{c}\mathrm{CC}(\mathrm{OC}(\mathrm{NC}(\mathrm{C}(\mathrm{NNCC}(\mathrm{CCCCCCCCCCCCCC})=0)=0) \mathrm{CC} 1=\mathrm{CC}= \\
\mathrm{CC}=\mathrm{C} 1)=\mathrm{O})(\mathrm{C}) \mathrm{C}\end{array}$ & (ROGERS, 2018) \\
\hline GID016 & $\begin{array}{c}\mathrm{C} 1=\mathrm{CC}=\mathrm{CC} 2=\mathrm{C} 1 \mathrm{C}(=\mathrm{CN} 2) \mathrm{C}(\mathrm{C}(=\mathrm{O}) \mathrm{OC}) \mathrm{NC}(=\mathrm{O}) \mathrm{CCCCCCCCCC} \\
\operatorname{CCCCCCCCC}\end{array}$ & (ROGERS, 2018) \\
\hline GID017 & $\begin{array}{c}\mathrm{C}(\mathrm{NC}(=\mathrm{O}) \operatorname{cccccccc} \mathrm{Ccccccc} \mathrm{CC})(\mathrm{C} 1=\mathrm{CC}=\mathrm{CC}=\mathrm{C} 1) \mathrm{C}(= \\
\mathrm{O}) \mathrm{OC}\end{array}$ & (ROGERS, 2018) \\
\hline GID018 & $\begin{array}{c}\mathrm{C}(\mathrm{NC}(=\mathrm{O}) \operatorname{Cccccccccccccccccc})(\mathrm{C} 1=\mathrm{CC}=\mathrm{C}(\mathrm{C}=\mathrm{C} 1) \mathrm{O}) \mathrm{C} \\
(=\mathrm{O}) \mathrm{OC}\end{array}$ & (ROGERS, 2018) \\
\hline GID019 & $\begin{array}{c}\operatorname{ccccccccc} \operatorname{cccccc} 1=\mathrm{CC}=\mathrm{CC}(=\mathrm{C} 1) \mathrm{OCC}[\mathrm{N}] 2 \mathrm{C}=\mathrm{C}(\mathrm{N}=\mathrm{N} 2) \\
\operatorname{coc} 3 \mathrm{C}(\mathrm{C}(\mathrm{OC}(\mathrm{C} 3 \mathrm{O}) \mathrm{O}) \operatorname{CO}) \mathrm{O}\end{array}$ & (ROGERS, 2018) \\
\hline GID020 & $\begin{array}{c}\mathrm{C} 1(=\mathrm{CC}=\mathrm{CC}=\mathrm{C} 1) \mathrm{COC}(\mathrm{NC}(\mathrm{C}(\mathrm{NCCCCCCCCCCCCCCCCC})=0) \\
\mathrm{C}(\mathrm{CC}) \mathrm{C})=\mathrm{O}\end{array}$ & (ROGERS, 2018) \\
\hline GID021 & $\begin{array}{c}\operatorname{coOC}(=0) N C(C(C) C) C(=0) N C C C C C C \operatorname{CccccNC}(=O) C(C(C \\
) C) N C(=O) O C C\end{array}$ & (ROGERS, 2018) \\
\hline GID022 & $\operatorname{CCOC}(=0) N C(C(C) C) C(=O) N C C N C(=O) C(C(C) C) N C(=O) O C C$ & (ROGERS, 2018) \\
\hline GID023 & $\begin{array}{c}\operatorname{cccccccccc} \operatorname{coc}(\operatorname{NC}(\operatorname{CCC}(O)=O)=O) C C 1=C C=C C=C 1) \\
=O\end{array}$ & (FENG et al., 2014) \\
\hline GID024 & 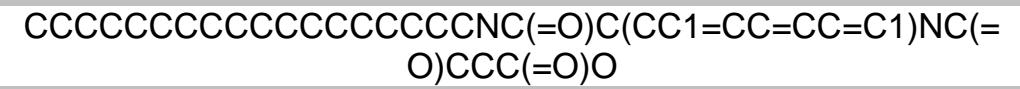 & (FENG et al., 2014) \\
\hline GID025 & $\operatorname{cccccccccccc}(=0) \operatorname{NC}(\mathrm{C}) \mathrm{C}(=\mathrm{O}) \mathrm{OC}$ & (ROGERS, 2018) \\
\hline GID026 & $\operatorname{cccccccccccc}(=0) N C(C) C(=0) O C C$ & (ROGERS, 2018) \\
\hline GID027 & $\operatorname{ccccccccccccccccc}(=0) N C(C) C(=0) O C$ & (ROGERS, 2018) \\
\hline GID028 & $\operatorname{coccccccccccccccc}(=0) \mathrm{NC}(\mathrm{C}) \mathrm{C}(=\mathrm{O}) \mathrm{OCC}$ & (ROGERS, 2018) \\
\hline GID029 & $\operatorname{cocccccccccc}(=0) N C(C) C(=0) O$ & (ROGERS, 2018) \\
\hline GID030 & $\operatorname{cccccccccccccccccc}(=0) \mathrm{NC}(\mathrm{C}) \mathrm{C}(=\mathrm{O}) \mathrm{O}$ & (ROGERS, 2018) \\
\hline GID031 & 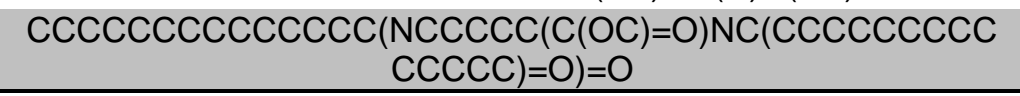 & (ROGERS, 2018) \\
\hline
\end{tabular}




\begin{tabular}{|c|c|c|}
\hline GID032 & $\begin{aligned} \operatorname{ccccccccccccccccccNC}(=\mathrm{O}) \mathrm{C}(\mathrm{C}(\mathrm{C}) \mathrm{CC}) \mathrm{NC}(=\mathrm{O}) \mathrm{OCC} 1= \\
\mathrm{CC}=\mathrm{CC}=\mathrm{C} 1\end{aligned}$ & (ROGERS, 2018) \\
\hline GID033 & $\begin{array}{c}\operatorname{ccccccccccccccccccNC}(=\mathrm{O}) \mathrm{C}(\mathrm{C}(\mathrm{C}) \mathrm{C}) \mathrm{NC}(=\mathrm{O}) \mathrm{C}(\mathrm{C}(\mathrm{C}) \mathrm{C}) \\
\mathrm{NC}(=\mathrm{O}) \mathrm{OCC} 1=\mathrm{CC}=\mathrm{CC}=\mathrm{C} 1\end{array}$ & (ROGERS, 2018) \\
\hline GID034 & $\begin{array}{c}\mathrm{CC}(\mathrm{C}) \mathrm{C}(\mathrm{C}(=\mathrm{O}) \mathrm{NCCCCCCCCCCCCNC}(=\mathrm{O}) \mathrm{C}(\mathrm{C}(\mathrm{C}) \mathrm{C}) \mathrm{NC}(=\mathrm{O}) \mathrm{O} \\
\mathrm{CC} 1=\mathrm{CC}=\mathrm{CC}=\mathrm{C} 1) \mathrm{NC}(=\mathrm{O}) \mathrm{OCC} 2=\mathrm{CC}=\mathrm{CC}=\mathrm{C} 2\end{array}$ & (ROGERS, 2018) \\
\hline GID035 & $\begin{array}{c}\mathrm{CC}(\mathrm{C}) \mathrm{NC}(=\mathrm{O}) \mathrm{CCC}(\mathrm{C}) \mathrm{C} 1 \mathrm{CCC} 2 \mathrm{C} 1(\mathrm{C}(\mathrm{CC} 3 \mathrm{C} 2 \mathrm{C}(\mathrm{CC} 4 \mathrm{C} 3(\mathrm{CCC}(\mathrm{C} 4) \\
\mathrm{O}) \mathrm{C}) \mathrm{O}) \mathrm{O}) \mathrm{C}\end{array}$ & (ROGERS, 2018) \\
\hline GID036 & $\begin{array}{c}\operatorname{\operatorname {cccccccccccccNC}}(=0) \operatorname{C} 1(\operatorname{CC}(\mathrm{CC}(\mathrm{C} 1) \mathrm{C}(=\mathrm{O}) \mathrm{NCCCCCCC} \\
\operatorname{Ccccc}) \mathrm{C}(=\mathrm{O}) \mathrm{NCCCCCCCCCCCCC})\end{array}$ & (ROGERS, 2018) \\
\hline GID037 & 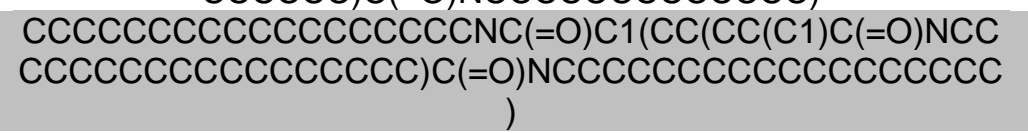 & $\begin{array}{l}\text { (HANABUSA et al., } \\
\text { 1997b) }\end{array}$ \\
\hline GID038 & $\operatorname{ccccccc}(\operatorname{ccccccccccc}(=0) 0) 0$ & (ROGERS, 2018) \\
\hline GID039 & $\operatorname{cccccccccccccccc}(=0) 0 \operatorname{Occ}(\operatorname{c1c}(\mathrm{C}(\mathrm{CO} 1) \mathrm{O}) \mathrm{O})$ & (ROGERS, 2018) \\
\hline GID040 & $\operatorname{ccccccccccccc}(\operatorname{ccccc}(=0) 0) 0$ & $\begin{array}{l}\text { (ABRAHAM et al., } \\
\text { 2012) }\end{array}$ \\
\hline GID041 & $\operatorname{ccccccccccc}(\operatorname{ccccccc}(=0) 0) 0$ & $\begin{array}{l}\text { (ABRAHAM et al., } \\
\text { 2012) }\end{array}$ \\
\hline GID042 & $\operatorname{ccccccccc}(\operatorname{ccc} \operatorname{ccccc}(=0) 0) 0$ & $\begin{array}{l}\text { (ABRAHAM et al., } \\
\text { 2012) }\end{array}$ \\
\hline GID043 & $\operatorname{ccccc}(\operatorname{coc} \operatorname{coc} \operatorname{ccc} \operatorname{ccc}(=0) 0) 0$ & $\begin{array}{l}\text { (ABRAHAM et al., } \\
\text { 2012) }\end{array}$ \\
\hline GID044 & $\underset{\mathrm{C}}{\operatorname{Cccccccccccccccc} C}(=\mathrm{O}) \mathrm{NC}(\mathrm{CC} 1=\mathrm{CC}=\mathrm{CC}=\mathrm{C} 1) \mathrm{C}(=\mathrm{O}) \mathrm{O}$ & $\begin{array}{l}\text { (BASTIAT; } \\
\text { LEROUX, 2009) }\end{array}$ \\
\hline GID045 & $\begin{array}{c}\operatorname{ccccccccccccccccc}(=\mathrm{O}) \mathrm{NC}(\mathrm{CC} 1=\mathrm{CC}=\mathrm{C}(\mathrm{C}=\mathrm{C} 1) \mathrm{O}) \mathrm{C}(= \\
\mathrm{O}) \mathrm{OC}\end{array}$ & $\begin{array}{l}\text { (BASTIAT; } \\
\text { LEROUX, 2009) }\end{array}$ \\
\hline GID046 & 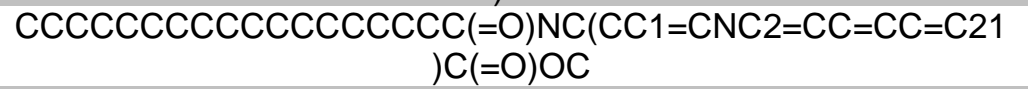 & $\begin{array}{l}\text { (BASTIAT; } \\
\text { LEROUX, 2009) }\end{array}$ \\
\hline GID047 & $\operatorname{ccccccccccc}(=O) N C(C C 1=C C=C C=C 1) C(=O) O C$ & $\begin{array}{l}\text { (BASTIAT; } \\
\text { LEROUX, 2009) }\end{array}$ \\
\hline GID048 & $\operatorname{cccccccccccC}(=0) N C(C C 1=C C=C(C=C 1) O) C(=O) O C$ & $\begin{array}{l}\text { (BASTIAT; } \\
\text { LEROUX, 2009) }\end{array}$ \\
\hline GID049 & $\begin{array}{c}\operatorname{cccccc} c \operatorname{coc} c \operatorname{ccc} c \operatorname{ccc}(=\mathrm{O}) \mathrm{NC}(\mathrm{CC} 1=\mathrm{CC}=\mathrm{CC}=\mathrm{C} 1) \mathrm{C} \\
(=\mathrm{O}) \mathrm{OC}\end{array}$ & $\begin{array}{l}\text { (BASTIAT; } \\
\text { LEROUX, 2009) }\end{array}$ \\
\hline GID050 & $\begin{array}{c}\operatorname{cccccccccccccccccccccC}(=\mathrm{O}) \mathrm{NC}(\mathrm{CC} 1=\mathrm{CC}=\mathrm{C}(\mathrm{C}=\mathrm{C} 1) \\
\mathrm{O}) \mathrm{C}(=\mathrm{O}) \mathrm{OC}\end{array}$ & $\begin{array}{l}\text { (BASTIAT; } \\
\text { LEROUX, 2009) }\end{array}$ \\
\hline GID051 & $\operatorname{cccccccccccccccc}(=O) N C(C C 1=C C=C C=C 1) C(=O) O$ & $\begin{array}{l}\text { (BASTIAT; } \\
\text { LEROUX, 2009) }\end{array}$ \\
\hline GID052 & $\begin{array}{c}\operatorname{cccccccccccccccc}(=O) N C(C C 1=C C=C(C=C 1) O) C(= \\
\text { O)O }\end{array}$ & $\begin{array}{l}\text { (BASTIAT; } \\
\text { LEROUX, 2009) }\end{array}$ \\
\hline GID053 & 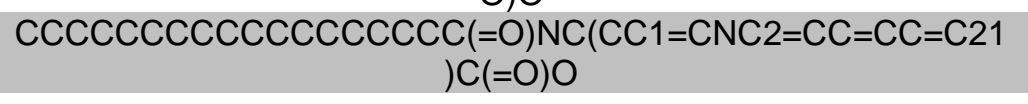 & $\begin{array}{l}\text { (BASTIAT; } \\
\text { LEROUX, 2009) }\end{array}$ \\
\hline GID054 & $\operatorname{cccccc} \operatorname{coc} \operatorname{coc} \operatorname{ccc}(\mathrm{C}(=\mathrm{O}) \mathrm{O}) \mathrm{O}$ & $\begin{array}{l}\text { (ABRAHAM et al. } \\
2012)\end{array}$ \\
\hline GID055 & $\operatorname{ccccccccc} \operatorname{coc} \operatorname{ccc}(\operatorname{cc}(=0) 0) 0$ & $\begin{array}{l}\text { (ABRAHAM et al., } \\
\text { 2012) }\end{array}$ \\
\hline GID056 & $\operatorname{cccccccccccccccccc}(=0) O \operatorname{Occ}(\operatorname{C1C}(\mathrm{C}(\mathrm{CO} 1) \mathrm{O}) \mathrm{O}) \mathrm{O}$ & $\begin{array}{l}\text { (BEHERA et al., } \\
\text { 2012) }\end{array}$ \\
\hline GID057 & $\mathrm{C} 2(\mathrm{OC} 1 \mathrm{C}(\mathrm{C}(\mathrm{C}(\mathrm{CO}) \mathrm{O}) \mathrm{OC} 1 \mathrm{O} 2) \mathrm{O})(\mathrm{CC}) \mathrm{CC}$ & $\begin{array}{l}\text { (BIELEJEWSKI et } \\
\text { al., 2009) }\end{array}$ \\
\hline GID058 & $\operatorname{ccccccc}(\operatorname{ccccccccccc}(=0) N \operatorname{ccc} C) \mathrm{O}$ & $\begin{array}{l}\text { (BONNET et al., } \\
\text { 2015) }\end{array}$ \\
\hline GID059 & $\operatorname{cccccc}(\operatorname{Cccccccccc}(\mathrm{NCCCCCCCC})=0) 0$ & $\begin{array}{l}\text { (BONNET et al., } \\
\text { 2015) }\end{array}$ \\
\hline GID060 & $\operatorname{ccccccccccccNC}(=0) \operatorname{ccccccccccc}(\operatorname{cccccc}) \mathrm{O}$ & $\begin{array}{l}\text { (BONNET et al., } \\
\text { 2015) }\end{array}$ \\
\hline GID061 & 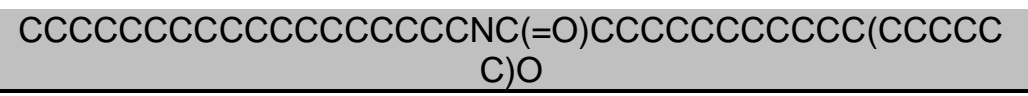 & $\begin{array}{l}\text { (BONNET et al., } \\
\text { 2015) }\end{array}$ \\
\hline
\end{tabular}




\begin{tabular}{|c|c|c|}
\hline GID062 & $\begin{array}{c}\mathrm{C} 1=\mathrm{CC}=\mathrm{C}(\mathrm{C}=\mathrm{C} 1) \mathrm{CC}(\mathrm{C}(=\mathrm{O}) \mathrm{NN2C}(=\mathrm{O}) \mathrm{C} 3=\mathrm{CC}=\mathrm{CC} 4=\mathrm{C} 3 \mathrm{C}(=\mathrm{CC}= \\
\mathrm{C} 4) \mathrm{C} 2=\mathrm{O}) \mathrm{NC}(=\mathrm{O}) \mathrm{OCC}=\mathrm{CC}=\mathrm{CC}=\mathrm{C} 5\end{array}$ & $\begin{array}{l}\text { (CURCIO et al., } \\
\text { 2011) }\end{array}$ \\
\hline GID063 & $\begin{array}{c}\mathrm{CC}(\mathrm{C}) \mathrm{CC}(\mathrm{C}(=\mathrm{O}) \mathrm{NN} 1 \mathrm{C}(=\mathrm{O}) \mathrm{C} 2=\mathrm{CC}=\mathrm{CC} 3=\mathrm{C} 2 \mathrm{C}(=\mathrm{CC}=\mathrm{C} 3) \mathrm{C} 1=\mathrm{O}) \\
\mathrm{NC}(=\mathrm{O}) \mathrm{OCC} 4=\mathrm{CC}=\mathrm{CC}=\mathrm{C} 4\end{array}$ & $\begin{array}{l}\text { (CURCIO et al., } \\
\text { 2011) }\end{array}$ \\
\hline GID064 & $\begin{array}{c}\mathrm{CC}(\mathrm{C}(=\mathrm{O}) \mathrm{NN} 3 \mathrm{C}(=\mathrm{O}) \mathrm{C} 1=\mathrm{CC}=\mathrm{CC} 2=\mathrm{C} 1 \mathrm{C}(=\mathrm{CC}=\mathrm{C} 2) \mathrm{C} 3=\mathrm{O}) \mathrm{NC}(=\mathrm{O} \\
) \mathrm{OCC} 4=\mathrm{CC}=\mathrm{CC}=\mathrm{C} 4\end{array}$ & $\begin{array}{l}\text { (CURCIO et al., } \\
\text { 2011) }\end{array}$ \\
\hline GID065 & $\begin{array}{c}\mathrm{C}(\mathrm{C}(\mathrm{C}(=\mathrm{O}) \mathrm{NN} 3 \mathrm{C}(=\mathrm{O}) \mathrm{C} 1=\mathrm{CC}=\mathrm{CC} 2=\mathrm{C} 1 \mathrm{C}(=\mathrm{CC}=\mathrm{C} 2) \mathrm{C} 3=\mathrm{O}) \mathrm{NC}(= \\
\mathrm{O}) \mathrm{OCC} 4=\mathrm{CC}=\mathrm{CC}=\mathrm{C} 4)(\mathrm{C}) \mathrm{C}\end{array}$ & $\begin{array}{l}\text { (CURCIO et al., } \\
\text { 2011) }\end{array}$ \\
\hline GID066 & $\begin{array}{c}\mathrm{C}(\mathrm{C}(\mathrm{C}(=\mathrm{O}) \mathrm{NN} 3 \mathrm{C}(=\mathrm{O}) \mathrm{C} 1=\mathrm{CC}=\mathrm{CC} 2=\mathrm{C} 1 \mathrm{C}(=\mathrm{CC}=\mathrm{C} 2) \mathrm{C} 3=\mathrm{O}) \mathrm{NC}(= \\
\mathrm{O}) \mathrm{OCC} 4=\mathrm{CC}=\mathrm{CC}=\mathrm{C} 4)(\mathrm{CC}) \mathrm{C}\end{array}$ & $\begin{array}{l}\text { (CURCIO et al., } \\
\text { 2011) }\end{array}$ \\
\hline GID067 & $\begin{array}{c}\mathrm{C} 1=\mathrm{CC}=\mathrm{C} 2 \mathrm{C}(=\mathrm{C} 1) \mathrm{C}(=\mathrm{CN} 2) \mathrm{CC}(\mathrm{C}(=\mathrm{O}) \mathrm{NN} 5 \mathrm{C}(=\mathrm{O}) \mathrm{C} 3=\mathrm{CC}=\mathrm{CC} 4= \\
\mathrm{C} 3 \mathrm{C}(=\mathrm{CC}=\mathrm{C} 4) \mathrm{C} 5=\mathrm{O}) \mathrm{NC}(=\mathrm{O}) \mathrm{OCC}=\mathrm{C}=\mathrm{C}=\mathrm{CC}=\mathrm{C} 6\end{array}$ & $\begin{array}{l}\text { (CURCIO et al., } \\
\text { 2011) }\end{array}$ \\
\hline GID068 & $\begin{array}{c}\mathrm{CC}(\mathrm{C})(\mathrm{C}) \mathrm{OC}(=\mathrm{O}) \mathrm{NC}(\mathrm{CC} 1=\mathrm{CC}=\mathrm{CC}=\mathrm{C} 1) \mathrm{C}(=\mathrm{O}) \mathrm{NN} 2 \mathrm{C}(=\mathrm{O}) \mathrm{C} 3=\mathrm{CC} \\
=\mathrm{CC} 4=\mathrm{C} 3 \mathrm{C}(=\mathrm{CC}=\mathrm{C} 4) \mathrm{C} 2=\mathrm{O}\end{array}$ & $\begin{array}{l}\text { (CURCIO et al., } \\
\text { 2011) }\end{array}$ \\
\hline GID069 & $\begin{array}{c}\mathrm{CC}(\mathrm{C}) \mathrm{CC}(\mathrm{C}(=\mathrm{O}) \mathrm{NN} 1 \mathrm{C}(=\mathrm{O}) \mathrm{C} 2=\mathrm{CC}=\mathrm{CC} 3=\mathrm{C} 2 \mathrm{C}(=\mathrm{CC}=\mathrm{C} 3) \mathrm{C} 1=\mathrm{O}) \\
\mathrm{NC}(=\mathrm{O}) \mathrm{OC}(\mathrm{C})(\mathrm{C}) \mathrm{C}\end{array}$ & $\begin{array}{l}\text { (CURCIO et al., } \\
\text { 2011) }\end{array}$ \\
\hline GID070 & $\begin{array}{c}\mathrm{C} 16=\mathrm{C}(\mathrm{C}(\mathrm{C} 2=\mathrm{C} 1 \mathrm{C}=\mathrm{CC}=\mathrm{C} 2) \mathrm{COC}(\mathrm{NC}(\mathrm{CC}(\mathrm{C}) \mathrm{C}) \mathrm{C}(=\mathrm{O}) \mathrm{NN} 5 \mathrm{C}(=\mathrm{O}) \\
\mathrm{C} 3=\mathrm{CC}=\mathrm{CC} 4=\mathrm{C} 3 \mathrm{C}(=\mathrm{CC}=\mathrm{C} 4) \mathrm{C}=\mathrm{O})=\mathrm{O}) \mathrm{C}=\mathrm{CC}=\mathrm{C} 6\end{array}$ & $\begin{array}{l}\text { (CURCIO et al., } \\
\text { 2011) }\end{array}$ \\
\hline GID071 & $\begin{aligned} \mathrm{C} 1 \mathrm{C} 2 \mathrm{C}(\mathrm{C}(\mathrm{OC}(\mathrm{O} 2) \mathrm{C} 3=\mathrm{CC}=\mathrm{CC} & =\mathrm{C} 3) \mathrm{C}(\mathrm{CO}) \mathrm{O}) \mathrm{OC}(\mathrm{O} 1) \mathrm{C} 4=\mathrm{CC}=\mathrm{CC} \\
& =\mathrm{C} 4\end{aligned}$ & $\begin{array}{l}\text { (DIEHN et al., } \\
\text { 2014) }\end{array}$ \\
\hline GID072 & 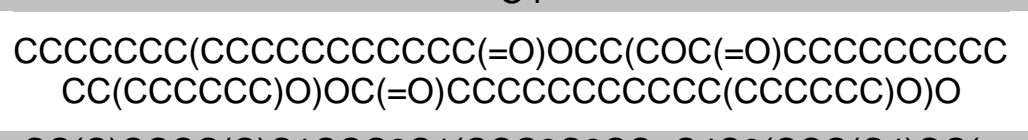 & $\begin{array}{c}\text { (ELLIGER; } \\
\text { GUADAGNI; } \\
\text { DUNLAP, 1972) }\end{array}$ \\
\hline GID073 & $\begin{array}{c}\mathrm{CC}(\mathrm{C}) \mathrm{CCCC}(\mathrm{C}) \mathrm{C} 1 \mathrm{CCC} 2 \mathrm{C} 1(\mathrm{CCC} 3 \mathrm{C} 2 \mathrm{CC}=\mathrm{C} 4 \mathrm{C} 3(\mathrm{CCC}(\mathrm{C} 4) \mathrm{OC}(= \\
\mathrm{O}) \mathrm{CCCOC}=\mathrm{CC} 6=\mathrm{CC} 7=\mathrm{CC}=\mathrm{CC}=\mathrm{C} 7 \mathrm{C}=\mathrm{C} 6 \mathrm{C}=\mathrm{C} 5) \mathrm{C}) \mathrm{C}\end{array}$ & $\begin{array}{l}\text { (FURMAN; WEISS, } \\
\text { 1993) }\end{array}$ \\
\hline GID074 & $\mathrm{C}(\mathrm{C}(\mathrm{C}(\mathrm{C}(\mathrm{C}(\mathrm{CO}) \mathrm{O}) \mathrm{O}) \mathrm{O}) \mathrm{O}) \mathrm{O}$ & $\begin{array}{l}\text { (GRASSI et al., } \\
\text { 2011) }\end{array}$ \\
\hline GID075 & $\begin{array}{c}\operatorname{ccccccccNC}(=)) C(C(C(C(\operatorname{COC}(=O) C 1=C C=C C=C 1) O) O) O) \\
O\end{array}$ & $\begin{array}{l}\text { (HANABUSA et al., } \\
\text { 1997a) }\end{array}$ \\
\hline GID076 & 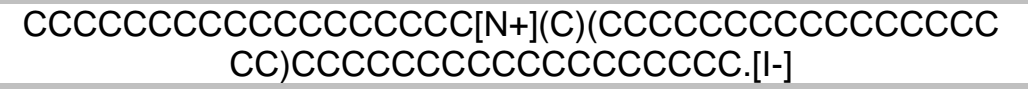 & $\begin{array}{l}\text { (HANABUSA et al., } \\
\text { 1997a) }\end{array}$ \\
\hline GID077 & $\begin{array}{c}\operatorname{CcC}(\mathrm{C}) \mathrm{C}(\mathrm{C}(=\mathrm{O}) \mathrm{NCCCCCCCCCCCCNC}(=\mathrm{O}) \mathrm{C}(\mathrm{C}(\mathrm{C}) \mathrm{CC}) \mathrm{NC}(=\mathrm{O}) \\
\mathrm{OCC}) \mathrm{NC}(=\mathrm{O}) \mathrm{OCC}\end{array}$ & $\begin{array}{l}\text { (HANABUSA et al., } \\
\text { 1997a) }\end{array}$ \\
\hline GID078 & $\begin{array}{c}\operatorname{CCC}(\mathrm{C}) \mathrm{C}(\mathrm{C}(=\mathrm{O}) \mathrm{NCCCCCCCCCCCCNC}(=\mathrm{O}) \mathrm{C}(\mathrm{C}(\mathrm{C}) \mathrm{CC}) \mathrm{NC}(=\mathrm{O}) \\
\mathrm{OCC} 1=\mathrm{CC}=\mathrm{CC}=\mathrm{C} 1) \mathrm{NC}(=\mathrm{O}) \mathrm{OCC} 2=\mathrm{CC}=\mathrm{CC}=\mathrm{C} 2\end{array}$ & $\begin{array}{l}\text { (HANABUSA et al., } \\
\text { 1997a) }\end{array}$ \\
\hline GID079 & $\begin{array}{c}\operatorname{CCCCCCNC}(=0) \operatorname{C1CC}(\operatorname{CC}(\mathrm{C} 1) \mathrm{C}(=0) \operatorname{NCCCCCC}) \mathrm{C}(=0) \operatorname{NCCC} \\
\operatorname{CCC}\end{array}$ & $\begin{array}{l}\text { (HANABUSA et al., } \\
\text { 1997b) }\end{array}$ \\
\hline GID080 & $\begin{aligned} & \operatorname{CcccccccccccNC}(=0) \operatorname{C1CC}(\operatorname{CC}(\mathrm{C} 1) \mathrm{C}(=\mathrm{O}) \mathrm{NCCCCCCCCC} \\
&\operatorname{CcC}) \mathrm{C}(=0) \mathrm{NCCCCCCCCCCCC}\end{aligned}$ & $\begin{array}{l}\text { (HANABUSA et al., } \\
\text { 1997b) }\end{array}$ \\
\hline GID081 & $\begin{array}{c}\mathrm{CC}(\mathrm{C}) \operatorname{CCCC}(\mathrm{C}) \mathrm{CCNC}(=\mathrm{O}) \mathrm{C} 1 \mathrm{CC}(\mathrm{CC}(\mathrm{C} 1) \mathrm{C}(=\mathrm{O}) \mathrm{NCCC}(\mathrm{C}) \mathrm{CCCC} \\
(\mathrm{C}) \mathrm{C}) \mathrm{C}(=\mathrm{O}) \mathrm{NCCC}(\mathrm{C}) \operatorname{CCCC}(\mathrm{C}) \mathrm{C}\end{array}$ & $\begin{array}{l}\text { (HANABUSA et al., } \\
\text { 1997b) }\end{array}$ \\
\hline GID082 & $\begin{array}{c}\mathrm{CC}(\mathrm{CCC}(=\mathrm{O}) \mathrm{O}) \mathrm{C} 1 \mathrm{CCC} 2 \mathrm{C} 1(\mathrm{C}(\mathrm{CC} 3 \mathrm{C} 2 \mathrm{C}(\mathrm{CC} 4 \mathrm{C} 3(\mathrm{CCC}(\mathrm{C} 4) \mathrm{O}) \mathrm{C}) \\
\mathrm{O}) \mathrm{O}) \mathrm{C}\end{array}$ & $\begin{array}{l}\text { (HISHIKAWA et al., } \\
\text { 1998) }\end{array}$ \\
\hline GID083 & $\begin{array}{c}\mathrm{CC}(\mathrm{CCC}(=\mathrm{O}) \mathrm{NC}) \mathrm{C} 1 \mathrm{CCC} 2 \mathrm{C} 1(\mathrm{C}(\mathrm{CC} 3 \mathrm{C} 2 \mathrm{C}(\mathrm{CC} 4 \mathrm{C} 3(\mathrm{CCC}(\mathrm{C} 4) \mathrm{O}) \mathrm{C}) \\
\text { O)O }) \mathrm{C}\end{array}$ & $\begin{array}{l}\text { (HISHIKAWA et al., } \\
\text { 1998) }\end{array}$ \\
\hline GID084 & $\begin{array}{c}\mathrm{CC}(\mathrm{CCC}(=\mathrm{O}) \mathrm{NCC}) \mathrm{C} 1 \mathrm{CCC} 2 \mathrm{C} 1(\mathrm{C}(\mathrm{CC} 3 \mathrm{C} 2 \mathrm{C}(\mathrm{CC} 4 \mathrm{C} 3(\mathrm{CCC}(\mathrm{C} 4) \mathrm{O}) \\
\mathrm{C}) \mathrm{O}) \mathrm{O}) \mathrm{C}\end{array}$ & $\begin{array}{l}\text { (HISHIKAWA et al., } \\
1998)\end{array}$ \\
\hline GID085 & $\begin{array}{c}\operatorname{CCCNC}(=0) \operatorname{CCC}(\mathrm{C}) \mathrm{C} 1 \mathrm{CCC} 2 \mathrm{C} 1(\mathrm{C}(\mathrm{CC} 3 \mathrm{C} 2 \mathrm{C}(\mathrm{CC} 4 \mathrm{C} 3(\mathrm{CCC}(\mathrm{C} 4) \\
\mathrm{O}) \mathrm{C}) \mathrm{O}) \mathrm{O}) \mathrm{C}\end{array}$ & $\begin{array}{l}\text { (HISHIKAWA et al., } \\
\text { 1998) }\end{array}$ \\
\hline GID086 & $\begin{array}{c}\operatorname{CC}(\operatorname{CCC}(=0) N C C C C C C C C C C C C C C C C C C) C 1 C C C 2 C 1(C(C C \\
\text { 3C2C }(\operatorname{CC} 4 \mathrm{C} 3(\operatorname{CCC}(\mathrm{C} 4) \mathrm{O}) \mathrm{C}) \mathrm{O}) \mathrm{O}) \mathrm{C}\end{array}$ & $\begin{array}{l}\text { (HISHIKAWA et al., } \\
\text { 1998) }\end{array}$ \\
\hline GID087 & $\operatorname{coc} \operatorname{coc} \operatorname{coc} \operatorname{coc} \operatorname{coc}(=0) O$ & $\begin{array}{l}\text { (LAM; ROGERS, } \\
\text { 2011) }\end{array}$ \\
\hline GID088 & $\operatorname{OcC}(=0) \operatorname{cccccccccc}(0) \operatorname{cccccc}$ & $\begin{array}{l}\text { (LAN; CORRADINI; } \\
\text { ROGERS, 2014) }\end{array}$ \\
\hline GID089 & $\operatorname{NCC}(=0) \operatorname{cccccccccc}(0) \operatorname{cccccc}$ & $\begin{array}{l}\text { (LAN; CORRADINI; } \\
\text { ROGERS, 2014) }\end{array}$ \\
\hline GID090 & $\operatorname{CNCC}(=0) \operatorname{Cccccccccc}(0) \operatorname{cccccc}$ & $\begin{array}{c}\text { (LAN; CORRADINI; } \\
\text { ROGERS, 2014) }\end{array}$ \\
\hline
\end{tabular}




\begin{tabular}{|c|c|c|}
\hline GID091 & $\operatorname{CCNCC}(=0) \operatorname{cccccccccc}(0) \operatorname{cccccc}$ & $\begin{array}{l}\text { (LAN; CORRADINI; } \\
\text { ROGERS, 2014) }\end{array}$ \\
\hline GID092 & $\operatorname{CcCNCC}(=0) \operatorname{Cccccccccc}(0) \operatorname{Cccccc}$ & $\begin{array}{l}\text { (LAN; CORRADINI; } \\
\text { ROGERS, 2014) }\end{array}$ \\
\hline GID093 & $\operatorname{CcccNCC}(=0) \operatorname{cccccccccc}(0) \operatorname{cccccc}$ & $\begin{array}{l}\text { (LAN; CORRADINI; } \\
\text { ROGERS, 2014) }\end{array}$ \\
\hline GID094 & $\begin{array}{c}\operatorname{CCCCCCCCCCCCCCCCCCNCC~}(=0) \operatorname{CCCCCCCCCC~}(0) \operatorname{CCC} \\
\operatorname{CCC}\end{array}$ & $\begin{array}{l}\text { (LAN; CORRADINI; } \\
\text { ROGERS, 2014) }\end{array}$ \\
\hline GID095 & $\operatorname{CCCCCCC}(\operatorname{CCCCCCCCCCCN)O~}$ & $\begin{array}{l}\text { (LAN; CORRADINI; } \\
\text { ROGERS, 2014) }\end{array}$ \\
\hline GID096 & $\operatorname{CcCCCC}(\operatorname{CcCCCCCCCCCNC)O}$ & $\begin{array}{l}\text { (LAN; CORRADINI; } \\
\text { ROGERS, 2014) }\end{array}$ \\
\hline GID097 & $\operatorname{cCCCCCC}(\operatorname{CCCCCCCCCCCNCC)O~}$ & $\begin{array}{l}\text { (LAN; CORRADINI; } \\
\text { ROGERS, 2014) }\end{array}$ \\
\hline GID098 & $\operatorname{CCCCCCC}(\operatorname{CCCCCCCCCCCNCCC}) \mathrm{O}$ & $\begin{array}{l}\text { (LAN; CORRADINI; } \\
\text { ROGERS, 2014) }\end{array}$ \\
\hline GID099 & $\operatorname{CCCCCCC}(\operatorname{CCCCCCCCCCCNCCCC)O~}$ & $\begin{array}{l}\text { (LAN; CORRADINI; } \\
\text { ROGERS, 2014) }\end{array}$ \\
\hline GID100 & CCCCCCCCCCCCCCCCCCNCCCCCCCCCCCC(CCCCCC)O & $\begin{array}{l}\text { (LAN; CORRADINI; } \\
\text { ROGERS, 2014) }\end{array}$ \\
\hline GID101 & $\mathrm{ClC} 1=\mathrm{CC}=\mathrm{C}(\mathrm{C}=\mathrm{C} 1) \mathrm{C} 2 \mathrm{OC} 3 \mathrm{C}(\mathrm{CO} 2) \mathrm{OC}(\mathrm{C}(\mathrm{C} 3 \mathrm{O}) \mathrm{O}) \mathrm{OC}$ & $\begin{array}{l}\text { (LAN; CORRADINI; } \\
\text { ROGERS, 2014) }\end{array}$ \\
\hline GID102 & $\begin{array}{c}\mathrm{CC}(\mathrm{CCC}(=\mathrm{O}) \mathrm{OC}) \mathrm{C} 1 \mathrm{CCC} 2 \mathrm{C} 1(\mathrm{CCC} 3 \mathrm{C} 2 \mathrm{CCC} 4 \mathrm{C} 3(\mathrm{CCC}(\mathrm{C} 4) \mathrm{OC}(= \\
\text { O) } \mathrm{C} 5=\mathrm{CC} 6=\mathrm{C}(\mathrm{C}=\mathrm{C} 5) \mathrm{C}(=\mathrm{O}) \mathrm{C} 7=\mathrm{CC}=\mathrm{CC}=\mathrm{C} 7 \mathrm{C} 6=\mathrm{O}) \mathrm{C}) \mathrm{C}\end{array}$ & $\begin{array}{l}\text { (LAN; CORRADINI; } \\
\text { ROGERS, 2014) }\end{array}$ \\
\hline GID103 & $\begin{array}{c}\mathrm{CC}(\mathrm{C}) \mathrm{CCCC}(\mathrm{C}) \mathrm{C} 1 \mathrm{CCC} 2 \mathrm{C} 1(\mathrm{CCC} 3 \mathrm{C} 2 \mathrm{CCC} 4 \mathrm{C} 3(\mathrm{CCC}(\mathrm{C} 4) \mathrm{OC}(=\mathrm{O} \\
) \mathrm{C} 5=\mathrm{CC} 6=\mathrm{C}(\mathrm{C}=\mathrm{C} 5) \mathrm{C}(=\mathrm{O}) \mathrm{C} 7=\mathrm{CC}=\mathrm{CC}=\mathrm{C} 7 \mathrm{C} 6=\mathrm{O}) \mathrm{C}) \mathrm{C}\end{array}$ & $\begin{array}{l}\text { (LAN; CORRADINI; } \\
\text { ROGERS, 2014) }\end{array}$ \\
\hline GID104 & $\begin{array}{c}\mathrm{CCC}(\mathrm{C}=\mathrm{CC}(\mathrm{C}) \mathrm{C} 1 \mathrm{CCC} 2 \mathrm{C} 1(\mathrm{CCC} 3 \mathrm{C} 2 \mathrm{CC}=\mathrm{C} 4 \mathrm{C} 3(\mathrm{CCC}(\mathrm{C} 4) \mathrm{OC}(=\mathrm{O} \\
\mathrm{C} 5=\mathrm{CC} 6=\mathrm{C}(\mathrm{C}=\mathrm{C} 5) \mathrm{C}(=\mathrm{O}) \mathrm{C} 7=\mathrm{CC}=\mathrm{CC}=\mathrm{C} 7 \mathrm{C} 6=\mathrm{O}) \mathrm{C}) \mathrm{C}) \mathrm{C}(\mathrm{C}) \mathrm{C}\end{array}$ & $\begin{array}{l}\text { (LAN; CORRADINI; } \\
\text { ROGERS, 2014) }\end{array}$ \\
\hline GID105 & $\begin{array}{c}\operatorname{CCC}(\mathrm{CCC}(\mathrm{C}) \mathrm{C} 1 \mathrm{CCC} 2 \mathrm{C} 1(\mathrm{CCC} 3 \mathrm{C} 2 \mathrm{CCC} 4 \mathrm{C} 3(\mathrm{CCC}(\mathrm{C} 4) \mathrm{OC}(=\mathrm{O}) \mathrm{C} \\
5=\mathrm{CC} 6=\mathrm{C}(\mathrm{C}=\mathrm{C} 5) \mathrm{C}(=\mathrm{O}) \mathrm{C} 7=\mathrm{CC}=\mathrm{CC}=\mathrm{C} 7 \mathrm{C} 6=\mathrm{O}) \mathrm{C}) \mathrm{C}) \mathrm{C}(\mathrm{C}) \mathrm{C}\end{array}$ & $\begin{array}{l}\text { (LAN; CORRADINI; } \\
\text { ROGERS, 2014) }\end{array}$ \\
\hline GID106 & $\begin{array}{l}\mathrm{CC}(\mathrm{C}) \mathrm{CCCC}(\mathrm{C}) \mathrm{C} 1 \mathrm{CCC} 2 \mathrm{C} 1(\mathrm{CCC} 3 \mathrm{C} 2 \mathrm{CC}=\mathrm{C} 4 \mathrm{C} 3(\mathrm{CCC}(\mathrm{C} 4) \mathrm{OC}(= \\
\mathrm{O}) \mathrm{C} 5=\mathrm{CC} 6=\mathrm{C}(\mathrm{C}=\mathrm{C} 5) \mathrm{C}(=\mathrm{O}) \mathrm{C} 7=\mathrm{CC}=\mathrm{CC}=\mathrm{C} 7 \mathrm{C} 6=\mathrm{O}) \mathrm{C}) \mathrm{C}\end{array}$ & $\begin{array}{l}\text { (LAN; CORRADINI; } \\
\text { ROGERS, 2014) }\end{array}$ \\
\hline GID107 & $\begin{array}{c}\mathrm{CC}(\mathrm{C}) \mathrm{CCCC}(\mathrm{C}) \mathrm{C} 1 \mathrm{CCC} 2 \mathrm{C} 1(\mathrm{CCC} 3 \mathrm{C} 2 \mathrm{CCC} 4 \mathrm{C} 3(\mathrm{CCC}(\mathrm{C} 4) \mathrm{OC}(=\mathrm{O} \\
) \mathrm{NC} 5=\mathrm{CC} 6=\mathrm{CC}=\mathrm{CC}=\mathrm{C} 6 \mathrm{C}=\mathrm{C} 5) \mathrm{C}) \mathrm{C}\end{array}$ & $\begin{array}{l}\text { (LAN; CORRADINI; } \\
\text { ROGERS, 2014) }\end{array}$ \\
\hline GID108 & $\begin{array}{c}\mathrm{CC}(\mathrm{C}) \mathrm{CCCC}(\mathrm{C}) \mathrm{C} 1 \mathrm{CCC} 2 \mathrm{C} 1(\mathrm{CCC} 3 \mathrm{C} 2 \mathrm{CC}=\mathrm{C} 4 \mathrm{C} 3(\mathrm{CCC}(\mathrm{C} 4) \mathrm{OC}(= \\
\mathrm{O}) \mathrm{NC}=\mathrm{CC} 6=\mathrm{CC}=\mathrm{CC}=\mathrm{C} 6 \mathrm{C}=\mathrm{C} 5) \mathrm{C}) \mathrm{C}\end{array}$ & $\begin{array}{l}\text { (LAN; CORRADINI; } \\
\text { ROGERS, 2014) }\end{array}$ \\
\hline GID109 & $\begin{array}{c}\mathrm{CC}(\mathrm{C}) \mathrm{CCCC}(\mathrm{C}) \mathrm{C} 1 \mathrm{CCC} 2 \mathrm{C} 1(\mathrm{CCC} 3 \mathrm{C} 2 \mathrm{CC}=\mathrm{C} 4 \mathrm{C} 3(\mathrm{CCC}(\mathrm{C} 4) \mathrm{OC}(= \\
\mathrm{O}) \mathrm{C} 5=\mathrm{CC}=\mathrm{C}(\mathrm{C}=\mathrm{C} 5) \mathrm{N}=\mathrm{NC} 6=\mathrm{CC}=\mathrm{CC}=\mathrm{C} 6) \mathrm{C}) \mathrm{C}\end{array}$ & $\begin{array}{l}\text { (LAN; CORRADINI; } \\
\text { ROGERS, 2014) }\end{array}$ \\
\hline GID110 & $\begin{array}{l}\mathrm{CC}(\mathrm{C}) \mathrm{CCCC}(\mathrm{C}) \mathrm{C} 1 \mathrm{CCC} 2 \mathrm{C} 1(\mathrm{CCC} 3 \mathrm{C} 2 \mathrm{CC}=\mathrm{C} 4 \mathrm{C} 3(\mathrm{CCC}(\mathrm{C} 4) \mathrm{OC}(= \\
\mathrm{O}) \mathrm{C} 5=\mathrm{CC}=\mathrm{C}(\mathrm{C}=\mathrm{C} 5) \mathrm{N}=\mathrm{NC} 6=\mathrm{CC}=\mathrm{C}(\mathrm{C}=\mathrm{C} 6) \mathrm{OC}) \mathrm{C}) \mathrm{C}\end{array}$ & $\begin{array}{l}\text { (LAN; CORRADINI; } \\
\text { ROGERS, 2014) }\end{array}$ \\
\hline GID111 & $\begin{array}{c}\mathrm{CCOC} 1=\mathrm{CC}=\mathrm{C}(\mathrm{C}=\mathrm{C} 1) \mathrm{N}=\mathrm{NC} 2=\mathrm{CC}=\mathrm{C}(\mathrm{C}=\mathrm{C} 2) \mathrm{C}(=\mathrm{O}) \mathrm{OC} 6 \mathrm{CCC}(\mathrm{C} \\
) \mathrm{C} 4 \mathrm{CCC} 3(\mathrm{C}) \mathrm{C}(\mathrm{CCC} 3 \mathrm{C} 4 \mathrm{CC}=\mathrm{C} 5 \mathrm{C} 6) \mathrm{C}(\mathrm{C}) \mathrm{CCCC}(\mathrm{C}) \mathrm{C}\end{array}$ & $\begin{array}{l}\text { (LAN; CORRADINI; } \\
\text { ROGERS, 2014) }\end{array}$ \\
\hline GID112 & $\begin{array}{c}\mathrm{CCCOC} 1=\mathrm{CC}=\mathrm{C}(\mathrm{C}=\mathrm{C} 1) \mathrm{N}=\mathrm{NC} 2=\mathrm{CC}=\mathrm{C}(\mathrm{C}=\mathrm{C} 2) \mathrm{C}(=\mathrm{O}) \mathrm{OC} 3 \mathrm{CCC} 4( \\
\mathrm{C} 5 \mathrm{CcC} 6(\mathrm{C}(\mathrm{C} 5 \mathrm{CC}=\mathrm{C} 4 \mathrm{C} 3) \mathrm{CCC} 6 \mathrm{C}(\mathrm{C}) \operatorname{CcCC}(\mathrm{C}) \mathrm{C}) \mathrm{C}) \mathrm{C}\end{array}$ & $\begin{array}{l}\text { (LAN; CORRADINI; } \\
\text { ROGERS, 2014) }\end{array}$ \\
\hline GID113 & $\begin{array}{c}\mathrm{CccCOC} 1=\mathrm{CC}=\mathrm{C}(\mathrm{C}=\mathrm{C} 1) \mathrm{N}=\mathrm{NC} 2=\mathrm{CC}=\mathrm{C}(\mathrm{C}=\mathrm{C} 2) \mathrm{C}(=\mathrm{O}) \mathrm{OC} 3 \mathrm{CCC} \\
4(\mathrm{C} 5 \mathrm{CcC} 6(\mathrm{C}(\mathrm{C} 5 \mathrm{CC}=\mathrm{C} 4 \mathrm{C} 3) \mathrm{CCC} 6 \mathrm{C}(\mathrm{C}) \mathrm{CCCC}(\mathrm{C}) \mathrm{C}) \mathrm{C}) \mathrm{C}\end{array}$ & $\begin{array}{l}\text { (LAN; CORRADINI; } \\
\text { ROGERS, 2014) }\end{array}$ \\
\hline GID114 & 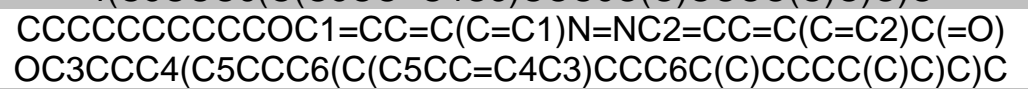 & $\begin{array}{l}\text { (LAN; CORRADINI; } \\
\text { ROGERS, 2014) }\end{array}$ \\
\hline GID115 & $\begin{array}{l}\mathrm{CC}(\mathrm{C}) \mathrm{CCCC}(\mathrm{C}) \mathrm{C} 1 \mathrm{CCC} 2 \mathrm{C} 1(\mathrm{CCC} 3 \mathrm{C} 2 \mathrm{CC}=\mathrm{C} 4 \mathrm{C} 3(\mathrm{CCC}(\mathrm{C} 4) \mathrm{OC}(= \\
\mathrm{O}) \mathrm{C} 5=\mathrm{CC}=\mathrm{C}(\mathrm{C}=\mathrm{C} 5) \mathrm{N}=\mathrm{NC} 6=\mathrm{CC}=\mathrm{C}(\mathrm{C}=\mathrm{C} 6) \mathrm{N}(\mathrm{C}) \mathrm{C}) \mathrm{C}) \mathrm{C}\end{array}$ & $\begin{array}{l}\text { (LAN; CORRADINI; } \\
\text { ROGERS, 2014) }\end{array}$ \\
\hline GID116 & $\begin{array}{l}\mathrm{CCN}(\mathrm{CC}) \mathrm{C} 1=\mathrm{CC}=\mathrm{C}(\mathrm{C}=\mathrm{C} 1) \mathrm{N}=\mathrm{NC} 2=\mathrm{CC}=\mathrm{C}(\mathrm{C}=\mathrm{C} 2) \mathrm{C}(=\mathrm{O}) \mathrm{OC} 3 \mathrm{CC} \\
\mathrm{C} 4(\mathrm{C} 5 \mathrm{CCC} 6(\mathrm{C}(\mathrm{C} 5 \mathrm{CC}=\mathrm{C} 4 \mathrm{C} 3) \mathrm{CCC} 6 \mathrm{C}(\mathrm{C}) \mathrm{CCCC}(\mathrm{C}) \mathrm{C}) \mathrm{C}) \mathrm{C}\end{array}$ & $\begin{array}{l}\text { (LAN; CORRADINI; } \\
\text { ROGERS, 2014) }\end{array}$ \\
\hline GID117 & $\begin{array}{c}\mathrm{CC}(\mathrm{C}) \mathrm{CCCC}(\mathrm{C}) \mathrm{C} 1 \mathrm{CCC} 2 \mathrm{C} 1(\mathrm{CCC} 3 \mathrm{C} 2 \mathrm{CC}=\mathrm{C} 4 \mathrm{C} 3(\mathrm{CCC}(\mathrm{C} 4) \mathrm{OC}(= \\
\mathrm{O}) \mathrm{COC}=\mathrm{CC}=\mathrm{C}(\mathrm{C}=\mathrm{C} 5) \mathrm{N}=\mathrm{NC} 6=\mathrm{CC} 7=\mathrm{C}(\mathrm{C}=\mathrm{C} 6) \mathrm{OCCOCCOCCO} \\
\mathrm{CCO}) \mathrm{C}) \mathrm{C}\end{array}$ & $\begin{array}{l}\text { (LAN; CORRADINI; } \\
\text { ROGERS, 2014) }\end{array}$ \\
\hline GID118 & $\begin{array}{c}\mathrm{CC}(\mathrm{C}) \mathrm{CCCC}(\mathrm{C}) \mathrm{C} 1 \mathrm{CCC} 2 \mathrm{C} 1(\mathrm{CCC} 3 \mathrm{C} 2 \mathrm{CC}=\mathrm{C} 4 \mathrm{C} 3(\mathrm{CCC}(\mathrm{C} 4) \mathrm{OC}(= \\
\mathrm{O}) \mathrm{COC}=\mathrm{CC}=\mathrm{C}(\mathrm{C}=\mathrm{C} 5) \mathrm{N}=\mathrm{NC} 6=\mathrm{CC} 7=\mathrm{C}(\mathrm{C}=\mathrm{C} 6) \mathrm{OCCOCCOCCO} \\
\mathrm{CCOCCO}) \mathrm{C}) \mathrm{C}\end{array}$ & $\begin{array}{l}\text { (LAN; CORRADINI; } \\
\text { ROGERS, 2014) }\end{array}$ \\
\hline GID119 & $\begin{array}{c}\mathrm{CccccoC} 1=\mathrm{CC}=\mathrm{C}(\mathrm{C}=\mathrm{C} 1) \mathrm{N}=\mathrm{NC} 2=\mathrm{CC}=\mathrm{C}(\mathrm{C}=\mathrm{C} 2) \mathrm{C}(=\mathrm{O}) \mathrm{OC} 3 \mathrm{CC} \\
\mathrm{C} 4(\mathrm{C} 5 \mathrm{CCC} 6(\mathrm{C}(\mathrm{C} 5 \mathrm{CC}=\mathrm{C} 4 \mathrm{C} 3) \mathrm{CCC} 6 \mathrm{C}(\mathrm{C}) \mathrm{CCCC}(\mathrm{C}) \mathrm{C}) \mathrm{C}) \mathrm{C}\end{array}$ & $\begin{array}{l}\text { (LAN; CORRADINI; } \\
\text { ROGERS, 2014) }\end{array}$ \\
\hline
\end{tabular}




\begin{tabular}{|c|c|c|}
\hline GID120 & $\begin{array}{l}\mathrm{CCCN}(\mathrm{CCC}) \mathrm{C} 1=\mathrm{CC}=\mathrm{C}(\mathrm{C}=\mathrm{C} 1) \mathrm{N}=\mathrm{NC} 2=\mathrm{CC}=\mathrm{C}(\mathrm{C}=\mathrm{C} 2) \mathrm{C}(=\mathrm{O}) \mathrm{OC} 3 \\
\operatorname{CCC} 4(\mathrm{C} 5 \mathrm{CCC} 6(\mathrm{C}(\mathrm{C} 5 \mathrm{CC}=\mathrm{C} 4 \mathrm{C} 3) \mathrm{CCC} 6 \mathrm{C}(\mathrm{C}) \mathrm{CCC}(\mathrm{C}) \mathrm{C}) \mathrm{C}) \mathrm{C}\end{array}$ & $\begin{array}{l}\text { (LAN; CORRADINI; } \\
\text { ROGERS, 2014) }\end{array}$ \\
\hline GID121 & $\mathrm{OC}(\mathrm{CO}) \mathrm{C} 2 \mathrm{OCC} 1 \mathrm{OC}(\mathrm{OC} 1 \mathrm{C} 2 \mathrm{O})(\mathrm{CC}) \mathrm{CC}$ & $\begin{array}{l}\text { (LAN; CORRADINI; } \\
\text { ROGERS 2014) }\end{array}$ \\
\hline GID122 & $\begin{array}{c}\mathrm{C} 1=\mathrm{CC}=\mathrm{C}(\mathrm{C}=\mathrm{C} 1) \mathrm{C} 2 \mathrm{OC}(\mathrm{C}(\mathrm{O} 2) \mathrm{C} 3 \mathrm{C}(\mathrm{OC}(\mathrm{O} 3) \mathrm{C} 4=\mathrm{CC}=\mathrm{CC}=\mathrm{C} 4) \mathrm{CO} \\
\text { CO }\end{array}$ & $\begin{array}{l}\text { (LAN; CORRADINI; } \\
\text { ROGERS, 2014) }\end{array}$ \\
\hline GID123 & $\operatorname{cccccccccccccccccco}$ & $\begin{array}{l}\text { (LAN; CORRADINI; } \\
\text { ROGERS, 2014) }\end{array}$ \\
\hline GID124 & $\mathrm{C} 1 \mathrm{C}(\mathrm{C}(\mathrm{C}(\mathrm{O} 1) \mathrm{C}(\mathrm{CO}) \mathrm{O}) \mathrm{O}) \mathrm{O}$ & $\begin{array}{l}\text { (LAN; CORRADINI; } \\
\text { ROGERS, 2014) }\end{array}$ \\
\hline GID125 & $\mathrm{CNC}(=\mathrm{O}) \mathrm{NC}$ & $\begin{array}{l}\text { (LAN; CORRADINI; } \\
\text { ROGERS, 2014) }\end{array}$ \\
\hline GID126 & $\mathrm{C}(\mathrm{NC}(=\mathrm{O}) \mathrm{NCO}) \mathrm{O}$ & $\begin{array}{l}\text { (LAN; CORRADINI; } \\
\text { ROGERS, 2014) }\end{array}$ \\
\hline GID127 & $\mathrm{C} 1 \mathrm{CCC}(\mathrm{CC} 1) \mathrm{NC}(=\mathrm{O}) \mathrm{NC} 2 \mathrm{CCCCC} 2$ & $\begin{array}{l}\text { (LAN; CORRADINI; } \\
\text { ROGERS, 2014) }\end{array}$ \\
\hline GID128 & $\operatorname{CCCCNC}(=0) \operatorname{NCCCC}$ & $\begin{array}{l}\text { (LAN; CORRADINI; } \\
\text { ROGERS, 2014) }\end{array}$ \\
\hline GID129 & $\mathrm{C} 1=\mathrm{CC}=\mathrm{C}(\mathrm{C}=\mathrm{C} 1) \mathrm{CNC}(=\mathrm{O}) \mathrm{NCC} 2=\mathrm{CC}=\mathrm{CC}=\mathrm{C} 2$ & $\begin{array}{l}\text { (LAN; CORRADINI; } \\
\text { ROGERS, 2014) }\end{array}$ \\
\hline GID130 & $\begin{array}{l}\mathrm{CC}(\mathrm{C}) \mathrm{CCCC}(\mathrm{C}) \mathrm{C} 1 \mathrm{CCC} 2 \mathrm{C} 1(\mathrm{CCC} 3 \mathrm{C} 2 \mathrm{CC}=\mathrm{C} 4 \mathrm{C} 3(\mathrm{CCC}(\mathrm{C} 4) \mathrm{OC}(= \\
\mathrm{O}) \mathrm{CCCOC} 5=\mathrm{CC} 6=\mathrm{C}(\mathrm{C}=\mathrm{C} 5) \mathrm{C}(=\mathrm{O}) \mathrm{C} 7=\mathrm{CC}=\mathrm{CC}=\mathrm{C} 7 \mathrm{C} 6=\mathrm{O}) \mathrm{C}) \mathrm{C}\end{array}$ & (LAN et al., 2015) \\
\hline GID131 & $\begin{array}{c}\mathrm{CC}(\mathrm{C}) \mathrm{CCCC}(\mathrm{C}) \mathrm{C} 1 \mathrm{CCC} 2 \mathrm{C} 1(\mathrm{CCC} 3 \mathrm{C} 2 \mathrm{CC}=\mathrm{C} 4 \mathrm{C} 3(\mathrm{CCC}(\mathrm{C} 4) \mathrm{OCC} \\
\mathrm{OC} 5=\mathrm{CC} 6=\mathrm{C}(\mathrm{C}=\mathrm{C} 5) \mathrm{C}(=\mathrm{O}) \mathrm{C} 7=\mathrm{CC}=\mathrm{CC}=\mathrm{C} 7 \mathrm{C} 6=\mathrm{O}) \mathrm{C}) \mathrm{C}\end{array}$ & (LAN et al., 2015) \\
\hline GID132 & $\begin{array}{l}\mathrm{CC}(\mathrm{C}) \mathrm{CCCC}(\mathrm{C}) \mathrm{C} 1 \mathrm{CCC} 2 \mathrm{C} 1(\mathrm{CCC} 3 \mathrm{C} 2 \mathrm{CC}=\mathrm{C} 4 \mathrm{C} 3(\mathrm{CCC}(\mathrm{C} 4) \mathrm{SC}(= \\
\mathrm{O}) \mathrm{C} 5=\mathrm{CC} 6=\mathrm{C}(\mathrm{C}=\mathrm{C} 5) \mathrm{C}(=\mathrm{O}) \mathrm{C} 7=\mathrm{CC}=\mathrm{CC}=\mathrm{C} 7 \mathrm{C} 6=\mathrm{O}) \mathrm{C}) \mathrm{C}\end{array}$ & (LAN et al., 2015) \\
\hline GID133 & $\operatorname{Coc} 1 \mathrm{C}(\mathrm{C}(\mathrm{C} 2 \mathrm{C}(\mathrm{O} 1) \mathrm{COC}(\mathrm{O} 2) \mathrm{C} 3=\mathrm{CC}=\mathrm{CC}=\mathrm{C} 3) \mathrm{O}) \mathrm{O}$ & (LAN et al., 2015) \\
\hline GID134 & $\begin{array}{c}\mathrm{C} 1 \mathrm{C} 2 \mathrm{C}(\mathrm{C}(\mathrm{C}(\mathrm{C}(\mathrm{O} 2) \mathrm{OC} 3=\mathrm{CC}=\mathrm{C}(\mathrm{C}=\mathrm{C} 3)[\mathrm{N}+](=\mathrm{O})[\mathrm{O}- \\
]) \mathrm{O}) \mathrm{O}) \mathrm{OC}(\mathrm{O} 1) \mathrm{C} 4=\mathrm{CC}=\mathrm{CC}=\mathrm{C} 4\end{array}$ & (LAN et al., 2015) \\
\hline GID135 & $\operatorname{ccccccccccccc}(=0) \operatorname{Nccccc}(C(=)) O C) N C(=0) \operatorname{ccccc}$ & (LI et al., 2016) \\
\hline GID136 & $\operatorname{coccccc}(\operatorname{ccc} \operatorname{coc} \operatorname{ccc}(=0) \mathrm{N}) \mathrm{O}$ & $\begin{array}{l}\text { (MALLIA et al., } \\
\text { 2009) }\end{array}$ \\
\hline GID137 & $\operatorname{ccccccc}(\operatorname{ccccccccccc}(=0) \mathrm{NC}) \mathrm{O}$ & $\begin{array}{l}\text { (MALLIA et al., } \\
\text { 2009) }\end{array}$ \\
\hline GID138 & $\operatorname{ccccccc}(\operatorname{coc} \operatorname{coc} \operatorname{coc}(=O) N C C) O$ & $\begin{array}{l}\text { (MALLIA et al., } \\
\text { 2009) }\end{array}$ \\
\hline GID139 & $\operatorname{ccccccc}(\operatorname{cccccccccc}(=0) \mathrm{NCcC}) \mathrm{O}$ & $\begin{array}{l}\text { (MALLIA et al., } \\
\text { 2009) }\end{array}$ \\
\hline GID140 & $\operatorname{coc} \operatorname{coc} c \operatorname{coc} \operatorname{coc} c \cos (=0) \mathrm{N}$ & $\begin{array}{l}\text { (MALLIA et al., } \\
\text { 2009) }\end{array}$ \\
\hline GID141 & $\operatorname{cccCcCcCCCCCCCCCCCN~}$ & $\begin{array}{l}\text { (MALLIA et al., } \\
\text { 2009) }\end{array}$ \\
\hline GID142 & CCCCCCCCCCCCCCCCCCNCCCCCCCCCCCCCCCCCC & $\begin{array}{l}\text { (MALLIA et al., } \\
\text { 2009) }\end{array}$ \\
\hline GID143 & $\mathrm{C} 1(=\mathrm{NC}(=\mathrm{NC}(=\mathrm{N} 1) \mathrm{N}) \mathrm{N}) \mathrm{N}$ & (NIU et al., 2013) \\
\hline GID144 & $\operatorname{ccccc}(C C) \operatorname{COP}(=O)(\operatorname{CC}(C C) \operatorname{CCCC}) O$ & (NIU et al., 2013) \\
\hline GID145 & $\mathrm{C} 1=\mathrm{CC}=\mathrm{C}(\mathrm{C}=\mathrm{C} 1) \mathrm{C} 2 \mathrm{OC}(\mathrm{C}(\mathrm{C}(\mathrm{O} 2) \mathrm{C}(\mathrm{CO}) \mathrm{O}) \mathrm{O}) \mathrm{CO}$ & $\begin{array}{l}\text { (OKESOLA et al., } \\
\text { 2015) }\end{array}$ \\
\hline GID146 & $\begin{array}{c}\mathrm{C} 1 \mathrm{C}(\mathrm{OC}(\mathrm{O} 1) \mathrm{C} 2=\mathrm{CC}=\mathrm{CC}=\mathrm{C} 2) \mathrm{C} 3 \mathrm{C} 4 \mathrm{C}(\mathrm{COC}(\mathrm{O} 4) \mathrm{C} 5=\mathrm{CC}=\mathrm{CC}=\mathrm{C} 5 \\
) \mathrm{OC}(\mathrm{O} 3) \mathrm{C} 6=\mathrm{CC}=\mathrm{CC}=\mathrm{C} 6\end{array}$ & $\begin{array}{l}\text { (OKESOLA et al., } \\
\text { 2015) }\end{array}$ \\
\hline GID147 & $\begin{aligned} \mathrm{C} 1 \mathrm{C} 2 \mathrm{C}(\mathrm{C}(\mathrm{OC}(\mathrm{O} 2) \mathrm{C} 3 & =\mathrm{CC}=\mathrm{C}(\mathrm{C}=\mathrm{C} 3) \mathrm{C}(=\mathrm{O}) \mathrm{O}) \mathrm{C}(\mathrm{CO}) \mathrm{O}) \mathrm{OC}(\mathrm{O} 1) \mathrm{C} 4 \\
& =\mathrm{CC}=\mathrm{C}(\mathrm{C}=\mathrm{C} 4) \mathrm{C}(=\mathrm{O}) \mathrm{O}\end{aligned}$ & $\begin{array}{l}\text { (OKESOLA et al., } \\
\text { 2015) }\end{array}$ \\
\hline GID148 & $\begin{aligned} \mathrm{C} 1 \mathrm{C} 2 \mathrm{C}(\mathrm{C}(\mathrm{OC}(\mathrm{O} 2) \mathrm{C} 3 & =\mathrm{CC}=\mathrm{C}(\mathrm{C}=\mathrm{C} 3) \mathrm{C}(=\mathrm{O}) \mathrm{NN}) \mathrm{C}(\mathrm{CO}) \mathrm{O}) \mathrm{OC}(\mathrm{O} 1) \\
\mathrm{C} 4 & =\mathrm{CC}=\mathrm{C}(\mathrm{C}=\mathrm{C} 4) \mathrm{C}(=\mathrm{O}) \mathrm{NN}\end{aligned}$ & $\begin{array}{l}\text { (OKESOLA et al., } \\
\text { 2015) }\end{array}$ \\
\hline GID149 & $\begin{array}{c}\operatorname{CccccC}(=0) \mathrm{OCC}\left(\mathrm{C}_{1} \mathrm{C} 2 \mathrm{C}(\mathrm{COC}(\mathrm{O} 2) \mathrm{C} 3=\mathrm{CC}=\mathrm{CC}=\mathrm{C} 3) \mathrm{OC}(\mathrm{O} 1) \mathrm{C}\right. \\
4=\mathrm{CC}=\mathrm{CC}=\mathrm{C} 4) \mathrm{O}\end{array}$ & $\begin{array}{l}\text { (OKESOLA et al., } \\
\text { 2015) }\end{array}$ \\
\hline GID150 & $\begin{array}{c}\operatorname{cccccccccC}(=\mathrm{O}) \mathrm{OCC}(\mathrm{C} 1 \mathrm{C} 2 \mathrm{C}(\mathrm{COC}(\mathrm{O} 2) \mathrm{C} 3=\mathrm{CC}=\mathrm{CC}=\mathrm{C} 3) \mathrm{OC} \\
(\mathrm{O} 1) \mathrm{C} 4=\mathrm{CC}=\mathrm{CC}=\mathrm{C} 4) \mathrm{O}\end{array}$ & $\begin{array}{l}\text { (OKESOLA et al., } \\
\text { 2015) }\end{array}$ \\
\hline
\end{tabular}




\begin{tabular}{|c|c|c|}
\hline GID151 & $\begin{array}{c}\operatorname{cccccccccccccccC}(=\mathrm{O}) \mathrm{OCC}(\mathrm{C} 1 \mathrm{C} 2 \mathrm{C}(\mathrm{COC}(\mathrm{O} 2) \mathrm{C} 3=\mathrm{CC}=\mathrm{C} \\
\mathrm{C}=\mathrm{C} 3) \mathrm{OC}(\mathrm{O} 1) \mathrm{C} 4=\mathrm{CC}=\mathrm{CC}=\mathrm{C} 4) \mathrm{O}\end{array}$ & $\begin{array}{l}\text { (OKESOLA et al., } \\
\text { 2015) }\end{array}$ \\
\hline GID152 & $\begin{array}{c}\operatorname{ccccccccccccccccccC}(=\mathrm{O}) \mathrm{OCC}(\mathrm{C} 1 \mathrm{C} 2 \mathrm{C}(\mathrm{COC}(\mathrm{O} 2) \mathrm{C} 3= \\
\mathrm{CC}=\mathrm{CC}=\mathrm{C} 3) \mathrm{OC}(\mathrm{O} 1) \mathrm{C} 4=\mathrm{CC}=\mathrm{CC}=\mathrm{C} 4) \mathrm{O}\end{array}$ & $\begin{array}{l}\text { (OKESOLA et al., } \\
\text { 2015) }\end{array}$ \\
\hline GID153 & $\begin{array}{c}\operatorname{CC}(\mathrm{C}) \operatorname{CccccccccC}(=\mathrm{O}) \mathrm{OC}(\mathrm{COC}(=\mathrm{O}) \mathrm{CCCCCCC}) \mathrm{C} 1 \mathrm{OC}(\mathrm{OC} \\
2 \mathrm{COC}(\mathrm{OC} 12) \mathrm{C} 3=\mathrm{CC}=\mathrm{CC}=\mathrm{C} 3) \mathrm{C} 4=\mathrm{CC}=\mathrm{CC}=\mathrm{C} 4\end{array}$ & $\begin{array}{l}\text { (OKESOLA et al., } \\
\text { 2015) }\end{array}$ \\
\hline GID154 & $\begin{aligned} \mathrm{C}=\mathrm{C}(\mathrm{C}) \mathrm{C}(=\mathrm{O}) \mathrm{OCCNC}(=\mathrm{O}) \mathrm{OCC}(\mathrm{OC}(=\mathrm{O}) \mathrm{NCCOC}(=\mathrm{O}) \mathrm{C}(=\mathrm{C}) \mathrm{C}) \mathrm{C} 1 \\
\mathrm{OC}(\mathrm{OC} 2 \mathrm{COC}(\mathrm{OC} 12) \mathrm{C} 3=\mathrm{CC}=\mathrm{CC}=\mathrm{C} 3) \mathrm{C} 4=\mathrm{CC}=\mathrm{CC}=\mathrm{C} 4\end{aligned}$ & $\begin{array}{l}\text { (OKESOLA et al., } \\
\text { 2015) }\end{array}$ \\
\hline GID155 & $\begin{aligned} \operatorname{COC}(\mathrm{CO}) \mathrm{C} 1 \mathrm{C} 2 \mathrm{C}(\mathrm{COC}(\mathrm{O} 2) \mathrm{C} 3 & =\mathrm{CC}=\mathrm{CC}=\mathrm{C} 3) \mathrm{OC}(\mathrm{O} 1) \mathrm{C} 4=\mathrm{CC}=\mathrm{CC} \\
& =\mathrm{C} 4\end{aligned}$ & $\begin{array}{l}\text { (OKESOLA et al., } \\
\text { 2015) }\end{array}$ \\
\hline GID156 & $\begin{array}{c}\mathrm{CCC} 1=\mathrm{CC}=\mathrm{C}(\mathrm{C}=\mathrm{C} 1) \mathrm{C} 2 \mathrm{OC}(\mathrm{C} 3 \mathrm{C}(\mathrm{O} 2) \mathrm{C}(\mathrm{OC}(\mathrm{O} 3) \mathrm{C} 4=\mathrm{CC}=\mathrm{C}(\mathrm{C}=\mathrm{C} 4 \\
) \mathrm{CC}) \mathrm{C}(\mathrm{CO}) \mathrm{O}) \mathrm{CC}=\mathrm{C}\end{array}$ & $\begin{array}{l}\text { (OKESOLA et al., } \\
\text { 2015) }\end{array}$ \\
\hline GID157 & $\begin{array}{c}\operatorname{Cccc} 1 \mathrm{C} 2 \mathrm{C}(\mathrm{C}(\mathrm{OC}(\mathrm{O} 2) \mathrm{C} 3=\mathrm{CC}=\mathrm{C}(\mathrm{C}=\mathrm{C} 3) \mathrm{CC}) \mathrm{C}(\mathrm{CO}) \mathrm{O}) \mathrm{OC}(\mathrm{O} 1) \mathrm{C} \\
4=\mathrm{CC}=\mathrm{C}(\mathrm{C}=\mathrm{C} 4) \mathrm{CC}\end{array}$ & $\begin{array}{l}\text { (OKESOLA et al., } \\
2015 \text { ) }\end{array}$ \\
\hline GID158 & $\begin{array}{c}\mathrm{CCCC} 1 \mathrm{C} 2 \mathrm{C}(\mathrm{C}(\mathrm{OC}(\mathrm{O} 2) \mathrm{C} 3=\mathrm{CC}=\mathrm{C}(\mathrm{C}=\mathrm{C} 3) \mathrm{CCC}) \mathrm{C}(\mathrm{CO}) \mathrm{O}) \mathrm{OC}(\mathrm{O} 1) \\
\mathrm{C} 4=\mathrm{CC}=\mathrm{C}(\mathrm{C}=\mathrm{C} 4) \mathrm{CCC}\end{array}$ & $\begin{array}{l}\text { (OKESOLA et al., } \\
\text { 2015) }\end{array}$ \\
\hline GID159 & $\begin{array}{c}\mathrm{CCCC} 1=\mathrm{CC}=\mathrm{C}(\mathrm{C}=\mathrm{C} 1) \mathrm{C} 2 \mathrm{OC}(\mathrm{C} 3 \mathrm{C}(\mathrm{O} 2) \mathrm{C}(\mathrm{OC}(\mathrm{O}) \mathrm{C} 4=\mathrm{CC}=\mathrm{C}(\mathrm{C}=\mathrm{C} \\
4) \mathrm{CCC}) \mathrm{C}(\mathrm{CO}) \mathrm{O}) \mathrm{CC}=\mathrm{C}\end{array}$ & $\begin{array}{l}\text { (OKESOLA et al., } \\
\text { 2015) }\end{array}$ \\
\hline GID160 & $\begin{aligned} \mathrm{CCCOC} 1=\mathrm{CC}=\mathrm{C}(\mathrm{C}=\mathrm{C} 1) \mathrm{C} 2 \mathrm{OC}(\mathrm{C} 3 \mathrm{C}(\mathrm{O} 2) \mathrm{C}(\mathrm{OC}(\mathrm{O}) \mathrm{C} 4=\mathrm{CC}=\mathrm{C}(\mathrm{C} \\
\\
=\mathrm{C} 4) \mathrm{OCCC}) \mathrm{C}(\mathrm{CO}) \mathrm{O}) \mathrm{CC}=\mathrm{C}\end{aligned}$ & $\begin{array}{l}\text { (OKESOLA et al., } \\
\text { 2015) }\end{array}$ \\
\hline GID161 & $\begin{array}{c}\mathrm{CCCC} 1 \mathrm{C} 2 \mathrm{C}(\mathrm{C}(\mathrm{OC}(\mathrm{O} 2) \mathrm{C} 3=\mathrm{CC}=\mathrm{C}(\mathrm{C}=\mathrm{C} 3) \mathrm{OCCC}) \mathrm{C}(\mathrm{CO}) \mathrm{O}) \mathrm{OC}(\mathrm{O} 1 \\
) \mathrm{C} 4=\mathrm{CC}=\mathrm{C}(\mathrm{C}=\mathrm{C} 4) \mathrm{OCCC}\end{array}$ & $\begin{array}{l}\text { (OKESOLA et al., } \\
\text { 2015) }\end{array}$ \\
\hline GID162 & $\begin{array}{c}\mathrm{OCC}(\mathrm{O}) \mathrm{C} 1 \mathrm{OC}(\mathrm{OC} 2 \mathrm{COC}(\mathrm{OC} 12) \mathrm{C} 3=\mathrm{C}(\mathrm{C}=\mathrm{C}(\mathrm{C}=\mathrm{C} 3 \mathrm{C}) \mathrm{C}) \mathrm{C}) \mathrm{C} 4=\mathrm{C}( \\
\mathrm{C}=\mathrm{C}(\mathrm{C}=\mathrm{C} 4 \mathrm{C}) \mathrm{C}) \mathrm{C}\end{array}$ & $\begin{array}{l}\text { (OKESOLA et al., } \\
\text { 2015) }\end{array}$ \\
\hline GID163 & $\begin{array}{c}\mathrm{CC} 1=\mathrm{CC}(=\mathrm{C}(\mathrm{C}=\mathrm{C} 1 \mathrm{C} 2 \mathrm{OCC} 3 \mathrm{C}(\mathrm{O} 2) \mathrm{C}(\mathrm{OC}(\mathrm{O} 3) \mathrm{C} 4=\mathrm{CC}(=\mathrm{C}(\mathrm{C}=\mathrm{C} 4 \mathrm{C} \\
\mathrm{C}) \mathrm{C}) \mathrm{C}(\mathrm{CO}) \mathrm{O}) \mathrm{C}) \mathrm{C}\end{array}$ & $\begin{array}{l}\text { (OKESOLA et al., } \\
\text { 2015) }\end{array}$ \\
\hline GID164 & $\begin{array}{c}\mathrm{CC} 1=\mathrm{C}(\mathrm{C}=\mathrm{C}(\mathrm{C}=\mathrm{C} 1) \mathrm{C} 2 \mathrm{OCC} 3 \mathrm{C}(\mathrm{O} 2) \mathrm{C}(\mathrm{OC}(\mathrm{O}) \mathrm{C} 4=\mathrm{CC}(=\mathrm{C}(\mathrm{C}=\mathrm{C} 4) \\
\mathrm{C}) \mathrm{C}) \mathrm{C}(\mathrm{CO}) \mathrm{O}) \mathrm{C}\end{array}$ & $\begin{array}{l}\text { (OKESOLA et al., } \\
\text { 2015) }\end{array}$ \\
\hline GID165 & $\begin{array}{c}\mathrm{O}=\mathrm{C}(\mathrm{OC}) \mathrm{C}(\mathrm{CC} 1=\mathrm{CC}=\mathrm{CC}=\mathrm{C} 1) \mathrm{NC}(=\mathrm{O}) \mathrm{CC}(\mathrm{NC}(=\mathrm{O}) \mathrm{C} 2=\mathrm{CC}=\mathrm{C}(\mathrm{C}= \\
\mathrm{C} 2) \mathrm{C}(=\mathrm{O}) \mathrm{NC}(\mathrm{CC}(=\mathrm{O}) \mathrm{NC}(\mathrm{CC}=\mathrm{CC}=\mathrm{CC}=\mathrm{C} 3) \mathrm{C}(=\mathrm{O}) \mathrm{OC}) \mathrm{C}(=\mathrm{O}) \mathrm{OC} \\
\qquad \mathrm{C}(=\mathrm{O}) \mathrm{OC}\end{array}$ & (QING et al., 2014) \\
\hline GID166 & $\begin{array}{c}\mathrm{O}=\mathrm{C}(\mathrm{NC}(\mathrm{CC}(=\mathrm{O}) \mathrm{NC}(\mathrm{C}(=\mathrm{O}) \mathrm{OC}) \mathrm{C}(\mathrm{C}) \mathrm{C}) \mathrm{C}(=\mathrm{O}) \mathrm{OC}) \mathrm{C} 1=\mathrm{CC}=\mathrm{C}(\mathrm{C}= \\
\mathrm{C} 1) \mathrm{C}(=\mathrm{O}) \mathrm{NC}(\mathrm{CC}(=\mathrm{O}) \mathrm{NC}(\mathrm{C}(=\mathrm{O}) \mathrm{OC}) \mathrm{C}(\mathrm{C}) \mathrm{C}) \mathrm{C}(=\mathrm{O}) \mathrm{OC}\end{array}$ & (QING et al., 2014) \\
\hline GID167 & $\begin{array}{c}\mathrm{O}=\mathrm{C}(\mathrm{C}(\mathrm{C}) \mathrm{NC}(=\mathrm{O}) \mathrm{C} 1=\mathrm{CC}=\mathrm{C}(\mathrm{C}=\mathrm{C} 1) \mathrm{C}(=\mathrm{O}) \mathrm{NC}(\mathrm{C}) \mathrm{C}(=\mathrm{O}) \mathrm{N} 2 \mathrm{CCCC} \\
2 \mathrm{C}(=\mathrm{O}) \mathrm{OC}) \mathrm{N} 3 \mathrm{CCCC} \mathrm{C}(=\mathrm{O}) \mathrm{OC}\end{array}$ & (QING et al., 2014) \\
\hline GID168 & $\begin{array}{c}\mathrm{O}=\mathrm{C}(\mathrm{NC}(\mathrm{CC}(\mathrm{C}) \mathrm{C}) \mathrm{C}(=\mathrm{O}) \mathrm{NC}(\mathrm{C}(=\mathrm{O}) \mathrm{OC}) \mathrm{C}(\mathrm{C}) \mathrm{C}) \mathrm{C} 1=\mathrm{CC}=\mathrm{C}(\mathrm{C}=\mathrm{C} 1) \\
\mathrm{C}(=\mathrm{O}) \mathrm{NC}(\mathrm{CC}(\mathrm{C}) \mathrm{C}) \mathrm{C}(=\mathrm{O}) \mathrm{NC}(\mathrm{C}(=\mathrm{O}) \mathrm{OC}) \mathrm{C}(\mathrm{C}) \mathrm{C}\end{array}$ & (QING et al., 2014) \\
\hline GID169 & $\begin{aligned} \mathrm{O}= & \mathrm{C}(\mathrm{OC}) \mathrm{C}(\mathrm{CC} 1=\mathrm{CC}=\mathrm{CC}=\mathrm{C} 1) \mathrm{NC}(=\mathrm{O}) \mathrm{C}(\mathrm{C}) \mathrm{NC}(=\mathrm{O}) \mathrm{C} 2=\mathrm{CC}=\mathrm{C}(\mathrm{C} \\
& =\mathrm{C} 2) \mathrm{C}(=\mathrm{O}) \mathrm{NC}(\mathrm{C}) \mathrm{C}(=\mathrm{O}) \mathrm{NC}(\mathrm{CC} 3=\mathrm{CC}=\mathrm{CC}=\mathrm{C} 3) \mathrm{C}(=\mathrm{O}) \mathrm{OC}\end{aligned}$ & (QING et al., 2014) \\
\hline GID170 & $\begin{aligned} \mathrm{O}=\mathrm{C}(\mathrm{OC}) \mathrm{C}(\mathrm{NC}(=\mathrm{O}) \mathrm{C} 1=\mathrm{CC}=\mathrm{CC}=\mathrm{C} 1) \mathrm{CC}(=\mathrm{O}) \mathrm{NC}(\mathrm{CC} 2=\mathrm{CC}=\mathrm{CC}= \\
\mathrm{C} 2) \mathrm{C}(=\mathrm{O}) \mathrm{OC}\end{aligned}$ & (QING et al., 2014) \\
\hline GID171 & $\mathrm{O}=\mathrm{C}(\mathrm{OC}) \mathrm{C}(\mathrm{N}) \mathrm{CC}(=\mathrm{O}) \mathrm{NC}(\mathrm{CC} 1=\mathrm{CC}=\mathrm{C}(\mathrm{C}=\mathrm{C} 1) \mathrm{CCC}) \mathrm{C}(=\mathrm{O}) \mathrm{OC}$ & (QING et al., 2014) \\
\hline GID172 & $\begin{aligned} \operatorname{CccccC}(=O) N N C(=O) C O C 1 & =C C 2=C(C=C 1) C(=O) C 3=C C=C C \\
& =C 3 C 2=O\end{aligned}$ & $\begin{array}{l}\text { (RAYNAL; } \\
\text { BOUTEILLER, } \\
\text { 2011) }\end{array}$ \\
\hline GID173 & $\begin{array}{c}C 1=C C=C 2 C=C(C=C C 2=C 1) S(=O)(=O) N C C N C(=O) C(C(C(C(C \\
O) O) O) O) O\end{array}$ & $\begin{array}{l}\text { (RAYNAL; } \\
\text { BOUTEILLER, } \\
\text { 2011) }\end{array}$ \\
\hline GID174 & 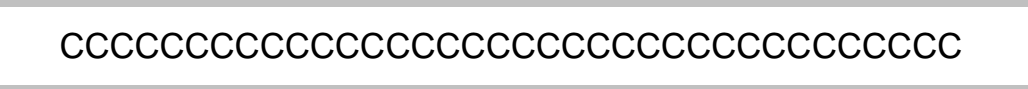 & $\begin{array}{l}\text { (ROGERS; WEISS, } \\
\text { 2015) }\end{array}$ \\
\hline GID175 & $\operatorname{cccccccccccccccccc}(=0)[\mathrm{O}-] \cdot[\mathrm{K}+]$ & $\begin{array}{l}\text { (ROGERS; WEISS, } \\
\text { 2015) }\end{array}$ \\
\hline GID176 & $\operatorname{cccccccccccccccc}(=0)[0-] \cdot[\mathrm{K}+]$ & $\begin{array}{l}\text { (ROGERS; WEISS, } \\
\text { 2015) }\end{array}$ \\
\hline GID177 & 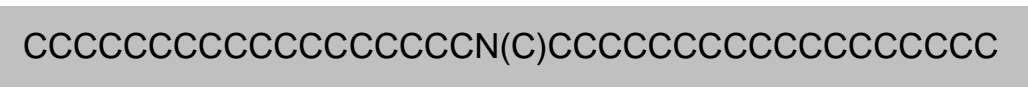 & $\begin{array}{l}\text { (ROGERS; WEISS, } \\
\text { 2015) }\end{array}$ \\
\hline GID178 & 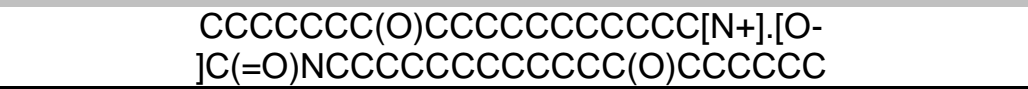 & $\begin{array}{l}\text { (MALLIA et al., } \\
\text { 2009) }\end{array}$ \\
\hline
\end{tabular}




\begin{tabular}{|c|c|c|}
\hline GID179 & $\begin{array}{l}\text { CCCCCCCCCCCCCCCCCC[N].[O- } \\
] \mathrm{C}(=\mathrm{O}) \mathrm{NCCCCCCCCCCCCCCCCCC}\end{array}$ & $\begin{array}{l}\text { (MALLIA et al., } \\
\text { 2009) }\end{array}$ \\
\hline GID180 & 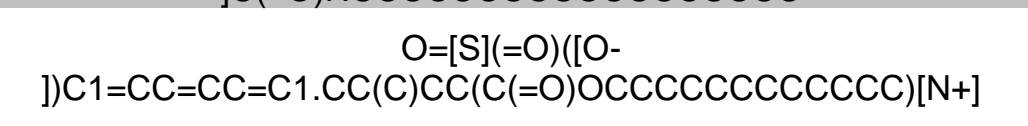 & $\begin{array}{l}\text { (RAYNAL; } \\
\text { BOUTEILLER, } \\
\text { 2011) }\end{array}$ \\
\hline GID181 & ] $\mathrm{C}(=\mathrm{O}) \backslash \mathrm{C}(=\mathrm{C}(\backslash \mathrm{C} 1=\mathrm{CC}=\mathrm{CC}(=\mathrm{C} 1) \mathrm{Br})) \cdot \mathrm{C} 2 \mathrm{CCCCC} 2[\mathrm{~N}+] \mathrm{C} 3 \mathrm{CcccC}$ & $\begin{array}{l}\text { (RAYNAL; } \\
\text { BOUTEILLER, } \\
\text { 2011) }\end{array}$ \\
\hline GID182 & 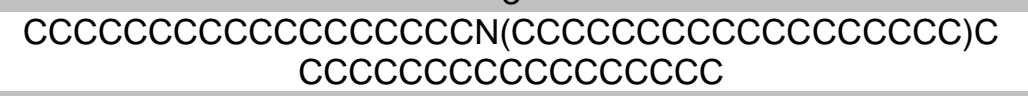 & $\begin{array}{l}\text { (ROGERS; WEISS, } \\
\text { 2015) }\end{array}$ \\
\hline GID183 & $\begin{array}{c}\operatorname{ccccccccc}[N+] \cdot \operatorname{ccccccccccN}(\operatorname{ccccccccc}) \\
]])=0\end{array}$ & $\begin{array}{l}\text { (ROGERS; WEISS, } \\
\text { 2015) }\end{array}$ \\
\hline GID184 & $\begin{array}{c}\operatorname{ccccccccccc}[N+] \cdot \operatorname{CccCCCCCCCCCN}(\operatorname{Cccccccccc} C \\
\operatorname{C}) \mathrm{C}\left(\left[\mathrm{O}_{-}\right]\right)=0\end{array}$ & $\begin{array}{l}\text { (ROGERS; WEISS, } \\
\text { 2015) }\end{array}$ \\
\hline GID185 & 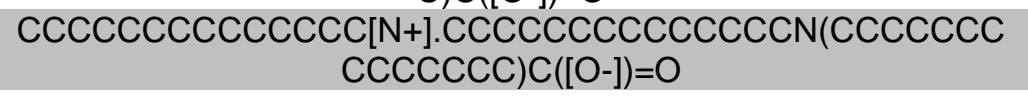 & $\begin{array}{l}\text { (ROGERS; WEISS, } \\
\text { 2015) }\end{array}$ \\
\hline GID186 & 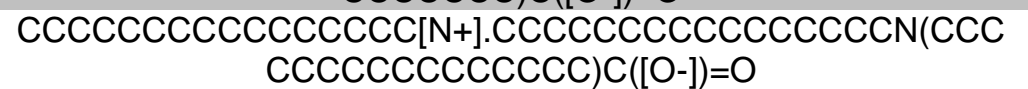 & $\begin{array}{l}\text { (ROGERS; WEISS, } \\
\text { 2015) }\end{array}$ \\
\hline GID187 & 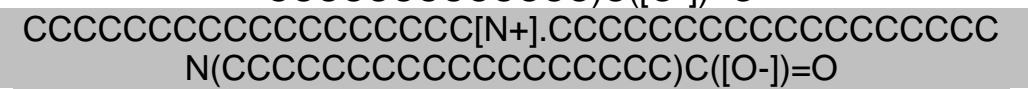 & $\begin{array}{l}\text { (ROGERS; WEISS, } \\
\text { 2015) }\end{array}$ \\
\hline GID188 & $\begin{array}{c}\operatorname{cccccccc}[N+] \operatorname{Cccccccc} . \operatorname{CcccccccN}(\operatorname{Ccccccc}) \\
\mathrm{O}-])=\mathrm{O}([\end{array}$ & $\begin{array}{l}\text { (ROGERS; WEISS, } \\
\text { 2015) }\end{array}$ \\
\hline GID189 & 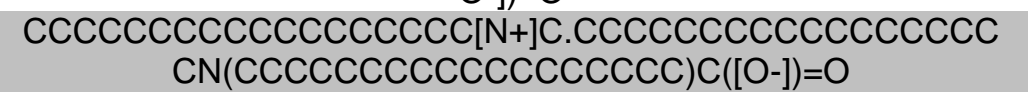 & $\begin{array}{l}\text { (ROGERS; WEISS, } \\
\text { 2015) }\end{array}$ \\
\hline GID190 & 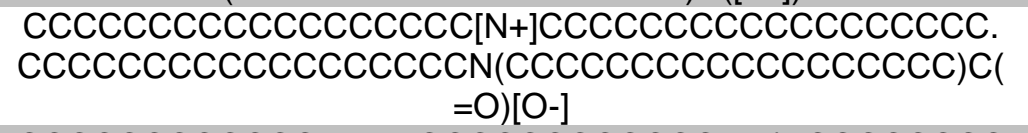 & $\begin{array}{l}\text { (ROGERS; WEISS, } \\
\text { 2015) }\end{array}$ \\
\hline GID191 & $\begin{array}{c}\operatorname{ccccccccccc} N[N+] . \operatorname{CccCCCCCCCCCNN}(\operatorname{NCCCCCCCC} \\
\operatorname{CCC}) \mathrm{C}([\mathrm{O}-])=\mathrm{O}\end{array}$ & $\begin{array}{l}\text { (ROGERS; WEISS, } \\
\text { 2015) }\end{array}$ \\
\hline GID192 & $\operatorname{CCCCCCCCCCN~}$ & $\begin{array}{l}\text { (ROGERS; WEISS, } \\
\text { 2015) }\end{array}$ \\
\hline GID193 & $\operatorname{CCCCCCCCCCCCN~}$ & $\begin{array}{l}\text { (ROGERS; WEISS, } \\
\text { 2015) }\end{array}$ \\
\hline GID194 & CCCCCCCCCCCCCCN & $\begin{array}{l}\text { (ROGERS; WEISS, } \\
\text { 2015) }\end{array}$ \\
\hline GID195 & $\operatorname{CcCcCcCcCCCCCCCCN~}$ & $\begin{array}{l}\text { (ROGERS; WEISS, } \\
\text { 2015) }\end{array}$ \\
\hline GID196 & CCCCCCCCNCCCCCCCC & $\begin{array}{l}\text { (ROGERS; WEISS, } \\
\text { 2015) }\end{array}$ \\
\hline GID197 & CCCCCCCCCCCCCCCCCCNC & $\begin{array}{l}\text { (ROGERS; WEISS, } \\
\text { 2015) }\end{array}$ \\
\hline GID198 & CCCCCCCCCCCCNN & $\begin{array}{l}\text { (ROGERS; WEISS, } \\
\text { 2015) }\end{array}$ \\
\hline GID199 & 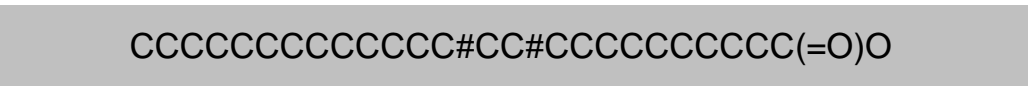 & $\begin{array}{l}\text { (ROGERS; WEISS, } \\
\text { 2015) }\end{array}$ \\
\hline GID200 & 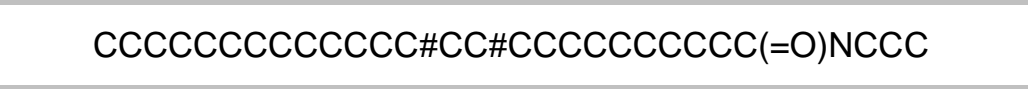 & $\begin{array}{l}\text { (ROGERS; WEISS, } \\
\text { 2015) }\end{array}$ \\
\hline GID201 & ссссссссссссС\#СС\#СссссссСсC(=O)NCCсC & $\begin{array}{l}\text { (ROGERS; WEISS, } \\
\text { 2015) }\end{array}$ \\
\hline GID202 & 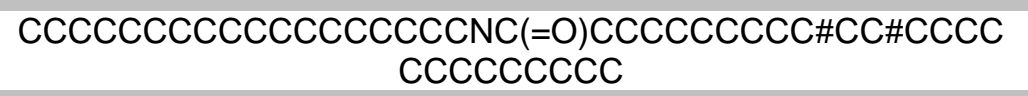 & $\begin{array}{l}\text { (ROGERS; WEISS, } \\
\text { 2015) }\end{array}$ \\
\hline GID203 & 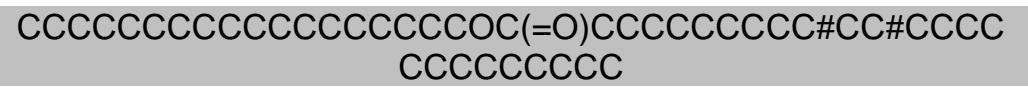 & $\begin{array}{l}\text { (ROGERS; WEISS, } \\
\text { 2015) }\end{array}$ \\
\hline GID204 & 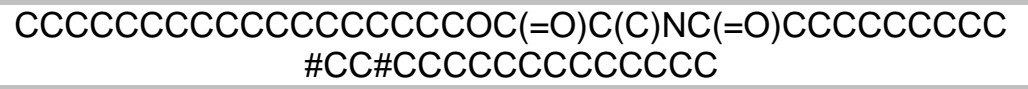 & $\begin{array}{l}\text { (ROGERS; WEISS, } \\
\text { 2015) }\end{array}$ \\
\hline GID205 & 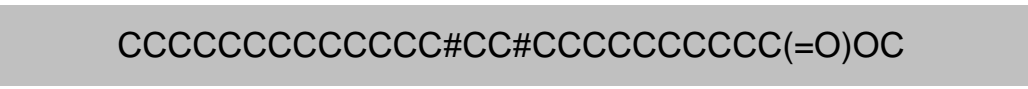 & $\begin{array}{l}\text { (ROGERS; WEISS, } \\
\text { 2015) }\end{array}$ \\
\hline GID206 & $\operatorname{ccccccc}(\operatorname{ccccccccccc}(=0)[0-]) O \cdot[\mathrm{Na}+]$ & $\begin{array}{l}\text { (ROGERS; WEISS, } \\
\text { 2015) }\end{array}$ \\
\hline
\end{tabular}




\begin{tabular}{|c|c|c|}
\hline GID207 & $\operatorname{ccccccc}(\operatorname{ccccccccccc}(=0)[0-]) O \cdot[\mathrm{Li}+]$ & $\begin{array}{l}\text { (ROGERS; WEISS, } \\
\text { 2015) }\end{array}$ \\
\hline GID208 & $\operatorname{ccccccc}(\operatorname{ccccccccccc}(=0)[0-]) O \cdot[K+]$ & $\begin{array}{l}\text { (ROGERS; WEISS, } \\
\text { 2015) }\end{array}$ \\
\hline GID209 & $\operatorname{ccccccc}(\operatorname{ccccccccccc}(=0)[0-]) O \cdot[R b+]$ & $\begin{array}{l}\text { (ROGERS; WEISS, } \\
\text { 2015) }\end{array}$ \\
\hline GID210 & $\operatorname{ccccccc}(\operatorname{ccccccccccc}(=0)[0-]) O \cdot[\mathrm{Cs}+]$ & $\begin{array}{l}\text { (ROGERS; WEISS, } \\
\text { 2015) }\end{array}$ \\
\hline GID211 & $\operatorname{coccccc}(=0) \operatorname{coc} \operatorname{coc} \operatorname{ccc}(=0) 0$ & $\begin{array}{l}\text { (ROGERS; WEISS, } \\
\text { 2015) }\end{array}$ \\
\hline GID212 & $\operatorname{ccccc}(=0) \operatorname{ccccccccccccc}(=0) 0$ & $\begin{array}{l}\text { (ROGERS; WEISS, } \\
\text { 2015) }\end{array}$ \\
\hline GID213 & $\operatorname{cccccccccc}(=0) \operatorname{coc} \operatorname{ccc}(=0) 0$ & $\begin{array}{l}\text { (ROGERS; WEISS, } \\
\text { 2015) }\end{array}$ \\
\hline GID214 & $\operatorname{ccccccccc}(=0) \operatorname{ccc} \operatorname{ccccc}(=0) 0$ & $\begin{array}{l}\text { (ROGERS; WEISS, } \\
\text { 2015) }\end{array}$ \\
\hline GID215 & $\operatorname{cccccccccccC}(=0) \mathrm{NCCCO}$ & $\begin{array}{l}\text { (ROGERS; WEISS, } \\
\text { 2015) }\end{array}$ \\
\hline GID216 & $\mathrm{C}(\mathrm{CCCN}) \mathrm{CCN}$ & $\begin{array}{l}\text { (ROGERS; WEISS, } \\
\text { 2015) }\end{array}$ \\
\hline GID217 & $\mathrm{C}(\operatorname{cccccccc}(=0) 0) \operatorname{ccccccco}$ & $\begin{array}{l}\text { (ROGERS; WEISS, } \\
\text { 2015) }\end{array}$ \\
\hline GID218 & cera de girassol & $\begin{array}{l}\text { (BLAKE; CO; } \\
\text { MARANGONI, } \\
\text { 2014) }\end{array}$ \\
\hline GID219 & 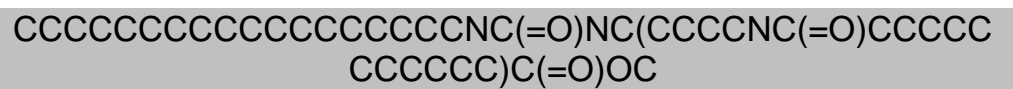 & $\begin{array}{l}\text { (SUZUKI et al., } \\
\text { 2008) }\end{array}$ \\
\hline GID220 & 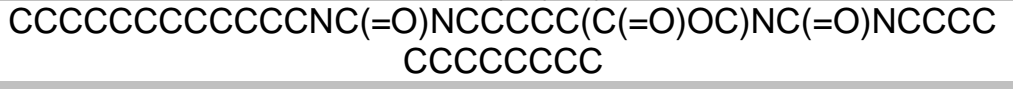 & $\begin{array}{l}\text { (SUZUKI et al., } \\
\text { 2008) }\end{array}$ \\
\hline GID221 & $\begin{array}{c}\operatorname{ccccccccccccccc}(\mathrm{C}(\mathrm{C}(\mathrm{CO}) \mathrm{NC}(=\mathrm{O}) \mathrm{NCccccccccccc}) \\
\mathrm{O}) \mathrm{O}\end{array}$ & $\begin{array}{c}\text { (SUZUKI; } \\
\text { UEMATSU; } \\
\text { HANABUSA, 2016) }\end{array}$ \\
\hline GID222 & $\operatorname{ccccccccccccccc}(\mathrm{C}(\mathrm{C}(\mathrm{CO}) \mathrm{NC}(=\mathrm{O}) \mathrm{NCCCCCC}) \mathrm{O}) \mathrm{O}$ & $\begin{array}{c}\text { (SUZUKI; } \\
\text { UEMATSU; } \\
\text { HANABUSA, 2016) }\end{array}$ \\
\hline GID223 & $\operatorname{ccccccccccccccc}(\mathrm{C}(\mathrm{C}(\mathrm{CO}) \mathrm{NC}(=\mathrm{O}) \mathrm{NCCCC}) \mathrm{O}) \mathrm{O}$ & $\begin{array}{l}\text { (SUZUKI; } \\
\text { UEMATSU; } \\
\text { HANABUSA, 2016) }\end{array}$ \\
\hline GID224 & $\operatorname{CcccccccccccccC}(\mathrm{C}(\mathrm{C}(\mathrm{CO}) \mathrm{NC}(=\mathrm{O}) \mathrm{NCC}(\mathrm{CC}) \mathrm{CCCC}) \mathrm{O}) \mathrm{O}$ & $\begin{array}{c}\text { (SUZUKI; } \\
\text { UEMATSU; } \\
\text { HANABUSA, 2016) }\end{array}$ \\
\hline GID225 & $\underset{\mathrm{O}}{\operatorname{coc} \operatorname{coc} \operatorname{coc} \operatorname{coc}}(\mathrm{C}(\mathrm{C}(\mathrm{CO}) \mathrm{NC}(=\mathrm{O}) \mathrm{NC} 1=\mathrm{CC}=\mathrm{CC}=\mathrm{C} 1) \mathrm{O})$ & $\begin{array}{l}\text { (SUZUKI; } \\
\text { UEMATSU; } \\
\text { HANABUSA, 2016) }\end{array}$ \\
\hline GID226 & $\operatorname{ccccccccccccccc}(\mathrm{C}(\mathrm{C}(\mathrm{CO}) \mathrm{NC}(=\mathrm{O}) \operatorname{ccccC}) \mathrm{O}) \mathrm{O}$ & $\begin{array}{c}\text { (SUZUKI; } \\
\text { UEMATSU; } \\
\text { HANABUSA, 2016) }\end{array}$ \\
\hline GID227 & $\operatorname{cccccccccccccc}(\mathrm{C}(\mathrm{C}(\mathrm{CO}) \mathrm{NC}(=\mathrm{O}) \mathrm{C}(\mathrm{CC}) \operatorname{CccC}) \mathrm{O}) \mathrm{O}$ & $\begin{array}{l}\text { (SUZUKI; } \\
\text { UEMATSU; } \\
\text { HANABUSA, 2016) }\end{array}$ \\
\hline GID228 & $\mathrm{C} 1 \mathrm{CCC}(\mathrm{CC} 1)[\mathrm{N}+] \mathrm{C} 2 \mathrm{CCCCC} 2 . \mathrm{C} 1=\mathrm{CC}=\mathrm{C}(\mathrm{C}=\mathrm{C} 1) \mathrm{CC}(\mathrm{C}(=\mathrm{O})[\mathrm{O}-])$ & $\begin{array}{l}\text { (TRIVEDI et al., } \\
\text { 2004) }\end{array}$ \\
\hline GID229 & $\mathrm{CC}(\mathrm{C})(\mathrm{C}) \mathrm{OC}(=\mathrm{O}) \mathrm{NCC}(=\mathrm{O})[\mathrm{O}-] \cdot \mathrm{C} 1 \mathrm{CCC}(\mathrm{CC} 1)[\mathrm{N}+] \mathrm{C} 2 \mathrm{CCCCC} 2$ & (WEISS, 2014) \\
\hline GID230 & $\begin{array}{c}\operatorname{COCC}(\mathrm{C} 1 \mathrm{C} 2 \mathrm{C}(\mathrm{COC}(\mathrm{O} 2) \mathrm{C} 3=\mathrm{CC}=\mathrm{CC}=\mathrm{C} 3) \mathrm{OC}(\mathrm{O} 1) \mathrm{C} 4=\mathrm{CC}=\mathrm{CC}= \\
\mathrm{C} 4) \mathrm{O}\end{array}$ & $\begin{array}{l}\text { (YAMASAKI et al., } \\
\text { 1995) }\end{array}$ \\
\hline GID231 & $\begin{aligned} & C 1=C C 2=C 3 C(=C 1) C=C C 4=C(C=C C(=C 43) C=C 2) S(=O)(=O) N \\
& C C N C(=O) C(C(C(C(C O) O) O) O) O\end{aligned}$ & (YAN et al., 2013b) \\
\hline GID232 & $\begin{array}{c}C 1=C C 2=C 3 C(=C 1) C=C C 4=C(C=C C(=C 43) C=C 2) S(=O)(=O) N \\
\operatorname{CCCNC}(=O) C(C(C(C(C O) O) O) O) O\end{array}$ & (YAN et al., 2013b) \\
\hline
\end{tabular}




\begin{tabular}{|c|c|c|}
\hline GID233 & $\begin{array}{c}\mathrm{C} 1=\mathrm{CC} 2=\mathrm{C} 3 \mathrm{C}(=\mathrm{C} 1) \mathrm{C}=\mathrm{CC} 4=\mathrm{C}(\mathrm{C}=\mathrm{CC}(=\mathrm{C} 43) \mathrm{C}=\mathrm{C} 2) \mathrm{S}(=\mathrm{O})(=\mathrm{O}) \mathrm{N} \\
\operatorname{CCCCNC}(=\mathrm{O}) \mathrm{C}(\mathrm{C}(\mathrm{C}(\mathrm{C}(\mathrm{CO}) \mathrm{O}) \mathrm{O}) \mathrm{O}) \mathrm{O}\end{array}$ & (YAN et al., 2013b) \\
\hline GID234 & $\begin{array}{c}\mathrm{C} 1=\mathrm{CC} 2=\mathrm{C} 3 \mathrm{C}(=\mathrm{C} 1) \mathrm{C}=\mathrm{CC} 4=\mathrm{C}(\mathrm{C}=\mathrm{CC}(=\mathrm{C} 43) \mathrm{C}=\mathrm{C} 2) \mathrm{S}(=\mathrm{O})(=\mathrm{O}) \mathrm{N} \\
\operatorname{CCCCCCNC}(=\mathrm{O}) \mathrm{C}(\mathrm{C}(\mathrm{C}(\mathrm{C}(\mathrm{CO}) \mathrm{O}) \mathrm{O}) \mathrm{O}) \mathrm{O}\end{array}$ & (YAN et al., 2013b) \\
\hline GID235 & $\begin{aligned} C 1=C C 2= & C 3 C(=C 1) \mathrm{C}=C C 4=C(C=C C(=C 43) C=C 2) S(=O)(=O) N \\
& C C C C C C C N C(=O) C(C(C(C(C O) O) O) O) O\end{aligned}$ & (YAN et al., 2013b) \\
\hline GID236 & $\begin{aligned} C 1=C C 2= & C 3 C(=C 1) C=C C 4=C(C=C C(=C 43) C=C 2) S(=O)(=O) N \\
& \operatorname{CcccccccNC}(=O) C(C(C(C(C O) O) O) O) O\end{aligned}$ & (YAN et al., 2013b) \\
\hline GID237 & $\begin{array}{c}\mathrm{C} 1=\mathrm{CC}=\mathrm{C} 2 \mathrm{C}=\mathrm{C}(\mathrm{C}=\mathrm{CC} 2=\mathrm{C} 1) \mathrm{S}(=\mathrm{O})(=\mathrm{O}) \mathrm{NNC}(=\mathrm{O}) \mathrm{C}(\mathrm{C}(\mathrm{C}(\mathrm{C}(\mathrm{CO}) \\
\mathrm{O}) \mathrm{O}) \mathrm{O}) \mathrm{O}\end{array}$ & (YAN et al., 2013a) \\
\hline GID238 & $\begin{aligned} \mathrm{C} 1=\mathrm{CC}=\mathrm{C} 2 \mathrm{C}=\mathrm{C}(\mathrm{C}=\mathrm{CC} 2=\mathrm{C} 1) \mathrm{S}(=\mathrm{O})(=\mathrm{O}) \mathrm{NCCCNC}(=\mathrm{O}) \mathrm{C}(\mathrm{C}(\mathrm{C}(\mathrm{C}( \\
\mathrm{CO}(\mathrm{O}) \mathrm{O}) \mathrm{O}) \mathrm{O}) \mathrm{O}\end{aligned}$ & (YAN et al., 2013a) \\
\hline GID239 & $\begin{array}{c}\mathrm{C} 1=\mathrm{CC}=\mathrm{C} 2 \mathrm{C}=\mathrm{C}(\mathrm{C}=\mathrm{CC} 2=\mathrm{C} 1) \mathrm{S}(=\mathrm{O})(=\mathrm{O}) \mathrm{NCCCCNC}(=\mathrm{O}) \mathrm{C}(\mathrm{C}(\mathrm{C}( \\
\mathrm{C}(\mathrm{CO}) \mathrm{O}) \mathrm{O}) \mathrm{O}) \mathrm{O}\end{array}$ & (YAN et al., 2013a) \\
\hline GID240 & $\begin{array}{c}\mathrm{C} 1=\mathrm{CC}=\mathrm{C} 2 \mathrm{C}=\mathrm{C}(\mathrm{C}=\mathrm{CC} 2=\mathrm{C} 1) \mathrm{S}(=\mathrm{O})(=\mathrm{O}) \mathrm{NCCCCCCNC}(=\mathrm{O}) \mathrm{C}(\mathrm{C}( \\
\mathrm{C}(\mathrm{C}(\mathrm{CO}) \mathrm{O}) \mathrm{O}) \mathrm{O}) \mathrm{O}\end{array}$ & (YAN et al., 2013a) \\
\hline GID241 & 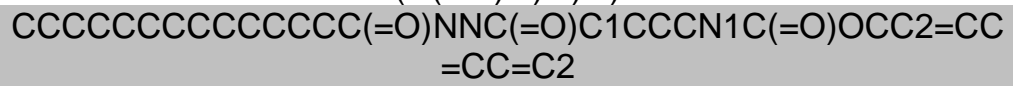 & (YU et al., 2016) \\
\hline GID242 & $\begin{aligned} \operatorname{ccccccccccccccc} C( & =\mathrm{O}) \mathrm{NNC}(=\mathrm{O}) \mathrm{C}(\mathrm{NC}(=\mathrm{O}) \mathrm{OC}(\mathrm{C})(\mathrm{C}) \mathrm{C}) \mathrm{C} \\
\mathrm{C} 1 & =\mathrm{CC}=\mathrm{CC}=\mathrm{C} 1\end{aligned}$ & (YU et al., 2017) \\
\hline GID243 & $\begin{array}{c}\mathrm{CC}(\mathrm{CCC}=\mathrm{C}(\mathrm{C}) \mathrm{C}) \mathrm{C} 1 \mathrm{CCC} 2(\mathrm{C} 1(\mathrm{CCC} 34 \mathrm{C} 2 \mathrm{CCC} 5 \mathrm{C} 3(\mathrm{C} 4) \mathrm{CCC}(\mathrm{C} 5( \\
\mathrm{C}) \mathrm{C}) \mathrm{OC}(=\mathrm{O}) \mathrm{C}=\mathrm{CC} 6=\mathrm{CC}(=\mathrm{C}(\mathrm{C}=\mathrm{C} 6) \mathrm{O}) \mathrm{OC}) \mathrm{C}) \mathrm{C}\end{array}$ & $\begin{array}{l}\text { (ROGERS et al., } \\
\text { 2014) }\end{array}$ \\
\hline GID244 & $\begin{array}{c}\operatorname{CCC}(\operatorname{CCC}(\mathrm{C}) \mathrm{C} 1 \mathrm{CCC} 2 \mathrm{C} 1(\operatorname{CCC} 3 \mathrm{C} 2 \mathrm{CC}=\mathrm{C} 4 \mathrm{C} 3(\operatorname{CCC}(\mathrm{C} 4) \mathrm{O}) \mathrm{C}) \mathrm{C}) \mathrm{C} \\
(\mathrm{C}) \mathrm{C}\end{array}$ & $\begin{array}{l}\text { (ROGERS et al., } \\
\text { 2014) }\end{array}$ \\
\hline GID245 & $\operatorname{cccccc} \operatorname{coc} \operatorname{coc} s \operatorname{scc} \operatorname{coc} \operatorname{cccccc}$ & $\begin{array}{l}\text { (ABDALLAH; LU; } \\
\text { WEISS, 1999) }\end{array}$ \\
\hline GID246 & $\begin{array}{l}\mathrm{CC}(\mathrm{C}) \mathrm{CCCC}(\mathrm{C}) \mathrm{C} 1 \mathrm{CCC} 2 \mathrm{C} 1(\mathrm{CCC} 3 \mathrm{C} 2 \mathrm{CC}=\mathrm{C} 4 \mathrm{C} 3(\mathrm{CCC}(\mathrm{C} 4) \mathrm{OC}(= \\
\mathrm{O}) \mathrm{C} 5=\mathrm{CC} 6=\mathrm{C}(\mathrm{C} 7=\mathrm{CC}=\mathrm{CC}=\mathrm{C} 7 \mathrm{C}(=\mathrm{C} 6 \mathrm{C}=\mathrm{C} 5) \mathrm{OC}) \mathrm{OC}) \mathrm{C}) \mathrm{C}\end{array}$ & $\begin{array}{l}\text { (ABDALLAH; } \\
\text { WEISS, 2000) }\end{array}$ \\
\hline GID247 & 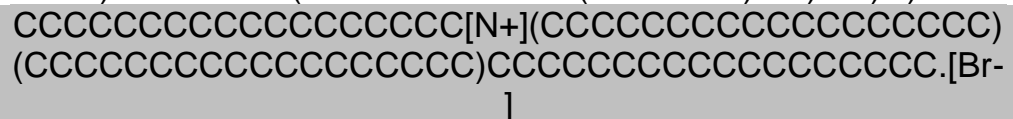 & $\begin{array}{l}\text { (ABDALLAH; } \\
\text { WEISS, 2000) }\end{array}$ \\
\hline GID248 & $\begin{array}{c}\mathrm{CC}(\mathrm{C}) \mathrm{CCCC}(\mathrm{C}) \mathrm{C} 1 \mathrm{CCC} 2 \mathrm{C} 1(\mathrm{CCC} 3 \mathrm{C} 2 \mathrm{CC}=\mathrm{C} 4 \mathrm{C} 3(\mathrm{CCC}(\mathrm{C} 4) \mathrm{OC}(= \\
\mathrm{O}) \mathrm{C} 5=\mathrm{CC} 6=\mathrm{CC} 7=\mathrm{CC}=\mathrm{CC}=\mathrm{C} 7 \mathrm{C}=\mathrm{C} 6 \mathrm{C}=\mathrm{C} 5) \mathrm{C}) \mathrm{C}\end{array}$ & $\begin{array}{l}\text { (ABDALLAH; } \\
\text { WEISS, 2000) }\end{array}$ \\
\hline GID249 & $\begin{array}{c}\mathrm{CC}(\mathrm{C}) \mathrm{CCCC}(\mathrm{C}) \mathrm{C} 1 \mathrm{CCC} 2 \mathrm{C} 1(\mathrm{CCC} 3 \mathrm{C} 2 \mathrm{CC}=\mathrm{C} 4 \mathrm{C} 3(\mathrm{CCC}(\mathrm{C} 4) \mathrm{OC}(= \\
\mathrm{O}) \mathrm{C} 5=\mathrm{C} 6 \mathrm{C}=\mathrm{CC}=\mathrm{CC} 6=\mathrm{CC} 7=\mathrm{CC}=\mathrm{CC}=\mathrm{C} 75) \mathrm{C}) \mathrm{C}\end{array}$ & $\begin{array}{l}\text { (ABDALLAH; } \\
\text { WEISS, 2000) }\end{array}$ \\
\hline GID250 & $\begin{array}{c}\operatorname{cccccccccccoc} 1=\mathrm{CC} 2=\mathrm{CC} 3=\mathrm{CC}=\mathrm{CC}=\mathrm{C} 3 \mathrm{C}=\mathrm{C} 2 \mathrm{C}=\mathrm{C} 1 \mathrm{OC} \\
\operatorname{CCCCCCCCCCC}\end{array}$ & $\begin{array}{l}\text { (ABDALLAH; } \\
\text { WEISS, 2000) }\end{array}$ \\
\hline GID251 & 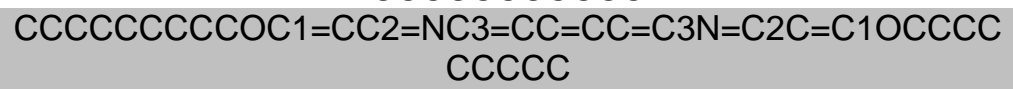 & $\begin{array}{l}\text { (ABDALLAH; } \\
\text { WEISS, 2000) }\end{array}$ \\
\hline GID252 & $\begin{aligned} \operatorname{Cccccccccccoc} 1 & =\mathrm{CC} 2=\mathrm{NC} 3=\mathrm{CC}=\mathrm{CC}=\mathrm{C} 3 \mathrm{~N}=\mathrm{C} 2 \mathrm{C}=\mathrm{C} 1 \mathrm{OCC} \\
& \operatorname{CCCCCCCCC}\end{aligned}$ & $\begin{array}{l}\text { (ABDALLAH; } \\
\text { WEISS, 2000) }\end{array}$ \\
\hline GID253 & $\begin{array}{c}\operatorname{ccccccccccc\operatorname {coc}1}=\mathrm{C}(\mathrm{C}=\mathrm{C} 2 \mathrm{C}(=\mathrm{C} 1) \mathrm{C}(=\mathrm{O}) \mathrm{C} 3=\mathrm{CC}=\mathrm{CC}=\mathrm{C} 3 \\
\mathrm{C2}=\mathrm{O}) \mathrm{OCC \operatorname {ccc } c \operatorname { c c c } C}\end{array}$ & $\begin{array}{l}\text { (ABDALLAH; } \\
\text { WEISS, 2000) }\end{array}$ \\
\hline GID254 & 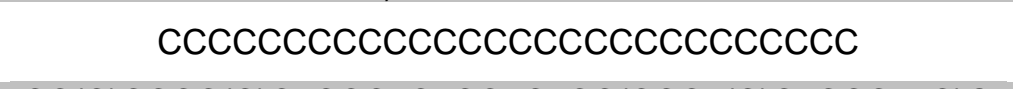 & $\begin{array}{l}\text { (ABDALLAH; } \\
\text { WEISS, 2000) }\end{array}$ \\
\hline GID255 & $\begin{array}{c}\mathrm{CC}(\mathrm{C}) \mathrm{CCCC}(\mathrm{C}) \mathrm{C} 3 \mathrm{CCC} 4 \mathrm{C} 2 \mathrm{CC}=\mathrm{C} 1 \mathrm{CC}(\mathrm{CCC} 1(\mathrm{C}) \mathrm{C} 2 \mathrm{CCC} 34 \mathrm{C}) \mathrm{O} \\
\mathrm{C}(=\mathrm{O}) \mathrm{COC} 5=\mathrm{CC}=\mathrm{C}(\mathrm{C}=\mathrm{C} 5) \mathrm{C}=\mathrm{CC} 7=\mathrm{CC}=\mathrm{C} 6 \mathrm{OCCOCCOCCOCC} \\
\mathrm{OCCOC} 6=\mathrm{C} 7\end{array}$ & $\begin{array}{l}\text { (ABDALLAH; } \\
\text { WEISS, 2000) }\end{array}$ \\
\hline GID256 & $\begin{array}{c}\operatorname{CcccccccccccNC}(=0) \operatorname{NCCCCC} 1=C C=C(S 1) \operatorname{CcccNC}(=0) \\
\text { NCCCCCCCCCCCC }\end{array}$ & $\begin{array}{l}\text { (ABDALLAH; } \\
\text { WEISS, 2000) }\end{array}$ \\
\hline GID257 & 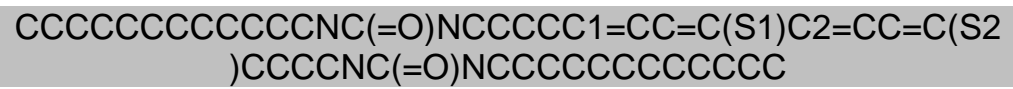 & $\begin{array}{l}\text { (ABDALLAH; } \\
\text { WEISS, 2000) }\end{array}$ \\
\hline GID258 & $\begin{array}{c}\mathrm{CC} 1=\mathrm{C}(\mathrm{SC}(=\mathrm{C} 2 \mathrm{SC}(=\mathrm{C}(\mathrm{S} 2) \mathrm{SCCCCCCC}(\mathrm{C}(=\mathrm{O}) \mathrm{NC}(\mathrm{CO})(\mathrm{CO}) \mathrm{CO}) \\
\mathrm{C}(=\mathrm{O}) \mathrm{NC}(\mathrm{CO})(\mathrm{CO}) \mathrm{CO}) \mathrm{C}) \mathrm{S} 1) \operatorname{SCCCCCCC}(\mathrm{C}(=\mathrm{O}) \mathrm{NC}(\mathrm{CO})(\mathrm{CO}) \mathrm{C} \\
\mathrm{O}) \mathrm{C}(=\mathrm{O}) \mathrm{NC}(\mathrm{CO})(\mathrm{CO}) \mathrm{CO}\end{array}$ & $\begin{array}{l}\text { (ABDALLAH; } \\
\text { WEISS, 2000) }\end{array}$ \\
\hline GID259 & $\begin{array}{c}\mathrm{O}=\mathrm{C}(\mathrm{NC} 1=\mathrm{CC}=\mathrm{C}(\mathrm{C}=\mathrm{C} 1) \mathrm{F}) \mathrm{NC}(\mathrm{CC}(=\mathrm{O}) \mathrm{OCC}(\mathrm{F})(\mathrm{F}) \mathrm{C}(\mathrm{F})(\mathrm{F}) \mathrm{C}(\mathrm{F})(\mathrm{F}) \\
\mathrm{C}(\mathrm{F})(\mathrm{F}) \mathrm{C}(\mathrm{F})(\mathrm{F}) \mathrm{C}(\mathrm{F})(\mathrm{F}) \mathrm{C}(\mathrm{F})(\mathrm{F}) \mathrm{C}(\mathrm{F})(\mathrm{F}) \mathrm{F}) \mathrm{C}(=\mathrm{O}) \mathrm{OCC}(\mathrm{F})(\mathrm{F}) \mathrm{C}(\mathrm{F})(\mathrm{F}) \\
\mathrm{C}(\mathrm{F})(\mathrm{F}) \mathrm{C}(\mathrm{F})(\mathrm{F}) \mathrm{C}(\mathrm{F})(\mathrm{F}) \mathrm{C}(\mathrm{F})(\mathrm{F}) \mathrm{C}(\mathrm{F})(\mathrm{F}) \mathrm{C}(\mathrm{F})(\mathrm{F}) \mathrm{F}\end{array}$ & $\begin{array}{l}\text { (ABDALLAH; } \\
\text { WEISS, 2000) }\end{array}$ \\
\hline
\end{tabular}




\begin{tabular}{|c|c|c|}
\hline GID260 & $\begin{array}{c}\mathrm{C} 1=\mathrm{CC}=\mathrm{CC}(=\mathrm{C} 1) \mathrm{NC}(\mathrm{NC}(\mathrm{C}(\mathrm{OCC}(\mathrm{C}(\mathrm{C}(\mathrm{C}(\mathrm{C}(\mathrm{C}(\mathrm{C}(\mathrm{C}(\mathrm{F})(\mathrm{F}) \mathrm{F})(\mathrm{F}) \mathrm{F})( \\
\mathrm{F}) \mathrm{F})(\mathrm{F}) \mathrm{F})(\mathrm{F}) \mathrm{F})(\mathrm{F}) \mathrm{F})(\mathrm{F}) \mathrm{F})(\mathrm{F}) \mathrm{F})=\mathrm{O}) \mathrm{CC}(\mathrm{OCC}(\mathrm{C}(\mathrm{C}(\mathrm{C}(\mathrm{C}(\mathrm{C}(\mathrm{C}(\mathrm{C}(\mathrm{F})(\mathrm{F}) \\
\mathrm{F})(\mathrm{F}) \mathrm{F})(\mathrm{F}) \mathrm{F})(\mathrm{F}) \mathrm{F})(\mathrm{F}) \mathrm{F})(\mathrm{F}) \mathrm{F})(\mathrm{F}) \mathrm{F})(\mathrm{F}) \mathrm{F})=\mathrm{O})=\mathrm{O}\end{array}$ & $\begin{array}{l}\text { (ABDALLAH; } \\
\text { WEISS, 2000) }\end{array}$ \\
\hline GID261 & $\begin{array}{c}\text { CCCCCCNC }(=O) N C(C C(=O) O C C(C) C(C(C) C(C(C)(F)(F) F)(F) F) \\
(F) F)(F) F)(F) F)(F) F)(F) F)(F) F) C(=O) O C C(C(C)(C(C)(C(C(C)(F)(F) \\
F)(F) F)(F) F)(F) F)(F) F)(F) F)(F) F)(F) F\end{array}$ & $\begin{array}{l}\text { (ABDALLAH; } \\
\text { WEISS, 2000) }\end{array}$ \\
\hline GID262 & $\begin{array}{c}\text { CCCCCCNC }(=\mathrm{O}) \mathrm{NC}(\mathrm{CC}(=\mathrm{O}) \mathrm{OCC}(\mathrm{C}(\mathrm{C}(\mathrm{C}(\mathrm{C}(\mathrm{C}(\mathrm{C}(\mathrm{C}(\mathrm{F})(\mathrm{F}) \mathrm{F})(\mathrm{F}) \mathrm{F}) \\
(\mathrm{F}) \mathrm{F})(\mathrm{F}) \mathrm{F})(\mathrm{F}) \mathrm{F})(\mathrm{F}) \mathrm{F})(\mathrm{F}) \mathrm{F})(\mathrm{F}) \mathrm{F}) \mathrm{C}(=\mathrm{O}) \mathrm{OCC}(\mathrm{C}(\mathrm{C}(\mathrm{C}(\mathrm{C}(\mathrm{C}(\mathrm{C}(\mathrm{C}(\mathrm{F})(\mathrm{F}) \\
\mathrm{F})(\mathrm{F}) \mathrm{F})(\mathrm{F}) \mathrm{F})(\mathrm{F}) \mathrm{F})(\mathrm{F}) \mathrm{F})(\mathrm{F}) \mathrm{F})(\mathrm{F}) \mathrm{F})(\mathrm{F}) \mathrm{F}\end{array}$ & $\begin{array}{l}\text { (ABDALLAH; } \\
\text { WEISS, 2000) }\end{array}$ \\
\hline GID263 & $\operatorname{ccccccccccc}(=0) N C 1 \operatorname{ccc} 1 \mathrm{NC}(=0) \operatorname{ccc} \operatorname{ccccccc}$ & $\begin{array}{l}\text { (ABDALLAH; } \\
\text { WEISS, 2000) }\end{array}$ \\
\hline GID264 & $\begin{aligned} & {[\mathrm{Br}-} \\
& \text { ].C }\mathrm{N}+](\mathrm{C})(\mathrm{C}) \mathrm{CCCCOC} 1=\mathrm{CC}=\mathrm{C}(\mathrm{C}=\mathrm{C} 1) \mathrm{N}=\mathrm{NC} 2=\mathrm{CC}=\mathrm{C}(\mathrm{C}=\mathrm{C} 2) \mathrm{C}( \\
&=0) \mathrm{OC} 6 \operatorname{CCC} 5(\mathrm{C}) \mathrm{C} 4 \mathrm{CCC} 3(\mathrm{C}) \mathrm{C}(\mathrm{CCC} 3 \mathrm{C} 4 \mathrm{CC}=\mathrm{C} 5 \mathrm{C} 6) \mathrm{C}(\mathrm{C}) \mathrm{CCCC}( \\
&\mathrm{C}) \mathrm{C}\end{aligned}$ & $\begin{array}{l}\text { (ABDALLAH; } \\
\text { WEISS, 2000) }\end{array}$ \\
\hline GID265 & $\begin{array}{c}\mathrm{CcccoC} 1=\mathrm{CC}=\mathrm{C}(\mathrm{C}=\mathrm{C} 1) \mathrm{N}=\mathrm{NC} 2=\mathrm{CC}=\mathrm{C}(\mathrm{C}=\mathrm{C} 2) \mathrm{C}(=\mathrm{O}) \mathrm{OC} 3 \mathrm{CCC} \\
4(\mathrm{C} 5 \mathrm{Ccc} 6(\mathrm{C}(\mathrm{C} 5 \mathrm{CC}=\mathrm{C} 4 \mathrm{C} 3) \mathrm{CCC} 6 \mathrm{C}(\mathrm{C}) \mathrm{CCCC}(\mathrm{C}) \mathrm{C}) \mathrm{C}) \mathrm{C}\end{array}$ & $\begin{array}{l}\text { (ABDALLAH; } \\
\text { WEISS, 2000) }\end{array}$ \\
\hline GID266 & $\operatorname{ccccccccNC}(=0) \mathrm{C}(\mathrm{C}(\mathrm{C}(\mathrm{C}(\mathrm{COC}(=\mathrm{O}) \mathrm{C} 1 \operatorname{ccccc} 1) \mathrm{O}) \mathrm{O}) \mathrm{O}) \mathrm{O}$ & $\begin{array}{l}\text { (ABDALLAH; } \\
\text { WEISS, 2000) }\end{array}$ \\
\hline GID267 & 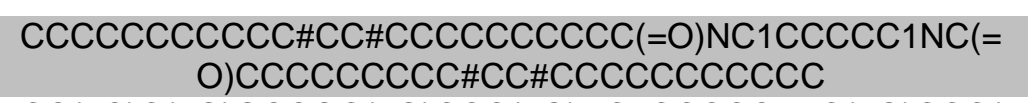 & $\begin{array}{l}\text { (ABDALLAH; } \\
\text { WEISS, 2000) }\end{array}$ \\
\hline GID268 & $\begin{aligned} \mathrm{CC}(=\mathrm{C}) \mathrm{C}(=\mathrm{O}) \mathrm{OCcOC}(=\mathrm{O}) \operatorname{CcC}(=\mathrm{O}) \mathrm{NC} 1 \operatorname{Ccccc} 1 \mathrm{NC}(=\mathrm{O}) \operatorname{CcC}( \\
=\mathrm{O}) \mathrm{OCCOC}(=\mathrm{O}) \mathrm{C}(=\mathrm{C}) \mathrm{C}\end{aligned}$ & $\begin{array}{l}\text { (ABDALLAH; } \\
\text { WEISS, 2000) }\end{array}$ \\
\hline GID269 & $\begin{aligned} \mathrm{O}=\mathrm{C}(\mathrm{NC} 1 \mathrm{CCCCC} 1 \mathrm{NC}(=\mathrm{O}) \mathrm{NCC}(=\mathrm{O}) \mathrm{OCCOC}(=\mathrm{O}) \mathrm{C}(=\mathrm{C}) \mathrm{C}) \mathrm{NCC}( \\
=\mathrm{O}) \mathrm{OCCOC}(=\mathrm{O}) \mathrm{C}(=\mathrm{C}) \mathrm{C}\end{aligned}$ & $\begin{array}{l}\text { (ABDALLAH; } \\
\text { WEISS, 2000) }\end{array}$ \\
\hline GID270 & $\begin{array}{c}\operatorname{ccccccccccccNC}(=0) \operatorname{CcC}(\mathrm{C}(=0) \mathrm{NCCCCCCCCCCCC}) \mathrm{NC} \\
(=\mathrm{O}) \operatorname{CCNC}(=\mathrm{O}) \mathrm{O}\end{array}$ & $\begin{array}{l}\text { (ABDALLAH; } \\
\text { WEISS, 2000) }\end{array}$ \\
\hline GID271 & $\begin{array}{c}\operatorname{ccccccccccccNC}(=\mathrm{O}) \operatorname{CCC}(\mathrm{C}(=\mathrm{O}) \mathrm{NCCCCCCCCCCCC}) \mathrm{NC} \\
(=\mathrm{O}) \operatorname{CCNC}(=\mathrm{O}) \mathrm{OCC} 1=\mathrm{CC}=\mathrm{CC}=\mathrm{C} 1\end{array}$ & $\begin{array}{l}\text { (ABDALLAH; } \\
\text { WEISS, 2000) }\end{array}$ \\
\hline GID272 & 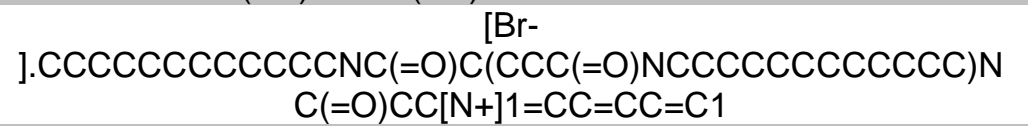 & $\begin{array}{l}\text { (ABDALLAH; } \\
\text { WEISS, 2000) }\end{array}$ \\
\hline GID273 & $\mathrm{CC}(\mathrm{C})(\mathrm{C}) \mathrm{C} 1 \mathrm{CCC}(\mathrm{CC} 1) \mathrm{C}(\mathrm{C} 2=\mathrm{CC}=\mathrm{CC}=\mathrm{C} 2) \mathrm{O}$ & $\begin{array}{l}\text { (ABDALLAH; } \\
\text { WEISS, 2000) }\end{array}$ \\
\hline GID274 & {$[\mathrm{N}+] \mathrm{CCCC} \cdot[\mathrm{O}-] \mathrm{C}(=\mathrm{O}) \mathrm{C} 2=\mathrm{C} 1 \mathrm{C}=\mathrm{CC}=\mathrm{CC} 1=\mathrm{CC} 3=\mathrm{CC}=\mathrm{CC}=\mathrm{C} 23$} & $\begin{array}{l}\text { (AYABE et al., } \\
\text { 2003) }\end{array}$ \\
\hline GID275 & {$[\mathrm{N}+] \mathrm{CCCCC} \cdot[\mathrm{O}-] \mathrm{C}(=\mathrm{O}) \mathrm{C} 2=\mathrm{C} 1 \mathrm{C}=\mathrm{CC}=\mathrm{CC} 1=\mathrm{CC} 3=\mathrm{CC}=\mathrm{CC}=\mathrm{C} 23$} & $\begin{array}{l}\text { (AYABE et al., } \\
\text { 2003) }\end{array}$ \\
\hline GID276 & {$[\mathrm{N}+] \mathrm{CCCCCC} \cdot[\mathrm{O}-] \mathrm{C}(=\mathrm{O}) \mathrm{C} 2=\mathrm{C} 1 \mathrm{C}=\mathrm{CC}=\mathrm{CC} 1=\mathrm{CC} 3=\mathrm{CC}=\mathrm{CC}=\mathrm{C} 23$} & $\begin{array}{l}\text { (AYABE et al., } \\
\text { 2003) }\end{array}$ \\
\hline GID277 & $\begin{array}{c}{[\mathrm{N}+] \mathrm{CCCCCCC} .[\mathrm{O}-} \\
\mathrm{C}(=\mathrm{O}) \mathrm{C} 2=\mathrm{C} 1 \mathrm{C}=\mathrm{CC}=\mathrm{CC} 1=\mathrm{CC} 3=\mathrm{CC}=\mathrm{CC}=\mathrm{C} 23\end{array}$ & $\begin{array}{l}\text { (AYABE et al., } \\
\text { 2003) }\end{array}$ \\
\hline GID278 & ] $\mathrm{C}(=\mathrm{O}) \mathrm{C} 2=\mathrm{C} 1 \mathrm{~N}+] \mathrm{CCCCCCCC} \cdot[\mathrm{O}-\mathrm{CC}=\mathrm{CC} 1=\mathrm{CC} 3=\mathrm{CC}=\mathrm{CC}=\mathrm{C} 23$ & $\begin{array}{l}\text { (AYABE et al., } \\
\text { 2003) }\end{array}$ \\
\hline GID279 & $\begin{array}{c}{[\mathrm{N}+] \mathrm{CCCCCCCCC} \cdot[\mathrm{O}-} \\
\mathrm{C}(=\mathrm{O}) \mathrm{C} 2=\mathrm{C} 1 \mathrm{C}=\mathrm{CC}=\mathrm{CC} 1=\mathrm{CC} 3=\mathrm{CC}=\mathrm{CC}=\mathrm{C} 23\end{array}$ & $\begin{array}{l}\text { (AYABE et al., } \\
\text { 2003) }\end{array}$ \\
\hline GID280 & $\begin{array}{c}{[\mathrm{N}+] \mathrm{CCCCCCCCCC} \cdot[\mathrm{O}-} \\
\mathrm{C}(=\mathrm{O}) \mathrm{C} 2=\mathrm{C} 1 \mathrm{C}=\mathrm{CC}=\mathrm{CC} 1=\mathrm{CC} 3=\mathrm{CC}=\mathrm{CC}=\mathrm{C} 23\end{array}$ & $\begin{array}{l}\text { (AYABE et al., } \\
\text { 2003) }\end{array}$ \\
\hline GID281 & $\begin{array}{l}{[\mathrm{N}+] \mathrm{CCCCCCCCCCC} \cdot[\mathrm{O}-} \\
\mathrm{C}(=\mathrm{O}) \mathrm{C} 2=\mathrm{C} 1 \mathrm{C}=\mathrm{CC}=\mathrm{CC} 1=\mathrm{CC} 3=\mathrm{CC}=\mathrm{CC}=\mathrm{C} 23\end{array}$ & $\begin{array}{l}\text { (AYABE et al., } \\
2003)\end{array}$ \\
\hline GID282 & $\begin{array}{c}{[\mathrm{N}+] \mathrm{CCCCCCCCCCC} .[\mathrm{O}-} \\
\mathrm{C}(=\mathrm{O}) \mathrm{C} 2=\mathrm{C} 1 \mathrm{C}=\mathrm{CC}=\mathrm{CC} 1=\mathrm{CC} 3=\mathrm{CC}=\mathrm{CC}=\mathrm{C} 23\end{array}$ & $\begin{array}{l}\text { (AYABE et al., } \\
\text { 2003) }\end{array}$ \\
\hline GID283 & ] $\mathrm{C}(=\mathrm{O}) \mathrm{C}+]=\mathrm{CCCCCCCCCCCCCCC} \cdot[\mathrm{O}-$ & $\begin{array}{l}\text { (AYABE et al., } \\
\text { 2003) }\end{array}$ \\
\hline GID284 & 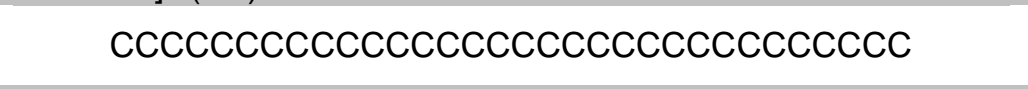 & $\begin{array}{l}\text { (CO; MARANGONI, } \\
\text { 2012) }\end{array}$ \\
\hline GID285 & 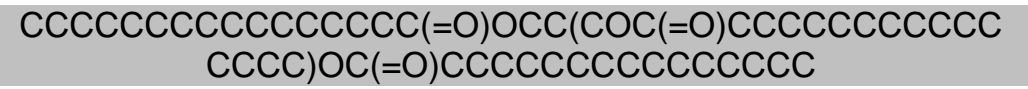 & $\begin{array}{l}\text { (CO; MARANGONI, } \\
\text { 2012) }\end{array}$ \\
\hline GID286 & 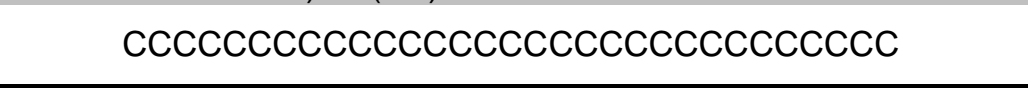 & $\begin{array}{l}\text { (CO; MARANGONI, } \\
\text { 2012) }\end{array}$ \\
\hline
\end{tabular}




\begin{tabular}{|c|c|c|}
\hline GID287 & $\operatorname{ccccccc}(\operatorname{Cc}=\operatorname{ccc} \operatorname{coc} c \cos (=0) 0) 0$ & $\begin{array}{l}\text { (CO; MARANGONI, } \\
\text { 2012) }\end{array}$ \\
\hline GID288 & $\operatorname{cccccccccccccccc}(=0) O \operatorname{Occ}(\mathrm{CO}) \mathrm{O}$ & $\begin{array}{l}\text { (CO; MARANGONI, } \\
\text { 2012) }\end{array}$ \\
\hline GID289 & $\operatorname{cccccccccccccccccc}(=0) \mathrm{Occ}(\operatorname{co}) \mathrm{O}$ & $\begin{array}{l}\text { (CO; MARANGONI, } \\
\text { 2012) }\end{array}$ \\
\hline GID290 & $\mathrm{CC}(\mathrm{C}) \mathrm{CCCC}(\mathrm{C}) \mathrm{C} 1 \mathrm{CCC} 2 \mathrm{C} 1(\mathrm{CCC} 3 \mathrm{C} 2 \mathrm{CCC} 4 \mathrm{C} 3(\mathrm{CCC}(\mathrm{C} 4) \mathrm{O}) \mathrm{C}) \mathrm{C}$ & $\begin{array}{l}\text { (CO; MARANGONI, } \\
\text { 2012) }\end{array}$ \\
\hline GID291 & $\mathrm{CC}(\mathrm{C}) \mathrm{CCCC}(\mathrm{C}) \mathrm{C} 1 \mathrm{CCC} 2 \mathrm{C} 1(\mathrm{CCC} 3 \mathrm{C} 2 \mathrm{CC}=\mathrm{C} 4 \mathrm{C} 3(\mathrm{CCC}(\mathrm{C} 4) \mathrm{O}) \mathrm{C}) \mathrm{C}$ & $\begin{array}{l}\text { (CO; MARANGONI, } \\
\text { 2012) }\end{array}$ \\
\hline GID292 & $\begin{array}{c}\mathrm{CCC}(\mathrm{C}=\mathrm{CC}(\mathrm{C}) \mathrm{C} 1 \mathrm{CCC} 2 \mathrm{C} 1(\mathrm{CCC} 3 \mathrm{C} 2 \mathrm{CC}=\mathrm{C} 4 \mathrm{C} 3(\mathrm{CCC}(\mathrm{C} 4) \mathrm{O}) \mathrm{C}) \mathrm{C}) \\
\mathrm{C}(\mathrm{C}) \mathrm{C}\end{array}$ & $\begin{array}{l}\text { (CO; MARANGONI, } \\
\text { 2012) }\end{array}$ \\
\hline GID293 & $\operatorname{coc} \operatorname{coc} \operatorname{coc} c \operatorname{coc}=\operatorname{cc}(\mathrm{C}(\operatorname{CO}) \mathrm{NC}(=\mathrm{O}) \mathrm{C}) \mathrm{O}$ & $\begin{array}{l}\text { (CO; MARANGONI, } \\
\text { 2012) }\end{array}$ \\
\hline GID294 & 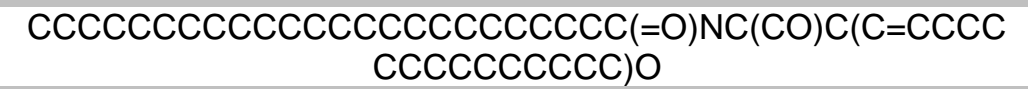 & $\begin{array}{l}\text { (CO; MARANGONI, } \\
\text { 2012) }\end{array}$ \\
\hline GID295 & $\begin{array}{c}\mathrm{CCC}(\mathrm{C}) \mathrm{C}(\mathrm{C}(=\mathrm{O}) \mathrm{NC}(\mathrm{CCCN}=\mathrm{C}(\mathrm{N}) \mathrm{N}) \mathrm{C}(=\mathrm{O}) \mathrm{O}) \mathrm{NC}(=\mathrm{O}) \mathrm{C}(\mathrm{CC} 1=\mathrm{CN} \\
=\mathrm{CN} 1) \mathrm{NC}(=\mathrm{O}) \mathrm{C}(\mathrm{CCSC}) \mathrm{NC}(=\mathrm{O}) \mathrm{C} 2 \mathrm{CCCN} 2 \mathrm{C}(=\mathrm{O}) \mathrm{C}(\mathrm{CC}(\mathrm{C}) \mathrm{C}) \mathrm{NC}( \\
=\mathrm{O}) \mathrm{C}(\mathrm{C}) \mathrm{N}\end{array}$ & $\begin{array}{l}\text { (CO; MARANGONI, } \\
\text { 2012) }\end{array}$ \\
\hline GID296 & $\operatorname{ccccccccccccc\operatorname {coc}} \operatorname{coccc}(=0) 0$ & $\begin{array}{l}\text { (DASSANAYAKE; } \\
\text { KODALI; UENO, } \\
\text { 2011) }\end{array}$ \\
\hline GID297 & 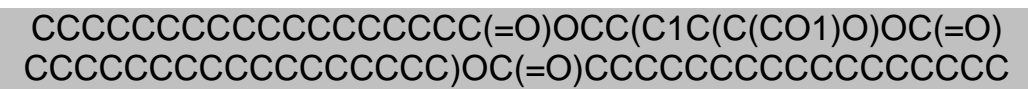 & $\begin{array}{l}\text { (HUGHES et al., } \\
\text { 2009) }\end{array}$ \\
\hline GID298 & ссссссссссесссссссссссссо & (LUPI et al., 2013) \\
\hline GID299 & ссссссссссссссссссссссссссо & (LUPI et al., 2013) \\
\hline GID300 & 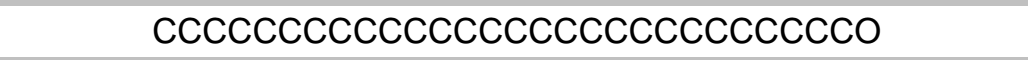 & (LUPI et al., 2013) \\
\hline GID301 & 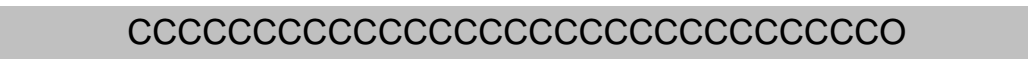 & (LUPI et al., 2013) \\
\hline GID302 & ссссссссссссссссссссссссссссссссо & (LUPI et al., 2013) \\
\hline GID303 & ссссссссссссссссссссссссссссссссссо & (LUPI et al., 2013) \\
\hline GID304 & $\begin{array}{c}\operatorname{\operatorname {ccccccccccccccc}(}(=0) \mathrm{OCC}(\operatorname{coc}(=0) \operatorname{cccccccccc} \\
\operatorname{cccc}) \mathrm{O}\end{array}$ & $\begin{array}{l}\text { (PERNETTI et al., } \\
\text { 2007b) }\end{array}$ \\
\hline GID305 & 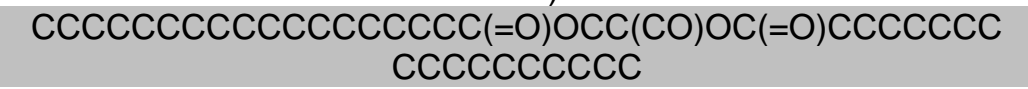 & $\begin{array}{l}\text { (PERNETTI et al., } \\
\text { 2007b) }\end{array}$ \\
\hline GID306 & $\operatorname{cccccccccccccccc}(=0) 0$ & $\begin{array}{l}\text { (PERNETTI et al., } \\
\text { 2007b) }\end{array}$ \\
\hline GID307 & $\operatorname{coc} \operatorname{coc} c \operatorname{coc} \operatorname{coc} \operatorname{coc}(=0) 0$ & $\begin{array}{l}\text { (PERNETTI et al., } \\
\text { 2007b) }\end{array}$ \\
\hline GID308 & 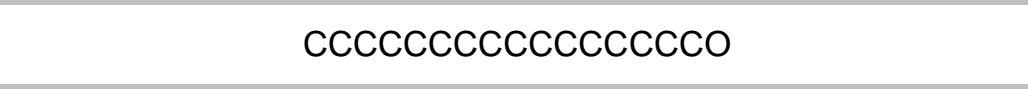 & $\begin{array}{l}\text { (PERNETTI et al., } \\
\text { 2007b) }\end{array}$ \\
\hline GID309 & сcссссссссссссссссссо & $\begin{array}{l}\text { (PERNETTI et al., } \\
\text { 2007b) }\end{array}$ \\
\hline GID310 & 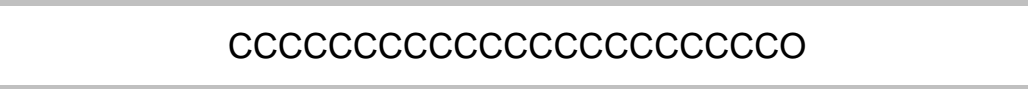 & $\begin{array}{l}\text { (PERNETTI et al., } \\
\text { 2007b) }\end{array}$ \\
\hline GID311 & $\begin{array}{c}\operatorname{CC}(\mathrm{C}) \operatorname{CccC}(\mathrm{C}) \mathrm{C} 1 \mathrm{CCC} 2(\mathrm{C} 1(\mathrm{CCC} 3=\mathrm{C} 2 \mathrm{CCC} 4 \mathrm{C} 3(\mathrm{CCC}(\mathrm{C} 4(\mathrm{C}) \mathrm{C}) \\
\mathrm{O}) \mathrm{C}) \mathrm{C}) \mathrm{C}\end{array}$ & $\begin{array}{l}\text { (TERECH; WEISS, } \\
\text { 1997) }\end{array}$ \\
\hline GID312 & $\operatorname{CCCC} 1(\operatorname{CCC} 2 \mathrm{C} 3 \mathrm{CCC} 4 \mathrm{CC}(\mathrm{CCC} 4(\mathrm{C} 3 \mathrm{CCC} 2(\mathrm{~N} 1 \mathrm{O}) \mathrm{C}) \mathrm{C}) \mathrm{O}) \mathrm{CCC}$ & $\begin{array}{l}\text { (TERECH; WEISS, } \\
\text { 1997) }\end{array}$ \\
\hline GID313 & $\operatorname{cccc} 1(\operatorname{Ccc} 2 \mathrm{C} 3 \mathrm{CCC} 4 \mathrm{CC}(\mathrm{CcC} 4(\mathrm{C} 3 \mathrm{CCC} 2(\mathrm{~N} 1) \mathrm{C}) \mathrm{C}) \mathrm{O}) \mathrm{CcC}$ & $\begin{array}{l}\text { (TERECH; WEISS, } \\
\text { 1997) }\end{array}$ \\
\hline GID314 & $\begin{array}{c}\operatorname{cccccccccoc} 1=\mathrm{CC} 2=\mathrm{CC} 3=\mathrm{CC}=\mathrm{CC}=\mathrm{C} 3 \mathrm{C}=\mathrm{C} 2 \mathrm{C}=\mathrm{C} 1 \mathrm{OCCC} \\
\operatorname{CCCCCCC}\end{array}$ & $\begin{array}{l}\text { (TERECH; WEISS, } \\
\text { 1997) }\end{array}$ \\
\hline GID315 & 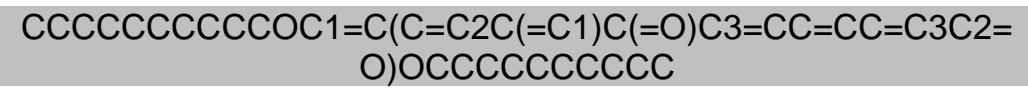 & $\begin{array}{l}\text { (TERECH; WEISS, } \\
\text { 1997) }\end{array}$ \\
\hline GID316 & $\begin{array}{l}\mathrm{CC}(\mathrm{C}) \mathrm{CCCC}(\mathrm{C}) \mathrm{C} 1 \mathrm{CCC} 2 \mathrm{C} 1(\mathrm{CCC} 3 \mathrm{C} 2 \mathrm{CC}=\mathrm{C} 4 \mathrm{C} 3(\mathrm{CCC}(\mathrm{C} 4) \mathrm{OC}(= \\
\mathrm{O}) \mathrm{CcCCOC}=\mathrm{CC} 6=\mathrm{CC} 7=\mathrm{CC}=\mathrm{CC}=\mathrm{C} 7 \mathrm{C}=\mathrm{C} 6 \mathrm{C}=\mathrm{C} 5) \mathrm{C}) \mathrm{C}\end{array}$ & $\begin{array}{l}\text { (TERECH; WEISS, } \\
\text { 1997) }\end{array}$ \\
\hline GID317 & $\begin{array}{c}\mathrm{CC}(\mathrm{C}) \mathrm{CCCC}(\mathrm{C}) \mathrm{C} 3 \mathrm{CCC} 4 \mathrm{C} 2 \mathrm{CC}=\mathrm{C} 1 \mathrm{CC}(\mathrm{CCC} 1(\mathrm{C}) \mathrm{C} 2 \mathrm{CCC} 34 \mathrm{C}) \mathrm{O} \\
\mathrm{C} 6=\mathrm{CC}=\mathrm{C} 5 \mathrm{C}(\mathrm{C} 7=\mathrm{C}(\mathrm{C}(\mathrm{C} 5=\mathrm{C} 6)=\mathrm{O}) \mathrm{C}=\mathrm{CC}=\mathrm{C} 7)=\mathrm{O}\end{array}$ & $\begin{array}{l}\text { (TERECH; WEISS, } \\
\text { 1997) }\end{array}$ \\
\hline
\end{tabular}




\begin{tabular}{|c|c|c|}
\hline GID318 & $\begin{aligned} \operatorname{cccccccccc}(\operatorname{CCCCCCCC}) \operatorname{COC}(=O) C 1=C C=C(C=C 1) N C( \\
=O) N C 2=C C=C C 3=C C=C C=C 32\end{aligned}$ & $\begin{array}{c}\text { (TERECH; WEISS, } \\
\text { 1997) }\end{array}$ \\
\hline GID319 & $\begin{array}{c}\operatorname{cccccccccccccccc}(=\mathrm{O}) \mathrm{C} 1=\mathrm{CC}(=\mathrm{C}(\mathrm{C}=\mathrm{C} 1) \mathrm{OC}(=\mathrm{O}) \mathrm{C}(\mathrm{C}) \mathrm{N} \\
\mathrm{C}(=\mathrm{O}) \mathrm{OCC} 2=\mathrm{CC}=\mathrm{CC}=\mathrm{C} 2)[\mathrm{N}+](=\mathrm{O})[\mathrm{O}-]\end{array}$ & $\begin{array}{l}\text { (TERECH; WEISS, } \\
\text { 1997) }\end{array}$ \\
\hline GID320 & $\begin{array}{c}\operatorname{ccccccccc} 2 \operatorname{ccccccNC}(=\mathrm{O}) \mathrm{C}(\mathrm{CCC}) \mathrm{NC}(=\mathrm{O}) \mathrm{C}(\mathrm{CCC}) \mathrm{NC} \\
(=\mathrm{O}) \mathrm{OCC} 1=\mathrm{CC}=\mathrm{CC}=\mathrm{C} 1\end{array}$ & $\begin{array}{l}\text { (TERECH; WEISS, } \\
\text { 1997) }\end{array}$ \\
\hline GID321 & 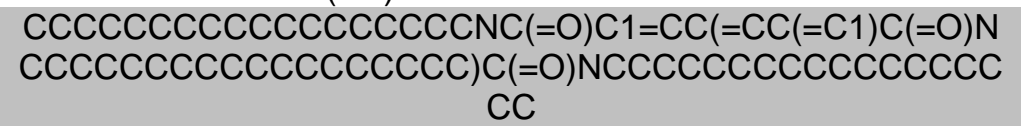 & $\begin{array}{l}\text { (TERECH; WEISS, } \\
\text { 1997) }\end{array}$ \\
\hline GID322 & $\operatorname{Cc}(C) \operatorname{Cccc}(C) \operatorname{Ccoc}(=0) \operatorname{Ccc} 1 C(=0) N C(C(=0) N 1) C(C) C$ & $\begin{array}{l}\text { (TERECH; WEISS, } \\
\text { 1997) }\end{array}$ \\
\hline GID323 & $\operatorname{CC}(C) \operatorname{CC} 1 C(=O) N C(C(=O) O C C(=O) N 1) \operatorname{CC}(C) C$ & $\begin{array}{l}\text { (TERECH; WEISS, } \\
\text { 1997) }\end{array}$ \\
\hline GID324 & $\mathrm{C} 1 \mathrm{C}(=\mathrm{O}) \mathrm{NCC}(=\mathrm{O}) \mathrm{OCC}(=\mathrm{O}) \mathrm{N} 1$ & $\begin{array}{l}\text { (TERECH; WEISS, } \\
\text { 1997) }\end{array}$ \\
\hline GID325 & $\begin{aligned} \operatorname{CC}(\mathrm{C}) \mathrm{C} 1 \mathrm{NC}(=\mathrm{O}) \mathrm{C}(\mathrm{NC}(=\mathrm{O}) \mathrm{COC}(=\mathrm{O}) \mathrm{C}(\mathrm{NC}(=\mathrm{O}) \mathrm{C}(\mathrm{NC}(=\mathrm{O}) \mathrm{COC} 1 \\
=\mathrm{O}) \mathrm{C}(\mathrm{C}) \mathrm{C}) \mathrm{C}(\mathrm{C}) \mathrm{C}) \mathrm{C}(\mathrm{C}) \mathrm{C}\end{aligned}$ & $\begin{array}{l}\text { (TERECH; WEISS, } \\
\text { 1997) }\end{array}$ \\
\hline GID326 & $\begin{array}{c}\mathrm{CC}(\mathrm{C}) \mathrm{C} 1 \mathrm{NC}(=\mathrm{O}) \mathrm{C}(\mathrm{CC}(\mathrm{C}) \mathrm{C}) \mathrm{NC}(=\mathrm{O}) \mathrm{COC}(=\mathrm{O}) \mathrm{C}(\mathrm{NC}(=\mathrm{O}) \mathrm{C}(\mathrm{NC}(= \\
\mathrm{O}) \mathrm{COC} 1=\mathrm{O}) \mathrm{CC}(\mathrm{C}) \mathrm{C}) \mathrm{C}(\mathrm{C}) \mathrm{C}\end{array}$ & $\begin{array}{l}\text { (TERECH; WEISS, } \\
\text { 1997) }\end{array}$ \\
\hline GID327 & 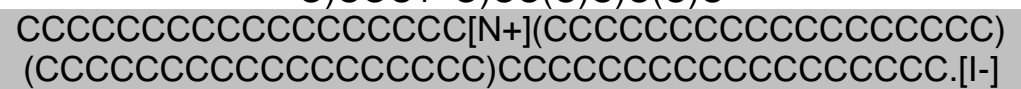 & $\begin{array}{l}\text { (TERECH; WEISS, } \\
\text { 1997) }\end{array}$ \\
\hline GID328 & 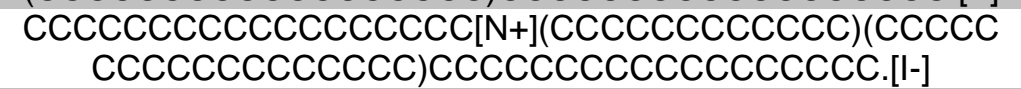 & $\begin{array}{l}\text { (TERECH; WEISS, } \\
\text { 1997) }\end{array}$ \\
\hline GID329 & 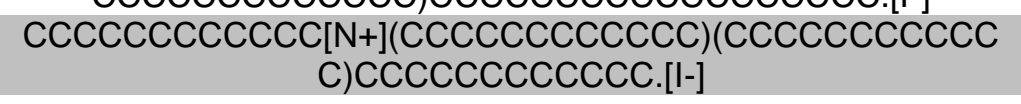 & $\begin{array}{l}\text { (TERECH; WEISS, } \\
\text { 1997) }\end{array}$ \\
\hline GID330 & $\operatorname{ccccc}(\mathrm{CC}) \mathrm{OP}(=\mathrm{O})(\mathrm{O}) \mathrm{OC}(\mathrm{CC}) \operatorname{cccc}$ & $\begin{array}{c}\text { (TERECH; WEISS, } \\
\text { 1997) }\end{array}$ \\
\hline GID331 & 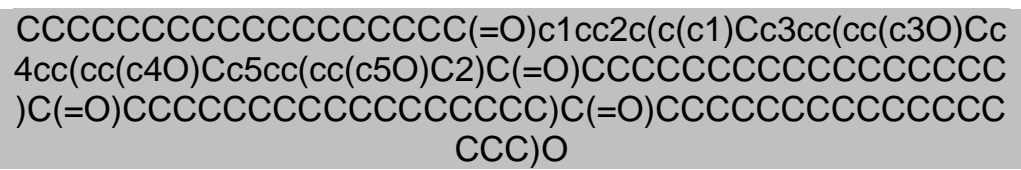 & $\begin{array}{l}\text { (TERECH; WEISS, } \\
\text { 1997) }\end{array}$ \\
\hline GID332 & 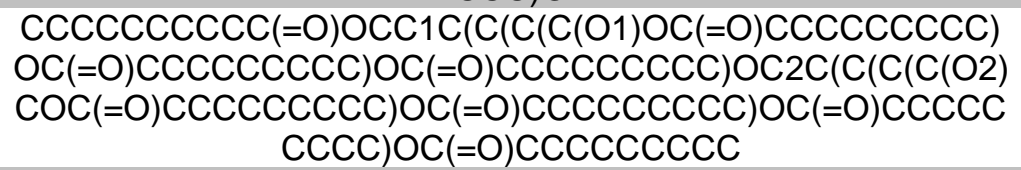 & $\begin{array}{l}\text { (TERECH; WEISS, } \\
\text { 1997) }\end{array}$ \\
\hline GID333 & $\mathrm{C} 1=\mathrm{CC}=\mathrm{NC}=\mathrm{C} 1$ & $\begin{array}{l}\text { (TERECH; WEISS, } \\
\text { 1997) }\end{array}$ \\
\hline GID334 & $\begin{array}{c}\operatorname{ccccccccccccccccc} \mathrm{CCC}(=\mathrm{O}) \mathrm{C}(\mathrm{NC}(=\mathrm{O}) \mathrm{CC}(\mathrm{NC}(=\mathrm{O}) \mathrm{OCC} \\
1=\mathrm{CC}=\mathrm{CC}=\mathrm{C} 1) \mathrm{C}(\mathrm{C}) \mathrm{C}) \mathrm{C}(\mathrm{C}) \mathrm{C}\end{array}$ & $\begin{array}{l}\text { (HANABUSA et al., } \\
\text { 1993) }\end{array}$ \\
\hline GID335 & 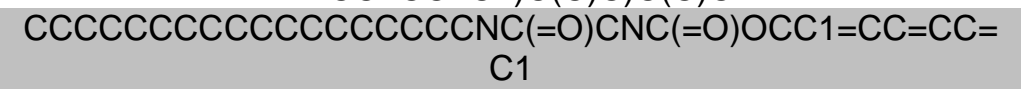 & $\begin{array}{l}\text { (HANABUSA et al., } \\
\text { 1993) }\end{array}$ \\
\hline GID336 & $\begin{array}{r}\operatorname{ccccccccccccccccccNC}(=O) C(C C(C) C) N C(=0) O C C 1= \\
\qquad C=C C=C 1\end{array}$ & $\begin{array}{l}\text { (HANABUSA et al., } \\
\text { 1993) }\end{array}$ \\
\hline GID337 & 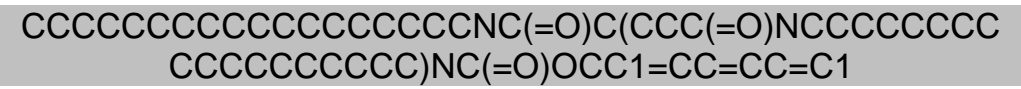 & $\begin{array}{l}\text { (HANABUSA et al., } \\
\text { 1993) }\end{array}$ \\
\hline GID338 & 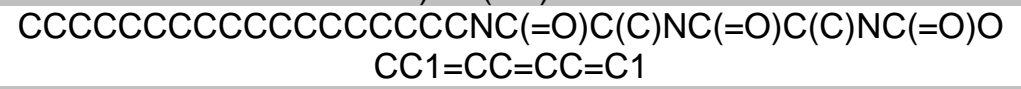 & $\begin{array}{l}\text { (HANABUSA et al., } \\
\text { 1993) }\end{array}$ \\
\hline GID339 & $\begin{array}{c}\operatorname{CCCCNC}(=0) C(N C(=O) C(N C(=O) O C C 1=C C=C C=C 1) C(C) C) C( \\
C) C\end{array}$ & $\begin{array}{l}\text { (HANABUSA et al., } \\
\text { 1993) }\end{array}$ \\
\hline GID340 & 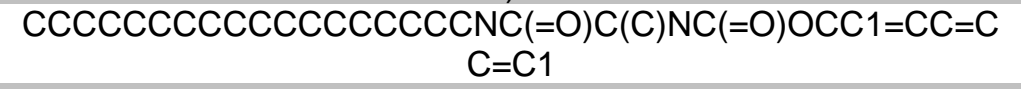 & $\begin{array}{l}\text { (HANABUSA et al., } \\
\text { 1993) }\end{array}$ \\
\hline GID341 & 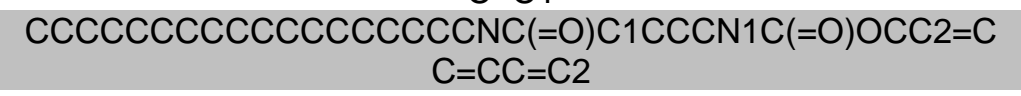 & $\begin{array}{l}\text { (HANABUSA et al., } \\
\text { 1993) }\end{array}$ \\
\hline GID342 & 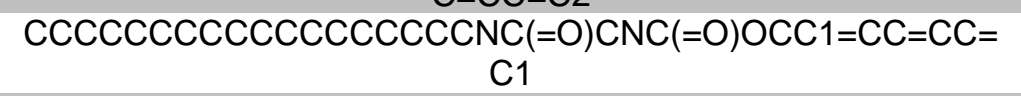 & $\begin{array}{l}\text { (HANABUSA et al., } \\
\text { 1993) }\end{array}$ \\
\hline GID343 & $\begin{array}{c}\mathrm{CC}(\mathrm{C}) \mathrm{C}(\mathrm{N}) \mathrm{C}(=\mathrm{O}) \mathrm{NC}(\mathrm{C}(\mathrm{C}) \mathrm{C}) \mathrm{C}(=\mathrm{O}) \mathrm{NCCCCCCCCCCCCCCccC} \\
\mathrm{C}\end{array}$ & $\begin{array}{l}\text { (HANABUSA et al., } \\
\text { 1993) }\end{array}$ \\
\hline GID344 & $\begin{array}{c}\operatorname{ccccccccccccccccccN}(=O) \mathrm{C}(\mathrm{NC}(=\mathrm{O}) \mathrm{C}(\mathrm{NC}(=\mathrm{O}) \mathrm{OCcC} \\
\operatorname{coccccc}) \mathrm{C}(\mathrm{C}) \mathrm{C}) \mathrm{C}(\mathrm{C}) \mathrm{C}\end{array}$ & $\begin{array}{l}\text { (HANABUSA et al., } \\
\text { 1993) }\end{array}$ \\
\hline
\end{tabular}




\begin{tabular}{|c|c|c|}
\hline GID345 & $\begin{aligned} \operatorname{ccccccccccccccccccNC}(=O) C(C(C) C) N C(=O) O C C 1=C \\
C=C C=C 1\end{aligned}$ & $\begin{array}{l}\text { (HANABUSA et al., } \\
\text { 1993) }\end{array}$ \\
\hline GID346 & $\begin{array}{c}\operatorname{ccccccccccccccccccNC}(=O) \operatorname{CcNC}(=O) C(N C(=O) O C C \\
1=C C=C C=C 1) C(C) C\end{array}$ & $\begin{array}{l}\text { (HANABUSA et al., } \\
\text { 1993) }\end{array}$ \\
\hline GID347 & 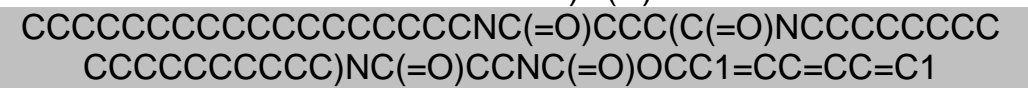 & $\begin{array}{l}\text { (HANABUSA et al., } \\
\text { 1993) }\end{array}$ \\
\hline GID348 & $\begin{array}{c}\mathrm{CC}(\mathrm{C}) \mathrm{C}(\mathrm{NC}(=\mathrm{O}) \mathrm{OCC} 1=\mathrm{CC}=\mathrm{CC}=\mathrm{C} 1) \mathrm{C}(=\mathrm{O}) \mathrm{NC}(\mathrm{C}(\mathrm{C}) \mathrm{C}) \mathrm{C}(=\mathrm{O}) \mathrm{NC} \\
\mathrm{CCCCCCCCCCCCCCCCCCNC}(=\mathrm{O}) \mathrm{C}(\mathrm{NC}(=\mathrm{O}) \mathrm{C}(\mathrm{NC}(=\mathrm{O}) \mathrm{OCC} \\
2=\mathrm{CC}=\mathrm{CC}=\mathrm{C} 2) \mathrm{C}(\mathrm{C}) \mathrm{C}) \mathrm{C}(\mathrm{C}) \mathrm{C}\end{array}$ & $\begin{array}{l}\text { (HANABUSA et al., } \\
\text { 1993) }\end{array}$ \\
\hline GID349 & $\begin{array}{c}\operatorname{CCCCCCCCNC}(=0) C(N C(=O) C(N C(=O) O C C 1=C C=C C=C 1) C( \\
C) C) C(C) C\end{array}$ & $\begin{array}{l}\text { (HANABUSA et al., } \\
\text { 1993) }\end{array}$ \\
\hline GID350 & $\begin{array}{c}\operatorname{Cccccccccccc} \mathrm{C} C(=\mathrm{O}) \mathrm{C}(\mathrm{NC}(=\mathrm{O}) \mathrm{C}(\mathrm{NC}(=\mathrm{O}) \mathrm{OCC} 1=\mathrm{CC}=\mathrm{CC}= \\
\mathrm{C} 1) \mathrm{C}(\mathrm{C}) \mathrm{C}) \mathrm{C}(\mathrm{C}) \mathrm{C}\end{array}$ & $\begin{array}{l}\text { (HANABUSA et al., } \\
\text { 1993) }\end{array}$ \\
\hline GID351 & $\begin{aligned} & \operatorname{CCCCCCCCCCCCNC}(=\mathrm{O}) \mathrm{C}(\mathrm{NC}(=\mathrm{O}) \mathrm{C}(\mathrm{NC}(=\mathrm{O}) \mathrm{OCC} 1=\mathrm{CC}=\mathrm{CC}= \\
&\mathrm{C} 1) \mathrm{C}(\mathrm{C}) \mathrm{C}) \mathrm{C}(\mathrm{C}) \mathrm{C}\end{aligned}$ & $\begin{array}{l}\text { (HANABUSA et al., } \\
\text { 1993) }\end{array}$ \\
\hline GID352 & $\begin{aligned} \operatorname{ccccccccc} c \operatorname{ccc} c \operatorname{cccNC}(=\mathrm{O}) \mathrm{CCNC}(=\mathrm{O}) \mathrm{C}(\mathrm{CC}(\mathrm{C}) \mathrm{C}) \mathrm{NC}( \\
=0) \mathrm{OCC} 1=\mathrm{CC}=\mathrm{CC}=\mathrm{C} 1\end{aligned}$ & $\begin{array}{l}\text { (HANABUSA et al., } \\
1993 \text { ) }\end{array}$ \\
\hline GID353 & $\begin{array}{c}\operatorname{CccccccccccCNC}(=0) N C 1=C C=C(C=C 1) C C 2=C C=C(C=C \\
2) N C(=0) N C \operatorname{NCCCCCCCCC~}\end{array}$ & $\begin{array}{l}\text { (HANABUSA et al., } \\
\text { 1996) }\end{array}$ \\
\hline GID354 & $\begin{array}{c}\operatorname{ccccccccccc} 2 N C(=S) N C 1=C C=C(C=C 1) C C 2=C C=C(C=C \\
\text { 2) NC }(=S) N C C C C C C C C C C C C\end{array}$ & $\begin{array}{l}\text { (HANABUSA et al., } \\
\text { 1996) }\end{array}$ \\
\hline GID355 & $\operatorname{CcCCNC}(=0) N C 1 \operatorname{CcCCC} 1 N C(=0) N C C C C$ & $\begin{array}{l}\text { (HANABUSA et al., } \\
\text { 1996) }\end{array}$ \\
\hline GID356 & $\begin{array}{c}\operatorname{CcccccccccccNC}(=0) \operatorname{NC} 1 \operatorname{Ccccc} 1 \mathrm{NC}(=0) \mathrm{NCCCCCCCC} \\
\operatorname{CCCC}\end{array}$ & $\begin{array}{c}\text { (HANABUSA et al., } \\
\text { 1996) }\end{array}$ \\
\hline GID357 & 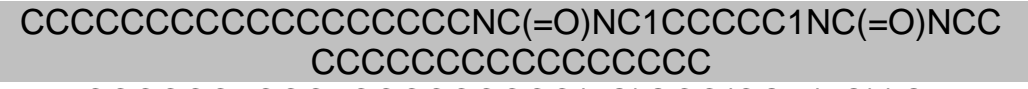 & $\begin{array}{l}\text { (HANABUSA et al., } \\
\text { 1996) }\end{array}$ \\
\hline GID358 & 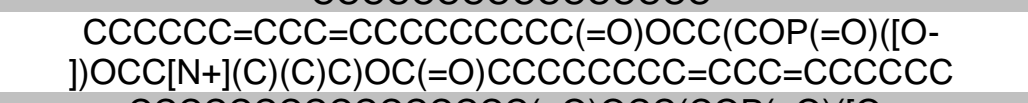 & $\begin{array}{c}\text { (VINTILOIU; } \\
\text { LEROUX, 2008) }\end{array}$ \\
\hline GID359 & $\begin{array}{l}\operatorname{Cccccccccccccccc}(=0) O \operatorname{OCC}(\operatorname{COP}(=O)([\mathrm{O}- \\
]) \mathrm{OCC}[\mathrm{N}+](\mathrm{C})(\mathrm{C}) \mathrm{C}) \mathrm{OC}(=\mathrm{O}) \operatorname{cccccccccccccc}\end{array}$ & $\begin{array}{l}\text { (VINTILOIU; } \\
\text { LEROUX, 2008) }\end{array}$ \\
\hline GID360 & $\begin{array}{c}\operatorname{CccCN}(\operatorname{CCCC}) \mathrm{C}(=\mathrm{O}) \mathrm{C}(\mathrm{NC}(=\mathrm{O}) \operatorname{CCCCCCCCCCC}) \operatorname{CCC}(=\mathrm{O}) \mathrm{NC} \\
\operatorname{CCC}\end{array}$ & $\begin{array}{l}\text { (VINTILOIU; } \\
\text { LEROUX, 2008) }\end{array}$ \\
\hline GID361 & 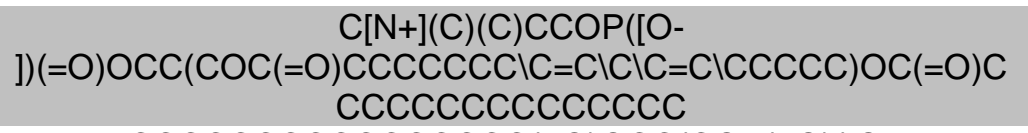 & $\begin{array}{l}\text { (VINTILOIU; } \\
\text { LEROUX, 2008) }\end{array}$ \\
\hline GID362 & 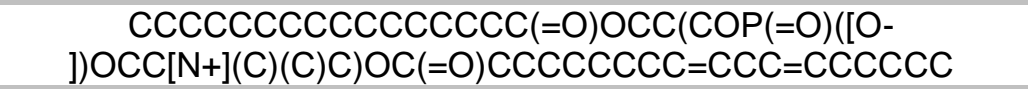 & $\begin{array}{l}\text { (VINTILOIU; } \\
\text { LEROUX, 2008) }\end{array}$ \\
\hline GID363 & $\operatorname{cccccccccccc}(=0) O \operatorname{Occ}(\operatorname{c1c}(\operatorname{C}(\operatorname{CO} 1) O) O) O$ & $\begin{array}{l}\text { (VINTILOIU; } \\
\text { LEROUX, 2008) }\end{array}$ \\
\hline GID364 & $\operatorname{cccccccccccccccccc}(=0) \mathrm{NC}(\mathrm{C}) \mathrm{C}(=\mathrm{O}) \mathrm{OC}$ & $\begin{array}{l}\text { (VINTILOIU; } \\
\text { LEROUX, 2008) }\end{array}$ \\
\hline GID365 & $\operatorname{cccccccccccccccccc}(=0) \mathrm{NC}(\mathrm{C}) \mathrm{C}(=\mathrm{O}) \mathrm{OCC}$ & $\begin{array}{l}\text { (VINTILOIU; } \\
\text { LEROUX, 2008) }\end{array}$ \\
\hline GID366 & $\operatorname{cccccccccccccccc}(=0) \mathrm{NC}(\mathrm{C}) \mathrm{C}(=\mathrm{O}) \mathrm{OC}$ & (HU et al., 2018) \\
\hline GID367 & $\operatorname{coccccc} \operatorname{coc} c c c(=0) N C(C) C(=0) O C$ & (HU et al., 2018) \\
\hline GID368 & $\operatorname{cccccccccccccccccccc}(=0) N C(C) C(=0) O C$ & (HU et al., 2018) \\
\hline GID369 & $\begin{aligned} \operatorname{ccccccccccc} & =(=\mathrm{C}) \mathrm{NCCN}(\mathrm{CC}) \mathrm{C} 1=\mathrm{CC}=\mathrm{C}(\mathrm{C}=\mathrm{C} 1) \mathrm{N}=\mathrm{NC} 2 \\
& =\mathrm{CC}=\mathrm{C}(\mathrm{C}=\mathrm{C} 2)[\mathrm{N}+](=\mathrm{O})[\mathrm{O}-]\end{aligned}$ & $\begin{array}{l}\text { (BELÉN MARCO et } \\
\text { al., 2018) }\end{array}$ \\
\hline GID370 & 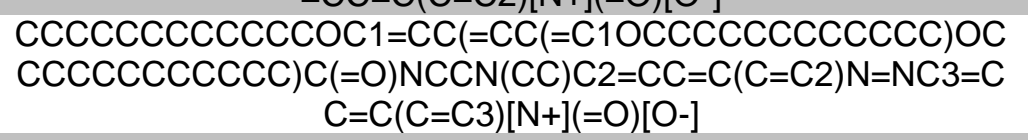 & $\begin{array}{l}\text { (BELÉN MARCO et } \\
\text { al., 2018) }\end{array}$ \\
\hline GID371 & $\begin{array}{c}\operatorname{ccccccccccccoc} 1=\mathrm{CC}(=\mathrm{CC}(=\mathrm{C} 10 \mathrm{OCCCCCCCCCCC}) \mathrm{OC} \\
\operatorname{ccccccccccc}) \mathrm{C}(=\mathrm{O}) \mathrm{OCCN}(\mathrm{CC}) \mathrm{C} 2=\mathrm{CC}=\mathrm{C}(\mathrm{C}=\mathrm{C} 2) \mathrm{N}=\mathrm{NC} 3=\mathrm{C} \\
\mathrm{C}=\mathrm{C}(\mathrm{C}=\mathrm{C} 3)[\mathrm{N}+](=\mathrm{O})[\mathrm{O}-]\end{array}$ & $\begin{array}{l}\text { (BELÉN MARCO et } \\
\text { al., 2018) }\end{array}$ \\
\hline GID372 & $\begin{array}{c}\operatorname{CcccccccccccNC}(=\mathrm{O}) \mathrm{NCCN}(\mathrm{C}) \mathrm{C} 1=\mathrm{CC}=\mathrm{C}(\mathrm{C}=\mathrm{C} 1) \mathrm{C}=\mathrm{C} 3 \mathrm{C}= \\
\operatorname{C2SC}(\mathrm{C}=\mathrm{C} 2 \mathrm{~S} 3)=\mathrm{C}(\mathrm{C} \# \mathrm{~N}) \mathrm{C} \# \mathrm{~N}\end{array}$ & $\begin{array}{l}\text { (BELÉN MARCO et } \\
\text { al., 2018) }\end{array}$ \\
\hline GID373 & $\begin{aligned} \mathrm{N} \# \mathrm{CC}(\mathrm{C \# N})=\mathrm{C} 2 \mathrm{C}=\mathrm{CC}(=\mathrm{CC} 1=\mathrm{CC}=\mathrm{C}(\mathrm{C}=\mathrm{C} 1) \mathrm{N}(\mathrm{C}) \mathrm{CCNC}(=\mathrm{O}) \mathrm{NC} \\
\\
\mathrm{CCCCCCCCCCC}) \mathrm{S} 2\end{aligned}$ & $\begin{array}{l}\text { (BELÉN MARCO et } \\
\text { al., 2018) }\end{array}$ \\
\hline
\end{tabular}




\begin{tabular}{|c|c|c|}
\hline GID374 & $\begin{array}{c}\mathrm{CC} 1(\mathrm{C}) \mathrm{OC}(\mathrm{C}(=\mathrm{C} 1 \mathrm{C}=\mathrm{CC} 2=\mathrm{CC}=\mathrm{C}(\mathrm{C}=\mathrm{C} 2) \mathrm{N}(\mathrm{C}) \mathrm{CCNC}(=\mathrm{O}) \mathrm{NCCCC} \\
\mathrm{CCCCCCCC}) \mathrm{C \# N})=\mathrm{C}(\mathrm{C \# N}) \mathrm{C \# N}\end{array}$ & $\begin{array}{l}\text { (BELÉN MARCO et } \\
\text { al., 2018) }\end{array}$ \\
\hline GID375 & $\begin{array}{c}\operatorname{ccccccccccccNC}(=\mathrm{O}) \mathrm{NCCN}(\mathrm{C}) \mathrm{C} 1=\mathrm{CC}=\mathrm{C}(\mathrm{C}=\mathrm{C} 1) \mathrm{C}=\mathrm{C} 3 \mathrm{SC} \\
2=\mathrm{C}(\mathrm{C}) \mathrm{C}(\mathrm{SC} 2=\mathrm{C} 3 \mathrm{C})=\mathrm{C}(\mathrm{C \# N}) \mathrm{C \# N}\end{array}$ & $\begin{array}{l}\text { (BELÉN MARCO et } \\
\text { al., 2018) }\end{array}$ \\
\hline GID376 & $\mathrm{C} 1=\mathrm{CC}(=\mathrm{CC}(=\mathrm{C} 1) \mathrm{C}=\mathrm{CC}(=\mathrm{O}) \mathrm{O}) \mathrm{Br} . \mathrm{C} 2 \mathrm{CCC}(\mathrm{CC} 2) \mathrm{NC} 3 \mathrm{CCCCC} 3$ & $\begin{array}{l}\text { (TRIVEDI et al., } \\
\text { 2004) }\end{array}$ \\
\hline GID377 & $\mathrm{C} 1=\mathrm{C}(\mathrm{C}=\mathrm{CC}(=\mathrm{C} 1) \mathrm{Br}) \mathrm{C}=\mathrm{CC}(=\mathrm{O}) \mathrm{O} \cdot \mathrm{C} 2 \mathrm{CCC}(\mathrm{CC} 2) \mathrm{NC} 3 \mathrm{CCCCC} 3$ & $\begin{array}{l}\text { (TRIVEDI et al., } \\
\text { 2004) }\end{array}$ \\
\hline GID378 & $\mathrm{C} 1=\mathrm{C}(\mathrm{C}=\mathrm{CC}(=\mathrm{C} 1) \mathrm{C}) \mathrm{C}=\mathrm{CC}(=\mathrm{O}) \mathrm{O} . \mathrm{C} 2 \mathrm{CCC}(\mathrm{CC} 2) \mathrm{NC} 3 \mathrm{CCCCC} 3$ & $\begin{array}{l}\text { (TRIVEDI et al., } \\
\text { 2004) }\end{array}$ \\
\hline GID379 & $\mathrm{OC}(\mathrm{C}(\mathrm{O}) \mathrm{COC}(=\mathrm{O}) \mathrm{CCC}) \mathrm{C}(\mathrm{O}) \mathrm{C}(\mathrm{O}) \mathrm{COC}(=\mathrm{O}) \mathrm{CCC}$ & $\begin{array}{l}\text { (SINGH; } \\
\text { AUZANNEAU; } \\
\text { ROGERS, 2017) }\end{array}$ \\
\hline GID380 & $\mathrm{OC}(\mathrm{C}(\mathrm{O}) \operatorname{coc}(=\mathrm{O}) \operatorname{cccccc}) \mathrm{C}(\mathrm{O}) \mathrm{C}(\mathrm{O}) \operatorname{coc}(=\mathrm{O}) \operatorname{cccccc}$ & $\begin{array}{l}\text { (SINGH; } \\
\text { AUZANNEAU; } \\
\text { ROGERS, 2017) }\end{array}$ \\
\hline GID381 & $\operatorname{cccccccccccc}(=0) N \operatorname{ccccc}(\mathrm{C}(=\mathrm{O}) \mathrm{O}) \mathrm{NC}(=\mathrm{O}) \operatorname{cccccc}$ & $\begin{array}{l}\text { (SUZUKI et al., } \\
\text { 2008) }\end{array}$ \\
\hline GID382 & $\mathrm{C}(\mathrm{CCC}(=\mathrm{O}) \mathrm{O}) \mathrm{CC}(=\mathrm{O}) \mathrm{O}$ & $\begin{array}{l}\text { (DASSANAYAKE; } \\
\text { KODALI; UENO; } \\
\text { 2011) }\end{array}$ \\
\hline GID383 & 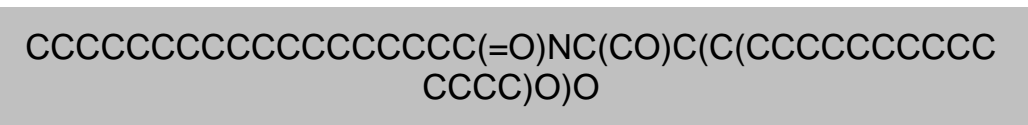 & $\begin{array}{c}\text { (SINGH; } \\
\text { AUZANNEAU; } \\
\text { ROGERS, 2017) }\end{array}$ \\
\hline GID384 & $\mathrm{C} 1=\mathrm{C}(\mathrm{C}=\mathrm{CC}(=\mathrm{C} 1)) \mathrm{C}=\mathrm{CC}(=\mathrm{O}) \mathrm{O} \cdot \mathrm{C} 2 \mathrm{CCC}(\mathrm{CC} 2) \mathrm{NC} 3 \mathrm{CCCCC} 3$ & $\begin{array}{l}\text { (TRIVEDI et al., } \\
\text { 2004) }\end{array}$ \\
\hline GID385 & 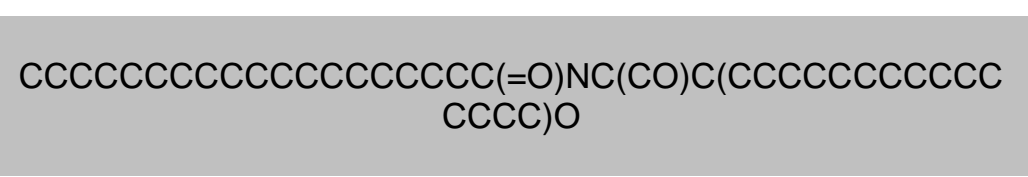 & $\begin{array}{c}\text { (ROGERS; } \\
\text { WRIGHT; } \\
\text { MARANGONI, } \\
\text { 2009) }\end{array}$ \\
\hline GID386 & $\mathrm{C}(\operatorname{ccccc}(=0) 0) \operatorname{cccc}(=0) 0$ & $\begin{array}{l}\text { (DASSANAYAKE; } \\
\text { KODALI; UENO, } \\
\text { 2011) }\end{array}$ \\
\hline GID387 & $\mathrm{C}(\operatorname{cccc}(=0) 0) \operatorname{ccc}(=0) 0$ & $\begin{array}{l}\text { (DASSANAYAKE; } \\
\text { KODALI; UENO, } \\
\text { 2011) }\end{array}$ \\
\hline GID388 & 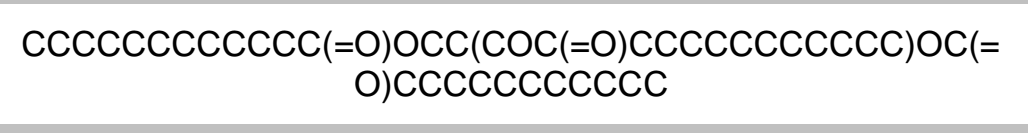 & $\begin{array}{l}\text { (DANIEL; } \\
\text { RAJASEKHARAN, } \\
\text { 2003) }\end{array}$ \\
\hline GID389 & 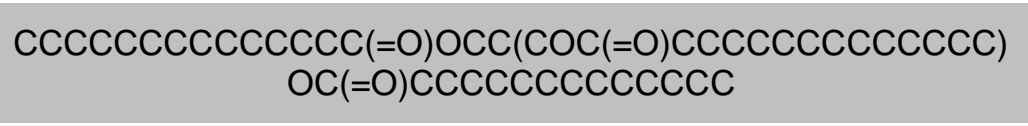 & $\begin{array}{l}\text { (DANIEL; } \\
\text { RAJASEKHARAN, } \\
\text { 2003) }\end{array}$ \\
\hline GID390 & 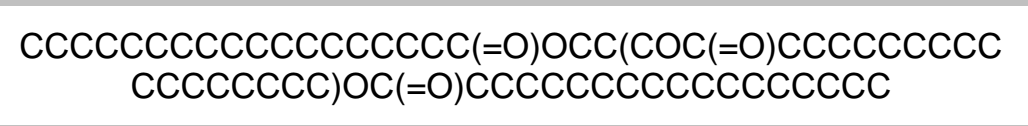 & $\begin{array}{l}\text { (DANIEL; } \\
\text { RAJASEKHARAN, } \\
\text { 2003) }\end{array}$ \\
\hline GID391 & $\begin{array}{c}\operatorname{ccccccccccccc}(=0) N C(\operatorname{ccccNC}(=0) \operatorname{cccccccccc}) \mathrm{C} \\
(=0) \mathrm{O}\end{array}$ & $\begin{array}{l}\text { (SUZUKI et al., } \\
\text { 2008) }\end{array}$ \\
\hline GID392 & $\mathrm{CC}(\mathrm{C}) \operatorname{CccC}(\mathrm{C}) \mathrm{C} 1 \mathrm{CCC} 2 \mathrm{C} 1(\mathrm{CCC} 3 \mathrm{C} 2 \mathrm{CCC} 4 \mathrm{C} 3(\mathrm{CCCC} 4) \mathrm{C}) \mathrm{C}$ & $\begin{array}{l}\text { (BOT; AGTEROF, } \\
\text { 2006) }\end{array}$ \\
\hline GID393 & $\begin{array}{c}\mathrm{CC}(\mathrm{C}) \mathrm{C}(\mathrm{C}) \mathrm{C}=\mathrm{CC}(\mathrm{C}) \mathrm{C} 1 \mathrm{CCC} 2 \mathrm{C} 1(\mathrm{CCC} 3 \mathrm{C} 2=\mathrm{CC}=\mathrm{C} 4 \mathrm{C} 3(\mathrm{CCC}(\mathrm{C} 4) \\
\mathrm{O}) \mathrm{C}) \mathrm{C}\end{array}$ & $\begin{array}{l}\text { (BOT; } \text { AGTEROF, } \\
\text { 2006) }\end{array}$ \\
\hline GID394 & $\begin{array}{c}\mathrm{CCCCCC}=\mathrm{CCC}=\mathrm{CCC}=\mathrm{CCC}=\mathrm{CCCCC}(=\mathrm{O}) \mathrm{OCC}(\mathrm{COC}(=\mathrm{O}) \mathrm{CCCC} \\
=\mathrm{CCC}=\mathrm{CCC}=\mathrm{CCC}=\mathrm{CCCCCC}) \mathrm{OC}(=\mathrm{O}) \mathrm{CCCC}=\mathrm{CCC}=\mathrm{CCC}=\mathrm{CCC} \\
=\mathrm{CCCCCC}\end{array}$ & $\begin{array}{l}\text { (HIGAKI et al., } \\
\text { 2003) }\end{array}$ \\
\hline GID395 & 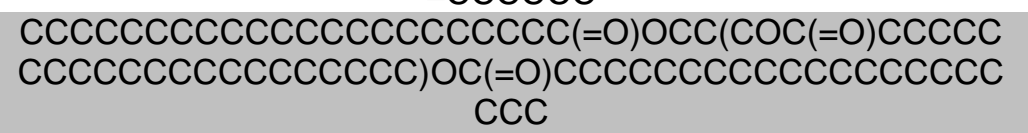 & $\begin{array}{l}\text { (HIGAKI et al., } \\
\text { 2003) }\end{array}$ \\
\hline GID396 & $\begin{array}{c}\text { óleo de colza totalmente hidrogenado com uma grande } \\
\text { quantidade de ácido beênico }\end{array}$ & $\begin{array}{l}\text { (HIGAKI et al., } \\
\text { 2003) }\end{array}$ \\
\hline
\end{tabular}




\begin{tabular}{|c|c|c|}
\hline GID397 & $\begin{array}{l}\text { óleo de colza totalmente hidrogenado com uma grande } \\
\text { quantidade de ácido esteárico }\end{array}$ & $\begin{array}{l}\text { (HIGAKI et al., } \\
\text { 2003) }\end{array}$ \\
\hline GID398 & gordura kokum & $\begin{array}{c}\text { (DANIEL; } \\
\text { RAJASEKHARAN, } \\
\text { 2003) }\end{array}$ \\
\hline GID399 & cera de abelha & $\begin{array}{c}\text { (SINGH; } \\
\text { AUZANNEAU; } \\
\text { ROGERS, 2017) }\end{array}$ \\
\hline GID400 & cera de candelila & $\begin{array}{l}\text { (BLAKE; CO; } \\
\text { MARANGONI, } \\
\text { 2014) }\end{array}$ \\
\hline GID401 & cera de carnauba & $\begin{array}{c}\text { (BLAKE; CO; } \\
\text { MARANGONI, } \\
\text { 2014) }\end{array}$ \\
\hline GID402 & rice bran wax & $\begin{array}{l}\text { (DASSANAYAKE } \\
\text { et al., 2009) }\end{array}$ \\
\hline GID403 & 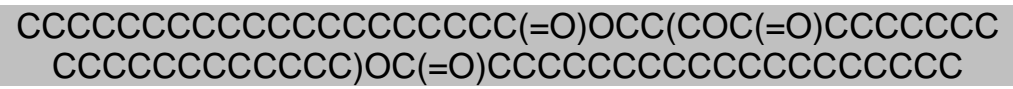 & $\begin{array}{l}\text { (HIGAKI et al., } \\
\text { 2003) }\end{array}$ \\
\hline GID404 & GID289 + GID288 (1:1) & (OJIJO et al., 2004) \\
\hline GID405 & GID087 + GID244 (4:1) & $\begin{array}{l}\text { (WANG; ROGERS, } \\
\text { 2015) }\end{array}$ \\
\hline GID406 & GID087 + GID244 (2:3) & $\begin{array}{l}\text { (WANG; ROGERS, } \\
\text { 2015) }\end{array}$ \\
\hline GID407 & GID087 + GID244 (1:4) & $\begin{array}{l}\text { (WANG; ROGERS, } \\
\text { 2015) }\end{array}$ \\
\hline GID408 & GID087 + GID291 (4:1) & $\begin{array}{l}\text { (WANG; ROGERS, } \\
\text { 2015) }\end{array}$ \\
\hline GID409 & GID087 + GID291 (2:3) & $\begin{array}{l}\text { (WANG; ROGERS, } \\
\text { 2015) }\end{array}$ \\
\hline GID410 & GID087 + GID291 (1:4) & $\begin{array}{l}\text { (WANG; ROGERS, } \\
\text { 2015) }\end{array}$ \\
\hline GID411 & GID243 + GID392 (2:3) & $\begin{array}{l}\text { (BOT; AGTEROF, } \\
\text { 2006) }\end{array}$ \\
\hline GID412 & GID243 + GID291 (2:3) & $\begin{array}{l}\text { (BOT; AGTEROF, } \\
\text { 2006) }\end{array}$ \\
\hline GID413 & GID243 + GID290 (2:3) & $\begin{array}{l}\text { (BOT; AGTEROF, } \\
\text { 2006) }\end{array}$ \\
\hline GID414 & GID243 + GID393 (2:3) & $\begin{array}{l}\text { (BOT; AGTEROF, } \\
\text { 2006) }\end{array}$ \\
\hline GID415 & GID243 + GID292 (2:3) & $\begin{array}{l}\text { (BOT; AGTEROF, } \\
\text { 2006) }\end{array}$ \\
\hline GID416 & GID243 + GID244 (2:3) & $\begin{array}{l}\text { (BOT; AGTEROF, } \\
\text { 2006) }\end{array}$ \\
\hline GID417 & GID087 + GID123 (7:3) & $\begin{array}{l}\text { (SCHAINK et al., } \\
\text { 2007) }\end{array}$ \\
\hline GID418 & GID087 + GID123 (1:1) & $\begin{array}{l}\text { (SCHAINK et al., } \\
\text { 2007) }\end{array}$ \\
\hline GID419 & GID087 + GID123 (3:7) & $\begin{array}{l}\text { (SCHAINK et al., } \\
\text { 2007) }\end{array}$ \\
\hline GID420 & 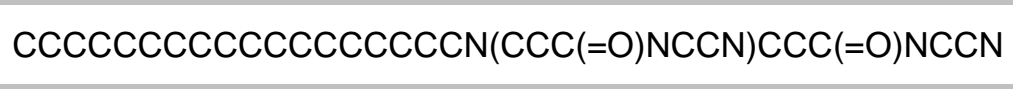 & $\begin{array}{l}\text { (DELBECQ et al., } \\
\text { 2020) }\end{array}$ \\
\hline GID421 & $\operatorname{cccccccc} \operatorname{coc} \operatorname{coc} c \operatorname{N}(\mathrm{CCC}(=0) \mathrm{NCCO}) \operatorname{CcC}(=0) \mathrm{NCCO}$ & $\begin{array}{l}\text { (DELBECQ et al., } \\
\text { 2020) }\end{array}$ \\
\hline GID422 & $\begin{array}{c}\operatorname{NCCNC}(=0) \operatorname{CCN}(\operatorname{CCC}(=0) \operatorname{NCCN}) \operatorname{CCNC}(=0) \operatorname{CCCCCCCCCCC} \\
\operatorname{CCCCCC}\end{array}$ & $\begin{array}{l}\text { (DELBECQ et al., } \\
\text { 2020) }\end{array}$ \\
\hline GID423 & $\begin{array}{c}\operatorname{NCCNC}(=0) \operatorname{CCN}(\operatorname{CCC}(=0) \operatorname{NCCN}) \operatorname{CCCCCCCCCCCCCCCCCC~} \\
\text { CCC }\end{array}$ & $\begin{array}{l}\text { (DELBECQ et al., } \\
\text { 2020) }\end{array}$ \\
\hline GID424 & $\begin{array}{c}\mathrm{NC}(=\mathrm{O}) \mathrm{NCCNC}(=\mathrm{O}) \operatorname{CCN}(\operatorname{CcC}(=\mathrm{O}) \operatorname{NCCNC}(\mathrm{N})=\mathrm{O}) \operatorname{CcCccccC} \\
\operatorname{CCCCCCCCCC~}\end{array}$ & $\begin{array}{c}\text { (DELBECQ et al., } \\
2020)\end{array}$ \\
\hline
\end{tabular}




\begin{tabular}{|c|c|c|}
\hline GID425 & $\begin{array}{c}\mathrm{CC}(\mathrm{NC}(=\mathrm{O}) \mathrm{CCN}(\mathrm{CCC}(=\mathrm{O}) \mathrm{NC}(\mathrm{C}) \mathrm{CO}) \mathrm{CCCCCCCCCCCCCCCC} \\
\mathrm{CC}) \mathrm{CO}\end{array}$ & $\begin{array}{l}\text { (DELBECQ et al., } \\
\text { 2020) }\end{array}$ \\
\hline GID426 & $\operatorname{cccccccccccccccccc}(=0) 0 \operatorname{Oco}$ & $\begin{array}{l}\text { (JIANG et al., } \\
\text { 2020) }\end{array}$ \\
\hline GID427 & $\operatorname{ccccccccccccсcсcсC~}(=0) O C$ & $\begin{array}{l}\text { (JIANG et al., } \\
\text { 2020) }\end{array}$ \\
\hline GID428 & $\begin{array}{c}\mathrm{CC} 1 \mathrm{CCC} 2(\mathrm{C}(\mathrm{C} 3 \mathrm{C}(\mathrm{O} 2) \mathrm{CC} 4 \mathrm{C} 3(\mathrm{CCC} 5 \mathrm{C} 4 \mathrm{CC}=\mathrm{C} 6 \mathrm{C} 5(\mathrm{CCC}(\mathrm{C} 6) \mathrm{O}) \mathrm{C} \\
) \mathrm{C}) \mathrm{C}) \mathrm{OC} 1\end{array}$ & $\begin{array}{l}\text { (JIANG et al., } \\
\text { 2020) }\end{array}$ \\
\hline
\end{tabular}


APÊNDICE B - Parâmetros de Solubilidade de Hansen para diferentes óleos.

\begin{tabular}{|c|c|c|c|c|c|c|c|}
\hline ID & ÓLEO & $\delta_{p}$ & $\delta_{h}$ & $\delta_{d}$ & $\delta_{t}$ & $\begin{array}{l}\text { Vol. Molec } \\
{\left[\mathrm{cm}^{3} \cdot \mathrm{mol}^{-1}\right]}\end{array}$ & REFERÊNCIA \\
\hline OID001 & óleo de brassica & 1,5 & 4,4 & 16,2 & 16,9 & & $\begin{array}{c}\text { (SOVTIĆ et al., } \\
2020)^{1}\end{array}$ \\
\hline OID002 & óleo de camélia & 3,2 & 4,5 & 16,4 & 17,2 & 952,8 & $\begin{array}{c}\text { (FIRESTONE, } \\
2006)^{2}\end{array}$ \\
\hline OID003 & óleo de canola & 3,4 & 4,1 & 16,2 & 17,1 & 952,2 & $\begin{array}{c}\text { (SAMYN et al., } \\
2012)^{2}\end{array}$ \\
\hline OID004 & óleo de canola & 2,1 & 2,6 & 16,5 & 16,8 & & $\begin{array}{l}\text { (DE LA PEÑA-GIL; } \\
\text { TORO-VAZQUEZ; } \\
\text { ROGERS, 2016)1 }\end{array}$ \\
\hline OID005 & óleo de castor & 7,0 & 7,6 & 16,4 & 19,4 & 961,6 & $\begin{array}{c}(\text { FIRESTONE, } \\
2006)^{2}\end{array}$ \\
\hline OID006 & óleo de castor & 2,9 & 9,2 & 15,6 & 18,3 & & $\begin{array}{c}\text { (SOVTIĆ et al., } \\
2020)^{1}\end{array}$ \\
\hline OID007 & óleo de castor & 1,2 & 9,1 & 15,8 & 18,3 & & $\begin{array}{c}\text { (SOVTIĆ et al., } \\
2020)^{1}\end{array}$ \\
\hline OID008 & óleo de castor & 6,0 & 10,5 & 13,6 & 18,2 & & $\begin{array}{c}\text { (SOVTIĆ et al., } \\
2020)^{1}\end{array}$ \\
\hline OID009 & manteiga de cacau & 3,0 & 5,2 & 16,4 & 17,5 & 952,8 & $\begin{array}{l}\text { (HIGAKI et al., } \\
2003)^{2}\end{array}$ \\
\hline OID010 & óleo de coco & 3,3 & 4,6 & 16,4 & 17,4 & 788,7 & $\begin{array}{c}\text { (FIRESTONE, } \\
2006)^{2}\end{array}$ \\
\hline OID011 & óleo de coco & 4,6 & 7,0 & 15,0 & 17,1 & & $\begin{array}{c}\text { (BATISTA; } \\
\text { GUIRARDELLO; } \\
\text { KRÄHENBÜHL, } \\
\text { 2015) }\end{array}$ \\
\hline OID012 & óleo de coco & 2,8 & 6,2 & 16,7 & 18,0 & & $\begin{array}{c}\text { (SOVTIĆ et al., } \\
2020)^{1}\end{array}$ \\
\hline OID013 & óleo de coco & 4,6 & 6,9 & 14,9 & 17,1 & & $\begin{array}{c}\text { (SOVTIĆ et al., } \\
2020)^{1}\end{array}$ \\
\hline OID014 & óleo de coco & 2,5 & 2,8 & 16,2 & 16,6 & & $\begin{array}{c}\text { (SOVTIĆ et al., } \\
2020)^{1}\end{array}$ \\
\hline OID015 & óleo de milho & 3,8 & 3,4 & 16,1 & 16,9 & 941,1 & $\begin{array}{c}\text { (FIRESTONE, } \\
2006)^{2}\end{array}$ \\
\hline OID016 & $\begin{array}{l}\text { óleo de semente de } \\
\text { algodão }\end{array}$ & 3,6 & 3,5 & 16,2 & 17,0 & 926,1 & $\begin{array}{c}\text { (FIRESTONE, } \\
2006)^{2}\end{array}$ \\
\hline OID017 & $\begin{array}{l}\text { óleo de semente de } \\
\text { algodão }\end{array}$ & 4,0 & 2,4 & 16,1 & 16,7 & 939,3 & $\begin{array}{c}\text { (FIRESTONE, } \\
\text { 2006) })^{2}\end{array}$ \\
\hline OID018 & óleo de peixe & 1,5 & 3,6 & 16,5 & 17,0 & & $\begin{array}{l}\text { (DE LA PEÑA-GIL; } \\
\text { TORO-VAZQUEZ; } \\
\text { ROGERS, 2016)1 }\end{array}$ \\
\hline OID019 & $\begin{array}{c}\text { óleo de semente de } \\
\text { uva }\end{array}$ & 4,0 & 3,9 & 16,1 & 17,1 & 861,6 & $\begin{array}{c}\text { (FIRESTONE, } \\
2006)^{2}\end{array}$ \\
\hline OID020 & óleo de amendoim & 3,4 & 3,7 & 16,2 & 17,0 & 930,7 & $\begin{array}{c}\text { (FIRESTONE, } \\
2006)^{2}\end{array}$ \\
\hline OID021 & óleo de avelã & 3,2 & 4,3 & 16,3 & 17,2 & 956,8 & $\begin{array}{c}\text { (FIRESTONE, } \\
2006)^{2}\end{array}$ \\
\hline OID022 & óleo de avelã & 3,8 & 3,2 & 16,1 & 16,8 & 957,1 & $\begin{array}{c}\text { (FIRESTONE, } \\
2006)^{2}\end{array}$ \\
\hline OID023 & óleo de jatropha & 3,1 & 5,9 & 16,5 & 17,8 & & $\begin{array}{l}\text { (FARFAN- } \\
\text { CABRERA et al., } \\
\text { 2018) }\end{array}$ \\
\hline OID024 & óleo de jatropha & 3,1 & 0,6 & 16,6 & 16,9 & & $\begin{array}{c}\text { (FARFAN- } \\
\text { CABRERA; } \\
\text { PÉREZ- } \\
\text { GONZÁLEZ; } \\
\text { GALLARDO- } \\
\end{array}$ \\
\hline
\end{tabular}




\begin{tabular}{|c|c|c|c|c|c|c|c|}
\hline & & & & & & & $\begin{array}{c}\text { HERNÁNDEZ, } \\
2018)^{1}\end{array}$ \\
\hline OID025 & óleo de jojoba & 1,3 & 2,0 & 16,8 & 17,0 & & $\begin{array}{c}\text { (SOVTIĆ et al., } \\
2020)^{1}\end{array}$ \\
\hline OID026 & óleo de lavanda & 3,7 & 6,4 & 16,8 & 18,4 & 180,2 & $\begin{array}{c}\text { (FIRESTONE, } \\
2006)^{2}\end{array}$ \\
\hline OID027 & óleo de linhaça & 4,4 & 3,3 & 16,0 & 16,9 & 950,7 & $\begin{array}{c}\text { (FIRESTONE, } \\
2006)^{2}\end{array}$ \\
\hline OID028 & óleo de linhaça & 1,5 & 4,7 & 15,7 & 16,5 & & $\begin{array}{c}\text { (SOVTIĆ et al., } \\
2020)^{1}\end{array}$ \\
\hline OID029 & óleo de linhaça & 3,5 & 3,7 & 13,9 & 14,8 & & $\begin{array}{c}\text { (SOVTIĆ et al., } \\
2020)^{1}\end{array}$ \\
\hline OID030 & óleo de linhaça & 2,1 & 2,9 & 16,3 & 16,7 & & $\begin{array}{c}\text { (SOVTIĆ et al., } \\
2020)^{1}\end{array}$ \\
\hline OID031 & óleo de mostarda & 5,3 & 2,2 & 15,7 & 16,7 & 928,7 & $\begin{array}{c}\text { (FIRESTONE, } \\
2006)^{2}\end{array}$ \\
\hline OID032 & óleo de oliva & 3,7 & 3,4 & 16,1 & 16,9 & 922,1 & $\begin{array}{c}\text { (HIGAKI et al., } \\
2003)^{2}\end{array}$ \\
\hline OID033 & óleo de oliva & 3,2 & 4,5 & 16,3 & 17,2 & 961,2 & $\begin{array}{c}(\text { FIRESTONE, } \\
2006)^{2}\end{array}$ \\
\hline OID034 & óleo de oliva & 1,5 & 4,7 & 16,2 & 16,9 & & $\begin{array}{c}\text { (SOVTIĆ et al., } \\
2020)^{1}\end{array}$ \\
\hline OID035 & óleo de oliva & 1,2 & 5,4 & 15,9 & 16,8 & & $\begin{array}{c}\text { (SOVTIĆ et al., } \\
2020)^{1}\end{array}$ \\
\hline OID036 & óleo de palma & 3,3 & 4,9 & 16,3 & 17,4 & 932,3 & $\begin{array}{l}\text { (SAMYN et al., } \\
\text { 2012) }\end{array}$ \\
\hline OID037 & óleo de palma & 3,3 & 4,1 & 17,5 & 18,3 & & $\begin{array}{c}\text { (BATISTA; } \\
\text { GUIRARDELLO; } \\
\text { KRÄHENBÜHL, } \\
\text { 2015) }{ }^{1}\end{array}$ \\
\hline OID038 & óleo de palma & 3,5 & 3,7 & 17,7 & 18,4 & & $\begin{array}{c}\text { (SOVTIĆ et al., } \\
2020)^{1}\end{array}$ \\
\hline OID039 & óleo de palma & 3,3 & 4,1 & 17,5 & 18,3 & & $\begin{array}{c}\text { (SOVTIĆ et al., } \\
2020)^{1}\end{array}$ \\
\hline OID040 & $\begin{array}{l}\text { super oleína de } \\
\text { palma }\end{array}$ & 3,5 & 3,7 & 16,2 & 17,0 & 936,0 & $\begin{array}{c}\text { (HIGAKI et al., } \\
2003)^{2}\end{array}$ \\
\hline OID041 & óleo de amendoim & 3,4 & 3,7 & 16,2 & 17,0 & 930,7 & $\begin{array}{c}\text { (SOVTIĆ et al., } \\
2020)^{2}\end{array}$ \\
\hline OID042 & óleo de pinho & 3,0 & 9,8 & 15,6 & 18,7 & & $\begin{array}{c}\text { (SOVTIĆ et al., } \\
2020)^{1}\end{array}$ \\
\hline OID043 & $\begin{array}{l}\text { óleo de semente de } \\
\text { romã }\end{array}$ & 5,4 & 2,5 & 15,7 & 16,8 & 924,9 & $\begin{array}{c}\text { (FIRESTONE, } \\
2006)^{2}\end{array}$ \\
\hline OID044 & $\begin{array}{c}\text { óleo de semente de } \\
\text { romã }\end{array}$ & 3,7 & 3,6 & 16,1 & 17,0 & 940,3 & $\begin{array}{c}\text { (FIRESTONE, } \\
2006)^{2}\end{array}$ \\
\hline OID045 & óleo de colza & 5,2 & 1,6 & 15,8 & 16,7 & 852,9 & $\begin{array}{c}\text { (FIRESTONE, } \\
2006)^{2}\end{array}$ \\
\hline OID046 & óleo de colza & 5,2 & 1,6 & 15,8 & 16,7 & 852,9 & $\begin{array}{c}\text { (SOVTIĆ et al., } \\
2020)^{2}\end{array}$ \\
\hline OID047 & óleo de colza & 2,1 & 2,5 & 16,5 & 16,8 & & $\begin{array}{c}\text { (SOVTIĆ et al., } \\
2020)^{1}\end{array}$ \\
\hline OID048 & óleo de colza & 4,7 & 4,2 & 15,8 & 17,0 & & $\begin{array}{c}\text { (SOVTIĆ et al., } \\
2020)^{1}\end{array}$ \\
\hline OID049 & óleo de cártamo & 4,2 & 2,3 & 16,1 & 16,8 & 886,2 & $\begin{array}{c}\text { (FIRESTONE, } \\
2006)^{2}\end{array}$ \\
\hline OID050 & óleo de cártamo & 4,0 & 2,8 & 16,1 & 16,8 & 944,3 & $\begin{array}{c}\text { (FIRESTONE, } \\
2006)^{2}\end{array}$ \\
\hline OID051 & sal gordura oleína & 3,4 & 4,5 & 16,2 & 17,2 & 968,2 & $\begin{array}{c}\text { (HIGAKI et al., } \\
2003)^{2}\end{array}$ \\
\hline OID052 & óleo de gergelim & 3,6 & 3,6 & 16,2 & 17,0 & 934,3 & $\begin{array}{c}\text { (FIRESTONE, } \\
2006)^{2}\end{array}$ \\
\hline
\end{tabular}




\begin{tabular}{|c|c|c|c|c|c|c|c|}
\hline OID053 & óleo de soja & 4,1 & 2,5 & 16,0 & 16,7 & 946,7 & FCF-USP 2 \\
\hline OID054 & óleo de soja & 2,1 & 2,6 & 16,5 & 16,9 & & $\begin{array}{c}\text { (SOVTIĆ et al., } \\
2020)^{1}\end{array}$ \\
\hline OID055 & óleo de soja & 1,5 & 4,6 & 15,4 & 16,1 & & $\begin{array}{c}\text { (SOVTIC et al., } \\
2020)^{1}\end{array}$ \\
\hline OID056 & óleo de soja & 2,0 & 2,7 & 16,5 & 16,8 & & $\begin{array}{c}\text { (SOVTIĆ et al., } \\
2020)^{1}\end{array}$ \\
\hline OID057 & óleo de girassol & 3,9 & 3,1 & 16,1 & 16,8 & 941,4 & $\begin{array}{c}\text { (SAMYN et al., } \\
2012)^{2}\end{array}$ \\
\hline OID058 & óleo de girassol & 4,1 & 1,9 & 16,0 & 16,7 & 947,9 & $\begin{array}{c}\text { (DANIEL; } \\
\text { RAJASEKHARAN, } \\
2003)^{2}\end{array}$ \\
\hline OID059 & óleo de girassol & 1,5 & 4,7 & 16,0 & 16,7 & & $\begin{array}{c}\text { (STORTZ; } \\
\text { MARANGONI, } \\
2014)^{1}\end{array}$ \\
\hline OID060 & óleo de girassol & 2,0 & 2,7 & 16,5 & 16,9 & & $\begin{array}{c}\text { (SOVTIĆ et al., } \\
2020)^{1}\end{array}$ \\
\hline OID061 & óleo de girassol & 2,0 & 2,7 & 16,5 & 16,9 & & $\begin{array}{c}\text { (SOVTIĆ et al., } \\
2020)^{1}\end{array}$ \\
\hline OID062 & óleo de girassol & 1,5 & 4,7 & 16,6 & 17,3 & & $\begin{array}{c}\text { (SOVTIĆ et al., } \\
2020)^{1}\end{array}$ \\
\hline OID063 & $\begin{array}{c}\text { óleo de amêndoa } \\
\text { doce }\end{array}$ & 3,3 & 4,1 & 16,3 & 17,1 & 951,5 & $\begin{array}{c}\text { (FIRESTONE, } \\
2006)^{2}\end{array}$ \\
\hline OID064 & $\begin{array}{c}\text { óleo de amêndoa } \\
\text { doce }\end{array}$ & 3,9 & 2,9 & 16,0 & 16,8 & 957,2 & $\begin{array}{c}\text { (FIRESTONE, } \\
2006)^{2}\end{array}$ \\
\hline OID065 & óleo trioleína & 3,8 & 3,3 & 16,0 & 16,8 & 967,3 & $($ ROGERS, 2018)2 \\
\hline OID066 & óleo de fritura usado & 3,8 & 6,9 & 15,4 & 17,2 & & $\begin{array}{c}\text { (BATISTA; } \\
\text { GUIRARDELLO; } \\
\text { KRÄHENBÜHL; } \\
2015)^{1}\end{array}$ \\
\hline OID067 & óleo vegetal & 1,5 & 4,7 & 16,0 & 16,7 & 906,1 & $\begin{array}{c}\text { (GRAVELLE et al., } \\
2016)^{2}\end{array}$ \\
\hline
\end{tabular}

1 - Referência para valores dos parâmetros de Hansen; ${ }^{2}$ - Referência para composição do óleo. 
APÊNDICE C - Lista de experimentos de gelificação.

\begin{tabular}{|c|c|c|c|}
\hline ESTRUTURANTE & ÓLEO & RESULTADO & REFERÊNCIA \\
\hline GID001 & óleo de linhaça & $G$ & (SUZUKI et al., 2008) \\
\hline GID001 & trioleína & $\mathrm{G}$ & (SUZUKI et al., 2008) \\
\hline GID002 & óleo de linhaça & G & (SUZUKI et al., 2008) \\
\hline GID002 & trioleína & $G$ & (SUZUKI et al., 2008) \\
\hline GID003 & trioleína & $G$ & (ROGERS, 2018) \\
\hline GID003 & óleo de linhaça & $\mathrm{G}$ & (SUZUKI et al., 2008) \\
\hline GID004 & trioleína & $G$ & (ROGERS, 2018) \\
\hline GID004 & óleo de linhaça & G & (SUZUKI et al., 2008) \\
\hline GID010 & óleo de linhaça & G & (ROGERS, 2018) \\
\hline GID011 & óleo de linhaça & $G$ & (ROGERS, 2018) \\
\hline GID012 & óleo de linhaça & G & (ROGERS, 2018) \\
\hline GID013 & óleo de oliva & $G$ & (YU et al., 2016) \\
\hline GID013 & óleo de soja & G & (YU et al., 2016) \\
\hline GID013 & óleo de castor & G & (YU et al., 2016) \\
\hline GID014 & óleo de oliva & $G$ & (YU et al., 2016) \\
\hline GID014 & óleo de soja & $G$ & (YU et al., 2016) \\
\hline GID014 & óleo de castor & G & (YU et al., 2016) \\
\hline GID015 & óleo de oliva & G & (ROGERS, 2018) \\
\hline GID015 & óleo de soja & G & (ROGERS, 2018) \\
\hline GID015 & óleo de castor & $G$ & (ROGERS, 2018) \\
\hline GID016 & óleo vegetal & G & (ROGERS, 2018) \\
\hline GID017 & óleo vegetal & G & (ROGERS, 2018) \\
\hline GID018 & óleo vegetal & $G$ & (ROGERS, 2018) \\
\hline GID019 & óleo de coco & $\mathrm{G}$ & $\begin{array}{c}\text { (SURYA PRAKASH RAO et al., } \\
\text { 2014) }\end{array}$ \\
\hline GID019 & óleo de mostarda & $\mathrm{G}$ & $\begin{array}{l}\text { (SURYA PRAKASH RAO et al., } \\
2014 \text { ) }\end{array}$ \\
\hline GID019 & óleo de soja & $\mathrm{G}$ & $\begin{array}{c}\text { (SURYA PRAKASH RAO et al., } \\
\text { 2014) }\end{array}$ \\
\hline GID020 & óleo vegetal & G & (ROGERS, 2018) \\
\hline GID020 & óleo de soja & G & (ROGERS, 2018) \\
\hline GID021 & óleo vegetal & G & (HANABUSA et al., 1997a) \\
\hline GID021 & óleo de soja & G & (HANABUSA et al., 1997a) \\
\hline GID022 & óleo vegetal & $G$ & (HANABUSA et al., 1997a) \\
\hline GID022 & óleo de soja & G & (HANABUSA et al., 1997a) \\
\hline GID023 & óleo de colza & G & (FENG et al., 2014) \\
\hline GID023 & óleo de amendoim & G & (FENG et al., 2014) \\
\hline GID023 & óleo de soja & G & (FENG et al., 2014) \\
\hline GID023 & óleo de camélia & $G$ & (FENG et al., 2014) \\
\hline GID024 & óleo de colza & $G$ & (FENG et al., 2014) \\
\hline GID024 & óleo de amendoim & G & (FENG et al., 2014) \\
\hline GID024 & óleo de soja & G & (FENG et al., 2014) \\
\hline GID024 & óleo de camélia & G & (FENG et al., 2014) \\
\hline GID025 & óleo de soja & G & (ROGERS, 2018) \\
\hline GID025 & óleo de cártamo & $G$ & (MOTULSKY et al., 2005) \\
\hline
\end{tabular}




\begin{tabular}{|c|c|c|c|}
\hline GID026 & óleo de soja & $G$ & (ROGERS, 2018) \\
\hline GID026 & óleo de cártamo & $\mathrm{G}$ & (MOTULSKY et al., 2005) \\
\hline GID027 & óleo de soja & $G$ & (ROGERS, 2018) \\
\hline GID027 & óleo de cártamo & $\mathrm{G}$ & (MOTULSKY et al., 2005) \\
\hline GID028 & óleo de soja & $G$ & (ROGERS, 2018) \\
\hline GID028 & óleo de cártamo & $G$ & (MOTULSKY et al., 2005) \\
\hline GID029 & óleo de soja & $G$ & (ROGERS, 2018) \\
\hline GID029 & óleo de cártamo & $G$ & (MOTULSKY et al., 2005) \\
\hline GID030 & óleo de soja & $G$ & (ROGERS, 2018) \\
\hline GID030 & óleo de cártamo & $G$ & (MOTULSKY et al., 2005) \\
\hline GID031 & óleo de oliva & $G$ & (ROGERS, 2018) \\
\hline GID031 & óleo de milho & $G$ & (ROGERS, 2018) \\
\hline GID031 & óleo de girassol & $G$ & (ROGERS, 2018) \\
\hline GID031 & óleo de soja & $G$ & (ROGERS, 2018) \\
\hline GID032 & óleo vegetal & $G$ & (HANABUSA et al., 1999a) \\
\hline GID032 & óleo de soja & $G$ & (HANABUSA et al., 1999a) \\
\hline GID033 & óleo de soja & $G$ & (HANABUSA et al., 1999b) \\
\hline GID034 & óleo vegetal & $G$ & (HANABUSA et al., 1997a) \\
\hline GID034 & óleo de soja & $G$ & (HANABUSA et al., 1999b) \\
\hline GID035 & óleo de colza & $G$ & (ROGERS, 2018) \\
\hline GID036 & óleo vegetal & $\mathrm{G}$ & (ROGERS, 2018) \\
\hline GID037 & óleo vegetal & $G$ & (HANABUSA et al., 1997b) \\
\hline GID038 & óleo de canola & $G$ & (CO; MARANGONI, 2012) \\
\hline GID038 & óleo de girassol & $G$ & (JIANG et al., 2020) \\
\hline GID039 & óleo de girassol & $G$ & (ROGERS, 2018) \\
\hline GID044 & óleo de cártamo & $G$ & (BASTIAT; LEROUX, 2009) \\
\hline GID045 & óleo de cártamo & $G$ & (BASTIAT; LEROUX, 2009) \\
\hline GID046 & óleo de cártamo & $G$ & (BASTIAT; LEROUX, 2009) \\
\hline GID047 & óleo de cártamo & G & (BASTIAT; LEROUX, 2009) \\
\hline GID048 & óleo de cártamo & $G$ & (BASTIAT; LEROUX, 2009) \\
\hline GID049 & óleo de cártamo & $G$ & (BASTIAT; LEROUX, 2009) \\
\hline GID050 & óleo de cártamo & $G$ & (BASTIAT; LEROUX, 2009) \\
\hline GID051 & óleo de cártamo & $G$ & (BASTIAT; LEROUX, 2009) \\
\hline GID052 & óleo de cártamo & $\mathrm{G}$ & (BASTIAT; LEROUX, 2009) \\
\hline GID053 & óleo de cártamo & G & (BASTIAT; LEROUX, 2009) \\
\hline GID056 & óleo de castor & $\mathrm{G}$ & (SÁNCHEZ et al., 2008) \\
\hline GID056 & óleo de oliva & $G$ & $\begin{array}{c}\text { (DASSANAYAKE; KODALI; } \\
\text { UENO, 2011) }\end{array}$ \\
\hline GID056 & óleo de gergelim & $G$ & $\begin{array}{c}\text { (DASSANAYAKE; KODALI; } \\
\text { UENO, 2011) }\end{array}$ \\
\hline GID056 & óleo de canola & $G$ & $\begin{array}{c}\text { (DASSANAYAKE; KODALI; } \\
\text { UENO, 2011) }\end{array}$ \\
\hline GID056 & óleo de girassol & $S$ & (JIANG et al., 2020) \\
\hline GID056 & óleo de amêndoa doce & G & (ALMEIDA et al., 2008) \\
\hline GID077 & óleo vegetal & $G$ & (HANABUSA et al., 1997a) \\
\hline GID077 & óleo de soja & $G$ & (HANABUSA et al., 1997a) \\
\hline GID078 & óleo vegetal & $G$ & (HANABUSA et al., 1997a) \\
\hline
\end{tabular}




\begin{tabular}{|c|c|c|c|}
\hline GID078 & óleo de soja & $G$ & (HANABUSA et al., 1997a) \\
\hline GID079 & óleo vegetal & I & (HANABUSA et al., 1997b) \\
\hline GID080 & óleo vegetal & G & (HANABUSA et al., 1997b) \\
\hline GID081 & óleo vegetal & 1 & (HANABUSA et al., 1997b) \\
\hline GID087 & óleo de colza & G & $\begin{array}{l}\text { (GANDOLFO; BOT; FLÖTER, } \\
\text { 2004) }\end{array}$ \\
\hline GID087 & óleo de soja & $G$ & $\begin{array}{c}\text { (GANDOLFO; BOT; FLÖTER, } \\
\text { 2004) }\end{array}$ \\
\hline GID087 & óleo de girassol & $\mathrm{G}$ & $\begin{array}{c}\text { (DASSANAYAKE; KODALI; } \\
\text { UENO, 2011) }\end{array}$ \\
\hline GID087 & óleo de canola & G & $\begin{array}{l}\text { (SINGH; AUZANNEAU; } \\
\text { ROGERS, 2017) }\end{array}$ \\
\hline GID123 & óleo de colza & $\mathrm{G}$ & $\begin{array}{l}\text { (DASSANAYAKE; KODALI; } \\
\text { UENO, 2011) }\end{array}$ \\
\hline GID123 & óleo de oliva & G & $\begin{array}{c}\text { (DASSANAYAKE; KODALI; } \\
\text { UENO, 2011) }\end{array}$ \\
\hline GID123 & óleo de girassol & $\mathrm{G}$ & $\begin{array}{l}\text { (DASSANAYAKE; KODALI; } \\
\text { UENO, 2011) }\end{array}$ \\
\hline GID123 & óleo de soja & $\mathrm{G}$ & $\begin{array}{l}\text { (DASSANAYAKE; KODALI; } \\
\text { UENO, 2011) }\end{array}$ \\
\hline GID135 & óleo de oliva & G & (LI et al., 2016) \\
\hline GID135 & óleo de milho & $G$ & (LI et al., 2016) \\
\hline GID135 & óleo de girassol & G & (LI et al., 2016) \\
\hline GID135 & óleo de soja & $G$ & (LI et al., 2016) \\
\hline GID218 & óleo de canola & $G$ & $\begin{array}{c}\text { (BLAKE; CO; MARANGONI, } \\
2014 \text { ) }\end{array}$ \\
\hline GID218 & óleo de oliva & $\mathrm{G}$ & $\begin{array}{c}\text { (SINGH; AUZANNEAU; } \\
\text { ROGERS, 2017) }\end{array}$ \\
\hline GID218 & óleo de soja & $G$ & $\begin{array}{l}\text { (SINGH; AUZANNEAU; } \\
\text { ROGERS, 2017) }\end{array}$ \\
\hline GID218 & óleo de avelã & $\mathrm{G}$ & $\begin{array}{l}\text { (SINGH; AUZANNEAU; } \\
\text { ROGERS, 2017) }\end{array}$ \\
\hline GID218 & óleo de colza & $G$ & (KUPIEC et al., 2020) \\
\hline GID221 & óleo de linhaça & $S$ & $\begin{array}{l}\text { (SUZUKI; UEMATSU; } \\
\text { HANABUSA, 2016) }\end{array}$ \\
\hline GID221 & óleo de castor & I & $\begin{array}{l}\text { (SUZUKI; UEMATSU; } \\
\text { HANABUSA, 2016) }\end{array}$ \\
\hline GID222 & óleo de linhaça & $G$ & $\begin{array}{l}\text { (SUZUKI; UEMATSU; } \\
\text { HANABUSA, 2016) }\end{array}$ \\
\hline GID222 & óleo de castor & $G$ & $\begin{array}{l}\text { (SUZUKI; UEMATSU; } \\
\text { HANABUSA, 2016) }\end{array}$ \\
\hline GID223 & óleo de linhaça & $G$ & $\begin{array}{l}\text { (SUZUKI; UEMATSU; } \\
\text { HANABUSA, 2016) }\end{array}$ \\
\hline GID223 & óleo de castor & $S$ & $\begin{array}{l}\text { (SUZUKI; UEMATSU; } \\
\text { HANABUSA, 2016) }\end{array}$ \\
\hline GID224 & óleo de linhaça & $G$ & $\begin{array}{l}\text { (SUZUKI; UEMATSU; } \\
\text { HANABUSA, 2016) }\end{array}$ \\
\hline GID224 & óleo de castor & $\mathrm{G}$ & $\begin{array}{l}\text { (SUZUKI; UEMATSU; } \\
\text { HANABUSA, 2016) }\end{array}$ \\
\hline GID225 & óleo de linhaça & $G$ & $\begin{array}{l}\text { (SUZUKI; UEMATSU; } \\
\text { HANABUSA, 2016) }\end{array}$ \\
\hline GID225 & óleo de castor & 1 & $\begin{array}{l}\text { (SUZUKI; UEMATSU; } \\
\text { HANABUSA, 2016) }\end{array}$ \\
\hline GID226 & óleo de linhaça & 1 & $\begin{array}{l}\text { (SUZUKI; UEMATSU; } \\
\text { HANABUSA, 2016) }\end{array}$ \\
\hline GID226 & óleo de castor & 1 & $\begin{array}{l}\text { (SUZUKI; UEMATSU; } \\
\text { HANABUSA, 2016) }\end{array}$ \\
\hline
\end{tabular}




\begin{tabular}{|c|c|c|c|}
\hline GID227 & óleo de linhaça & G & $\begin{array}{l}\text { (SUZUKI; UEMATSU; } \\
\text { HANABUSA, 2016) }\end{array}$ \\
\hline GID227 & óleo de castor & S & $\begin{array}{l}\text { (SUZUKI; UEMATSU; } \\
\text { HANABUSA, 2016) }\end{array}$ \\
\hline GID241 & óleo de oliva & G & (YU et al., 2016) \\
\hline GID241 & óleo de soja & G & (YU et al., 2016) \\
\hline GID241 & óleo de castor & G & (YU et al., 2016) \\
\hline GID242 & óleo de oliva & G & (YU et al., 2017) \\
\hline GID242 & óleo de soja & G & (YU et al., 2017) \\
\hline GID242 & óleo de castor & G & (YU et al., 2017) \\
\hline GID243 & óleo de girassol & G & $\begin{array}{c}\text { (DASSANAYAKE; KODALI; } \\
\text { UENO, 2011) }\end{array}$ \\
\hline GID243 & óleo de canola & G & $\begin{array}{l}\text { (SINGH; AUZANNEAU; } \\
\text { ROGERS, 2017) }\end{array}$ \\
\hline GID244 & óleo de canola & G & $\begin{array}{c}\text { (SINGH; AUZANNEAU; } \\
\text { ROGERS, 2017) }\end{array}$ \\
\hline GID284 & óleo de cártamo & G & $\begin{array}{l}\text { (DASSANAYAKE; KODALI; } \\
\text { UENO, 2011) }\end{array}$ \\
\hline GID285 & óleo de girassol & G & $\begin{array}{l}\text { (DANIEL; RAJASEKHARAN, } \\
\text { 2003) }\end{array}$ \\
\hline GID287 & óleo vegetal & G & (CO; MARANGONI, 2012) \\
\hline GID287 & óleo de canola & G & (CO; MARANGONI, 2012) \\
\hline GID287 & óleo de castor & G & (CO; MARANGONI, 2012) \\
\hline GID287 & óleo de colza & G & (PERNETTI et al., 2007b) \\
\hline GID287 & óleo de gergelim & G & (PERNETTI et al., 2007b) \\
\hline GID288 & óleo de oliva & G & (PERNETTI et al., 2007b) \\
\hline GID289 & óleo de oliva & G & (PERNETTI et al., 2007b) \\
\hline GID293 & óleo de canola & G & $\begin{array}{l}\text { (ROGERS; WRIGHT; } \\
\text { MARANGONI, 2009) }\end{array}$ \\
\hline GID296 & óleo de colza & G & $\begin{array}{l}\text { (GANDOLFO; BOT; FLÖTER, } \\
\text { 2004) }\end{array}$ \\
\hline GID296 & óleo de soja & $\mathrm{G}$ & $\begin{array}{c}\text { (GANDOLFO; BOT; FLÖTER, } \\
\text { 2004) }\end{array}$ \\
\hline GID296 & óleo de girassol & G & $\begin{array}{c}\text { (DASSANAYAKE; KODALI; } \\
\text { UENO, 2011) }\end{array}$ \\
\hline GID297 & óleo de girassol & G & (PERNETTI et al., 2007a) \\
\hline GID298 & óleo de girassol & G & $\begin{array}{c}\text { (DASSANAYAKE; KODALI; } \\
\text { UENO, 2011) }\end{array}$ \\
\hline GID299 & óleo de girassol & G & $\begin{array}{c}\text { (DASSANAYAKE; KODALI; } \\
\text { UENO, 2011) }\end{array}$ \\
\hline GID300 & óleo de girassol & $\mathrm{G}$ & $\begin{array}{c}\text { (DASSANAYAKE; KODALI; } \\
\text { UENO, 2011) }\end{array}$ \\
\hline GID301 & óleo de girassol & $\mathrm{G}$ & $\begin{array}{c}\text { (DASSANAYAKE; KODALI; } \\
\text { UENO, 2011) }\end{array}$ \\
\hline GID306 & óleo de colza & G & $\begin{array}{l}\text { (GANDOLFO; BOT; FLÖTER, } \\
2004 \text { ) }\end{array}$ \\
\hline GID306 & óleo de soja & G & $\begin{array}{l}\text { (GANDOLFO; BOT; FLÖTER, } \\
\text { 2004) }\end{array}$ \\
\hline GID306 & óleo de girassol & G & $\begin{array}{c}\text { (DASSANAYAKE; KODALI; } \\
\text { UENO, 2011) }\end{array}$ \\
\hline GID307 & óleo de colza & G & $\begin{array}{l}\text { (GANDOLFO; BOT; FLÖTER, } \\
\text { 2004) }\end{array}$ \\
\hline GID307 & óleo de soja & G & $\begin{array}{l}\text { (GANDOLFO; BOT; FLÖTER, } \\
\text { 2004) }\end{array}$ \\
\hline
\end{tabular}




\begin{tabular}{|c|c|c|c|}
\hline GID307 & óleo de girassol & G & $\begin{array}{c}\text { (DASSANAYAKE; KODALI; } \\
\text { UENO, 2011) }\end{array}$ \\
\hline GID308 & óleo de colza & $\mathrm{G}$ & $\begin{array}{c}\text { (DASSANAYAKE; KODALI; } \\
\text { UENO, 2011) }\end{array}$ \\
\hline GID308 & óleo de oliva & G & $\begin{array}{c}\text { (DASSANAYAKE; KODALI; } \\
\text { UENO, 2011) }\end{array}$ \\
\hline GID308 & óleo de girassol & $\mathrm{G}$ & $\begin{array}{c}\text { (DASSANAYAKE; KODALI; } \\
\text { UENO, 2011) }\end{array}$ \\
\hline GID308 & óleo de soja & G & $\begin{array}{c}\text { (DASSANAYAKE; KODALI; } \\
\text { UENO, 2011) }\end{array}$ \\
\hline GID309 & óleo de colza & G & $\begin{array}{c}\text { (DASSANAYAKE; KODALI; } \\
\text { UENO, 2011) }\end{array}$ \\
\hline GID309 & óleo de oliva & $\mathrm{G}$ & $\begin{array}{c}\text { (DASSANAYAKE; KODALI; } \\
\text { UENO, 2011) }\end{array}$ \\
\hline GID309 & óleo de girassol & $\mathrm{G}$ & $\begin{array}{c}\text { (DASSANAYAKE; KODALI; } \\
\text { UENO, 2011) }\end{array}$ \\
\hline GID309 & óleo de soja & $\mathrm{G}$ & $\begin{array}{c}\text { (DASSANAYAKE; KODALI; } \\
\text { UENO, 2011) }\end{array}$ \\
\hline GID310 & óleo de colza & $\mathrm{G}$ & $\begin{array}{c}\text { (DASSANAYAKE; KODALI; } \\
\text { UENO, 2011) }\end{array}$ \\
\hline GID310 & óleo de oliva & $\mathrm{G}$ & $\begin{array}{c}\text { (DASSANAYAKE; KODALI; } \\
\text { UENO, 2011) }\end{array}$ \\
\hline GID310 & óleo de girassol & $G$ & $\begin{array}{c}\text { (DASSANAYAKE; KODALI; } \\
\text { UENO, 2011) }\end{array}$ \\
\hline GID310 & óleo de soja & $\mathrm{G}$ & $\begin{array}{c}\text { (DASSANAYAKE; KODALI; } \\
\text { UENO, 2011) }\end{array}$ \\
\hline GID334 & óleo vegetal & $\mathrm{G}$ & (HANABUSA et al., 1993) \\
\hline GID334 & óleo de soja & $\mathrm{G}$ & (HANABUSA et al., 1993) \\
\hline GID376 & óleo de coco & G & (TRIVEDI et al., 2004) \\
\hline GID376 & óleo de semente de algodão & $S$ & (TRIVEDI et al., 2004) \\
\hline GID376 & óleo de amendoim & $S$ & (TRIVEDI et al., 2004) \\
\hline GID376 & óleo de girassol & 1 & (TRIVEDI et al., 2004) \\
\hline GID377 & óleo de coco & G & (TRIVEDI et al., 2004) \\
\hline GID377 & óleo de semente de algodão & G & (TRIVEDI et al., 2004) \\
\hline GID377 & óleo de amendoim & G & (TRIVEDI et al., 2004) \\
\hline GID377 & óleo de girassol & $G$ & (TRIVEDI et al., 2004) \\
\hline GID378 & óleo de coco & S & (TRIVEDI et al., 2004) \\
\hline GID378 & óleo de semente de algodão & $G$ & (TRIVEDI et al., 2004) \\
\hline GID378 & óleo de amendoim & G & (TRIVEDI et al., 2004) \\
\hline GID378 & óleo de girassol & $\mathrm{G}$ & (TRIVEDI et al., 2004) \\
\hline GID379 & óleo de coco & $\mathrm{G}$ & $\begin{array}{l}\text { (SINGH; AUZANNEAU; } \\
\text { ROGERS, 2017) }\end{array}$ \\
\hline GID379 & óleo de semente de uva & $\mathrm{G}$ & $\begin{array}{l}\text { (SINGH; AUZANNEAU; } \\
\text { ROGERS, 2017) }\end{array}$ \\
\hline GID379 & óleo de oliva & $\mathrm{G}$ & $\begin{array}{l}\text { (SINGH; AUZANNEAU; } \\
\text { ROGERS, 2017) }\end{array}$ \\
\hline GID379 & óleo de girassol & G & $\begin{array}{l}\text { (SINGH; AUZANNEAU; } \\
\text { ROGERS, 2017) }\end{array}$ \\
\hline GID379 & óleo de soja & $\mathrm{G}$ & $\begin{array}{l}\text { (SINGH; AUZANNEAU; } \\
\text { ROGERS, 2017) }\end{array}$ \\
\hline GID379 & óleo de canola & G & $\begin{array}{l}\text { (SINGH; AUZANNEAU; } \\
\text { ROGERS, 2017) }\end{array}$ \\
\hline GID380 & óleo de coco & $\mathrm{G}$ & $\begin{array}{l}\text { (SINGH; AUZANNEAU; } \\
\text { ROGERS, 2017) }\end{array}$ \\
\hline
\end{tabular}




\begin{tabular}{|c|c|c|c|}
\hline GID380 & óleo de semente de uva & $\mathrm{G}$ & $\begin{array}{l}\text { (SINGH; AUZANNEAU; } \\
\text { ROGERS, 2017) }\end{array}$ \\
\hline GID380 & óleo de oliva & $\mathrm{G}$ & $\begin{array}{l}\text { (SINGH; AUZANNEAU; } \\
\text { ROGERS, 2017) }\end{array}$ \\
\hline GID380 & óleo de girassol & G & $\begin{array}{l}\text { (SINGH; AUZANNEAU; } \\
\text { ROGERS, 2017) }\end{array}$ \\
\hline GID380 & óleo de soja & $\mathrm{G}$ & $\begin{array}{l}\text { (SINGH; AUZANNEAU; } \\
\text { ROGERS, 2017) }\end{array}$ \\
\hline GID380 & óleo de canola & $\mathrm{G}$ & $\begin{array}{l}\text { (SINGH; AUZANNEAU; } \\
\text { ROGERS, 2017) }\end{array}$ \\
\hline GID381 & óleo de linhaça & G & (SUZUKI et al., 2008) \\
\hline GID381 & trioleína & $S$ & (SUZUKI et al., 2008) \\
\hline GID382 & óleo de girassol & $\mathrm{G}$ & $\begin{array}{c}\text { (DASSANAYAKE; KODALI; } \\
\text { UENO, 2011) }\end{array}$ \\
\hline GID383 & óleo de canola & $\mathrm{S}$ & (WANG; ROGERS, 2015) \\
\hline GID384 & óleo de amendoim & 1 & (TRIVEDI et al., 2004) \\
\hline GID384 & óleo de coco & $G$ & (TRIVEDI et al., 2004) \\
\hline GID384 & óleo de semente de algodão & $S$ & (TRIVEDI et al., 2004) \\
\hline GID384 & óleo de girassol & $G$ & (TRIVEDI et al., 2004) \\
\hline GID385 & óleo de canola & G & $\begin{array}{l}\text { (ROGERS; WRIGHT; } \\
\text { MARANGONI, 2009) }\end{array}$ \\
\hline GID386 & óleo de girassol & $\mathrm{G}$ & $\begin{array}{c}\text { (DASSANAYAKE; KODALI; } \\
\text { UENO, 2011) }\end{array}$ \\
\hline GID387 & óleo de girassol & $\mathrm{G}$ & $\begin{array}{c}\text { (DASSANAYAKE; KODALI; } \\
\text { UENO, 2011) }\end{array}$ \\
\hline GID388 & óleo de girassol & $\mathrm{G}$ & $\begin{array}{c}\text { (DANIEL; RAJASEKHARAN, } \\
2003 \text { ) }\end{array}$ \\
\hline GID389 & óleo de girassol & $\mathrm{G}$ & $\begin{array}{c}\text { (DANIEL; RAJASEKHARAN, } \\
\text { 2003) }\end{array}$ \\
\hline GID390 & óleo de oliva & $S$ & (HIGAKI et al., 2003) \\
\hline GID390 & super oleína de palma & $S$ & (HIGAKI et al., 2003) \\
\hline GID390 & manteiga de cacau & $S$ & (HIGAKI et al., 2003) \\
\hline GID390 & sal gordura oleína & $S$ & (HIGAKI et al., 2003) \\
\hline GID390 & óleo de girassol & G & $\begin{array}{c}\text { (DANIEL; RAJASEKHARAN, } \\
\text { 2003) }\end{array}$ \\
\hline GID391 & óleo de linhaça & $S$ & (SUZUKI et al., 2008) \\
\hline GID391 & trioleína & $S$ & (SUZUKI et al., 2008) \\
\hline GID395 & óleo de oliva & $S$ & (HIGAKI et al., 2003) \\
\hline GID395 & super oleína de palma & $S$ & (HIGAKI et al., 2003) \\
\hline GID395 & manteiga de cacau & I & (HIGAKI et al., 2003) \\
\hline GID395 & sal gordura oleína & 1 & (HIGAKI et al., 2003) \\
\hline GID396 & óleo de oliva & $S$ & (HIGAKI et al., 2003) \\
\hline GID396 & super oleína de palma & $S$ & (HIGAKI et al., 2003) \\
\hline GID396 & manteiga de cacau & $G$ & (HIGAKI et al., 2003) \\
\hline GID396 & sal gordura oleína & $\mathrm{G}$ & (HIGAKI et al., 2003) \\
\hline GID397 & óleo de oliva & $S$ & (HIGAKI et al., 2003) \\
\hline GID397 & super oleína de palma & $S$ & (HIGAKI et al., 2003) \\
\hline GID397 & manteiga de cacau & $S$ & (HIGAKI et al., 2003) \\
\hline GID397 & sal gordura oleína & $S$ & (HIGAKI et al., 2003) \\
\hline GID398 & óleo de girassol & G & $\begin{array}{l}\text { (DANIEL; RAJASEKHARAN, } \\
\text { 2003) }\end{array}$ \\
\hline
\end{tabular}




\begin{tabular}{|c|c|c|c|}
\hline GID399 & óleo de oliva & G & $\begin{array}{l}\text { (SINGH; AUZANNEAU; } \\
\text { ROGERS, 2017) }\end{array}$ \\
\hline GID399 & óleo de canola & G & $\begin{array}{l}\text { (SINGH; AUZANNEAU; } \\
\text { ROGERS, 2017) }\end{array}$ \\
\hline GID399 & óleo de avelã & G & $\begin{array}{l}\text { (SINGH; AUZANNEAU; } \\
\text { ROGERS, 2017) }\end{array}$ \\
\hline GID399 & óleo de colza & G & (KUPIEC et al., 2020) \\
\hline GID399 & óleo de semente de uva & $\mathrm{G}$ & $\begin{array}{c}\text { (CANIZARES; ANGERS; RATTI, } \\
\text { 2020) }\end{array}$ \\
\hline GID400 & óleo de cártamo & G & (CO; MARANGONI, 2012) \\
\hline GID400 & óleo vegetal & $\mathrm{G}$ & (CO; MARANGONI, 2012) \\
\hline GID400 & óleo de canola & G & $\begin{array}{l}\text { (BLAKE; CO; MARANGONI, } \\
\text { 2014) }\end{array}$ \\
\hline GID400 & óleo de oliva & G & $\begin{array}{c}\text { (DASSANAYAKE; KODALI; } \\
\text { UENO, 2011) }\end{array}$ \\
\hline GID400 & óleo de girassol & G & $\begin{array}{l}\text { (DASSANAYAKE; KODALI; } \\
\text { UENO, 2011) }\end{array}$ \\
\hline GID400 & óleo de colza & G & (KUPIEC et al., 2020) \\
\hline GID400 & óleo de soja & G & (BARBOSA, 2018) \\
\hline GID401 & óleo vegetal & G & (DASSANAYAKE et al., 2009) \\
\hline GID401 & óleo de canola & G & $\begin{array}{c}\text { (BLAKE; CO; MARANGONI, } \\
\text { 2014) }\end{array}$ \\
\hline GID401 & óleo de cártamo & G & $\begin{array}{l}\text { (SINGH; AUZANNEAU; } \\
\text { ROGERS, 2017) }\end{array}$ \\
\hline GID401 & óleo de semente de romã & $\mathrm{G}$ & $\begin{array}{c}\text { (CANIZARES; ANGERS; RATTI, } \\
\text { 2020) }\end{array}$ \\
\hline GID401 & óleo de avelã & G & $\begin{array}{c}\text { (CANIZARES; ANGERS; RATTI, } \\
\text { 2020) }\end{array}$ \\
\hline GID401 & óleo de oliva & $G$ & (ÖĞÜTCÜ; YILMAZ, 2014) \\
\hline GID402 & óleo de camélia & G & (DASSANAYAKE et al., 2009) \\
\hline GID402 & óleo vegetal & G & (CO; MARANGONI, 2012) \\
\hline GID402 & óleo de canola & $\mathrm{G}$ & $\begin{array}{c}\text { (BLAKE; CO; MARANGONI, } \\
\text { 2014) }\end{array}$ \\
\hline GID402 & óleo vegetal & $\mathrm{G}$ & $\begin{array}{c}\text { (DASSANAYAKE; KODALI; } \\
\text { UENO, 2011) }\end{array}$ \\
\hline GID402 & óleo de oliva & $\mathrm{G}$ & $\begin{array}{c}\text { (DASSANAYAKE; KODALI; } \\
\text { UENO, 2011) }\end{array}$ \\
\hline GID402 & óleo de soja & G & (WOLFER et al., 2018) \\
\hline GID404 & óleo de girassol & $\mathrm{G}$ & (OJIJO et al., 2004) \\
\hline GID405 & óleo de canola & G & (WANG; ROGERS, 2015) \\
\hline GID406 & óleo de canola & G & (WANG; ROGERS, 2015) \\
\hline GID407 & óleo de canola & G & (WANG; ROGERS, 2015) \\
\hline GID408 & óleo de canola & $\mathrm{G}$ & (WANG; ROGERS, 2015) \\
\hline GID409 & óleo de canola & G & (WANG; ROGERS, 2015) \\
\hline GID410 & óleo de canola & G & (WANG; ROGERS, 2015) \\
\hline GID411 & óleo de girassol & 1 & (BOT; AGTEROF, 2006) \\
\hline GID412 & óleo de girassol & G & (BOT; AGTEROF, 2006) \\
\hline GID413 & óleo de girassol & G & (BOT; AGTEROF, 2006) \\
\hline GID414 & óleo de girassol & I & (BOT; AGTEROF, 2006) \\
\hline GID415 & óleo de girassol & G & (BOT; AGTEROF, 2006) \\
\hline GID416 & óleo de girassol & G & (BOT; AGTEROF, 2006) \\
\hline GID417 & óleo de girassol & G & (SCHAINK et al., 2007) \\
\hline
\end{tabular}




\begin{tabular}{llll}
\hline GID418 & óleo de girassol & $G$ & (SCHAINK et al., 2007) \\
GID419 & óleo de girassol & $G$ & (SCHAINK et al., 2007) \\
GID426 & óleo de girassol & $G$ & (JIANG et al., 2020) \\
GID427 & óleo de girassol & S & (JIANG et al., 2020) \\
GID428 & óleo de canola & $G$ & (ZENG et al., 2020) \\
\hline
\end{tabular}

Demais dados e arquivos estão livremente disponíveis para uso e consulta por meio de solicitação ao autor 